Simulador de controle de atitude e propagação de órbita aplicado a nanossatélites em órbita baixa terrestre: desenvolvimento e validação com dados de voo do nanossatélite PicSat 



\title{
Simulador de controle de atitude e propagação de órbita aplicado a nanossatélites em órbita baixa terrestre: desenvolvimento e validação com dados de voo do nanossatélite PicSat
}

\author{
Versão Corrigida
}

Dissertação de mestrado apresentada à Escola Politécnica da Universidade de São Paulo para obtenção do título de Mestre em Ciências.

Área de Concentração:

3139 - Engenharia de Sistemas

Orientador:

Prof. Dr. Felipe Miguel Pait

São Paulo

2020 
Autorizo a reprodução e divulgação total ou parcial deste trabalho, por qualquer meio convencional ou eletrônico, para fins de estudo e pesquisa, desde que citada a fonte.

Este exemplar foi revisado e corrigido em relação à versão original, sob responsabilidade única do autor e com a anuência de seu orientador.

São Paulo, de de

Assinatura do autor:

Assinatura do orientador:

\section{Catalogação-na-publicação}

\section{Menegaldo, Cauê}

Simulador de controle de atitude e propagação de órbita aplicado a nanossatélites em órbita baixa terrestre: desenvolvimento e validação com dados de voo do nanossatélite PicSat / C. Menegaldo -- versão corr. -- São Paulo, 2020.

$193 \mathrm{p.}$

Dissertação (Mestrado) - Escola Politécnica da Universidade de São Paulo. Departamento de Engenharia de Telecomunicações e Controle.

1.Nanossatélite 2.CubeSat 3.Modelo Dinâmico 4.Sistema de Controle de Atitude I.Universidade de São Paulo. Escola Politécnica. Departamento de Engenharia de Telecomunicações e Controle II.t. 
À minha amada esposa, Carla

Por seu companheirismo, encorajamento e amor 



\section{AGRADECIMENTOS}

Ainda que se atribua autoria única à essa monografia, a jornada de desenvolvimento envolveu diversas pessoas, as quais, nesse momento, tenho o prazer de agradecer.

Ao Prof. Dr. Fábio de Oliveira Fialho, que, por meio de seus direcionamentos, contribuiu enormemente para o meu amadurecimento profissional. E, ainda que diante das intemperes da vida e das estruturas, sempre mostrou-se diligente e disponível.

À banca de qualificação dessa dissertação, pelas valiosas críticas e importantes conselhos que lapidaram a proposta inicial desse trabalho, composta pelos professores Dr. Fuad Kassab Junior, Dr. Felipe Miguel Pait e Dr. Vanderlei da Cunha Parro. Esse último, em especial, por, juntamente com o Prof. Dr. Rodrigo Alvite Romano, ter me incentivado ao ingresso no programa de mestrado e por generosamente disponibilizar a infraestrutura do Instituto Mauá de Tecnologia para que eu desenvolvesse grande parte dessa monografia. Estendo meus agradecimentos aos amigos do Núcleo de Sistemas Eletrônicos Embarcados, pelos muitos cafés, discussões, contribuições e incentivos nesse período.

Ao amigo Prof. Me. Rafael Corsi Ferrão, pelo contínuo e extenso encorajamento ao longo de todo o processo. E, também, por disponibilizar parte da infraestrutura computacional de seu laboratório no Instituto de Pesquisa Insper.

Ao Prof. Dr. Vincent Lapeyrère do Observatório de Paris, por gentilmente disponibilizar dados tão preciosos que foram essenciais para o caráter sui generis de parte dessa dissertação.

Aos meus amigos e irmãos que, ao longa dessa jornada, me sustentaram e encorajaram nos dias maus.

À minha amada e virtuosa esposa, Carla, pelas inúmeras revisões do texto e, também, pela renúncia, resiliência, companheirismo, dedicação e paciência ao longo desses anos.

\section{Soli Deo Gloria.}



"The diversity of the phenomena of nature is so great and the treasures hidden in the heavens so rich precisely in order that the human mind shall never be lacking in fresh nourishment." [1] 



\section{RESUMO}

MENEGALDO, Cauê Garcia. Simulador de controle de atitude e propagação de órbita aplicado a nanossatélites em órbita baixa terrestre: desenvolvimento e validação com dados de voo do nanossatélite PicSat. 2020. Dissertação (Mestrado) - Escola Politécnica da Universidade de São Paulo, São Paulo, 2020.

Satélites artificiais são, em sua grande maioria, veículos sofisticados e de alto investimento. Inicialmente, eram lançados apenas por grandes empresas e agências espaciais governamentais, porém, após avanços tecnológicos, em 1999 foi proposto um nanossatélite de baixo custo e dimensões padronizadas denominado CubeSat. Essa nova proposta permitiu que outras instituições tivessem acesso ao espaço. Desde então, 1116 CubeSats foram lançados em órbita terrestre baixa com sucesso, entre eles veículos para fins educacionais, comerciais e científicos, sendo apenas 5 deles brasileiros. Diante desde cenário, o Instituto Mauá de Tecnologia (IMT) e o Instituto de Astronomia, Geofísica e Ciências Atmosféricas (IAG) da Universidade de São Paulo (USP) estão trabalhando em projetos de CubeSat a fim de fomentar produções acadêmicas e científicas. No entanto, um dado traz um alerta relevante: cerca de 23,7\% dos CubeSats lançados entre 2017 e 2018 apresentaram falha ainda durante o comissionamento ou estágios iniciais em decorrência da falta de testes e simulações adequadas ainda em solo. Esse trabalho se propõe a auxiliar o desenvolvimento desses nanossatélites e, consequentemente elevar a chance de sobrevivência após o comissionamento, desenvolvendo um simulador de atitude e órbita configurável, bem como malhas de controle de atitude capazes de serem implementadas em ambos os projetos. Como resultado, obteve-se um simulador em ambiente Simulink, validado com dados de voo do nanossatélite francês, PicSat, resultado inédito no cenário brasileiro, bem como um controle de atitude capaz de reduzir a velocidade angular do satélite após lançamento e realizar apontamentos para pontos fixos ou na direção da Terra.

Palavras-chave: Nanossatélite. CubeSat. Modelo Dinâmico. Sistema de Controle de Atitude. 



\begin{abstract}
MENEGALDO, Cauê Garcia. Attitude control simulator and orbit propagation applied to nanosatellites in low Earth orbit: development and validation with nanossatellite PicSat fligh data. 2020. Thesis (Masters) - Polytechnic School of the University of São Paulo, São Paulo, 2020.

Artificial satellites are mostly sophisticated and high cost vehicles. At first, they were launched only by big companies and space agencies; however, after several technological advances, in 1999 a low-cost, standardized-sized nanosatellite called CubeSat was proposed. This new proposition enabled other institutions to have access to space. Since then, 1116 Cubesats were successfully launched in low earth orbit, among them Cubesats for educational, commercial, and scientific purposes, being only 5 of them Brazilian. In view of this scenario, Instituto Mauá de Tecnologia (IMT) and Institute of Astronomy, Geophysics and Atmospheric Sciences (IAG) of the University of São Paulo (USP) have been working on CubeSat projects in order to foment academic and scientific projects. Notwithstanding, one data brings a relevant alert: about $23,7 \%$ of the CubeSats launched between 2017 and 2018 failed during commissioning or early stages due to the lack of proper tests and simulations prior to launch. The aim of this thesis is to assist in the development of nanosatellites and, consequently, increase the chance of their survival after commissioning, creating an adjustable attitude and orbit simulator, as well as attitude control loops capable of being implemented in both projects. The result is a simulator in Simulink environment, validated with flight data of the France nanosatellite, PicSat, an unprecedented result in the Brazilian scenario, and, also, an attitude control system able to reduce the angular rate of the satellite after launch and point targets in the celestial sphere or towards the Earth.
\end{abstract}

Keywords: Nanosatellites. CubeSat. Dynamic Modeling. Attitude control System. 



\section{LISTA DE ILUSTRAÇÕES}

Figura 1 - Ilustração de dimensões do CubeSats. . . . . . . . . . . . . . . . . . 33

Figura 2 - Ilustração das divisões do AODCS. . . . . . . . . . . . . . . . 35

Figura 3 - Relação entre o eixo inercial, $X Y Z$, e o eixo móvel, xyz. . . . . . . . . 39

Figura 4 - Rotação em torno dos eixos $X, Y$ e $Z$. . . . . . . . . . . . 41

Figura 5 - Rotação por Ângulos de Euler (ZXZ). . . . . . . . . . . . . . . . . 42

Figura 6 - Rotação por Eixo de Euler. . . . . . . . . . . . . . . 43

Figura 7 - Sistema de Coordenadas Geocêntrico Equatorial Inercial (GEI). . . . . 46

Figura 8 - Sistema de Coordenadas Geocêntrico Equatorial Terrestre (GET). . . . 46

Figura 9 - Sistema de Coordenadas Referente a Órbita do Satélite (ROS). . . . . 47

Figura 10 - Sistema de Coordenadas Referente ao Corpo do Satélite (RCS). . . . . 48

Figura 11 - Sistema de Coordenadas Referente aos Eixos Principais de Inércia (REP). 48

Figura 12 - Diagrama da cinemática do veículo. . . . . . . . . . . . . . 52

Figura 13 - Modelo elétrico do atuador magnético. . . . . . . . . . . . . 53

Figura 14 - Modelos elétrico e mecânico da roda de reação. . . . . . . . . . . . . . 54

Figura 15 - Veículo e seus principais subsistemas. . . . . . . . . . . . . 55

Figura 16 - Diagrama da dinâmica e cinemática de atitude. . . . . . . . . . . 57

Figura 17 - Ilustração de um satélite em órbita terrestre. . . . . . . . . . . . . . . 58

Figura 18 - Ilustração de um satélite sujeito ao arrasto atmosférico. . . . . . . . . . 60

Figura 19 - Projeção da área atingida por partículas atmosféricas. . . . . . . . . . . 61

Figura 20 - Ilustração das formas de incidência da radiação solar numa superfície. . 62

Figura 21 - Ilustração das condições de eclipse terrestre. . . . . . . . . . . . . . . 65

Figura 22 - Ilustração do torque devido ao gradiente de gravidade. . . . . . . . . . 66

Figura 23 - Exemplos de harmônicos esféricos. . . . . . . . . . . . . . . . 70

Figura 24 - Problema dos Três Corpos. . . . . . . . . . . . . . . . 72

Figura 25 - Diagrama das perturbações de atitude e órbita. . . . . . . . . . . 73

Figura 26 - Sistema de coordenadas do fooSAT-A1, fooSAT-I1 e fooSAT-I6. . . . . 78

Figura 27 - Movimento de nutação. . . . . . . . . . . . . . . . . . . 81

Figura 28 - Movimento de precessão. . . . . . . . . . . . . . . . . . . . 82

Figura 29 - Movimento devido ao atuador magnético. . . . . . . . . . . . . . 83

Figura 30 - Movimento devido à roda de reação. . . . . . . . . . . . . . . . . . . 84

Figura 31 - Simulação do movimento orbital. . . . . . . . . . . . . . . . 85

Figura 32 - Elementos presentes nas perturbações. . . . . . . . . . . . . . 86

Figura 33 - Torques de perturbação aplicados ao satélite, $T_{p r t} \ldots \ldots$. . . . . . 87

Figura 34 - Comparação das magnitudes dos torques de perturbação. . . . . . . . . 88

Figura 35 - Acelerações de perturbação aplicadas ao satélite, $a_{p r t} \ldots$. . . . . . . . 89

Figura 36 - Comparação das magnitudes das acelerações de perturbação. . . . . . . 89 
Figura $37-$ Tempo em órbita. . . . . . . . . . . . . . . . . . . . . . . . 90

Figura 38 - Ilustração e imagem do PicSat. . . . . . . . . . . . . . . . . . . . . . 92

Figura 39 - Velocidade angular do PicSat entre 22/01/2018 e 20/03/2018. . . . . . 94

Figura 40 - Comportamento de $\omega_{\text {free }} \ldots \ldots \ldots$. . . . . . . . . . . 96

Figura 41 - Estimação de parâmetros - Experimento 1a. . . . . . . . . . . . . . 98

Figura 42 - Médias e desvios padrões dos resíduos utilizados para estimar. . . . . . 98

Figura 43 - Validação de parâmetros - Experimento 1b. . . . . . . . . . . . . . . . 99

Figura 44 - Médias e desvios padrões dos resíduos utilizados para validar. . . . . . 99

Figura 45 - Estimação dos parâmetros de perturbação - Experimento 1a. . . . . . . 100

Figura 46 - Médias e desvios padrões dos resíduos utilizados para estimar. . . . . . 101

Figura 47 - Validação dos parâmetros de perturbação - Experimento 1b. . . . . . . 101

Figura 48 - Médias e desvios padrões dos resíduos utilizados para validar. . . . . . 102

Figura 49 - Influência das perturbações no tempo - Trecho 1. . . . . . . . . . . . . 103

Figura 50 - Médias e desvios padrões das frações de influência da perturbação. . 103

Figura 51 - Comparação da presença e ausência das perturbações no tempo. . . . . 104

Figura 52 - Atualizações dos TLEs do PicSat disponíveis. . . . . . . . . . . . . 105

Figura 53 - Quantidade de detecções com diferença de tempo entre TLEs. . . . . . 106

Figura 54 - Resultados do erro de propagação orbital. . . . . . . . . . . . . . . 106

Figura 55 - Diagrama de transição de estados do ACS. . . . . . . . . . . . . . . . . 110

Figura 56 - Diagrama do controlador de detumbling. . . . . . . . . . . . . . . 117

Figura 57 - Diagrama de Bode do filtro de estimação da derivada de campo magnético.117

Figura 58 - Desempenho do estimador da derivada do campo magnético terrestre. . 119

Figura 59 - Simulação de detumbling para velocidade angular inicial de 0,4 rad/s. 120

Figura 60 - Simulação de detumbling para velocidade angular inicial de 1,2 rad/s. . 121

Figura 61 - Norma da velocidade angular do PicSat durante o voo. . . . . . . . . . 122

Figura 62 - Estimação do ganho do detumbling. . . . . . . . . . . . . . . . . . . . . 123

Figura 63 - Validação do ganho do detumbling. . . . . . . . . . . . . . . . . . . . 124

Figura 64 - Diagrama do controlador de apontamento. . . . . . . . . . . . . . 131

Figura 65 - Desempenho do controle das rodas de reação. . . . . . . . . . . . . . . 132

Figura 66 - Desempenho do controle das rodas de reação. . . . . . . . . . . . . . 133

Figura 67 - Desempenho do controle de apontamento para direção fixa. . . . . . . . 135

Figura 68 - Desempenho do controle de apontamento para direção fixa com ajuste. 136

Figura 69 - Desempenho do controle de apontamento para direção Nadir. . . . . . 139

Figura 70 - Desempenho do controle de dessaturação das rodas de reação. . . . . . 140

Figura 71 - Apontamento com o controle de dessaturação ativado e desativado. . 141

Figura 72 - Simulação de um cenário com todos os modos do ACS. . . . . . . . . . 143

Figura 73 - Destaque dos modos de detumbling (Faixas 2 e 6) . . . . . . . . . . . 144

Figura 74 - Destaque dos modos de apontamento para direção Nadir (Faixas 3 e 7). 145

Figura B.1 - Estimação de parâmetros - Experimentos 2a a 7a. . . . . . . . . . . . 164 
Figura B.2 - Estimação de parâmetros - Experimentos 8a a 13a. . . . . . . . . . . . 165

Figura B.3-Estimação de parâmetros - Experimentos 14a a 19a. . . . . . . . . . . . 166

Figura B.4-Estimação de parâmetros - Experimentos 20a a 25a. . . . . . . . . . . . 167

Figura B.5 - Estimação de parâmetros - Experimentos 26a a 31a. . . . . . . . . . . . 168

Figura B.6 -Estimação de parâmetros - Experimento 32a. . . . . . . . . . . . . . . 169

Figura B.7 - Validação de parâmetros - Experimentos 2 b a 7b. . . . . . . . . . . . . 170

Figura B.8 - Validação de parâmetros - Experimentos 8b a 13b. . . . . . . . . . . . 171

Figura B.9 - Validação de parâmetros - Experimentos 14b a 19b. . . . . . . . . . . . 172

Figura B.10-Validação de parâmetros - Experimentos 20b a 25b. . . . . . . . . . . . 173

Figura B.11-Validação de parâmetros - Experimentos 26b a 31b. . . . . . . . . . . . 174

Figura B.12-Estimação dos parâmetros de perturbação - Experimentos 2a a 5a. . 175

Figura B.13-Validação dos parâmetros de perturbação - Experimentos 2b a 5b. . . . 176

Figura B.14-Influência das perturbações no tempo - Trechos 2 a 7. . . . . . . . . . . 177

Figura B.15-Influência das perturbações no tempo - Trechos 8 a 10 . . . . . . . . . . 178

Figura B.16-Comparação da presença e ausência das perturbações - Trechos 2 a 7. . 179

Figura B.17-Comparação da presença e ausência das perturbações - Trechos 8 a 10. 180 



\section{LISTA DE TABELAS}

Tabela 2 - Características do atuador magnético. . . . . . . . . . 76

Tabela 3 - Características da roda de reação. . . . . . . . . . . . . 76

Tabela 4 - Características do fooSAT-A1. . . . . . . . . . . . 77

Tabela 5 - Características do fooSAT-I1 e fooSAT-I6. . . . . . . . . . 78

Tabela 6 - Características das órbitas ISS e SSO . . . . . . . . . . . . . . . 79

Tabela 7 - Características do atuador magnético MTQ 200.20 . . . . . . . . . 92

Tabela 8 - Características do atuador magnético MTQ 200.10S. . . . . . . . . . 93

Tabela 9 - Características da roda de reação RW 210.60. . . . . . . . . . . . . 93

Tabela 10 - Resumo dos Requisitos Atingidos. . . . . . . . . . . . . . . 149 



\section{LISTA DE SIGLAS}

ACS Attitude Control System

ADCS Attitude Determination and Control System

ADS Attitude Determination System

AODCS Attitude and Orbit Determination and Control System

BGS British Geological Survey

BIBO Bounded Input Bounded Output

BLDC Brushless Direct Current Motors

COTS Commercial Off-The-Shelf

DCM Direct Cossine Matrix

DODGE Department of Defense Gravity Experiment

EGM2008 Earth Gravitational Model 2008

GEI Sistema de Coordenadas Geocêntrico Equatorial Inercial

GET Sistema de Coordenadas Geocêntrico Equatorial Terrestre

IAG Instituto de Astronomia, Geofísica e Ciências Atmosféricas da USP

IAGA International Association of Geomagnetism and Aeronomy

IGRF International Geomagnetic Reference Field

IMT Instituto Mauá de Tecnologia

ISRO Indian Space Research Organisation

ISS International Space Station

JD Julian Date

JSpOC Joint Space Operations Center

LDEF Long Duration Exposure Facility

LEO Low Earth Orbit

LESIA Laboratoire d'Études Spatiales et d'Instrumentation en Astrophysique 
LQR Linear-Quadratic Regulator

MSIS Mass Spectrometer Incoherent Scatter Radar

NGA U.S. National Geospatial-Intelligence Agency

NGDC United State National Geophysical Data Center

NRLMSISE-00 United States Naval Research Laboratory Mass Spectrometer and Incoherent Scatter Radar Exosphere

OCS Orbit Control System

ODCS Orbit Determination and Control System

ODS Orbit Determination System

ODTK Orbit Determination Tool Kit

POD Picosatellite Orbital Deployer

RCS Sistema de Coordenadas Referente ao Corpo do Satélite

REP Sistema de Coordenadas Referente aos Eixos Principais de Inércia

ROS Sistema de Coordenadas Referente à Órbita do Satélite

RW Reaction Wheels

SCT Spacecraft Control Toolbox

SSO Sun-Synchronous Orbit

STK Systems Tool Kit

TLE Two-Line Element

USP Universidade de São Paulo

UT1 Universal Time

WMM World Magnetic Model 


\section{LISTA DE SÍMBOLOS}

\begin{tabular}{|c|c|c|}
\hline Símbolo & Descrição & Unidade \\
\hline$\gamma$ & Direção do equinócio de março & - \\
\hline $\boldsymbol{\omega}_{T}$ & Velocidade angular da Terra & $\mathrm{rad} / \mathrm{s}$ \\
\hline$O^{s}$ & Origem do RCS & - \\
\hline$C M$ & Centro de massa do satélite & - \\
\hline$\theta_{G}$ & Tempo Sideral de Greenwich & grau \\
\hline$\theta_{G 0}$ & Tempo Sideral de Greenwich às $0 \mathrm{~h}$ & grau \\
\hline$t_{U}$ & Instante de tempo para determinar $\theta_{G}$ & h (UT1) \\
\hline$T_{0}$ & Tempo em séculos julianos desde J2000.0 & JD \\
\hline$d_{U}$ & Tempo em dias julianos desde J2000.0 & JD \\
\hline $\mathbf{v}_{v}$ & Velocidade do veículo & $\mathrm{km} / \mathrm{s}$ \\
\hline $\mathbf{r}_{v}$ & Posição do veículo & $\mathrm{km}$ \\
\hline$\left[\mathbf{I}_{v}\right]$ & Matriz de inércia do veículo & $\mathrm{kg} \mathrm{m}^{2}$ \\
\hline$\omega$ & Velocidade angular & $\mathrm{rad} / \mathrm{s}$ \\
\hline$[\Omega]$ & Matriz antissimétrica da velocidade angular & $\mathrm{rad} / \mathrm{s}$ \\
\hline $\mathbf{T}_{a t}$ & Torque proveniente dos atuador & $\mathrm{Nm}$ \\
\hline $\mathbf{T}_{p r t}$ & Torque proveniente das perturbações & $\mathrm{Nm}$ \\
\hline$e_{a m}$ & Tensão da bobina & $\mathrm{V}$ \\
\hline$R_{a m}$ & Resistência da bobina & $\Omega$ \\
\hline$i_{a m}$ & Corrente da bobina & $\mathrm{A}$ \\
\hline$L_{a m}$ & Indutância da bobina & $\mathrm{H}$ \\
\hline $\mathbf{m}_{a m}$ & Momento magnético total do atuador & $\mathrm{A} \mathrm{m}^{2}$ \\
\hline$m_{b}$ & Momento magnético da bobina & $\mathrm{A} \mathrm{m}^{2}$ \\
\hline$m_{n}$ & Momento magnético do núcleo da bobina & $\mathrm{A} \mathrm{m}^{2}$ \\
\hline$N_{a m}$ & Número de espiras da bobina & - \\
\hline$A_{a m}$ & Área média da seção da bobina & $\mathrm{m}^{2}$ \\
\hline$\mu_{n}$ & Coeficiente de permeabilidade magnética do núcleo da bobina & $\mathrm{H} / \mathrm{m}^{2}$ \\
\hline$\mu_{0}$ & Coeficiente de permeabilidade magnética do vácuo & $\mathrm{H} / \mathrm{m}^{2}$ \\
\hline $\mathbf{T}_{a m}$ & Torque do atuador magnético & $\mathrm{Nm}$ \\
\hline B & Campo magnético terrestre & $\mathrm{T}$ \\
\hline$L_{a}$ & Indutância de armadura do motor & $\mathrm{H}$ \\
\hline$i_{a}$ & Corrente de armadura do motor & $\mathrm{A}$ \\
\hline$R_{a}$ & Resistência de armadura do motor & $\Omega$ \\
\hline$e_{a}$ & Tensão de armadura do motor & $\mathrm{V}$ \\
\hline$k_{e}$ & Constante elétrica do motor & V s/rad \\
\hline
\end{tabular}




\begin{tabular}{|c|c|c|}
\hline Símbolo & Descrição & Unidade \\
\hline$\omega_{m}$ & Velocidade angular do motor & $\mathrm{rad} / \mathrm{s}$ \\
\hline$I_{r r}$ & Momento de inércia da roda de reação & $\mathrm{kg} \mathrm{m}^{2}$ \\
\hline$I_{d}$ & Momento de inércia do disco & $\mathrm{kg} \mathrm{m}^{2}$ \\
\hline$I_{m}$ & Momento de inércia do motor & $\mathrm{kg} \mathrm{m}^{2}$ \\
\hline$k_{t}$ & Constante de torque do motor & $\mathrm{Nm} / \mathrm{A}$ \\
\hline$b$ & Coeficiente de atrito viscoso & - \\
\hline $\mathbf{T}_{r r}$ & Torque total da roda de reação & $\mathrm{Nm}$ \\
\hline$\dot{\mathbf{H}}_{r r}$ & Torque de controle da roda de reação & $\mathrm{Nm}$ \\
\hline $\mathbf{H}_{r r}$ & Momento angular das rodas de reação & $\mathrm{kg} \mathrm{m}^{2} / \mathrm{s}$ \\
\hline$\hat{\mathbf{n}}_{a m}$ & Sentido do momento magnético do atuador magnético & - \\
\hline$\hat{\mathbf{n}}_{r r}$ & Sentido da velocidade angular da roda de reação & - \\
\hline $\mathbf{F}_{2 / 1}$ & Força gravitacional no corpo 2 exercida pelo corpo 1 & $\mathrm{~N}$ \\
\hline$G$ & Constante de gravitação universal & $\mathrm{km}^{3} /\left(\mathrm{kg} \mathrm{s}^{2}\right)$ \\
\hline$m_{1}$ & Massa do corpo 1 & $\mathrm{~kg}$ \\
\hline$m_{2}$ & Massa do corpo 2 & $\mathrm{~kg}$ \\
\hline $\mathbf{r}_{2 / 1}$ & Vetor posição entre dois corpos & $\mathrm{km}$ \\
\hline $\mathbf{a}_{v}$ & Aceleração do veículo & $\mathrm{km} / \mathrm{s}^{2}$ \\
\hline$\mu_{T}$ & Parâmetro de gravitação da Terra & $\mathrm{km}^{3} / \mathrm{s}^{2}$ \\
\hline$m_{T}$ & Massa da Terra & $\mathrm{kg}$ \\
\hline $\mathbf{T}_{d}$ & Torque devido ao arrasto atmosférico & $\mathrm{Nm}$ \\
\hline $\mathbf{T}_{\text {rad }}$ & Torque devido à pressão da radiação solar & $\mathrm{Nm}$ \\
\hline $\mathbf{T}_{g g}$ & Torque devido ao gradiente de gravidade & $\mathrm{Nm}$ \\
\hline $\mathbf{T}_{m r}$ & Torque devido ao dipolo magnético residual & $\mathrm{Nm}$ \\
\hline $\mathbf{F}_{d}$ & Força devido ao arrasto atmosférico & $\mathrm{N}$ \\
\hline$C_{D}$ & Coeficiente de arrasto & - \\
\hline$\rho$ & Densidade atmosférica & $\mathrm{kg} / \mathrm{m}^{3}$ \\
\hline $\mathbf{v}_{\text {rel }}$ & Velocidade do veículo em relação à atmosfera & $\mathrm{m} / \mathrm{s}$ \\
\hline$\hat{\mathbf{n}}_{\mathrm{d} A}$ & Versor normal à $\mathrm{d} A$ & - \\
\hline $\mathrm{d} A$ & Elemento de área & $\mathrm{m}^{2}$ \\
\hline $\mathbf{r}_{\mathrm{d} A}$ & Vetor posição do $C M$ ao $\mathrm{d} A$ & $\mathrm{~m}$ \\
\hline$A$ & Área da superfície do veículo & $\mathrm{m}^{2}$ \\
\hline$A_{d}$ & Área sujeita ao arrasto atmosférico & $\mathrm{m}^{2}$ \\
\hline$\hat{\mathbf{n}}_{i}$ & Versor normal à $A_{i}$ & - \\
\hline $\mathbf{r}_{c p_{i}}$ & Vetor posição do $C M$ até o centro de pressão da $A_{i}$ & $\mathrm{~m}$ \\
\hline$\hat{\mathbf{s}}_{\mathrm{d} A}$ & Versor paralelo ao d $A$ e na direção da projeção da radiação & - \\
\hline $\mathbf{F}_{r a}$ & Força devido à pressão da radiação solar absorvida & $\mathrm{N}$ \\
\hline$S$ & Intensidade média da radiação solar & $\mathrm{W} / \mathrm{m}^{2}$ \\
\hline
\end{tabular}




\begin{tabular}{|c|c|c|}
\hline Símbolo & Descrição & Unidade \\
\hline$c$ & Velocidade da luz & $\mathrm{m} / \mathrm{s}^{2}$ \\
\hline$c_{r a}$ & Coeficiente de radiação absorvida & - \\
\hline$\theta$ & Ângulo de incidência em relação a normal & grau \\
\hline $\mathbf{F}_{r r}$ & Força devido à pressão da radiação solar refletida & $\mathrm{N}$ \\
\hline$c_{r r}$ & Coeficiente de radiação refletida & - \\
\hline $\mathbf{F}_{r d}$ & Força devido à pressão da radiação solar difusa & $\mathrm{N}$ \\
\hline$c_{r d}$ & Coeficiente de radiação difusa & - \\
\hline $\mathbf{r}_{s / v}$ & Posição do Sol em relação ao veículo & $\mathrm{km}$ \\
\hline$A_{\text {rad }}$ & Área sujeita à pressão da radiação solar & $\mathrm{m}^{2}$ \\
\hline$\nu$ & Variável que indica situação de eclipse & - \\
\hline $\mathbf{r}_{s}$ & Posição do Sol em relação a Terra & $\mathrm{km}$ \\
\hline$\lambda$ & Longitude eclíptica & grau \\
\hline$\varepsilon$ & Obliquidade da eclíptica & grau \\
\hline$M$ & Anomalia média do Sol & grau \\
\hline$L$ & Longitude média do Sol & grau \\
\hline$n$ & Número de dias desde J2000.0 & JD \\
\hline $\mathrm{d} m$ & Elemento de massa & $\mathrm{kg}$ \\
\hline $\mathbf{F}_{g g}$ & Força devido ao gradiente de gravidade & $\mathrm{N}$ \\
\hline $\mathbf{r}_{T, \mathrm{~d} m}$ & Vetor posição do d $m$ em relação à Terra & $\mathrm{km}$ \\
\hline $\mathbf{r}_{\mathrm{d} m}$ & Vetor posição do $C M$ até o d $m$ & $\mathrm{~m}$ \\
\hline $\mathbf{m}_{m r}$ & Dipolo magnético residual & $\mathrm{A} \mathrm{m}^{2}$ \\
\hline $\mathbf{a}_{\text {pert }}$ & Aceleração de perturbação & $\mathrm{km} / \mathrm{s}^{2}$ \\
\hline $\mathbf{a}_{d}$ & Aceleração devido ao arrasto atmosférico & $\mathrm{km} / \mathrm{s}^{2}$ \\
\hline $\mathbf{a}_{r a d}$ & Aceleração devido à pressão da radiação solar & $\mathrm{km} / \mathrm{s}^{2}$ \\
\hline $\mathbf{a}_{g}$ & Aceleração devido à não homogeneidade da Terra & $\mathrm{km} / \mathrm{s}^{2}$ \\
\hline $\mathbf{a}_{t c}$ & Aceleração devido ao efeito de um terceiro corpo & $\mathrm{km} / \mathrm{s}^{2}$ \\
\hline$m_{v}$ & Massa do veículo & $\mathrm{kg}$ \\
\hline $\mathbf{a}_{P}$ & Aceleração da gravidade em um ponto $P$ qualquer & $\mathrm{km} / \mathrm{s}^{2}$ \\
\hline $\mathbf{U}$ & Potencial gravitacional & $\mathrm{J} / \mathrm{kg}$ \\
\hline$\nabla$ & Operador de gradiente & - \\
\hline$(r, \phi, \lambda)$ & Distância geocêntrica, longitude e latitude & (km,grau,grau) \\
\hline$R_{T}$ & Raio médio da Terra no equador & $\mathrm{km}$ \\
\hline$P_{n}^{m}$ & Polinômios associados de Legendre de grau $n$ e ordem $m$ & - \\
\hline$C_{n}^{m}$ & Coeficientes tesserais harmônicos de grau $n$ e ordem $m$ & - \\
\hline$S_{n}^{m}$ & Coeficientes sectoriais harmônicos de grau $n$ e ordem $m$ & - \\
\hline$\mu_{l}$ & Parâmetro de gravitação da Lua & $\mathrm{km}^{3} / \mathrm{s}^{2}$ \\
\hline $\mathbf{r}_{l / v}$ & Posição da Lua em relação ao veículo & $\mathrm{km}$ \\
\hline
\end{tabular}




\begin{tabular}{|c|c|c|}
\hline Símbolo & Descrição & Unidade \\
\hline $\mathbf{r}_{l}$ & Posição da Lua em relação à Terra & $\mathrm{km}$ \\
\hline$m_{l}$ & Massa da Lua & $\mathrm{kg}$ \\
\hline $\mathbf{a}_{t c_{l}}$ & Aceleração devido à influência da gravidade lunar & $\mathrm{km} / \mathrm{s}^{2}$ \\
\hline $\mathbf{a}_{t c_{s}}$ & Aceleração devido à influência da gravidade solar & $\mathrm{km} / \mathrm{s}^{2}$ \\
\hline$m_{s}$ & Massa do Sol & $\mathrm{kg}$ \\
\hline $\mathbf{T}_{\text {ext }}$ & Torque externo & $\mathrm{Nm}$ \\
\hline $\boldsymbol{\omega}_{f}$ & Velocidade angular final de um trecho & $\mathrm{rad} / \mathrm{s}$ \\
\hline $\boldsymbol{\omega}_{i}$ & Velocidade angular inicial de um trecho & $\mathrm{rad} / \mathrm{s}$ \\
\hline $\boldsymbol{\omega}_{\text {free }}$ & Velocidade angular de livre movimento & $\mathrm{rad} / \mathrm{s}$ \\
\hline $\boldsymbol{\omega}_{p r t}$ & Velocidade angular de perturbação & $\mathrm{rad} / \mathrm{s}$ \\
\hline $\mathbf{E}_{c}$ & Energia cinética do veículo & $\mathrm{J}$ \\
\hline $\mathbf{m}_{d}$ & Momento magnético desejado & $\mathrm{A} \mathrm{m}^{2}$ \\
\hline$k_{d e t}$ & Ganho do controlador de detumbling & - \\
\hline$\omega_{\text {orb }}$ & Velocidade angular orbital & $\mathrm{rad} / \mathrm{s}$ \\
\hline$\xi_{m}$ & Inclinação entre a órbita do veículo e o equador magnético & grau \\
\hline$I_{v_{\min }}$ & Menor momento principal de inércia do veículo & $\mathrm{kg} \mathrm{m}^{2}$ \\
\hline$V(\cdot)$ & Função de Lyapunov & - \\
\hline$\omega_{c}$ & Frequência de corte do filtro & $\mathrm{rad} / \mathrm{s}$ \\
\hline$T$ & Tempo de amostragem & $\mathrm{s}$ \\
\hline$[\mathbf{K}]$ & Matriz de ganho do LQR & - \\
\hline$[\mathbf{Q}]$ & Matriz de ponderação dos estados & - \\
\hline$[\mathbf{R}]$ & Matriz de ponderação do esforço de controle & - \\
\hline$\overline{\boldsymbol{q}}$ & Atitude de operação & - \\
\hline $\bar{\omega}$ & Velocidade angular de operação & $\mathrm{rad} / \mathrm{s}$ \\
\hline$\delta \boldsymbol{q}$ & Desvio de atitude & - \\
\hline$\delta \omega$ & Desvio da velocidade angular & $\mathrm{rad} / \mathrm{s}$ \\
\hline$[\mathbf{S}(\cdot)]$ & Matriz antissimétrica equivalente ao produto vetorial & - \\
\hline$[\mathcal{C}]$ & Matriz de controlabilidade & - \\
\hline$[\mathcal{O}]$ & Matriz de observabilidade & - \\
\hline$\rho_{Q}$ & Coeficiente de ponderação da matriz $[\mathbf{Q}]$ & - \\
\hline$\rho_{R}$ & Coeficiente de ponderação da matriz $[\mathbf{R}]$ & - \\
\hline$k_{m}$ & Ganho da roda de reação & - \\
\hline$\tau_{m}$ & Constante de tempo da roda de reação & $\mathrm{s}$ \\
\hline$k_{p}$ & Ganho proporcional & - \\
\hline$k_{i}$ & Ganho integrativo & - \\
\hline$\omega_{n}$ & Frequência natural & $\mathrm{rad} / \mathrm{s}$ \\
\hline$\xi$ & Coeficiente de amortecimento & - \\
\hline
\end{tabular}




\begin{tabular}{llc}
\hline Símbolo & Descrição & Unidade \\
\hline$e_{r}(\infty)$ & Erro em regime para entrada do tipo rampa & - \\
$t_{s}$ & Tempo de acomodação & $\mathrm{s}$ \\
$\omega_{r e f}$ & Sinal de referência de velocidade angular & $\mathrm{rad} / \mathrm{s}$ \\
$T_{r e f}$ & Sinal de referência de torque & $\mathrm{Nm}$ \\
$\mathbf{T}_{d s t}$ & Torque de dessaturação & $\mathrm{N} \mathrm{m}$ \\
$k_{d s t}$ & Ganho do controlador de dessaturação & - \\
$\mathbf{H}_{d}$ & Momento angular desejado das rodas de reação & $\mathrm{kg} \mathrm{m}^{2} / \mathrm{s}$ \\
$\mathbf{m}_{d s t}$ & Momento magnético de dessaturação & $\mathrm{A} \mathrm{m}{ }^{2}$ \\
\hline
\end{tabular}





\section{SUMÁRIO}

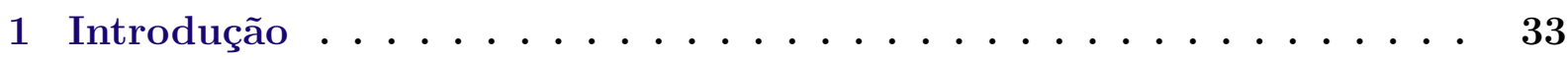

1.1 Motivações . . . . . . . . . . . . . . . . . . . . 34

1.2 Justificativas . . . . . . . . . . . . . . . . . . . 36

1.3 Objetivos e Contribuições . . . . . . . . . . . . . . . . 37

1.4 Metodologia de Desenvolvimento . . . . . . . . . . . . 37

1.5 Estrutura da Dissertação . . . . . . . . . . . . . . . . . . . 37

2 Representação de Atitude . . . . . . . . . . . . . . . 39

2.1 Matriz de Cossenos Diretores . . . . . . . . . . . . . . . . . 39

2.2 Ângulos de Euler e Yaw-Pitch-Roll . . . . . . . . . . . . . . . . . . . 40

2.3 Eixo de Euler, Parâmetros Simétricos de Euler e Quatérnios . . . . . . . 42

3 Sistemas de Coordenadas . . . . . . . . . . . . . . 45

3.1 Sistema de Coordenadas Geocêntrico Equatorial Inercial . . . . . . . . 45

3.2 Sistema de Coordenadas Geocêntrico Equatorial Terrestre . . . . . . . . 45

3.3 Sistema de Coordenadas Referente à Órbita do Satélite . . . . . . . . . . 47

3.4 Sistema de Coordenadas Referente ao Corpo do Satélite . . . . . . . . . . 47

3.5 Sistema de Coordenadas Referente aos Eixos Principais de Inércia . . . . 48

3.6 Rotação Entre os Sistemas de Coordenadas . . . . . . . . . . . . . . . . . 48

3.6.1 GEI e GET . . . . . . . . . . . . . . . . . . . . . . . . . . 49

3.6 .2 GEI e ROS . . . . . . . . . . . . . . . . . . . . . . . 49

3.6.3 RCS e REP . . . . . . . . . . . . . . . . . . 50

4 Modelagem Matemática . . . . . . . . . . . . . . 51

4.1 Modelagem Matemática do Satélite . . . . . . . . . . . . . . . 51

4.1 .1 Cinemática ............................ 51

4.1 .2 Dinâmica de Atitude . . . . . . . . . . . . . . . 52

4.1.2.1 Atuadores . . . . . . . . . . . . . . . . 52

4.1.2.2 Integração do Satélite . . . . . . . . . . . . . . 55

4.2 Modelagem Matemática da Dinâmica Orbital . . . . . . . . . . . . . 57

4.3 Modelagem Matemática das Perturbações . . . . . . . . . . . . . 58

4.3.1 Perturbações de Atitude . . . . . . . . . . . . . . . . . 58

4.3.1.1 Torque Devido ao Arrasto Atmosférico . . . . . . . . . . 59

4.3.1.2 Torque Devido à Pressão de Radiação Solar . . . . . . . 61

4.3.1.3 Torque Devido ao Gradiente de Gravidade . . . . . . . . 66

4.3.1.4 Torque Devido ao Dipolo Magnético Residual . . . . . . 67

4.3.2 Perturbações Orbitais . . . . . . . . . . . . . . . . . 67

4.3.2.1 Aceleração Devido ao Arrasto Atmosférico . . . . . . . . 68

4.3.2.2 Aceleração Devido à Pressão de Radiação Solar . . . . . 68 
4.3.2.3 Aceleração Devido à não Homogeneidade da Terra . . 68

4.3.2.4 Aceleração Devido ao Efeito de um Terceiro Corpo . . . 71

5 Resultados de Simulação da Modelagem Matemática . . . . . . . . 75

5.1 Nanossatélites Hipotéticos . . . . . . . . . . . . . . . 75

5.2 Órbitas Hipotéticas . . . . . . . . . . . . . . . . . . . . . . 77

5.3 Configurações de Simulação . . . . . . . . . . . . . . . . . . . . . 79

5.4 Simulação da Dinâmica do Satélite . . . . . . . . . . . . . 79

5.4.1 Movimento de Nutação . . . . . . . . . . . . . . . . . . . . . . . 79

5.4.2 Movimento de Precessão . . . . . . . . . . . . . . . . . . . . . . 80

5.4.3 Movimento Devido ao Atuador Magnético . . . . . . . . . . . . . 82

5.4.4 Movimento Devido à Roda de Reação . . . . . . . . . . . . . . . . 83

5.5 Simulação da Órbita do Satélite . . . . . . . . . . . . . . . . . . . . 84

5.6 Simulação das Perturbações . . . . . . . . . . . . . . . . . 86

6 Resultados de Validação da Modelagem Matemática . . . . . . . . . 91

6.1 O nanossatélite PicSat . . . . . . . . . . . . . . . . . . . . . . . 91

6.2 Validação da Dinâmica do Satélite . . . . . . . . . . . . . . . . . . . 94

6.2.1 Primeira Etapa de Validação da Dinâmica . . . . . . . . . . . . . 96

6.2.2 Segunda Etapa de Validação da Dinâmica . . . . . . . . . . . . . 98

6.3 Validação da Órbita do Satélite . . . . . . . . . . . . . . . . . . . . . 104

7 Sistema de Controle de Atitude . . . . . . . . . . . . . 109

7.1 Modos de Operação . . . . . . . . . . . . . . . . . . . . . . . . 109

7.2 Requisitos e Características . . . . . . . . . . . . . . . . . 110

7.3 Detumbling . . . . . . . . . . . . . . . . . . . 111

7.3.1 Controlador B-dot . . . . . . . . . . . . . . 111

7.3.2 Análise de Estabilidade . . . . . . . . . . . . . . . . . . . . . 113

7.3.3 Estimador da Derivada do Campo Magnético Terrestre . . . . . . 116

7.3.4 Resultados de Simulação do Controlador de Detumbling ... . . 116

7.3.5 Resultados de Comparação com Dados de Voo . . . . . . . . . . . 120

7.4 Apontamento . . . . . . . . . . . . . . . . . . . . 123

7.4.1 Regulador Quadrático Linear . . . . . . . . . . . . . . . . 123

7.4.1.1 Modelo Linear . . . . . . . . . . . . . . . . . 125

7.4.1.2 Controlabilidade, Observabilidade e Estabilidade . . . . 126

7.4.1.3 Projeto do Controlador . . . . . . . . . . . . . 127

7.4 .2 Controle das Rodas de Reação . . . . . . . . . . . . . . . . . . . . 128

7.4.3 Dessaturação das Rodas de Reação . . . . . . . . . . . . . . . . . 130

7.4.4 Resultados de Simulação do Controlador de Apontamento . . . . 132

8 Discussões e Conclusões . . . . . . . . . . . . . . . . . 147

8.1 Recomendações para Trabalhos Futuros . . . . . . . . . . . . . . . . . . 148 
Referências . . . . . . . . . . . . . . . . . . 151

APÊNDICE A Dinâmica do Corpo Rígido . . . . . . . . . 161

A.1 Teorema de Steiner . . . . . . . . . . . . . . . . . . . . . . . 162

APÊNDICE B Ilustrações de Validação . . . . . . . . . . . . . 163

ANEXO A Folha de Parâmetros do Motor Maxon EC 20 Flat [351100] 181

ANEXO B Artigo apresentado no III IAA Latin American CubeSat

Workshop . . . . . . . . . . . . 183 



\section{NOTAÇÃO MATEMÁTICA}

No texto, as grandezas vetoriais são representadas em negrito: $\mathbf{X}, \mathbf{y}$. Matrizes são representadas em negrito e entre colchetes: $[\mathbf{K}]$. Vetores unitários são representados com acento circunflexo sobrescrito à variável: n̂. Por ser uma exceção, o quatérnio é representado em negrito e itálico: $\boldsymbol{q}$. Grandezas escalares são representadas em itálico: $\alpha$, $\beta$. Quando necessário, as variáveis são acompanhadas de um termo subscrito à direita, como forma de indicar a qual elemento se refere: $\mathbf{X}_{a}, \alpha_{b}$.

Uma variável pode ser expressa em diferentes sistemas de coordenadas. Portanto, utiliza-se um termo sobrescrito à direita, como forma de indicar a qual sistema se refere: $\mathbf{y}^{i}$. Em algumas situações, também se faz necessário indicar que a variável é uma grandeza de um sistema de coordenadas em relação a outro. Neste caso, utiliza-se uma identificação subscrita a direita: $\boldsymbol{\omega}_{p / i}^{p}$ é a grandeza vetorial $\boldsymbol{\omega}$ do sistema de coordenadas $p$ em relação a $i$, expressa em $p$. O mesmo princípio vale para representar a relação entre sistemas de coordenas: $[\mathbf{Q}]_{p / i}$ é a matriz que representa o sistema $p$ em relação a $i ; \boldsymbol{q}_{s / t}$ é o quatérnio que representa o sistema $s$ em relação a $t$.

Os produtos escalar e vetorial são representados, respectivamente, por $(\cdot)$ e $(\times)$. 



\section{INTRODUÇÃO}

O primeiro satélite artificial lançado pelo homem foi o Sputnik 1, em 1957, pela, então, União Soviética. Desde então, cerca de 8000 novos satélites foram colocados no espaço com sucesso [2]. Tradicionalmente, os satélites são veículos sofisticados, pesados, volumosos e de alto investimento. Dentre outros motivos, isso se dá pela sua própria destinação, que, normalmente, requer alto desempenho e confiabilidade.

Em 1999, diante dos avanços tecnológicos que viabilizaram miniaturizar diversos equipamentos e produzir componentes prontos para uso, conhecidos em inglês por commercial off-the-shelf (COTS), a California Polytechnic State University e a Stanford University propuseram um novo conceito de nanossatélite*, denominado CubeSat [7]. Essa nova proposta transformou as possibilidades então existentes, permitindo que outras instituições, não capazes de produzir os satélites tradicionalmente conhecidos, lançassem seus próprios veículos, observando-se, dentro destas produções, suas limitações e finalidades específicas. Em sua concepção, o CubeSat é um satélite em forma de cubo de dimensões padronizadas, devendo 1 unidade $(1 \mathrm{U})$ ter $10 \mathrm{~cm} \times 10 \mathrm{~cm} \times 10 \mathrm{~cm}$ e massa inferior a $1,33 \mathrm{~kg}$. A combinação de unidades também é possível, permitindo desenvolver CubeSats de dimensões maiores: 2U, 3U, 6U, etc. A Figura 1 ilustra CubeSats de 1U, 3U e $6 \mathrm{U}$.

Figura 1 - Ilustração de dimensões do CubeSats.

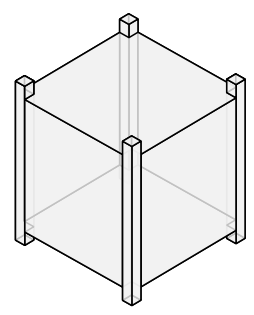

$1 \mathrm{U}$

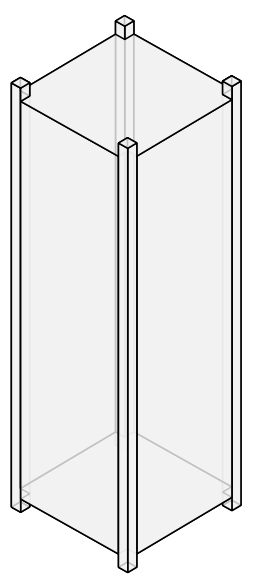

$3 \mathrm{U}$

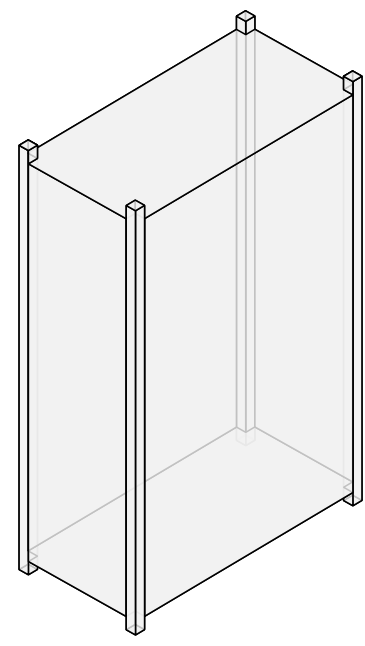

$6 \mathrm{U}$

Fonte: Autor.

*Uma das formas de classificação de satélites é com relação à massa. Entretanto, conforme discutido em [3], as diversas literaturas adotam classificações similares, mas não idênticas. Neste trabalho adota-se a classificação utilizada em [4],[5] e [6]. Denomina-se de satélite de pequeno porte, em inglês small satellite ou smallsat, quando a massa é inferior a $500 \mathrm{~kg}$. Dentro dessa categoria, são classificados como: minissatélite $((100-500) \mathrm{kg})$, microssatélite $((10-100) \mathrm{kg})$, nanossatélite $((1-10) \mathrm{kg})$ e picossatélite $(<1 \mathrm{~kg})$. 
Com o avanço tecnológico contínuo, também tornou-se atrativo o uso de CubeSats para fins comerciais e missões científicas (ver [8] e [9]) . Como exemplos, em 2017 a empresa Planet Labs, em um único lançamento, colocou 88 CubeSats em órbita para realizar imageamento da Terra [10]. E, em 2018, a NASA enviou para Marte dois CubeSats de 6U (MarCO-A e MarCO-B), para auxiliar na missão Mars Insight [11].

Segundo a base de dados Nanosats Database [4], até o dia 20 de abril de 2020, foram lançados 1118 CubeSats, dos quais 5 são brasileiros: NanosatC-BR1 [12] lançado em 2014, SERPENS [13] e AESP-14 [14] em 2015, ITASAT-1 [15] em 2018 e FloripaSat-1 [16] em 2019.

Diante desse cenário, o Instituto Mauá de Tecnologia (IMT), visando fomentar a produção acadêmica na área aeroespacial brasileira, iniciou o desenvolvimento de um CubeSat com tecnologia $100 \%$ nacional. Concomitantemente, o Instituto de Astronomia, Geofísica e Ciências Atmosféricas (IAG) da Universidade de São Paulo (USP) demonstrou interesse em desenvolver um CubeSat com uma carga útil científica.

\subsection{Motivações}

Ainda que menos exigente quando comparado aos satélites de grande porte, o projeto de um CubeSat é composto por vários subsistemas que precisam ser especificados, avaliados e testados para garantir o sucesso da missão. Apesar da divisão dos subsistemas variar de acordo com cada projeto, tipicamente é possível separá-los em [17]: (i) suprimento elétrico de potência: responsável por suprir as demandas de energia; (ii) sistema de determinação e controle de atitude $^{\dagger}$ e órbita, em inglês attitude and orbit determination and control system (AODCS): responsável por medir e alterar a orientação e posição do satélite; (iii) telemetria e comunicação: responsável pela comunicação com a estação de solo; (iv) comando e processamento de dados: responsável pelo gerenciamento dos outros subsistemas; (v) estrutura e mecanismos: responsável pela sustentação mecânica e dispositivos móveis; (vi) carga útil: elemento de finalidade da missão.

Villela et al.[9] analisaram 855 missões com CubeSats e identificaram que 23,7\% dos lançamentos realizados entre 2017 e 2018 apresentaram falha durante o comissionamento ou durante os estágios iniciais. Essa condição, chamada de "mortalidade infantil", é abordada também em [19], na qual Langer et al. identificam que a ocorrência é majoritariamente em satélites universitários devido à falta de testes e simulações adequadas ainda em solo. Em [20] apresenta-se uma importante discussão em relação à sobrevivência dos nanossatélites desenvolvidos nas universidades, dessa vez dando ênfase ao sistema de determinação e controle de atitude e a integração dos subsistemas. A simulação computacional é uma

\footnotetext{
†Atitude é o termo utilizado para descrever a orientação do satélite em um espaço tridimensional [18].
} 
etapa primordial, que aumenta a chance de sucesso da missão e ainda reduz custo de projeto e tempo de desenvolvimento.

De forma mais específica, a simulação de dinâmica de atitude e órbita do satélite permite avaliar a orientação, trajetória e condições ambientais às quais o veículo estará sujeito ao longo do tempo. Por conta disso, tal simulação é relevante para todos os subsistemas e, especialmente, para o desenvolvimento do AODCS.

O AODCS é uma síntese de outros subsistemas. A primeira divisão pode ser feita em relação à órbita e à atitude, gerando o Orbit Determination and Control System (ODCS) e o Attitude Determination and Control System (ADCS). A segunda divisão pode ser feita em relação à determinação e ao controle, gerando o Orbit Determination System (ODS), Orbit Control System (OCS), Attitude Determination System (ADS) e Attitude Control System (ACS). A Figura 2 ilustra as citadas divisões.

Figura 2 - Ilustração das divisões do AODCS.

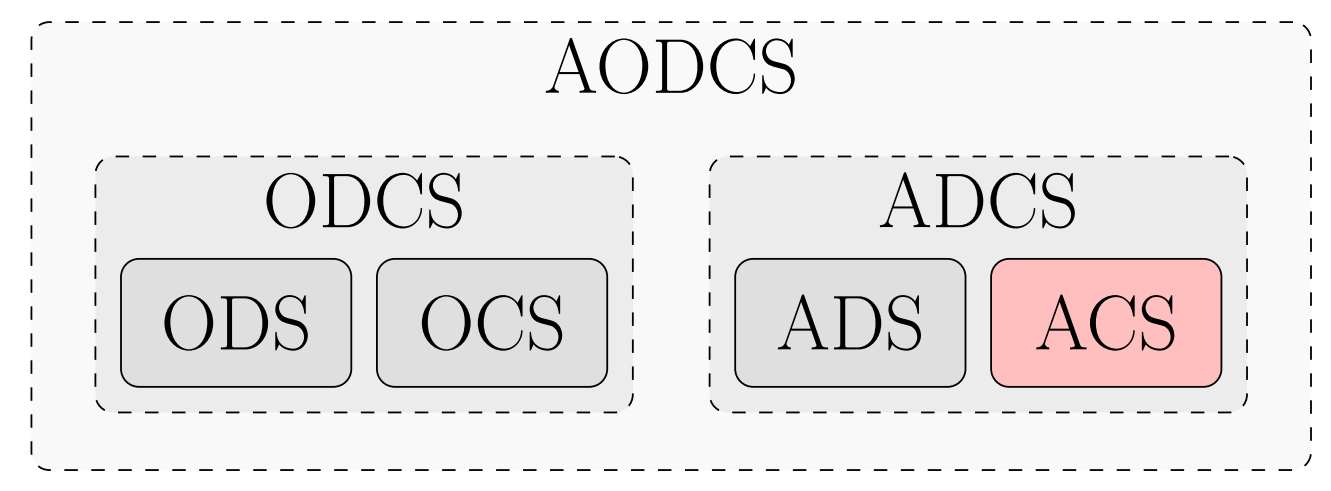

Fonte: Autor.

Os sistemas relacionados à determinação, ODS e ADS, são responsáveis por gerenciar os sensores e fornecer informação de posição orbital e orientação do veículo em relação à referencia inercial, respectivamente. Essas informações são transmitidas para os sistemas relacionados ao controle, OCS e ACS, que, por sua vez, gerenciam e acionam os atuadores, conforme as respectivas leis de controle.

Em CubeSats, o controle de órbita ainda é incomum. Isto se deve às limitações de energia, volume e massa do satélite, assim como da dependência de uma tecnologia altamente avançada, exigindo um elevado tempo de desenvolvimento [21]. Por outro lado, com relação ao controle de atitude, uma pesquisa realizada com 426 CubeSats lançados até janeiro de 2016 [22] identificou, dentre outros sistemas de controle, que $56 \%$ destes CubeSats utilizaram atuadores magnéticos, $44 \%$ utilizaram rodas de reação, $13 \%$ utilizaram um controle magnético passivo, contra $4 \%$ que não utilizaram nenhum tipo de controle. 


\subsection{Justificativas}

Mais uma vez a importância do simulador no desenvolvimento e concepção do veículo é destacada em [23]. Para Sebestyen et al. os modelos matemáticos de alta fidelidade devem conter, ao menos: (i) dinâmica do corpo rígido; (ii) modelo de mecânica orbital; (iii) modelo de campo magnético de alta fidelidade; (iv) modelo de densidade atmosférica de alta fidelidade; (v) torque devido ao arrasto atmosférico; (vi) torque devido à pressão da radiação solar; (vii) torque devido ao gradiente de gravidade; (viii) torque devido ao dipolo magnético residual; e (ix) posição do Sol. Essa colocação é feita no contexto de órbita de altitude inferior à $2000 \mathrm{~km}$, denominada de órbita terrestre baixa, em inglês Low Earth Orbit (LEO). Com exceção do MarCO-A e MarCO-B, todos os CubeSats foram lançados nessa faixa orbital, dos quais $76 \%$ foram na faixa de $(350-700) \mathrm{km}$ de altitude $[9,22]$.

Diversos simuladores acadêmicos, quando comparados às características supracitadas de um simulador de alta fidelidade matemática, apresentam-se deficitários em ao menos um dos itens. Isso ocorre tanto em simuladores para aplicações específicas, como o desenvolvimento do ACS e/ou ADS de um nanossatélite particular [24-38], quanto em simuladores com propostas mais abrangentes para servirem como plataforma de desenvolvimento [39-46].

Há também iniciativas de simuladores de código aberto e toolbox do MATLAB como o ODTBX desenvolvido pela NASA, mas que tem apenas dinâmica orbital [47]; KPS disponível em $\mathrm{C}++$, MATLAB e Pyton, mas que possui limitações de perturbação [48]; PROPAT disponível como toolbox do MATLAB, mas com limitações de perturbação [49]; SNAP disponível em Simulink e MATLAB, mas que possui somente dinâmica de atitude e limitações de perturbação [50]; e o OPEN-SESSAME desenvolvido em C++ [51].

E, por fim, como softwares pagos, existem os simuladores Systems Tool Kit (STK) e Orbit Determination Tool Kit (ODTK) da empresa AGI, que podem ser utilizados sozinhos ou integrados ao MATLAB [52]; MADS 3D que pode ser utilizado sozinho ou em hardware-in-the-loop [53]; e Spacecraft Control Toolbox (SCT) da empresa Princeton Satellite System, que funciona como um pacote do MATLAB [54]. Como os modelos matemáticos desse simuladores não estão disponíveis, não é possível compará-los com as colocações em [23]. Entretanto, todos informam ser simuladores de alta fidelidade matemática.

A maior parte dos simuladores citados não possui validação [39-43,48-51]. Isso se deve, principalmente, à dificuldade de se obter dados reais. Como alternativa, alguns trabalhos comparam os resultados com outro simulador acadêmico [46] ou comercial [44,45].

Em [55], uma equipe da NASA Jet Propulsion Laboratory utiliza os dados de voo do CubeSat MicroMAS-1 para validar o simulador. O mesmo é possível observar em [56], com o CubeSat UWE-3, e em [57] com o CubeSat ESTCube-1. Alguns trabalhos se dedicam a validar o desempenho de um dos subsistemas com dados de voo como em [58] 
os nanossatélites RAX-1 e RAX-2 e em [59] o ESTCube-1. Entretanto, um número maior de trabalhos utiliza os dados reais para uma análise geral de desempenho [60-66].

\subsection{Objetivos e Contribuições}

Diante de todo o acima exposto, este trabalho se propõe a desenvolver um simulador de atitude e órbita, validar o simulador com dados de voo do PicSat, nanossatélite francês desenvolvido pelo Observatório de Paris [67], uma première no cenário brasileiro, bem como malhas de controle de atitude passíveis de serem implementadas nos projetos do IMT e do IAG.

O simulador se propõe a: (i) ser configurável, permitindo e acomodando alterações nas características do satélite, atuadores, condições iniciais e ambiente externo; (ii) implementar modelos matemáticos relevantes no contexto de CubeSats, incluindo a dinâmica dos atuadores; (iii) ser aplicável a nanossatélite em órbita terrestre baixa.

O controle de atitude proposto tem como objetivo: (i) ser abrangente, permitindo ser implementado em diversas configurações de nanossatélites (e.g. CubeSats de 1U, $2 \mathrm{U}, 3 \mathrm{U}$, etc.); (ii) levar em conta detalhes e limitações de implementação, como a taxa de amostragem dos computadores de bordo, realização de derivadas numéricas, ruídos oriundos do ADS, etc.; (iii) basear-se em COTS; e (iv) ser capaz de reduzir a velocidade angular do satélite e apontar para uma direção solicitada.

\subsection{Metodologia de Desenvolvimento}

Para atingir os objetivos propostos, os seguintes passos foram seguidos: (i) estudo dos modelos matemáticos da dinâmica do satélite e da órbita, bem como das principais perturbações às quais o veículo está sujeito nessas condições; (ii) implementação dessas equações em ambiente computacional, utilizando os softwares MATLAB e Simulink; (iii) comparação dos resultados apresentados com as principais referências, e.g. [18,68-70]; (iv) validação dos resultados com dados de voo do PicSat; (v) estudo do controle de atitude; (vi) adição do controle de atitude ao modelo computacional; e (vii) comparação dos resultados com o esperado.

\subsection{Estrutura da Dissertação}

O restante deste trabalho está organizado da seguinte forma: O Capítulo 2 apresenta as possibilidades de representar a atitude de um corpo rígido em relação a uma referência inercial. O Capítulo 3 apresenta os sistemas de coordenadas utilizados ao longo deste trabalho. As modelagens matemáticas do satélite, da órbita e das perturbações são 
apresentadas no Capítulo 4. Os resultados de simulações são apresentados no Capítulo 5 e a validação com dados de voo do PicSat são apresentados no Capítulo 6. No Capítulo 7 é apresentado o sistema de controle de atitude proposto, bem como os resultados de simulação. Por fim, a conclusão é apresentada no Capítulo 8. 


\section{REPRESENTAÇÃO DE ATITUDE}

A orientação de um corpo rígido em relação a um referencial inercial é denominada de atitude e pode ser representada por diversas formas: matriz de cossenos diretores, ângulos de Euler, eixos de Euler e quatérnios [68].

Por conveniência didática, o sistema de coordenadas inercial XYZ, denominado por $i$, é formado pelos vetores unitários, ortogonais e dextrogiros, $\hat{\mathbf{X}}, \hat{\mathbf{Y}}$ e $\hat{\mathbf{Z}}$. E o sistema de coordenadas móvel xyz, denominado por $m$, é formado pelos eixos unitários, ortogonais e dextrogiros, $\hat{\mathbf{x}}, \hat{\mathbf{y}}$ e $\hat{\mathbf{z}}$.

\subsection{Matriz de Cossenos Diretores}

Conforme ilustrado na Figura 3, os elementos do sistema de coordenadas móvel, podem ser expressos no sistema de coordenas inercial em função dos seus componentes, i.e.,

$$
\left[\begin{array}{l}
\hat{\mathbf{x}} \\
\hat{\mathbf{y}} \\
\hat{\mathbf{z}}
\end{array}\right]=\left[\begin{array}{lll}
x_{1} & x_{2} & x_{3} \\
y_{1} & y_{2} & y_{3} \\
z_{1} & z_{2} & z_{3}
\end{array}\right]\left[\begin{array}{c}
\hat{\mathbf{X}} \\
\hat{\mathbf{Y}} \\
\hat{\mathbf{Z}}
\end{array}\right] .
$$

Figura 3 - Relação entre o eixo inercial, $X Y Z$, e o eixo móvel, $x y z$.

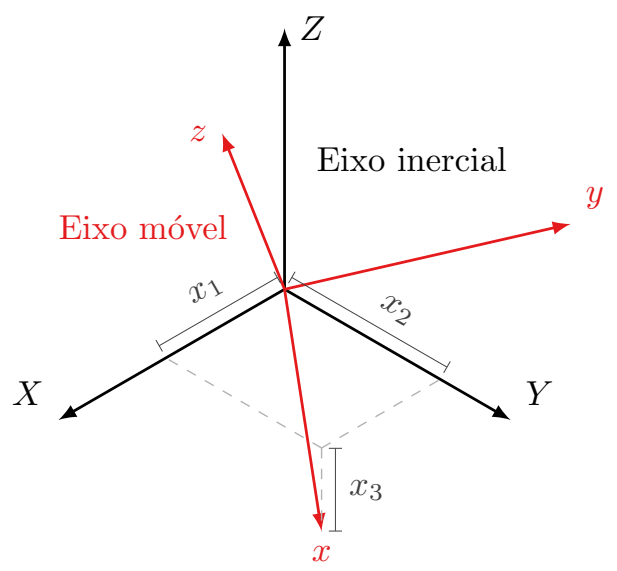

Fonte: Autor.

Assim, a matriz que representa o sistema móvel $m$ em relação ao sistema inercial $i$ é dada por

$$
[\mathbf{Q}]_{m / i}=\left[\begin{array}{ccc}
x_{1} & x_{2} & x_{3} \\
y_{1} & y_{2} & y_{3} \\
z_{1} & z_{2} & z_{3}
\end{array}\right]
$$


Por sua vez, os elementos da matriz $[\mathbf{Q}]$ podem ser escritos como

$$
[\mathbf{Q}]_{m / i}=\left[\begin{array}{lll}
\hat{\mathbf{X}} \cdot \hat{\mathbf{X}} & \hat{\mathbf{X}} \cdot \hat{\mathbf{Y}} & \hat{\mathbf{X}} \cdot \hat{\mathbf{Z}} \\
\hat{\mathbf{y}} \cdot \hat{\mathbf{X}} & \hat{\mathbf{y}} \cdot \hat{\mathbf{Y}} & \hat{\mathbf{y}} \cdot \hat{\mathbf{Z}} \\
\hat{\mathbf{z}} \cdot \hat{\mathbf{X}} & \hat{\mathbf{z}} \cdot \hat{\mathbf{Y}} & \hat{\mathbf{z}} \cdot \hat{\mathbf{Z}}
\end{array}\right]
$$

Tendo em vista que o produto escalar de dois vetores unitários é o cosseno do ângulo entre eles, a matriz $[\mathbf{Q}]_{m / i}$ é denominada como Matriz de Cossenos Diretores [18]. Em inglês é comum o uso da sigla DCM, uma abreviação de Direct Cossine Matrix. Ademais, também pode ser chamada de Matriz de Atitude, uma vez que relaciona a orientação do eixo móvel com o eixo inercial [69].

Conforme teorizado por Euler, apenas três ângulos são necessários para especificar a orientação de um corpo num sistema inercial. Sendo assim, a matriz de cossenos diretores apresenta seis termos de redundância, não sendo a forma mais otimizada de representar a atitude do satélite.

Contudo, a matriz de cossenos é bastante útil e prática quando utilizada como matriz de rotação, realizando transformações de coordenadas. De fato, outras formas de representar a atitude, como Ângulos de Euler e Quatérnios, quando utilizados para realizar uma transformação de base, são convertidos nesse formato matricial [69].

Seja a um vetor, expresso no sistema de coordenadas inercial, sua representação no sistema de coordenadas móvel é dada por

$$
\mathbf{a}^{m}=[\mathbf{Q}]_{m / i} \mathbf{a}^{i}
$$

Os vetores que compõem a matriz $[\mathbf{Q}]$ são unitários e ortogonais entre si, isto é, $[\mathbf{Q}][\mathbf{Q}]^{\top}=[1]$ e $[\mathbf{Q}]^{\top}=[\mathbf{Q}]^{-1}$. Isto posto, a transformação de bases no sentido contrário, ou seja, do sistema de coordenadas móvel para o sistema inercial, é dada por

$$
\mathbf{a}^{i}=[\mathbf{Q}]_{m / i}^{\top} \mathbf{a}^{m}
$$

Note que, $[\mathbf{Q}]_{m / i}^{\top}=[\mathbf{Q}]_{i / m}[18]$.

Outra propriedade importante das matrizes de rotação é a possibilidade de realizar, de forma simples, rotações sucessivas. Considere $[\mathbf{Q}]_{b / a}$ e $[\mathbf{Q}]_{c / b}$ matrizes que transformam, respectivamente, do sistema $a$ para $b$ e do sistema $b$ para $c$. A rotação de $a$ para $c$ é dada por

$$
[\mathbf{Q}]_{c / a}=[\mathbf{Q}]_{c / b}[\mathbf{Q}]_{b / a}
$$

\section{2 Ângulos de Euler e Yaw-Pitch-Roll}

As rotações em torno dos eixos inerciais $X, Y$ e $Z$, por um ângulo $\theta$, são ilustradas na Figura 4. 
Figura 4 - Rotação em torno dos eixos $X, Y$ e $Z$.

(a) Rotação em torno do eixo $X$.

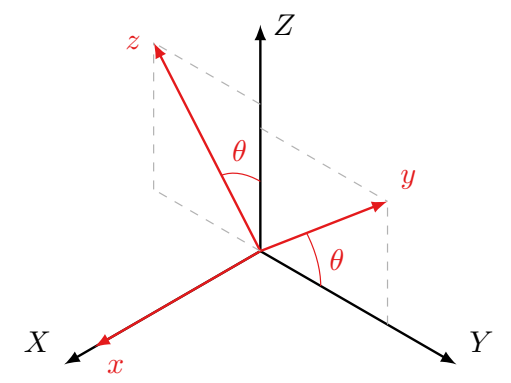

Fonte: Autor. (b) Rotação em torno do eixo $Y$.

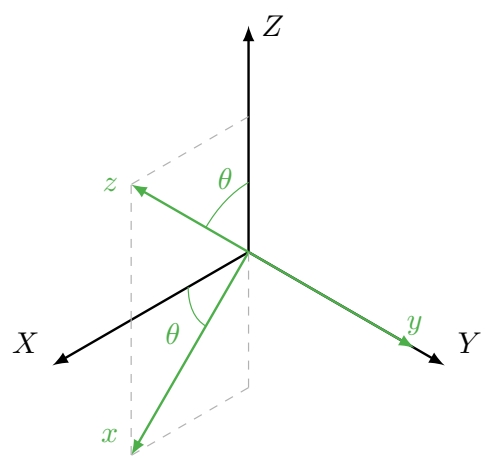

(c) Rotação em torno do eixo $Z$.

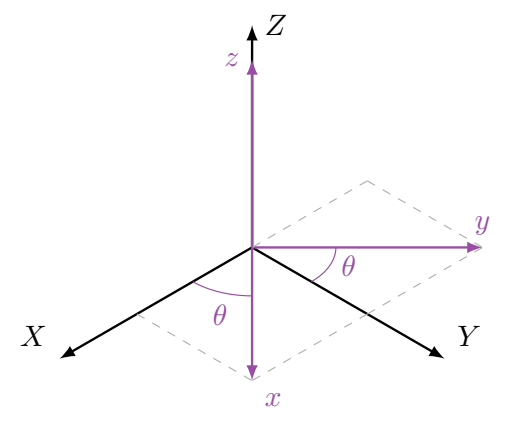

Suprimindo os termos subscritos, as matrizes de rotação em torno dos eixos $X, Y$ e $Z$ são dadas, respectivamente, por

$$
\begin{gathered}
{\left[\mathbf{Q}_{X}(\theta)\right]=\left[\begin{array}{ccc}
1 & 0 & 0 \\
0 & \cos \theta & \operatorname{sen} \theta \\
0 & -\operatorname{sen} \theta & \cos \theta
\end{array}\right]} \\
{\left[\mathbf{Q}_{Y}(\theta)\right]=\left[\begin{array}{ccc}
\cos \theta & 0 & -\operatorname{sen} \theta \\
0 & 1 & 0 \\
\operatorname{sen} \theta & 0 & \cos \theta
\end{array}\right]}
\end{gathered}
$$

$\mathrm{e}$

$$
\left[\mathbf{Q}_{Z}(\theta)\right]=\left[\begin{array}{ccc}
\cos \theta & \operatorname{sen} \theta & 0 \\
-\operatorname{sen} \theta & \cos \theta & 0 \\
0 & 0 & 1
\end{array}\right]
$$

Esses resultados são relevantes para facilitar a compreensão da rotação por Ângulos de Euler, uma vez que se tratam de três rotações elementares sucessivas permitindo relacionar dois eixos cartesianos distintos, como o eixo inercial e o eixo móvel. Porém, não são válidas duas rotações sucessivas em torno do mesmo eixo. Sendo sequenciais, é importante compreender que a terceira rotação ocorrerá no eixo já rotacionado pela segunda, que, por sua vez, ocorrerá no eixo já rotacionado pela primeira. As sequências possíveis, que repetem o primeiro e último eixo, são: (X Y X), (XZX), (YX Y), (Y ZY), (ZXZ) e (Z YZ). As sequências assimétricas possíveis são: (X YZ), (XZY), (YXZ), (YZX), (ZXY) e (Z Y X).

A Figura 5 representa a sequência (ZXZ), sendo a primeira rotação em torno do eixo $Z$, por um ângulo $\psi$, a segunda rotação em torno do eixo $x_{1}$, por um ângulo $\theta$, e a terceira rotação em torno do eixo $z_{2}$, por um ângulo $\phi$. Essa sequência é conhecida como Sequência Clássica dos Ângulos de Euler [68]. 
Figura 5 - Rotação por Ângulos de Euler (ZX Z).

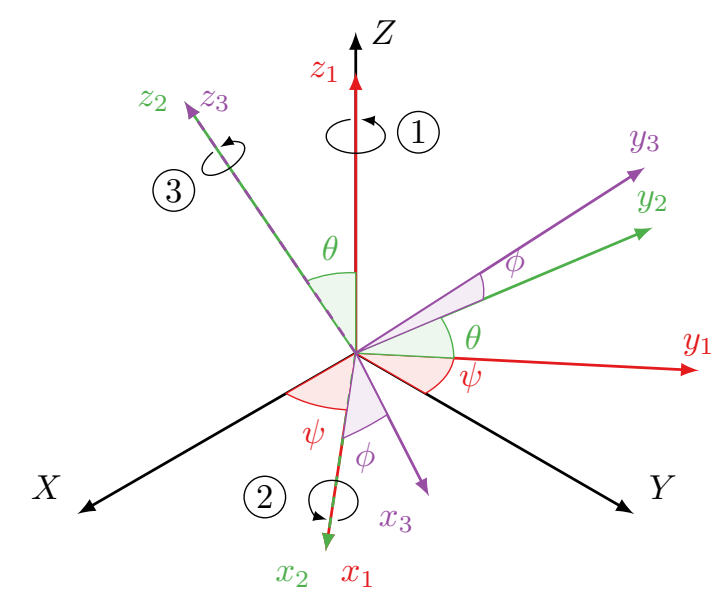

Fonte: Autor.

Utilizando-se dessa sequência, a matriz de rotação do sistema inercial para o móvel é dada por

$$
\begin{aligned}
{[\mathbf{Q}]_{m / i} } & =\left[\mathbf{Q}_{z_{2}}(\phi)\right]\left[\mathbf{Q}_{x_{1}}(\theta)\right]\left[\mathbf{Q}_{Z}(\psi)\right] \\
& =\left[\begin{array}{ccc}
\cos \phi & \operatorname{sen} \phi & 0 \\
-\operatorname{sen} \phi & \cos \phi & 0 \\
0 & 0 & 1
\end{array}\right]\left[\begin{array}{ccc}
\cos \theta & 0 & -\operatorname{sen} \theta \\
0 & 1 & 0 \\
\operatorname{sen} \theta & 0 & \cos \theta
\end{array}\right]\left[\begin{array}{ccc}
\cos \psi & \operatorname{sen} \psi & 0 \\
-\operatorname{sen} \psi & \cos \psi & 0 \\
0 & 0 & 1
\end{array}\right]
\end{aligned}
$$

A representação da atitude por ângulos de Euler apresenta grande vantagem de interpretação e visualização gráfica quando comparada às outras formas. Entretanto, em algumas regiões específicas, sofre de singularidade, isto é, não há uma solução única e, com isso, perde um dos três graus de liberdade. Esse efeito é conhecido como gimbal lock e ocorre, no caso das sequências em que repetem a primeira e a terceira rotações como a sequência clássica de Euler (ZXZ), quando o segundo ângulo de rotação, $\theta$, é $0^{\circ}$ ou $180^{\circ}$. Nas sequências assíncronas, ocorre quando $\theta$ é $\pm 90^{\circ}$. Uma forma de mitigar essa condição é adotar uma sequência e faixa de trabalho que, para a aplicação desejada, não se aproxime dos pontos onde a singularidade ocorre. Uma dessas alternativas, bastante comum e consolidada, é conhecida por Yaw-Pitch-Roll ou Ângulos de Tait-Bryan, que utiliza a sequência (ZYX) para aplicações em que $\theta$ esteja entre $\pm 90^{\circ}$. As áreas de aviação e naval, frequentemente, utilizam essa sequência, na qual Pitch é o ângulo de arfada [68,71].

\subsection{Eixo de Euler, Parâmetros Simétricos de Euler e Quatérnios}

Assim como três rotações elementares sucessivas permitem relacionar dois eixos distintos, Leonhard Euler também propôs que é possível relacionar dois sistemas de coordenas por 
uma única rotação em torno de um único eixo, passando pela origem comum desses sistemas. A Figura 6 representa a rotação em torno do eixo û por um ângulo $\theta$. Essa representação é chamada de Eixo [68], ou Ângulo-Eixo [18] de Euler e é uma alternativa às singularidades sofridas pela representação por Ângulos de Euler.

Figura 6 - Rotação por Eixo de Euler.

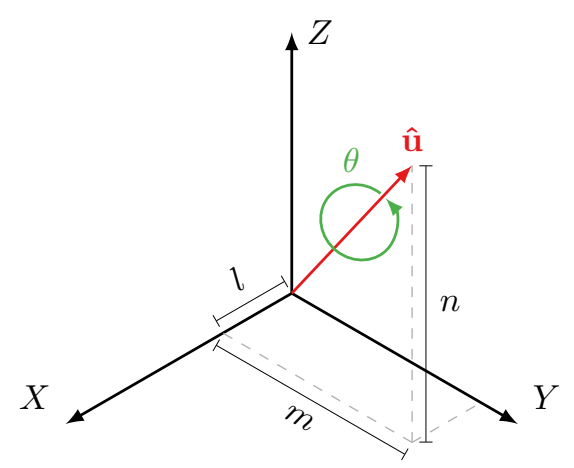

Fonte: Autor.

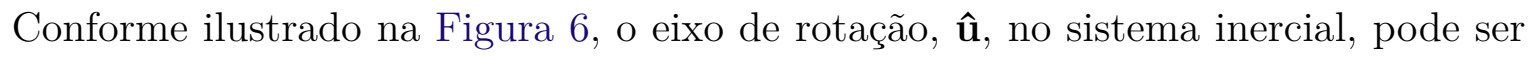
definido por

$$
\hat{\mathbf{u}}=l \hat{\mathbf{X}}+m \hat{\mathbf{Y}}+n \hat{\mathbf{Z}}
$$

sendo $l, m$ e $n$ as projeções do eixo $\hat{\mathbf{u}}$ nos eixos inerciais $X, Y$ e $Z$, respectivamente.

Conforme demonstrado em [68], utilizando-se de propriedades trigonométricas, a matriz de rotação do sistema inercial para o móvel é expressa por

$$
[\mathbf{Q}]_{m / i}=\left[\begin{array}{ccc}
l^{2}(1-\cos \theta)+\cos \theta & l m(1-\cos \theta)+n \operatorname{sen} \theta & l n(1-\cos \theta)-m \operatorname{sen} \theta \\
l m(1-\cos \theta)-n \operatorname{sen} \theta & m^{2}(1-\cos \theta)+\cos \theta & m n(1-\cos \theta)+l \operatorname{sen} \theta \\
l n(1-\cos \theta)+m \operatorname{sen} \theta & m n(1-\cos \theta)-l \operatorname{sen} \theta & n^{2}(1-\cos \theta)+\cos \theta
\end{array}\right]
$$

Apesar de ser uma clara representação física de rotação e não apresentar singularidade, quando comparado aos outros métodos apresentados, o Eixo de Euler depende de equações trigonométricas, exigindo relativo esforço computacional, e apresenta elevada complexidade trigonométrica para realizar duas rotações sucessivas em torno de eixos distintos [18].

Uma abordagem de representação da atitude, similar ao Eixo de Euler, que também não apresenta singularidades, são os Parâmetros Simétricos de Euler, porém sem dependência trigonométrica e conveniente implementação de sucessivas rotações [18]. Essa representação é denominada de quatérnios [68,69,72]. Isso deve-se à possibilidade de relacionar os parâmetros simétricos de Euler com os quatérnios, apresentado, inicialmente, pelo matemático irlandês Willian Hamilton em 1843.

O quatérnio é um número hipercomplexo e, como o próprio nome sugere, é composto 
por quatro parâmetros,

$$
\begin{aligned}
\boldsymbol{q} & =q_{0}+q_{1} \hat{\mathbf{i}}+q_{2} \hat{\mathbf{j}}+q_{3} \hat{\mathbf{k}} \\
& =q_{0}+\mathbf{q}
\end{aligned}
$$

sendo $q_{0}$ a parte escalar e $\mathbf{q}$ a parte vetorial ou imaginária [18]. Alternativamente, algumas literaturas, como $[18,69]$, representam $\boldsymbol{q}$ com a parte escalar expressa por $q_{4}$ no início: $\boldsymbol{q}=\left(q_{4}, \mathbf{q}\right)$; em outras, como [68], apresentam no fim: $\boldsymbol{q}=\left(\mathbf{q}, q_{4}\right)$.

Restringindo a condição do quatérnio ser unitário, isto é, $\|\boldsymbol{q}\|=\sqrt{q_{0}^{2}+q_{1}^{2}+q_{2}^{2}+q_{3}^{2}}=1$, é possível relacioná-lo com os parâmetros simétricos de Euler por

$$
\begin{aligned}
q_{0} & =\cos \frac{\theta}{2} \\
\mathbf{q} & =\operatorname{sen} \frac{\theta}{2} \hat{\mathbf{u}},
\end{aligned}
$$

no qual û é o eixo de Euler, apresentado na Equação (2.11), e $\theta$ o ângulo de rotação em torno desse eixo. O quatérnio unitário pode ser obtido por $\boldsymbol{q} /\|\boldsymbol{q}\|$.

Para fins de cálculo computacional, pode-se acomodar o quatérnio em um vetor,

$$
\boldsymbol{q}=\left[\begin{array}{l}
q_{0} \\
q_{1} \\
q_{2} \\
q_{3}
\end{array}\right]=\left[\begin{array}{l}
q_{0} \\
\mathbf{q}
\end{array}\right]
$$

e a matriz de rotação em função dos quatérnios pode ser expressa por

$$
[\mathbf{Q}]_{m / i}=\left[\begin{array}{ccc}
q_{0}^{2}+q_{1}^{2}-q_{2}^{2}-q_{3}^{2} & 2\left(q_{1} q_{2}+q_{0} q_{3}\right) & 2\left(q_{1} q_{3}-q_{0} q_{2}\right) \\
2\left(q_{1} q_{2}-q_{0} q_{3}\right) & q_{0}^{2}-q_{1}^{2}+q_{2}^{2}-q_{3}^{2} & 2\left(q_{2} q_{3}+q_{0} q_{1}\right) \\
2\left(q_{1} q_{3}+q_{0} q_{2}\right) & 2\left(q_{2} q_{3}-q_{0} q_{1}\right) & q_{0}^{2}-q_{1}^{2}-q_{2}^{2}+q_{3}^{2}
\end{array}\right]
$$




\section{SISTEMAS DE COORDENADAS}

Tanto a atitude do satélite quanto a órbita são representadas por elementos vetoriais e, para definir um vetor no espaço, faz-se necessário um sistema de referência. Na área aerospacial, comumente utiliza-se de sistemas de coordenadas esféricas e tridimensionais. Neste trabalho abordam-se, por conveniência, apenas coordenadas tridimensionais. Ademais, por praticidades de cálculo e compreensão gráfica, são definidos diferentes sistemas, apropriados a cada caso, que podem ser relacionados entre si por transformações de coordenadas.

\subsection{Sistema de Coordenadas Geocêntrico Equatorial Inercial}

A representação de elementos da dinâmica orbital e de gravitação são simplificados quando representados em um sistema de coordenadas inerciais, isto é, sem aceleração. É comum, em missões de órbita terrestre,definir esse sistema de coordenadas em relação à Terra, razão pela qual define-se o Sistema de Coordenadas Geocêntrico Equatorial Inercial (GEI). Tal sistema é denotado por $i$ e a origem coincide com o centro de massa da Terra. O eixo $x^{i}$ é na direção do equinócio de março* J2000. $0^{\dagger}$ e representado pela letra grega $\gamma$, o eixo $z^{i}$ é no sentido norte do eixo de rotação da Terra e o eixo $y^{i}$ completa o sistema dextrogiro, de modo que $x^{i} y^{i}$ formem um plano coincidente ao plano equatorial terrestre. A Figura 7 ilustra o GEI.

\subsection{Sistema de Coordenadas Geocêntrico Equatorial Terrestre}

Alguns elementos, como estações de solo, observadores, etc., não apresentam movimento relativo à Terra, o que torna conveniente definir um sistema de coordenadas que rotaciona com a Terra em relação ao GEI, razão pela qual define-se o Sistema de Coordenadas Geocêntrico Equatorial Terrestre (GET). Esse sistema é denotado por $t$ e, assim como o GEI, a origem coincide com o centro de massa da Terra. O eixo $x^{t}$ é na direção da

\footnotetext{
${ }^{*}$ Grande parte das literaturas norte-americana e europeia utilizam o termo vernal equinox, referindo-se ao equinócio de primavera. Porém, para o hemisfério sul, esse seria o equinócio de outono. Dessa forma adota-se o termo equinócio de março, para evitar dificuldade de compreensão ao leitor.

${ }^{\dagger}$ Por conta do movimento de precessão da Terra, o equinócio de março e outras efemérides sofrem alterações no decorrer do tempo. Portanto, tais informações devem ser acompanhadas de um referência temporal. Em astronomia, uma das unidades de tempo mais utilizadas são os dias julianos. Em inglês é comum a abreviação JD de julian date. A época juliana atual é denominada J2000.0, tendo seu início em 1 de Janeiro de 2000, às 12 h UT1 (Universal Time) e tem exatos 2451 545,0 dias julianos [73].
} 
Figura 7 - Sistema de Coordenadas Geocêntrico Equatorial Inercial (GEI).

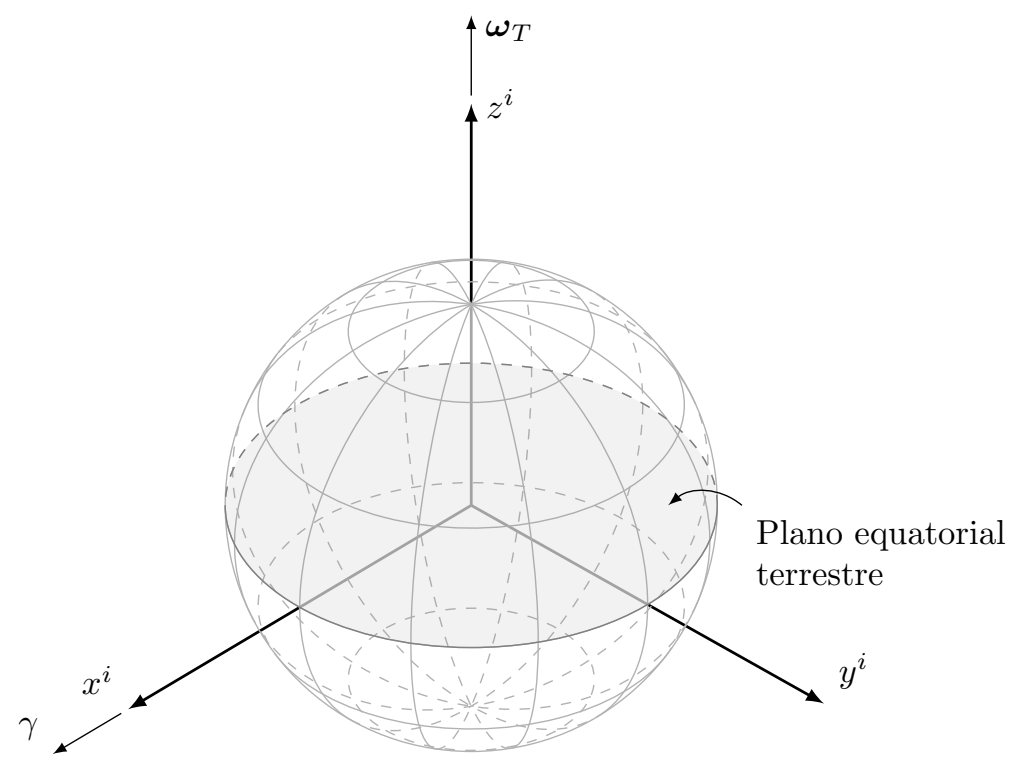

Fonte: Autor.

interseção do plano equatorial e do meridiano principal da Terra, o eixo $z^{t}$ é no sentido norte do eixo de rotação da Terra e o eixo $y^{t}$ completa o sistema dextrogiro, de forma que $x^{t} y^{t}$ forme um plano coincidente ao plano equatorial terrestre. A Figura 8 ilustra o GET.

Figura 8 - Sistema de Coordenadas Geocêntrico Equatorial Terrestre (GET).

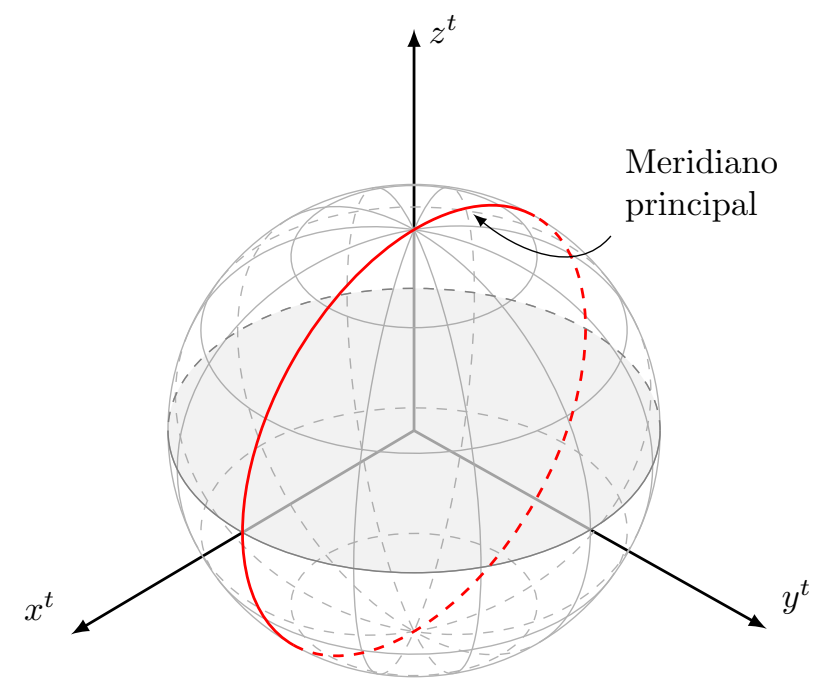

Fonte: Autor. 


\subsection{Sistema de Coordenadas Referente à Órbita do Satélite}

Para o controle de apontamento do satélite, torna-se útil definir um sistema de coordenadas em relação à órbita do veículo. Por essa razão, define-se o Sistema de Coordenadas Referente à Órbita do Satélite (ROS). Esse sistema é denotado por o e a origem coincide com o centro de massa do satélite $C M$. O eixo $x^{o}$ é na direção da velocidade do veículo, o eixo $z^{o}$ é na direção Nadir (direção do centro da Terra) e o eixo $y^{o}$ completa o sistema dextrogiro. A Figura 9 ilustra o ROS.

Figura 9 - Sistema de Coordenadas Referente a Órbita do Satélite (ROS).

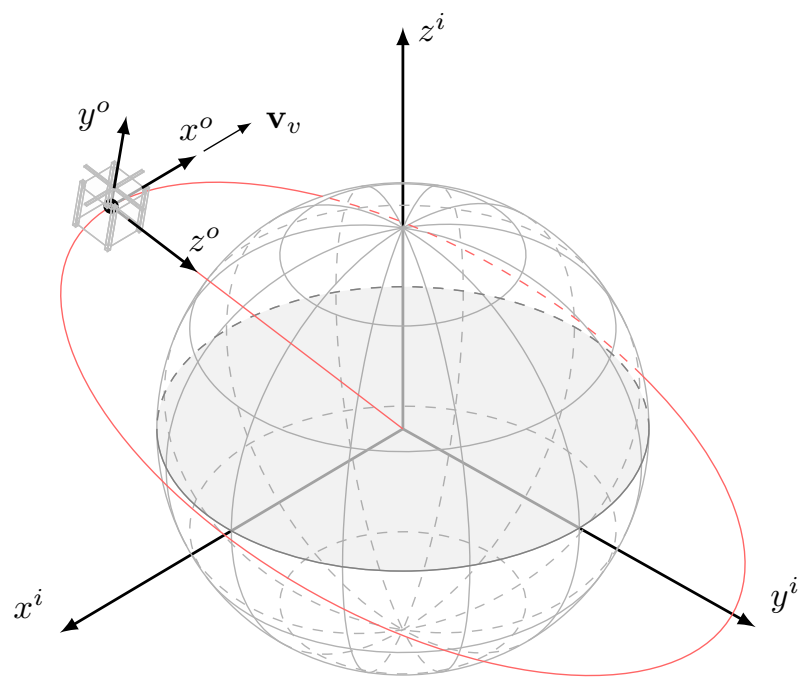

Fonte: Autor.

\subsection{Sistema de Coordenadas Referente ao Corpo do Satélite}

Da mesma forma, alguns componentes do veículo, como atuadores, sensores, antenas, etc., são oportunamente representados em relação ao corpo do satélite. Sendo assim, define-se o Sistema de Coordenadas Referente ao Corpo do Satélite (RCS). Esse sistema é fixo ao corpo do veículo e denotado por $s$. A origem do sistema pode ser qualquer ponto do veículo e a orientação dos eixos também pode ser qualquer uma, desde que forme um sistema dextrogiro. Por conveniência, define-se como origem uma das extremidades ou o centro geométrico do corpo principal do veículo. Os eixos também são escolhidos de forma que facilite a identificação visual. Como exemplo, no caso de um CubeSat de $1 \mathrm{U}$, a origem do sistema, $O^{s}$, coincide com o centro geométrico, definida e identificada no corpo. O eixo 
$z^{s}$ é normal à face que comporta as antenas, o eixo $x^{s}$ é normal à face lateral e o eixo $y^{s}$ completa o sistema dextrogiro. A Figura 10 ilustra o RCS em um CubeSat de 1U.

Figura 10 - Sistema de Coordenadas Referente ao Corpo do Satélite (RCS).

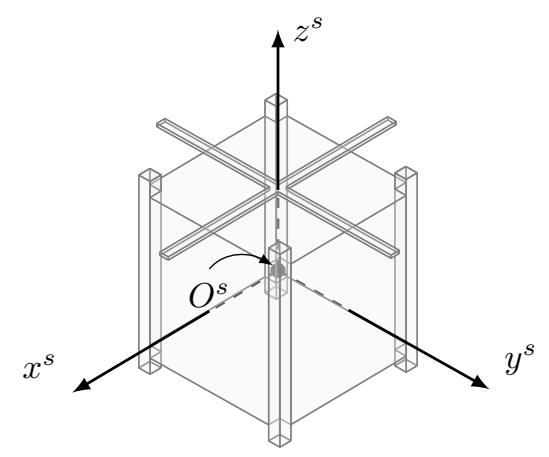

Fonte: Autor.

\subsection{Sistema de Coordenadas Referente aos Eixos Prin- cipais de Inércia}

A dinâmica do veículo é bastante simplificada se representada em relação aos eixos principais de inércia, razão pela qual define-se o Sistema de Coordenadas Referente aos Eixos Principais de Inércia (REP). Tal sistema é denotado por $p$ e a origem coincide com o centro de massa do veículo $C M$. O eixo $z^{p}$ é no sentido do maior momento principal de inércia, o eixo $x^{p}$ é no sentido do menor momento principal de inércia e o eixo $y^{p}$ completa o sistema dextrogiro. A Figura 11 ilustra o REP em um CubeSat de 1U.

Figura 11 - Sistema de Coordenadas Referente aos Eixos Principais de Inércia (REP).

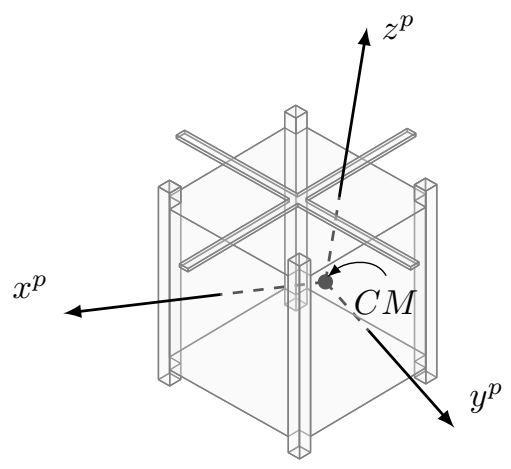

Fonte: Autor.

\subsection{Rotação Entre os Sistemas de Coordenadas}

Conforme citado na introdução do capítulo, é possível relacionar os sistemas de coordenadas entre si. 


\subsubsection{GEI e GET}

Uma vez que os planos $x y$ de GEI e GET são coplanares, a rotação entre eles é oriunda somente do movimento de rotação da Terra em torno do eixo $z$. Dessa forma, a matriz de rotação e sua representação em quatérnios são expressas por

$$
[\mathbf{Q}]_{t / i}=\left[\begin{array}{ccc}
\cos \theta_{G} & \operatorname{sen} \theta_{G} & 0 \\
-\operatorname{sen} \theta_{G} & \cos \theta_{G} & 0 \\
0 & 0 & 1
\end{array}\right]
$$

$\mathrm{e}$

$$
\boldsymbol{q}_{t / i}=\left[\begin{array}{cccc}
\cos \frac{\theta_{G}}{2} & 0 & 0 & \operatorname{sen} \frac{\theta_{G}}{2}
\end{array}\right]^{\top}
$$

no qual $\theta_{G}$ é o Tempo Sideral de Greenwich, ou seja, o ângulo, em graus, entre o equinócio de março e o meridiano principal. Conforme apresentado em [68],

$$
\theta_{G}=\theta_{G 0}+360,98564724 \frac{t_{U}}{24}
$$

na qual $t_{U}$ é o instante, em horas na escala UT1 em que se deseja determinar $\theta_{G}$, e $\theta_{G 0}$ é o Tempo Sideral de Greenwich às 0 h UT1.

Conforme apresentado em [73], $\theta_{G 0}$ é dado por

$$
\theta_{G 0}=100,4606184+36000,77004 T_{0}+0,000387933 T_{0}^{2}-2,583 \times 10^{-8} T_{0}^{3},
$$

na qual $T_{0}=d_{U} / 36525$, sendo $d_{U}$ o tempo em dias julianos desde J2000.0.

\subsubsection{GEI e ROS}

O ROS é definido em função de dois elementos, habitualmente, representados no GEI: a velocidade do veículo, $\mathbf{v}_{v}^{i}$, e a direção Nadir que, nesse caso, é no sentido contrário da posição do veículo, $\mathbf{r}_{v}^{i}$. Portanto,

$$
\begin{aligned}
& \mathbf{x}^{o}=\frac{\mathbf{v}_{v}^{i}}{v_{v}^{i}} \\
& \mathbf{z}^{o}=-\frac{\mathbf{r}_{v}^{i}}{r_{v}^{i}}
\end{aligned}
$$

$\mathrm{e}$

$$
\mathbf{y}^{o}=\mathbf{z}^{o} \times \mathbf{x}^{o}
$$

Dessa forma a matriz de rotação de ECI para ROS é expressa por

$$
[\mathbf{Q}]_{o / i}=\left[\begin{array}{lll}
\mathbf{x}^{o} & \mathbf{y}^{o} & \mathbf{z}^{o}
\end{array}\right]
$$




\subsubsection{RCS e REP}

Outra rotação bastante relevante é entre RCS e REP. Os subsistemas do satélite, como atuadores, sensores, câmeras, carga útil, etc., são definidos, por questões práticas, em função de RCS, entretanto as equações dinâmicas do veículo, apresentadas posteriormente, são definidas em função de REP. Quando a distribuição de massa do satélite é simétrica ao longo do corpo, não há rotação entre esses sistemas. No entanto, em rigor, essa condição é improvável.

A rotação de uma matriz de inércia $[\mathbf{J}]$, de um sistema a para um sistema $b$, é dada por

$$
[\mathbf{J}]^{b}=\left[\mathbf{Q}_{b / a}\right][\mathbf{J}]^{a}\left[\mathbf{Q}_{b / a}\right]^{\top}
$$

na qual $\left[\mathbf{Q}_{b / a}\right]$ é a matriz de rotação de $a$ para $b$. Observa-se que, em uma condição específica, é possível obter uma matriz de rotação tal que o resultado seja uma matriz diagonal. Isso é bastante útil, uma vez que o REP é definido em função dos eixos principais de inércia. Sendo assim, particularizando o caso,

$$
\left[\mathbf{I}_{v}\right]^{p}=\left[\mathbf{Q}_{p / s}\right]\left[\mathbf{I}_{v}\right]^{s}\left[\mathbf{Q}_{p / s}\right]^{\top}
$$

na qual $\left[\mathbf{I}_{v}\right]^{p}$ é a matriz diagonal de inércia do veículo no sistema REP, $\left[\mathbf{I}_{v}\right]^{s}$ é a matriz não diagonal de inércia do veículo no sistema RCS e $\left[\mathbf{Q}_{p / s}\right]$ é a matriz de rotação de RCS para REP.

Conforme apresentado em [68], a matriz $\left[\mathbf{I}_{v}\right]^{p}$ é formada, na diagonal principal, pelos autovalores de $\left[\mathbf{I}_{v}\right]^{s}$ e a matriz $\left[\mathbf{Q}_{p / s}\right]$ é formada pelos respectivos autovetores de $\left[\mathbf{I}_{v}\right]^{s}$. 


\section{MODELAGEM MATEMÁTICA}

Neste capítulo são apresentadas as modelagens matemáticas do satélite, da dinâmica orbital e das principais pertubações às quais o veículo está sujeito.

\subsection{Modelagem Matemática do Satélite}

As modelagens matemáticas relacionadas ao satélite, isto é, cinemática, dinâmica de atitude e dinâmica dos atuadores, estão acomodadas nesta seção.

\subsubsection{Cinemática}

Conforme apresentado no Capítulo 2, as equações diferenciais que representam a atitude do satélite podem ser expressas por diferentes métodos. Porém, os quatérnios são comumente, e preferencialmente, escolhidos para esse tipo de aplicação [68,69,74]. Isso é em decorrência, principalmente, ao fato dos quatérnios não apresentarem singularidades, como os Ângulos de Euler e, quando comparado às Matrizes de Cossenos Diretores, apresentarem menor custo computacional. Entretanto, a representação gráfica e a relação com o mundo real é de difícil compreensão. Sendo assim, todos os cálculos serão realizados em quatérnios, mas, para os fins de representação gráfica, serão, posteriormente, transformados em ângulos de Euler.

Em [69] apresenta-se a derivada temporal do quatérnio, o que permite relacionar a cinemática com a dinâmica do satélite. Considerando $\boldsymbol{\omega}_{p / i}^{p}=\left[\begin{array}{lll}\omega_{1} & \omega_{2} & \omega_{3}\end{array}\right]^{\top}$ como a velocidade angular do REP em relação ao GEI, a derivada dos quatérnios é dada por

$$
\frac{\mathrm{d}}{\mathrm{d} t} \boldsymbol{q}_{p / i}=\frac{1}{2}[\Omega] \boldsymbol{q}_{p / i}
$$

na qual $[\Omega]$ é definida como

$$
[\Omega]=\left[\begin{array}{cccc}
0 & -\omega_{1} & -\omega_{2} & -\omega_{3} \\
\omega_{1} & 0 & \omega_{3} & -\omega_{2} \\
\omega_{2} & -\omega_{3} & 0 & \omega_{1} \\
\omega_{3} & \omega_{2} & -\omega_{1} & 0
\end{array}\right]
$$

Para fins de simulação, a Equação (4.1) pode ser representada pelo diagrama ilustrado na Figura 12. 
Figura 12 - Diagrama da cinemática do veículo.

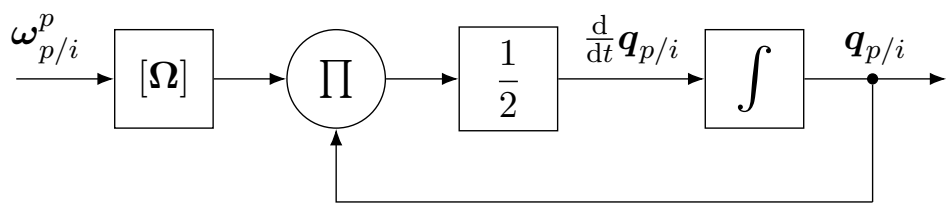

Fonte: Autor.

\subsubsection{Dinâmica de Atitude}

Conforme apresentado na Equação (4.1), a atitude do satélite, representada por quatérnios, depende da velocidade angular do veículo. A dinâmica de atitude descreve o movimento de rotação do satélite em função do torque aplicado $\mathbf{T}$, o qual pode ser proveniente dos atuadores, $\mathbf{T}_{a t}$, e perturbações, $\mathbf{T}_{p r t}$, internas ou externas ao satélite.

O satélite pode ser considerado um corpo rígido, desde que sua distribuição de massa permaneça constante ao longo do tempo. Sendo assim, algumas propriedades e princípios da Dinâmica do Corpo Rígido, apresentadas no Apêndice A, podem ser aplicados. A Equação (A.5), aplicada para o veículo, é dada por

$$
\mathbf{T}^{p}=\left[\mathbf{I}_{v}\right]^{p} \dot{\boldsymbol{\omega}}_{p / i}^{p}+\boldsymbol{\omega}_{p / i}^{p} \times\left(\left[\mathbf{I}_{v}\right]^{p} \boldsymbol{\omega}_{p / i}^{p}\right)
$$

na qual $\boldsymbol{\omega}_{p / i}^{p}$ é a velocidade angular do REP em relação ao GEI e $\left[\mathbf{I}_{v}\right]^{p}$ a matriz diagonal de inércia do veículo no sistema REP.

\subsubsection{Atuadores}

Com o objetivo de controlar a atitude do satélite, alguns atuadores são adicionados ao veículo. No caso dos CubeSats, os mais utilizados são atuadores magnéticos e rodas de reação [22].

\subsection{Atuador Magnético}

Para fins didáticos, o campo magnético terrestre pode ser aproximado por um dipolo magnético, cuja intensidade é inversamente proporcional ao cubo da distância da superfície terrestre. Assim sendo, em LEO a intensidade do campo magnético terrestre é significativa [18]. Controlando a intensidade do momento magnético de um dipolo artificial como, por exemplo, a corrente que passa por uma bobina, é possível produzir torque no satélite. Esses dipolos de corrente controlada são chamados de Atuadores Magnéticos, em inglês: Magnetorquers [75] ou Torquerods [69]. Alguns trabalhos brasileiros têm cunhado o termo Magnetotorqueadores.

O atuador magnético tem sido amplamente utilizado em CubeSats em virtude da sua facilidade de implementação, baixo custo e alta relação torque/massa [75]. Fisicamente, 
o atuador consiste em uma bobina com núcleo ferromagnético ou sem núcleo. Por isso, pode-se, pelas Leis de Kirchhoff, modelá-lo como um circuito resistor e indutor em série. O momento magnético é na direção normal ao plano da bobina e o sentido é dado pela Regra da Mão Direita. A intensidade é obtida pela Lei de Àmpere. Ilustra-se na Figura 13 o circuito elétrico e sentido do momento magnético do atuador.

Figura 13 - Modelo elétrico do atuador magnético.

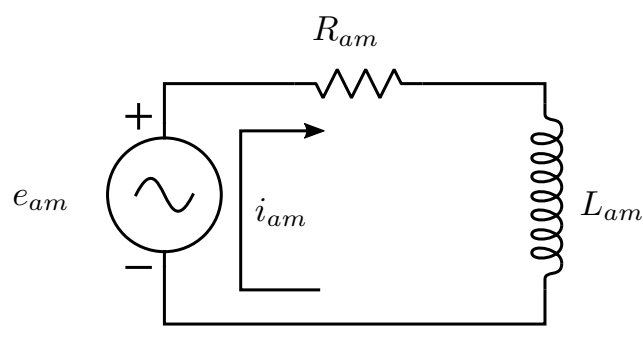

Fonte: Autor.

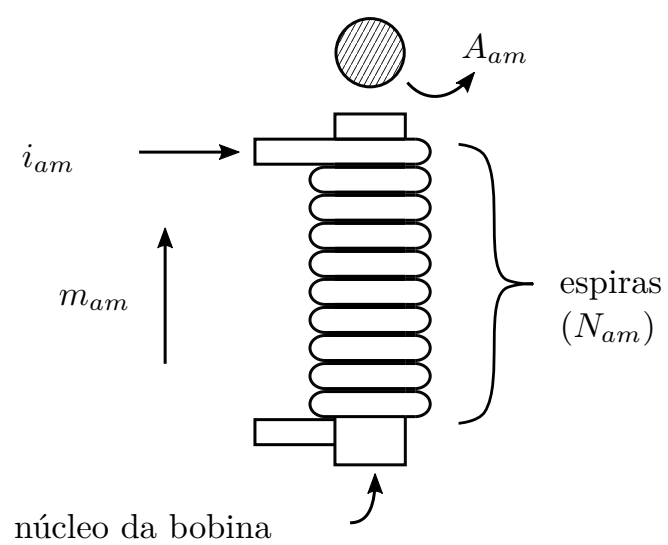

Desprezando o efeito de desmagnetização, a tensão na bobina, $e_{a m}$, é expressa por

$$
e_{a m}=R_{a m} i_{a m}+L_{a m} \frac{\mathrm{d} i_{a m}}{\mathrm{~d} t}
$$

na qual $i_{a m}, R_{a m}$ e $L_{a m}$ são, respectivamente, a corrente, a resistência e a indutância da bobina.

A intensidade total do momento magnético, $m_{a m}$, é a soma das intensidades dos momentos magnéticos gerados pela bobina, $m_{b}$, e pelo núcleo ferromagnético, $m_{n}$, portanto

$$
m_{a m}=m_{b}+m_{n}=N_{a m} i_{a m} A_{a m}+N_{a m} i_{a m}\left(\frac{\mu_{n}}{\mu_{0}}-1\right) A_{a m}
$$

tal que $\mu_{n}$ e $\mu_{0}$ são, respectivamente, os coeficientes de permeabilidade do núcleo e do vácuo e $N_{a m}$ e $A_{a m}$ são, respectivamente, o número de espiras e a área média da seção da bobina.

O torque oriundo do atuador magnético, na forma vetorial, $\mathbf{T}_{a m}$, é dado pelo produto vetorial do momento magnético do dipolo, $\mathbf{m}_{a m}$, e o campo magnético terrestre $\mathbf{B}$, isto é,

$$
\mathbf{T}_{a m}^{p}=\mathbf{m}_{a m}^{p} \times \mathbf{B}^{p}
$$

É importante observar que o torque resultante é nulo quando o momento magnético do atuador estiver paralelo ao campo magnético terrestre. 


\subsection{Roda de Reação}

As rodas de reação, em inglês reaction wheels (RW), são utilizadas quando deseja-se maior precisão de apontamento [75]. Trata-se de um disco de inércia acoplado ao rotor de um motor. O torque é proveniente da variação de velocidade angular desse conjunto.

Utilizam-se motores de corrente contínua com escovas ou, mais frequentemente, motores de corrente contínua sem escovas, em inglês: Brushless Direct Current Motors (BLDC). Estes têm sido escolhidos para aplicações aeroespaciais por conta da sua alta relação torque/massa, alta velocidade de rotação e baixo volume quando comparados a outros tipos de motores [76]. Outra vantagem é que a ausência de escovas aumenta a vida útil do equipamento. Quando conveniente, o BLDC pode ser aproximado e modelado como um motor de corrente contínua com escovas [69].

Seguindo essa abordagem, ilustra-se na Figura 14 as partes elétrica e mecânica do sistema roda de reação (motor + disco de inércia).

Figura 14 - Modelos elétrico e mecânico da roda de reação.
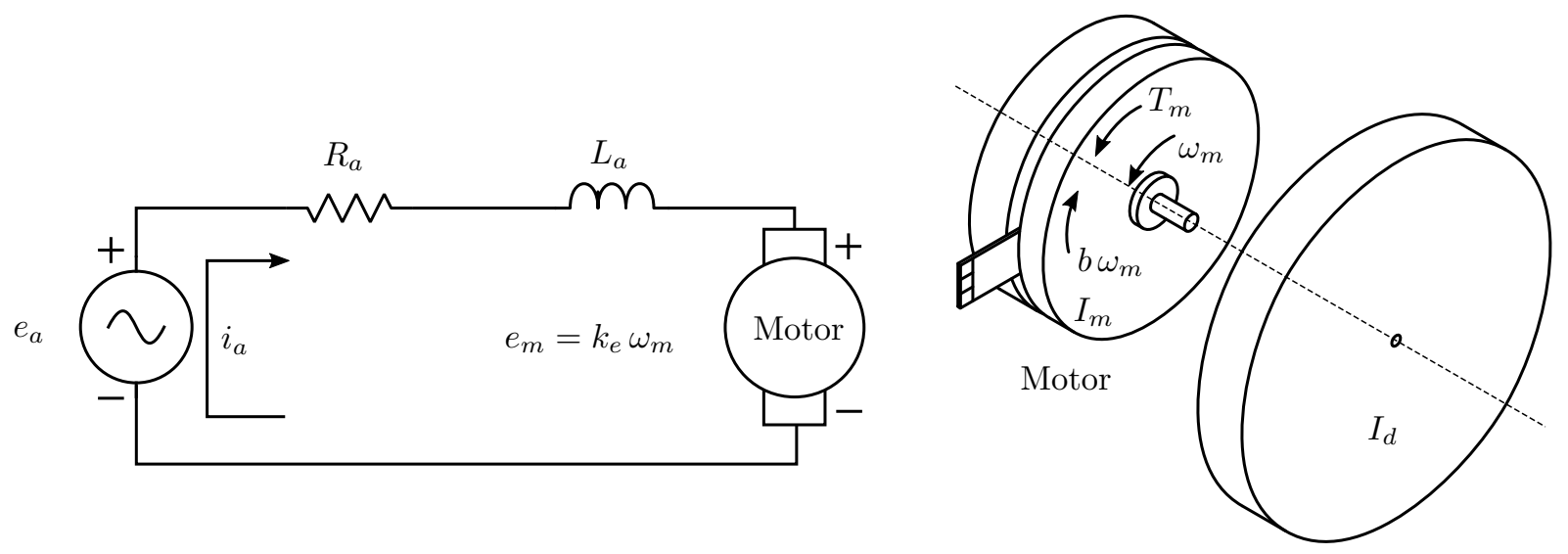

Disco de Inércia

Fonte: Autor.

Utilizando-se das Leis de Kirchhoff,

$$
L_{a} \frac{\mathrm{d} i_{a}}{\mathrm{~d} t}+R_{a} i_{a}=e_{a}-k_{e} \omega_{m}
$$

na qual $L_{a}$ é a indutância, $i_{a}$ é a corrente, $R_{a}$ é a resistência da armadura, e $e_{a}$ é a tensão na armadura. $k_{e}$ é a constante elétrica e $\omega_{m}$ é a velocidade angular do motor.

Utilizando-se das Leis de Newton,

$$
\begin{aligned}
I_{r r} & =I_{d}+I_{m} \\
I_{r r} \dot{\omega}_{m} & =k_{t} i_{a}-b \omega_{m}
\end{aligned}
$$

tal que $I_{d}$ e $I_{m}$ são, respectivamente, o momento de inércia do disco e do motor em relação ao eixo de rotação, $k_{t}$ é a constante de torque e $b$ é o coeficiente de atrito viscoso. 
A roda de reação também pode ser considerada um corpo rígido. Portanto, o torque, $\mathbf{T}_{r r}$, é obtido pela Equação de Euler (Eq. (A.2)). Seja $\mathbf{H}_{r r}^{p}$ o momento angular da roda de reação, $\boldsymbol{\omega}_{p / i}^{p}$ a velocidade angular do REP em relação ao GEI e levando em consideração o princípio da ação e reação,

$$
\mathbf{T}_{r r}^{p}=-\left(\dot{\mathbf{H}}_{r r}^{p}+\boldsymbol{\omega}_{p / i}^{p} \times \mathbf{H}_{r r}^{p}\right)
$$

A roda de reação gera, portanto, dois tipos de torque: um de controle $\left(\dot{\mathbf{H}}_{r r}^{p}\right)$ e um de perturbação, em decorrência do efeito giroscópico, $\left(\boldsymbol{\omega}_{p / i}^{p} \times \mathbf{H}_{r r}^{p}\right)$.

\subsubsection{Integração do Satélite}

Foram apresentadas nas seções anteriores as modelagens do satélite e dos subsistemas que geram torques internos. Nessa seção apresenta-se a integração desses módulos. Como estudo de caso, propõe-se um CubeSat de $1 \mathrm{U}$ composto de três atuadores magnéticos e três rodas de reação, posicionados ortogonalmente. A Figura 15 ilustra essa estrutura. Para fins didáticos, considera-se o vocábulo corpo como o satélite sem os atuadores e antena, e o vocábulo veículo o satélite integrado.

Figura 15 - Veículo e seus principais subsistemas.

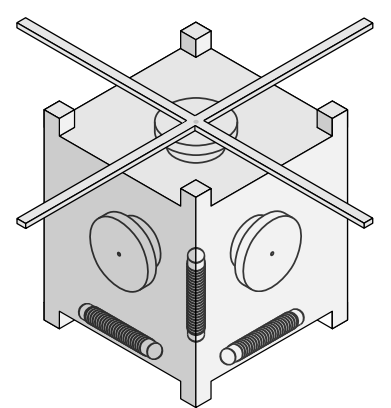

Veículo

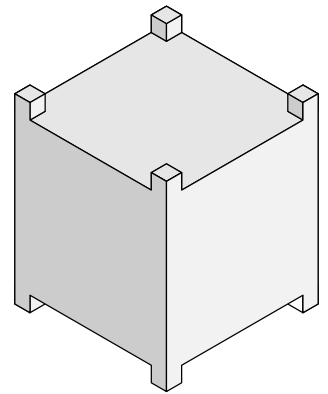

Corpo

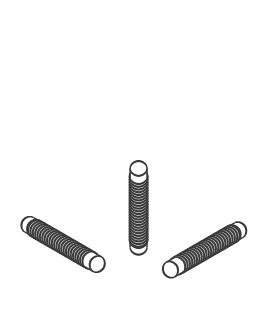

Atuadores Magnéticos
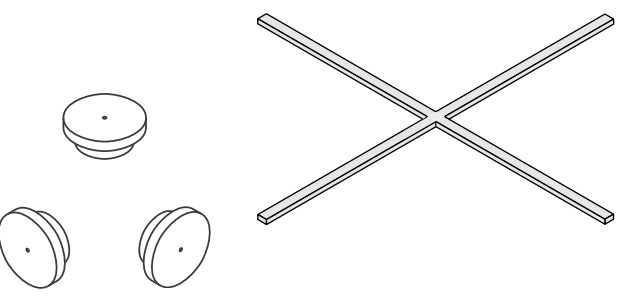

Rodas de Reação

Fonte: Autor.

\subsection{Disposição Geométrica dos Atuadores Magnéticos}

A depender do projeto e objetivo da missão, os atuadores magnéticos podem ser alocados no satélite em diferentes posições e orientações. Frequentemente, utilizam-se três atuadores dispostos ortogonalmente entre si. Isso permite gerar um momento magnético resultante em qualquer direção. Considerando o CubeSat proposto, os atuadores estão alinhados com os eixos do RCS, o que também é bastante comum, pois permite uma compreensão melhor dos fenômenos físicos. 
A matriz que representa essa disposição geométrica no RCS, $[\mathbf{Q}]_{s / a m}$, é formada pelos sentidos dos momentos magnéticos de cada atuador, $\hat{\mathbf{n}}_{a m_{i}}^{s}$, isto é,

$$
[\mathbf{Q}]_{s / a m}=\left[\begin{array}{lll}
\hat{\mathbf{n}}_{a m_{1}}^{s} & \hat{\mathbf{n}}_{a m_{2}}^{s} & \hat{\mathbf{n}}_{a m_{3}}^{s}
\end{array}\right]=\left[\begin{array}{lll}
1 & 0 & 0 \\
0 & 1 & 0 \\
0 & 0 & 1
\end{array}\right]
$$

Portanto, o momento magnético total no REP, $\mathbf{m}_{a m}^{p}$, é dado por

$$
\mathbf{m}_{a m}^{p}=[\mathbf{Q}]_{p / s}[\mathbf{Q}]_{s / a m}\left[\begin{array}{c}
\mathbf{m}_{a m_{1}} \\
\mathbf{m}_{a m_{2}} \\
\mathbf{m}_{a m_{3}}
\end{array}\right]
$$

Conforme apresentado na Equação (4.6), o torque dos atuadores magnéticos depende da interação com o campo magnético terrestre. Tal parâmetro é, geralmente, fornecido pelos modelos matemáticos no GET. Portanto, faz-se necessário rotacioná-lo para o REP, isto é, $\mathbf{B}^{p}=[\mathbf{Q}]_{p / t} \mathbf{B}^{t}$, sendo que $[\mathbf{Q}]_{p / t}=[\mathbf{Q}]_{p / i}[\mathbf{Q}]_{t / i}^{\top}$.

\subsection{Disposição Geométrica das Rodas de Reação}

A disposição geométrica das rodas de reação segue o mesmo princípio dos atuadores magnéticos. Para que haja redundância, alguns projetos ainda utilizam um número maior de rodas de reação.

Semelhante aos atuadores magnéticos, a matriz que representa essa disposição geométrica no RCS, $[\mathbf{Q}]_{s / r r}$, é formada pelos sentidos das velocidades angulares de cada roda de reação, $\hat{\mathbf{n}}_{r r_{i}}^{s}$, isto é,

$$
[\mathbf{Q}]_{s / r r}=\left[\begin{array}{lll}
\hat{\mathbf{n}}_{r r_{1}}^{s} & \hat{\mathbf{n}}_{r r_{2}}^{s} & \hat{\mathbf{n}}_{r r_{3}}^{s}
\end{array}\right]=\left[\begin{array}{ccc}
1 & 0 & 0 \\
0 & 1 & 0 \\
0 & 0 & 1
\end{array}\right] .
$$

Sendo assim, o torque proveniente das rodas de reação no REP, $\dot{\mathbf{H}}_{r r}^{p}$, é expresso por

$$
\dot{\mathbf{H}}_{r r}^{p}=[\mathbf{Q}]_{p / s}[\mathbf{Q}]_{s / r r}\left[\begin{array}{c}
I_{r r_{1}} \dot{\omega}_{r r_{1}} \\
I_{r r_{2}} \dot{\omega}_{r r_{2}} \\
I_{r r_{3}} \dot{\omega}_{r r_{3}}
\end{array}\right]
$$

\subsection{Modelo Dinâmico do Veículo}

Substituindo as Equações (4.6) e (4.9) na Equação (4.3), obtém-se o modelo dinâmico do veículo,

$$
\mathbf{T}_{a m}^{p}-\dot{\mathbf{H}}_{r r}^{p}+\mathbf{T}_{p r t}^{p}=\left[\mathbf{I}_{v}\right]^{p} \dot{\boldsymbol{\omega}}_{p / i}^{p}+\boldsymbol{\omega}_{p / i}^{p} \times\left(\left[\mathbf{I}_{v}\right]^{p} \boldsymbol{\omega}_{p / i}^{p}+\mathbf{H}_{r r}^{p}\right)
$$


A matriz de inércia do veículo $\left[\mathbf{I}_{v}\right]$ será a soma da matriz de inércia de cada um dos componentes. Para isso, pode-se utilizar o Teorema de Steiner, apresentado no Apêndice A.

Isolando a derivada da velocidade angular do satélite na Equação (4.14),

$$
\dot{\boldsymbol{\omega}}_{p / i}^{p}=\left(\left[\mathbf{I}_{v}\right]^{p}\right)^{-1}\left[\mathbf{T}_{a m}^{p}-\dot{\mathbf{H}}_{r r}^{p}+\mathbf{T}_{p r t}^{p}-\boldsymbol{\omega}_{p / i}^{p} \times\left(\left[\mathbf{I}_{v}\right]^{p} \boldsymbol{\omega}_{p / i}^{p}+\mathbf{H}_{r r}^{p}\right)\right]
$$

Levando-se em conta a Equação (4.15), pode-se representar a dinâmica e a cinemática (Eq. (4.1)) de atitude do veículo, para fins de simulação, como na Figura 16.

Figura 16 - Diagrama da dinâmica e cinemática de atitude.

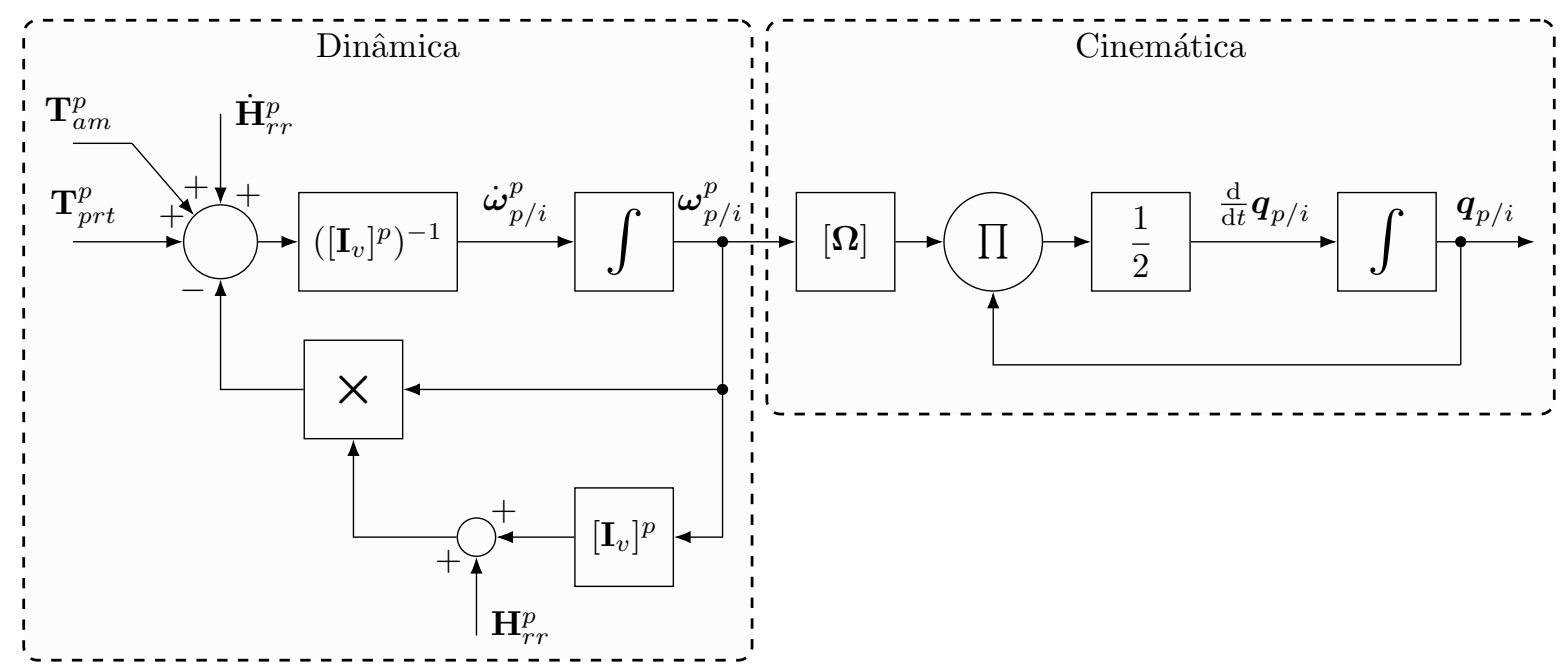

Fonte: Autor.

\subsection{Modelagem Matemática da Dinâmica Orbital}

No início do século XVII Johannes Kepler apresentou três leis sobre o movimento de interação entre dois corpos celestes, conhecidas como Leis de Kepler. Posteriormente, utilizando e justificando essas importantes observações, Isaac Newton apresenta a Lei da Gravitação Universal, a qual relaciona a força gravitacional entre dois corpos, considerandoos como pontos de massa [18],

$$
\mathbf{F}_{2 / 1}=-\frac{G\left(m_{1} m_{2}\right)}{r_{2 / 1}^{3}} \mathbf{r}_{2 / 1}
$$

na qual $\mathbf{F}_{2 / 1}$ é a força no corpo 2 exercida pelo corpo $1, G$ é a constante de gravitação, $m_{1}$ e $m_{2}$ são, respectivamente, as massas dos corpos 1 e 2 , e $\mathbf{r}_{2 / 1}$ o vetor posição do corpo 2 em relação ao corpo 1.

Utilizando-se da segunda Lei de Newton $(\mathbf{F}=m \mathbf{a})$, a aceleração de um veículo espacial, orbitando a Terra, pode ser expressa no GEI por

$$
\mathbf{a}_{v}^{i}=-\frac{\mu_{T}}{r_{v}^{3}} \mathbf{r}_{v}^{i}
$$


na qual $\mu_{T} \equiv G M_{T}=398600 \mathrm{~km}^{3} / \mathrm{s}^{2}$, sendo $M_{T}$ a massa da Terra, e $\mathbf{r}_{v}$ é o vetor posição do veículo. Tal situação é ilustrada na Figura 17.

Figura 17 - Ilustração de um satélite em órbita terrestre.

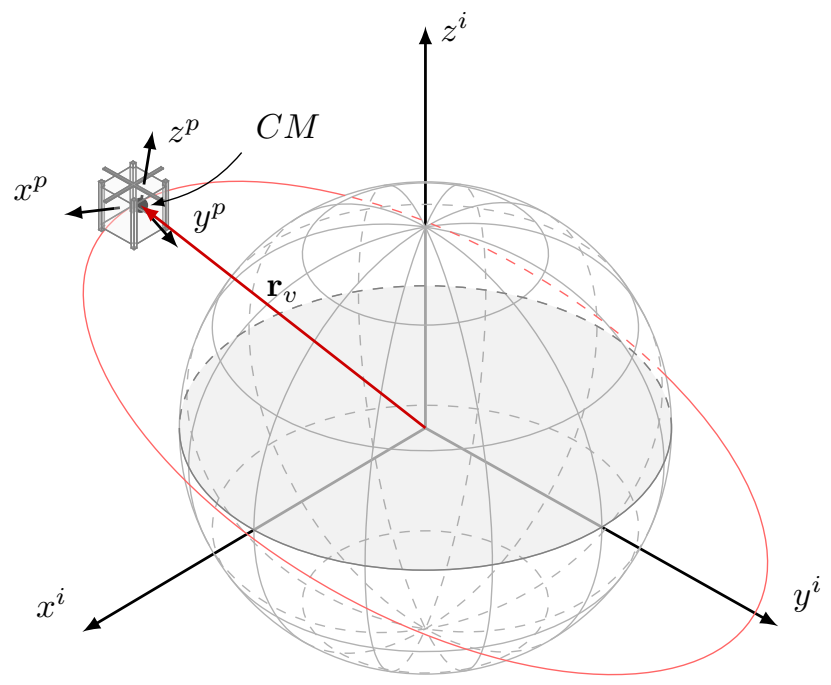

Fonte: Autor.

Esse movimento orbital é comumente conhecido na literatura por Órbita Kepleriana [18, $68,69]$ e é importante observar que somente é válido para dois pontos de massa ou, semelhantemente, objetos perfeitamente esféricos com massa distribuída uniformemente. O que, por exemplo, não é o caso da Terra. Ademais, não considera nenhum distúrbio externo. Posteriormente apresentar-se-ão perturbações orbitais relevantes para a aplicação.

\subsection{Modelagem Matemática das Perturbações}

O satélite está sujeito a perturbações que dependem da característica mecânica do veículo, missão, órbita, atividades solares, etc. Neste capítulo apresentam-se os principais torques de perturbação que interferem na atitude e as principais acelerações de perturbação que interferem na órbita do veículo.

\subsubsection{Perturbações de Atitude}

Em LEO as perturbações de atitude de maior influência são produzidos pelo arrasto atmosférico, pressão da radiação solar, gradiente de gravidade e dipolo magnético residual $[18,68,69,77]$. Sendo assim, em órbitas baixas, o torque de perturbação, $\mathbf{T}_{p r t}$, é dado pela soma de todos os distúrbios, isto é,

$$
\mathbf{T}_{p r t}^{p}=\mathbf{T}_{d}^{p}+\mathbf{T}_{r a d}^{p}+\mathbf{T}_{g g}^{p}+\mathbf{T}_{m r}^{p}
$$


na qual $\mathbf{T}_{d}$ é o torque devido ao arrasto atmosférico (aerodinâmico), $\mathbf{T}_{\text {rad }}$ é o torque devido à pressão da radiação solar, $\mathbf{T}_{g g}$, é o torque devido ao gradiente de gravidade $\mathrm{e}$ $\mathbf{T}_{m r}$ o torque devido ao dipolo magnético residual.

A seguir aborda-se individualmente a origem e equacionamento de cada um deles.

\subsubsection{Torque Devido ao Arrasto Atmosférico}

Durante o deslocamento em órbita, as partículas atmosféricas se chocam com a superfície do veículo exercendo uma força nessa superfície que, por sua vez, produzirá um torque em relação ao centro de massa do satélite. O modelo matemático do elemento de força, $\mathrm{d} \mathbf{F}_{d}$, aplicado num elemento de área, $\mathrm{d} A$, é frequentemente descrito na literatura $[18,68-70,72$, $78,79]$ e pode ser expresso por

$$
\mathrm{d} \mathbf{F}_{d}^{s}=-\frac{1}{2} C_{D} \rho v_{r e l}^{2}\left(\hat{\mathbf{n}}_{\mathrm{d} A}^{s} \cdot \hat{\mathbf{v}}_{r e l}^{s}\right) \hat{\mathbf{v}}_{r e l}^{s} \mathrm{~d} A
$$

na qual $C_{D}$ é o coeficiente de arrasto, $\rho$ é a densidade atmosférica, $v_{r e l}$ é a velocidade do veículo em relação à atmosfera, cuja direção é representada por $\hat{\mathbf{v}}_{r e l}$, e $\hat{\mathbf{n}}_{\mathrm{d} A}$ é o versor normal ao elemento de área.

O coeficiente de arrasto depende da estrutura da superfície e do ângulo em que a superfície é atingida pelas partículas atmosféricas, podendo ser obtido de forma empírica. Por ser complexo de realizar tais experimentos, são encontrados na literatura valores generalistas de referência. Em [78] sugere-se uma estimativa conservadora: $C_{D}=2,6$, enquanto em [68] Curtis sugere: $C_{D}=2,2$ e em [18], Wertz adota $C_{D}=2,0$. Experimentos com objetos de diferentes formas foram realizados em [80] e, para objetos com a forma de cubo, foi obtido $C_{D} \approx 2,1$. Esse valor será adotado nessa dissertação por conta da semelhança de formato dos nanossatélites que serão utilizados.

A velocidade relativa do veículo, $\mathbf{v}_{\text {rel }}$, por sua vez, pode ser aproximada por

$$
\mathbf{v}_{r e l}^{i}=\mathbf{v}_{v}^{i}-\left(\boldsymbol{\omega}_{T}^{i} \times \mathbf{r}_{v}^{i}\right)
$$

na qual $\mathbf{v}_{v}$ é a velocidade do veículo, $\boldsymbol{\omega}_{T}$ é a velocidade angular da Terra e $\mathbf{r}_{v}$ é vetor posição do veículo. E, o torque devido ao arrasto atmosférico, $\mathbf{T}_{d}$, é a soma dos torques de cada elemento de força, isto é,

$$
\mathbf{T}_{d}^{s}=\int_{0}^{A}\left(\mathbf{r}_{\mathrm{d} A}^{s} \times \mathrm{d} \mathbf{F}_{d}^{s}\right) \mathrm{d} A
$$

na qual $\mathbf{r}_{\mathrm{d} A}$ é o vetor posição do centro de massa do veículo, $C M$, até o elemento de área $\mathrm{d} A$ em que a força $\mathrm{d} \mathbf{F}_{d}$ está sendo aplicada.

A Figura 18 ilustra um satélite de forma cúbica, similar a um CubeSat de 1U, sujeito ao arrasto atmosférico.

O deslocamento do veículo se dá no sentido do vetor velocidade $\mathbf{v}_{r e l}$ e dado que a força de arrasto $\mathbf{F}_{d}$ é proveniente do choque das partículas atmosféricas na superfície do satélite, 
Figura 18 - Ilustração de um satélite sujeito ao arrasto atmosférico.

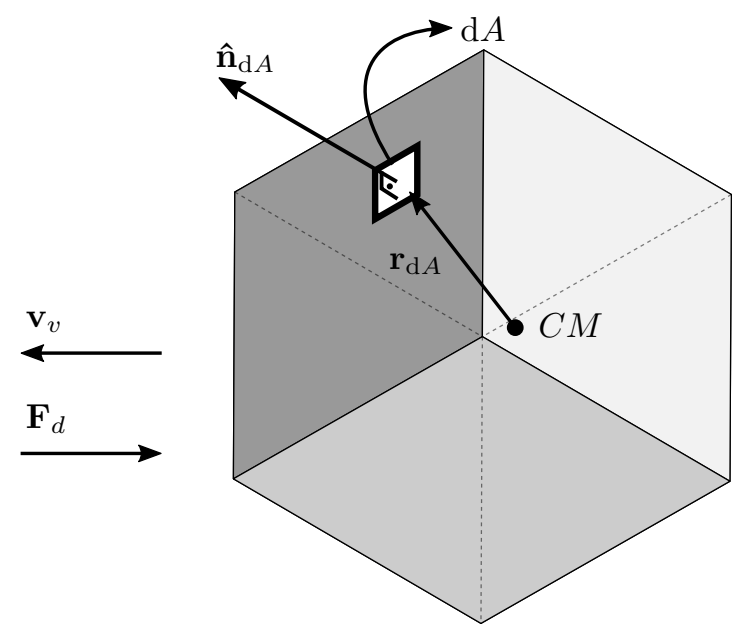

Fonte: Autor.

$\mathbf{v}_{\text {rel }}$ e $\mathbf{F}_{d}$ têm a mesma direção, mas sentidos opostos. Note que, a depender da orientação e/ou rotação do satélite, em um determinado instante, as partículas atmosféricas podem não se chocar com um elemento de área $\mathrm{d} A$, pois o mesmo pode estar na parte de trás do veículo. Tal situação pode ser identificada analisando-se o ângulo formado entre o vetor normal ao elemento de área $\hat{\mathbf{n}}_{\mathrm{d} A}$ e o vetor velocidade. Dessa forma, para fins de cálculo e simulação, apenas existirá força de atrito em um elemento de área d $A$ quando o ângulo entre o vetor normal ao elemento de área, $\hat{\mathbf{n}}_{\mathrm{d} A}$, e a velocidade do veículo $\mathbf{v}_{\text {rel }}$ estiver entre $-90^{\circ} \mathrm{e}+90^{\circ}$, isto é, $\left(\hat{\mathbf{n}}_{\mathrm{d} A}^{s} \cdot \hat{\mathbf{v}}_{r e l}^{s}\right)>0$.

Outra consideração relevante é com relação ao cálculo da área atingida a cada instante de tempo. Em alguns casos, a superfície do satélite pode ser dividida em partes de fácil cálculo geométrico. A superfície do satélite da Figura 18, por exemplo, pode ser dividida em seis áreas $A_{i}$ iguais. Isto posto, a área atingida, $A_{d_{i}}$, pode ser aproximada pela projetação da área $A_{i}$ no sentido da velocidade do veículo. A Figura 19 ilustra esse conceito.

Dessa forma $A_{d_{i}}$ é expressa por

$$
\int_{0}^{A}\left(\hat{\mathbf{n}}_{\mathrm{d} A}^{s} \cdot \hat{\mathbf{v}}_{r e l}^{s}\right) \mathrm{d} A \approx\left(\hat{\mathbf{n}}_{i}^{s} \cdot \hat{\mathbf{v}}_{r e l}^{s}\right) A_{i}=A_{d_{i}} .
$$

Sendo assim, pode-se reescrever a Equação (4.19), para cada área $i$ da superfície do satélite, como

$$
\mathbf{F}_{d_{i}}^{s}=\left\{\begin{array}{cll}
-\frac{1}{2} C_{D} \rho v_{r e l}^{2} A_{d_{i}} \hat{\mathbf{v}}_{r e l}^{s} & \text { se } & \left(\hat{\mathbf{n}}_{i}^{s} \cdot \hat{\mathbf{v}}_{r e l}^{s}\right)>0 \\
0 & \text { se } \quad\left(\hat{\mathbf{n}}_{i}^{s} \cdot \hat{\mathbf{v}}_{r e l}^{s}\right) \leq 0
\end{array}\right.
$$

E a Equação (4.21) como

$$
\mathbf{T}_{d}^{s}=\sum_{i=1}^{n}\left(\mathbf{r}_{c p_{i}}^{s} \times \mathbf{F}_{d_{i}}^{s}\right)
$$


Figura 19 - Projeção da área atingida por partículas atmosféricas.

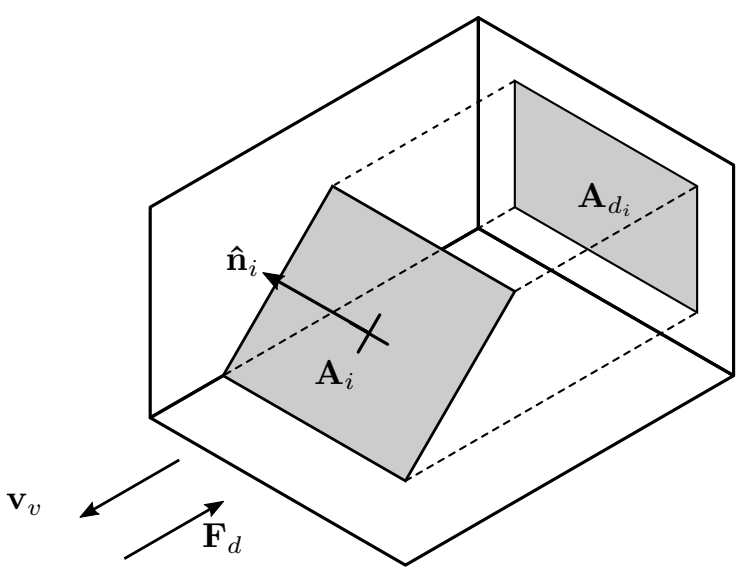

Fonte: Autor.

no qual $n$ é o número de áreas em que a superfície do satélite foi dividida, $\mathbf{r}_{c p_{i}}$ é o vetor posição do centro de massa do satélite ao centro de pressão $c p_{i}$, isto é, o ponto em que se considera a força $\mathbf{F}_{d_{i}}$ aplicada.

\subsection{Modelo Atmosférico}

A densidade $(\rho)$ e outras propriedades atmosféricas variam em função da altitude, temperatura, composição molecular, atividade solar, etc. Desde a década de 60 alguns modelos têm sido desenvolvidos e aprimoradas visando obter esses parâmetros com mais precisão [81]. Um dos modelos mais modernos e utilizados pela comunidade científica é o United States Naval Research Laboratory Mass Spectrometer and Incoherent Scatter Radar Exosphere (NRLMSISE-00) [82,83]. Trata-se de um modelo empírico da classe Mass Spectrometer Incoherent Scatter Radar (MSIS) lançado no ano 2001. Como entrada recebe a altitude, posição geográfica (latitude e longitude geodética), tempo em segundos (UT1) e data do ano. Podendo também receber os índices de fluxo solar, $F_{10.7}$, e geomagnético diário, $a_{p}$. Como saída fornece a temperatura e densidade dos gases: He, O, N2, O2, Ar, $\mathrm{H}$ e N, até uma altitude de $1000 \mathrm{~km}$. Neste trabalho utiliza-se o modelo NRLMSISE-00 integrado ao software Simulink.

\subsubsection{Torque Devido à Pressão de Radiação Solar}

Assim como o choque com partículas atmosféricas, a incidência de radiação eletromagnética na superfície do veículo gera perturbações de torque. A fonte de radiação pode ser variada, porém a principal é oriunda da radiação direta do Sol [18]. A intensidade e direção de incidência, a forma e as propriedades ópticas da superfície do satélite são os principais fatores que influenciam na determinação do torque devido à pressão da radiação solar [84]. 
De forma análoga ao torque devido ao arrasto atmosférico, uma das formas de modelar é dividir a superfície do veículo em elementos de área e determinar a força aplicada em cada um deles. Conforme ilustrado na Figura 20, dependendo das propriedades ópticas da superfície, a radiação pode ser absorvida (Figura 20a), refletida com a mesma inclinação de incidência (Figura 20b) ou refletida de forma difusa (Figura 20c).

Figura 20 - Ilustração das formas de incidência da radiação solar numa superfície.

(a) Absorção total da superfície.

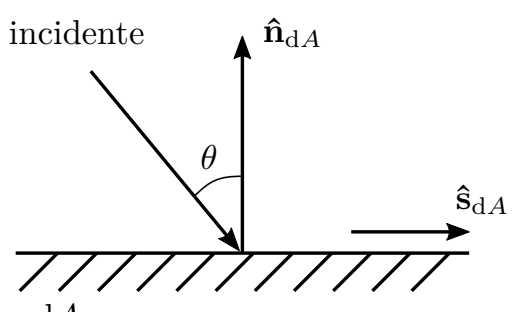

$\mathrm{d} A$ (b) Reflexão total da superfície.

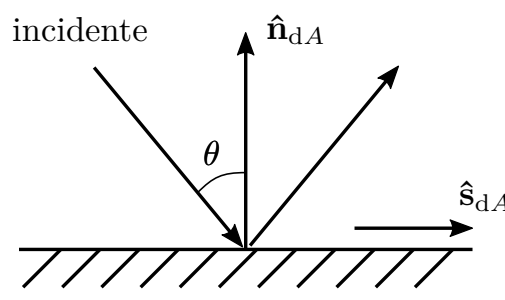

$\mathrm{d} A$ (c) Difusão total da superfície.

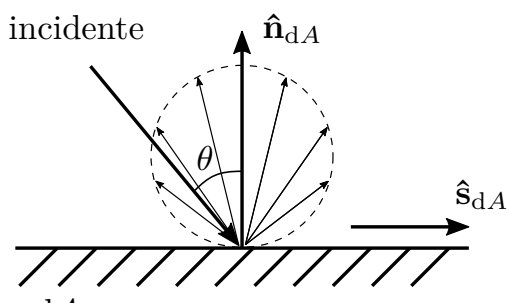

$\mathrm{d} A$

Fonte: Autor.

Os modelos matemáticos dos elementos de força para cada forma de radiação também são frequentemente descritos na literatura $[18,68,70,72,85]$ e, a começar pela força aplicada em cada elemento de área em razão da radiação absorvida, $\mathrm{d} \mathbf{F}_{r a}$, é dado por

$$
\mathrm{d} \mathbf{F}_{r a}^{s}=\frac{S}{c}\left[c_{r a}\left(-\cos \theta \hat{\mathbf{n}}_{\mathrm{d} A}^{s}+\operatorname{sen} \theta \hat{\mathbf{s}}_{\mathrm{d} A}^{s}\right)\right] \cos \theta \mathrm{d} A,
$$

na qual $S=1367 \mathrm{~W} / \mathrm{m}^{2}$ é a intensidade média de radiação solar, $c=299792458 \mathrm{~m} / \mathrm{s}$ é a velocidade da luz, $c_{r a}$ é o coeficiente de radiação absorvida, o qual depende do tipo de superfície, $\theta$ é o ângulo de incidência em relação à normal e $\hat{\mathbf{s}}_{\mathrm{d} A}$ é o versor paralelo à superfície e na direção da projeção da radiação.

De forma similar à radiação refletida, $\mathrm{d} \mathbf{F}_{r r}$, esta é dada por

$$
\left.\mathrm{d} \mathbf{F}_{r r}^{s}=\frac{S}{c}\left[\left(-1+c_{r r}\right) \cos \theta \hat{\mathbf{n}}_{\mathrm{d} A}^{s}+\left(1-c_{r r}\right) \operatorname{sen} \theta \hat{\mathbf{s}}_{\mathrm{d} A}^{s}\right)\right] \cos \theta \mathrm{d} A,
$$

na qual $c_{r r}$ é o coeficiente de radiação refletida e depende do tipo de superfície. Por fim, a radiação difusa, $\mathrm{d} \mathbf{F}_{r d}$, é dada por

$$
\mathrm{d} \mathbf{F}_{r d}^{s}=\frac{S}{c}\left[-\left(\cos \theta+\frac{2}{3} c_{r d}\right) \hat{\mathbf{n}}_{\mathrm{d} A}^{s}+\operatorname{sen} \theta \hat{\mathbf{s}}_{\mathrm{d} A}^{s}\right] \cos \theta \mathrm{d} A,
$$

na qual $c_{r d}$ é o coeficiente de radiação difusa e depende do tipo de superfície.

Sendo que, para o mesmo elemento de área, os coeficientes estão sujeitos à seguinte restrição: $0 \leq c_{r a}+c_{r r}+c_{r d} \leq 1$. De forma similar ao coeficiente de arrasto, esses coeficientes podem ser obtidos de forma empírica. Em [79], para superfícies de painéis solares é sugerido: $c_{r a}=0,79, c_{r r}=0,04$ e $c_{r d}=0,17$. Esses valores serão utilizados nessa dissertação por conta dos CubeSats terem, frequentemente, suas superfícies cobertas por painéis solares. 
Dessa forma, o torque devido à pressão da radiação solar pode ser definido por

$$
\mathbf{T}_{r a d}^{s}=\int_{0}^{A}\left[\left(\mathbf{r}_{\mathrm{d} A}^{s} \times \mathrm{d} \mathbf{F}_{r a}^{s}\right)+\left(\mathbf{r}_{\mathrm{d} A}^{s} \times \mathrm{d} \mathbf{F}_{r r}^{s}\right)+\left(\mathbf{r}_{\mathrm{d} A}^{s} \times \mathrm{d} \mathbf{F}_{r d}^{s}\right)\right] \mathrm{d} A,
$$

na qual $\mathbf{r}_{\mathrm{d} A}$ é o vetor posição do centro de massa do veículo até o elemento de área.

Semelhante à Subseção 4.3.1.1, a depender da orientação e/ou rotação do satélite, em um determinado instante, um elemento de área $\mathrm{d} A$ pode não sofrer incidência da radiação solar por estar na parte de trás do veículo. Neste caso, tal situação pode ser identificada analisando o ângulo formado entre o vetor normal ao elemento de área, $\hat{\mathbf{n}}_{\mathrm{d} A}$, e o versor do centro de massa do veículo em direção ao centro de massa do Sol, $\hat{\mathbf{r}}_{s / v}$. Portanto, para fins de cálculo e simulação, apenas existirá força, devido à pressão da radiação solar, quando o ângulo entre $\hat{\mathbf{n}}_{\mathrm{d} A}^{s}$ e $\hat{\mathbf{r}}_{s / v}^{s}$ estiver entre $-90^{\circ} \mathrm{e}+90^{\circ}$, isto é, $\left(\hat{\mathbf{r}}_{s / v}^{s} \cdot \hat{\mathbf{n}}_{\mathrm{d} A}^{s}\right)>0$.

Ademais, como visto anteriormente, em alguns casos, a superfície do satélite pode ser dividida em partes de fácil cálculo geométrico, como no satélite da Figura 18. A área atingida pela radiação, $A_{r_{i}}$, também pode ser aproximada pela projeção da área $A_{i}$, porém, neste caso, no sentido da incidência de radiação.

Sendo assim, $A_{\text {radi }_{i}}$ é obtida por

$$
\int \cos \theta \mathrm{d} A \approx \cos \theta A_{i}=A_{\text {rad }_{i}} .
$$

Quando o satélite estiver na região de sombra da Terra, numa situação de eclipse, também não haverá força devido à pressão da radiação solar. Portanto, utiliza-se o termo $\nu$ para identificar tal ocorrência. Quando o veículo está exposto à radiação solar: $\nu=1$; quando o veículo está em uma região de eclipse: $\nu=0$.

Dessa forma pode-se reescrever as Equações (4.25), (4.27) e (4.26), para cada área atingida $i$,

se $\left(\hat{\mathbf{r}}_{s / v}^{s} \cdot \hat{\mathbf{n}}_{\mathrm{d} A}^{s}\right) \leq 0$

$$
\mathbf{F}_{r a}^{s}=\mathbf{F}_{r r}^{s}=\mathbf{F}_{r d}^{s}=0
$$

se $\left(\hat{\mathbf{r}}_{s / v}^{s} \cdot \hat{\mathbf{n}}_{\mathrm{d} A}^{s}\right)>0$

$$
\begin{gathered}
\mathbf{F}_{r a_{i}}^{s}=\nu \frac{S}{c}\left[c_{r a}\left(-\cos \theta \hat{\mathbf{n}}_{\mathrm{d} A}^{s}+\operatorname{sen} \theta \hat{\mathbf{s}}_{\mathrm{d} A}^{s}\right)\right] A_{r a d_{i}}, \\
\left.\mathbf{F}_{r r_{i}}^{s}=\nu \frac{S}{c}\left[\left(-1+c_{r r}\right) \cos \theta \hat{\mathbf{n}}_{\mathrm{d} A}^{s}+\left(1-c_{r r}\right) \operatorname{sen} \theta \hat{\mathbf{s}}_{\mathrm{d} A}^{s}\right)\right] A_{r a d_{i}}
\end{gathered}
$$

$\mathrm{e}$

$$
\mathbf{F}_{r d_{i}}^{s}=\nu \frac{S}{c}\left[-\left(\cos \theta+\frac{2}{3} c_{r d}\right) \hat{\mathbf{n}}_{\mathrm{d} A}^{s}+\operatorname{sen} \theta \hat{\mathbf{s}}_{\mathrm{d} A}^{s}\right] A_{r a d_{i}} .
$$

Reescrevendo a Equação (4.28),

$$
\mathbf{T}_{r a d}^{s}=\sum_{i=1}^{n}\left[\left(\mathbf{r}_{c p_{i}}^{s} \times \mathbf{F}_{r a_{i}}^{s}\right)+\left(\mathbf{r}_{c p_{i}}^{s} \times \mathbf{F}_{r r_{i}}^{s}\right)+\left(\mathbf{r}_{c p_{i}}^{s} \times \mathbf{F}_{r d_{i}}^{s}\right)\right],
$$


no qual $\mathbf{r}_{c p_{i}}$ é vetor posição do centro de massa do satélite ao centro de pressão $c p_{i}$, isto é, o ponto em que se considera a força $\mathbf{F}$ aplicada.

\subsection{Posição Solar}

Apresenta-se nessa seção como obter o versor posição do Sol em relação ao veículo, $\hat{\mathbf{r}}_{s / v}$.

O vetor posição $\mathbf{r}_{s}$, definido do centro de massa da Terra ao centro de massa do Sol, pode ser expresso em função do vetor posição do veículo, $\mathbf{r}_{v}$, e do vetor posição do Sol em relação ao veículo, $\mathbf{r}_{s / v}$, como

$$
\mathbf{r}_{s}^{i}=\mathbf{r}_{v}^{i}+\mathbf{r}_{s / v}^{i}
$$

Porém, uma vez que $\mathbf{r}_{s / v}>>\mathbf{r}_{v}$, pode-se assumir que $\mathbf{r}_{s}^{i} \approx \mathbf{r}_{s / v}^{i}$.

Ademais, conforme apresentado em [68], o versor posição do Sol, $\hat{\mathbf{r}}_{s}$, e o seu módulo, $r_{s}$, são dados por

$$
\hat{\mathbf{r}}_{s}^{i}=\left[\begin{array}{lll}
\cos \lambda & \cos \varepsilon \operatorname{sen} \lambda & \operatorname{sen} \varepsilon \operatorname{sen} \lambda
\end{array}\right]^{\top}
$$

e

$$
r_{s}=(1,00017-0,01671 \cos M-0,000140 \cos 2 M) \mathrm{au}
$$

na qual $\lambda$ é a longitude eclíptica, ou seja, o ângulo entre o eixo do equinócio de março e o eixo Terra-Sol, $\varepsilon$ é a obliquidade da eclíptica, ou seja, o ângulo entre o eixo de rotação terrestre e o plano do equador celeste, $M$ é a anomalia média do Sol e au é a unidade astronômica. $1 \mathrm{au}=149597870,691 \mathrm{~km}$.

Conforme apresentado no Almanaque Astronômico de 2014 [86], $\lambda, M$ e $\varepsilon$ podem ser obtidos por

$$
\begin{gathered}
\lambda=L+1,915^{\circ} \operatorname{sen} M+0,0200^{\circ} \operatorname{sen} 2 M \quad\left(0^{\circ} \leq \lambda \leq 360^{\circ}\right), \\
M=357,529^{\circ}+0,98560023^{\circ} n \quad\left(0^{\circ} \leq M \leq 360^{\circ}\right)
\end{gathered}
$$

$\mathrm{e}$

$$
\varepsilon=23,439^{\circ}-3,56 \times 10^{-7} n
$$

tal que $n$ é o numero de dias desde J2000.0 e $L$ é a longitude média do Sol, que por sua vez pode ser obtida por

$$
L=280,459^{\circ}+0,98564736^{\circ} n \quad\left(0^{\circ} \leq L \leq 360^{\circ}\right) .
$$




\subsection{Eclipse}

Nessa seção apresenta-se como determinar a situação em que o veículo está na sombra da Terra, chamada de eclipse.

Do ponto de vista geocêntrico, considere o Sol e o veículo orbitando a Terra. $\mathbf{r}_{s}$ é o vetor posição do Sol com origem no centro da Terra e $\mathbf{r}_{v}$ o vetor posição do veículo com origem no centro da Terra. O plano formado por esses vetores é ilustrado na Figura 21, na qual $R$ é o raio médio da Terra, $\theta_{s}$ é ângulo formado entre o vetor posição do Sol e $R$ perpendicular à tangente da superfície da Terra com o Sol, $\theta_{v}$ é ângulo formado entre o vetor posição do veículo e $R$ perpendicular à tangente da superfície da Terra com o veículo, e $\theta$ é ângulo entre o vetor posição do Sol e o vetor posição do veículo.

Figura 21 - Ilustração das condições de eclipse terrestre.

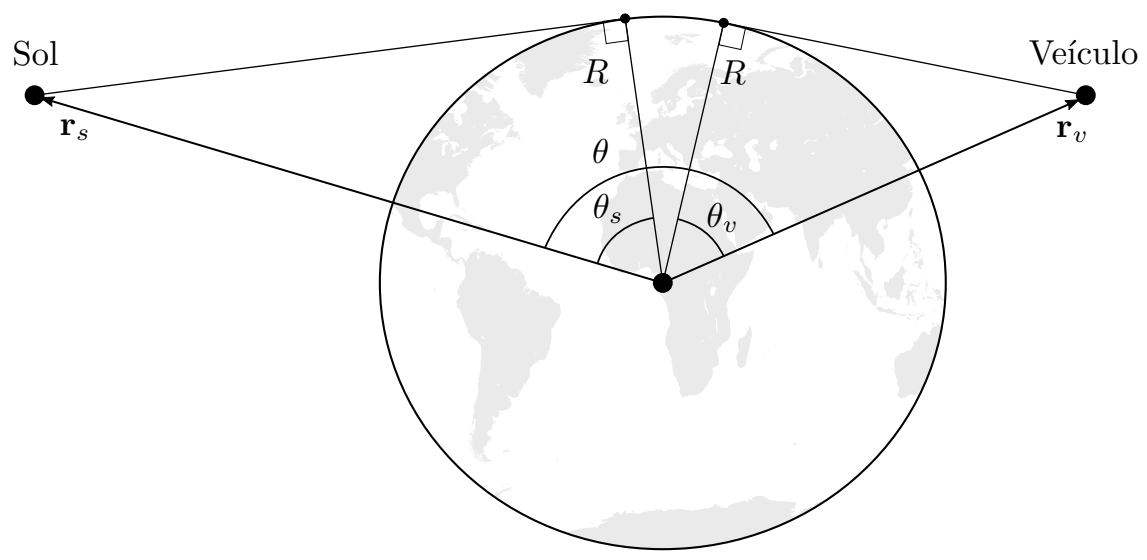

Fonte: Autor.

O ângulo formado entre $\mathbf{r}_{s}$ e $\mathbf{r}_{v}, \theta$, é dado por

$$
\theta=\cos ^{-1}\left(\frac{\mathbf{r}_{s} \cdot \mathbf{r}_{v}}{r_{s} r_{v}}\right)
$$

Os ângulos $\theta_{s}$ e $\theta_{v}$, da Figura 21, são dados por

$$
\theta_{s}=\cos ^{-1} \frac{R}{r_{s}} \quad \text { e } \quad \theta_{v}=\cos ^{-1} \frac{R}{r_{v}}
$$

Observe que o veículo estará sujeito à incidência de radiação somente se $\theta_{s}+\theta_{v} \geq \theta$. Pode-se, então, determinar $\nu$, a variável que carrega a informação de eclipse, por

$$
\nu= \begin{cases}1 & \text { se } \quad \theta_{s}+\theta_{v} \geq \theta \\ 0 & \text { se } \quad \theta_{s}+\theta_{v}<\theta .\end{cases}
$$

Portanto, quando o veículo está exposto a radiação solar: $\nu=1$ e $\mathbf{T}_{\text {rad }}$ é calculado; e quando o veículo está em uma região de sombra: $\nu=0$ e $\mathbf{T}_{\text {rad }}$ não é calculado. 


\subsubsection{Torque Devido ao Gradiente de Gravidade}

Conforme apresentado na Equação (4.16), a força gravitacional depende da distância e orientação do objeto. Dessa forma, cada elemento de massa do veículo está sujeito a uma força diferente. Essa variação de força produz torque quando a massa do satélite não é perfeitamente distribuída. Pode-se referir a esse fenômeno como gradiente de gravidade [18]. Alguns veículos, como o Department of Defense Gravity Experiment (DODGE), Explorer 49 e Long Duration Exposure Facility (LDEF), utilizam-se do gradiente de gravidade como forma de controle passivo de atitude para apontamento Nadir.

Conforme apresentado em [68], a força $\mathrm{d} \mathbf{F}_{g g}$ que atua no elemento de massa $\mathrm{d} m$ é dada por

$$
\mathrm{d} \mathbf{F}_{g g}^{i}=-\frac{\mu_{T} \mathbf{r}_{T, \mathrm{~d} m}^{i} \mathrm{~d} m}{r_{T, \mathrm{~d} m}^{3}},
$$

na qual $\mu_{T}$ é o parâmetro orbital (veja a Eq. (4.17)) e $\mathbf{r}_{T, \mathrm{~d} m}$ é o vetor posição do elemento de massa em relação à Terra.

E o torque devido ao gradiente de gravidade é dado por

$$
\mathbf{T}_{g g}^{s}=\int \mathbf{r}_{\mathrm{d} m}^{s} \times \mathrm{d} \mathbf{F}_{g g}^{s},
$$

na qual $\mathbf{r}_{\mathrm{d} m}$ é o vetor do centro de massa $C M$ ao elemento de massa $\mathrm{d} m$. A Figura 22 ilustra esses termos em um CubeSat de $1 \mathrm{U}$.

Figura 22 - Ilustração do torque devido ao gradiente de gravidade.

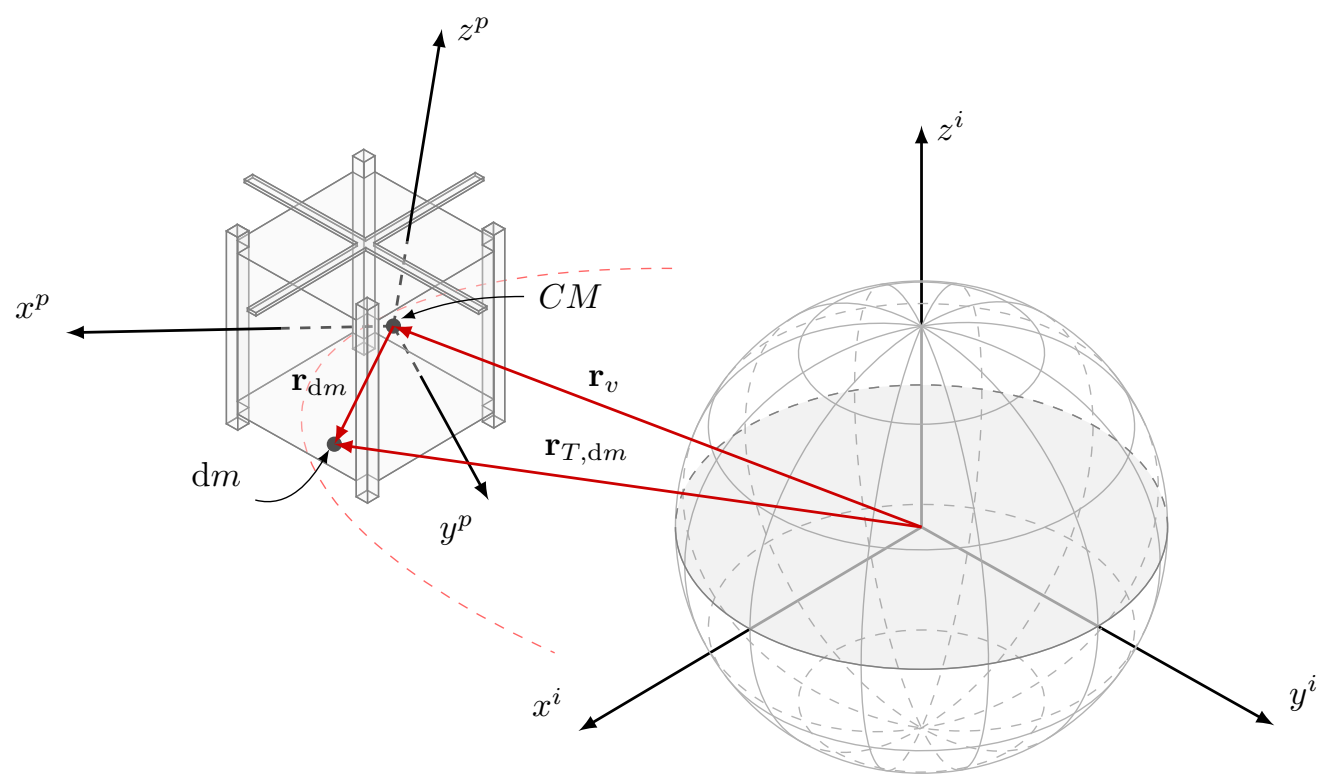

Fonte: Autor.

Conforme apresentado em [18] e [87], quando o torque $\mathbf{T}_{g g}$ é representado no REP, a Equação (4.46) pode ser reescrita como

$$
\mathbf{T}_{g g}^{p}=\frac{3 \mu_{T}}{r_{v}^{3}}\left[\hat{\mathbf{r}}_{v}^{p} \times\left(\left[\mathbf{I}_{v}\right]^{p} \hat{\mathbf{r}}_{v}^{p}\right)\right]
$$




\subsubsection{Torque Devido ao Dipolo Magnético Residual}

Conforme introduzido anteriormente, em órbitas terrestres o satélite está sujeito ao campo magnético da Terra e a interação desse campo com um dipolo no veículo produz torque. Esse dipolo pode ser desejado, como o atuador magnético apresentado na Subseção 4.1.2.1.1, ou pode ser não desejado, oriundo de corrente de Foucault, histerese e outros momentos magnéticos que podem surgir por conta de correntes que circulam nos circuitos eletrônicos do veículo. Chamando-o de dipolo magnético residual, $\mathbf{m}_{m r}$, e utilizando-se da Equação (4.9), o torque devido ao dipolo magnético residual, $\mathbf{T}_{m r}$, é dado por

$$
\mathbf{T}_{m r}^{p}=\mathbf{m}_{m r}^{p} \times \mathbf{B}^{p}
$$

na qual B é campo magnético terrestre e sua modelagem é tratada na Subseção 4.3.1.4.1.

O dipolo magnético residual, $\mathbf{m}_{m r}$, é obtido por meio de experimentos em laboratório, no qual os circuitos eletrônicos do satélite são ativados e o campo magnético produzido por eles é estimado. Em [88] esse procedimento foi realizado em um CubeSat de 3U e, como resultado, obtiveram $\mathbf{m}_{m r}^{s}=[-0,14-0,12-19,32]^{\top} 10^{-3} \mathrm{~A} \mathrm{~m}^{2}$. Esse valor será utilizado nessa dissertação como uma referência realista, pois trata-se de um nanossatélite de $3 \mathrm{U}$, assim como o PicSat, e foi obtido experimentalmente.

\subsection{Modelo do Campo Magnético Terrestre}

Com o auxílio de satélites e observatórios, modelos matemáticos do campo magnético terrestre vêm sendo desenvolvidos desde a década de 60. Os modelos mais utilizados pela comunidade científica são o International Geomagnetic Reference Field (IGRF)[89], desenvolvido pela International Association of Geomagnetism and Aeronomy (IAGA), e o World Magnetic Model (WMM)[90] desenvolvido pela United State National Geophysical Data Center (NGDC) e British Geological Survey (BGS). Ambos os modelos são atualizados a cada cinco anos e estão disponíveis publicamente. Softwares como o MATLAB e Simulink possuem esses modelos integrados. Neste trabalho utiliza-se o IGRF na versão IGRF-12 de 2015 .

\subsubsection{Perturbações Orbitais}

Na Seção 4.2 apresentou-se a Órbita Kepleriana, que não leva em consideração as perturbações orbitais. Dessa forma, a propagação da trajetória divergirá rapidamente da órbita real. Uma das formas de considerar as perturbações no modelo orbital é por meio da Formulação de Cowell [70]. Trata-se de uma modificação na Equação (4.17), considerando uma aceleração de perturbação, $\mathbf{a}_{p r t}$, isto é,

$$
\mathbf{a}_{v}^{i}=-\frac{\mu_{T}}{\mathbf{r}_{v}^{3}} \mathbf{r}_{v}^{i}+\mathbf{a}_{p r t}^{i}
$$


As perturbações orbitais mais influentes são oriundas do arrasto atmosférico, $\mathbf{a}_{d}$, pressão da radiação solar, $\mathbf{a}_{r a d}$, não homogeneidade da Terra, $\mathbf{a}_{g}$, e efeito de um terceiro corpo (Sol e Lua), $\mathbf{a}_{t c}$. Sendo assim, a aceleração de perturbação, $\mathbf{a}_{p r t}$, é dada pela soma de todos os distúrbios, isto é,

$$
\mathbf{a}_{p r t}^{i}=\mathbf{a}_{d}^{i}+\mathbf{a}_{r a d}^{i}+\mathbf{a}_{g}^{i}+\mathbf{a}_{t c}^{i}
$$

\subsubsection{Aceleração Devido ao Arrasto Atmosférico}

O arrasto atmosférico foi inicialmente explorado na Subseção 4.3.1.1 e, assim como produz perturbações de atitude, interfere na órbita do veículo.

Essa perturbação na aceleração, $\mathbf{a}_{d}$, é dada por

$$
\mathbf{a}_{d}^{i}=\frac{1}{m_{v}} \sum_{i=1}^{n} \mathbf{F}_{d_{i}}^{i}
$$

na qual $m_{v}$ é a massa do veículo e $\mathbf{F}_{d_{i}}$ é a força de arrasto em cada uma das áreas $i$ conforme apresentado na Equação (4.23).

\subsubsection{Aceleração Devido à Pressão de Radiação Solar}

De forma análoga ao arrasto, a pressão da radiação solar interfere na atitude e também na órbita do satélite.

A perturbação $\mathbf{a}_{r a d}$ é dada por

$$
\mathbf{a}_{r a d}^{i}=\frac{1}{m_{v}} \sum_{i=1}^{n}\left(\mathbf{F}_{r a_{i}}^{i}+\mathbf{F}_{r r_{i}}^{i}+\mathbf{F}_{r d_{i}}^{i}\right)
$$

na qual $m_{v}$ é a massa do veículo, $\mathbf{F}_{r a_{i}}$ é a força em razão da radiação absorvida (Eq. (4.31)), $\mathbf{F}_{r r_{i}}$ é a força em razão da radiação refletida (Eq. (4.32)), e $\mathbf{F}_{r d_{i}}$ é a força em razão da radiação difusa (Eq. (4.33)).

\subsubsection{Aceleração Devido à não Homogeneidade da Terra}

Para algumas aplicações, aproximações e até mesmo para fins didáticos, a Terra é considerada uma esfera de massa homogênea. Porém, é de conhecimento comum que esse não é o caso. A aceleração da gravidade depende diretamente da massa do corpo celeste. Dessa forma, a distribuição de massa não homogênea da Terra será refletida no campo gravitacional. Esse fenômeno é conhecido como perturbação gravitacional* .

*Apesar da perturbação de atitude, apresentada na Subseção 4.3.1.3, ser devido ao gradiente de gravidade, é importante compreender que não se trata do mesmo fenômeno. No caso da perturbação de atitude, essa ocorre em razão da força gravitacional não ser a mesma para todos os elementos de massa do veículo. Já no caso da perturbação orbital, essa se dá em decorrência da força gravitacional não ser a mesma ao longo da trajetória. 
Por se tratar de uma força conservativa, a aceleração da gravidade em um ponto qualquer $P$ pode ser expressa por meio do gradiente do potencial gravitacional $[68,69]$, isto é,

$$
\mathbf{a}_{P}=\nabla U
$$

Por conveniência, o potencial gravitacional, $U$, pode ser expresso em dois termos e em coordenadas esféricas, na qual, $r$ é a distância geocêntrica do ponto $P, \phi$ é a longitude e $\lambda$ a latitude

$$
U(r, \phi, \lambda)=\frac{\mu_{T}}{r}+U_{g}(r, \phi, \lambda),
$$

na qual o primeiro termo, $\mu_{T} / r$, se refere ao potencial gravitacional de massa uniformemente distribuída, de forma que $\nabla \mu_{T} / r$ resulta na própria Equação (4.17). O segundo termo, $U_{g}(r, \phi, \lambda)$, se refere ao potencial gravitacional da não uniformidade. Sendo assim,

$$
\mathbf{a}_{g}=\nabla U_{g}
$$

Uma forma de modelar $U_{g}(r, \phi, \lambda)$ é por meio de expansão harmônica esférica $[18,69$, $70,72]$, resultando em

$$
U_{g}(r, \phi, \lambda)=\frac{\mu_{T}}{r} \sum_{n=2}^{\infty}\left(\frac{R_{T}}{r}\right)^{n} \sum_{m=1}^{n} P_{n}^{m}(\operatorname{sen} \lambda)\left(C_{n}^{m} \cos m \phi+S_{n}^{m} \operatorname{sen} m \phi\right) .
$$

Trata-se de uma série infinita do potencial gravitacional em um ponto $P$ qualquer, na qual: $R_{T}=6378 \mathrm{~km}$ é o raio médio da Terra no equador; $P_{n}^{m}$ são os polinômios associados de Legendre de grau $n$ e ordem $m ; C_{n}^{m}$ são os coeficientes tesserais harmônicos; e $S_{n}^{m}$ os coeficientes sectoriais harmônicos. Esses coeficientes são inferidos por meio de observação de satélites e gravimetria, enquanto os polinômios associados de Legendre podem ser obtidos por $[18,70,72]$

$$
P_{n}^{m}(x)=\left(1-x^{2}\right)^{m / 2} \frac{\mathrm{d}^{m}}{\mathrm{~d}^{m} x}\left(\frac{1}{2^{n} n !} \frac{\mathrm{d}^{n}}{\mathrm{~d}^{n} x}\left(x^{2}-1\right)^{n}\right) .
$$

Os índices $m$ e $n$ determinam a quantidade de linhas de divisão na esfera no sentido de varredura da função, de forma que os harmônicos esféricos podem ser divididos em três classes: harmônicos zonais, para $m=0$; harmônicos sectoriais para $m=n$; e harmônicos tesserais para $0<m<n$. Para auxiliar na compreensão do leitor, a Figura 23 ilustra três exemplos.

Note que os harmônicos zonais produzem divisões ao longa da latitude, de forma que o potencial gravitacional em uma determinada latitude independe da longitude. Por outro lado, os harmônicos sectoriais produzem divisões ao longo da longitude, isto é, o potencial gravitacional em uma determinada longitude independe da latitude. Já os harmônicos tesserais dividem tanto na latitude quando na longitude. 
Figura 23 - Exemplos de harmônicos esféricos.

Harmônicos zonais.

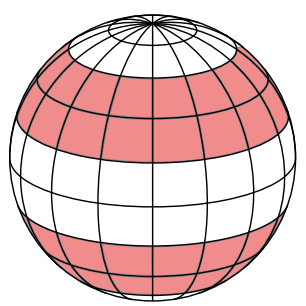

Harmônicos sectoriais.

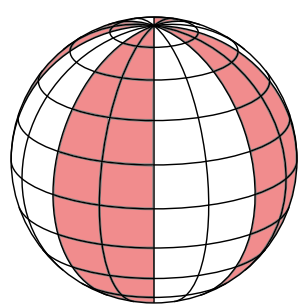

Harmônicos tesserais.

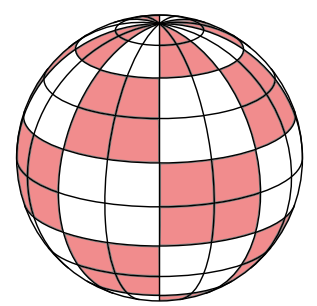

Fonte: Autor.

Retornando à Equação (4.55), o gradiente do potencial gravitacional, $\nabla U_{g}$, pode ser expresso por derivadas parciais utilizando a regra da cadeia, isto é,

$$
\boldsymbol{\nabla} U_{g}(r, \phi, \lambda)=\frac{\partial U_{g}}{\partial r} \nabla r+\frac{\partial U_{g}}{\partial \phi} \nabla \phi+\frac{\partial U_{g}}{\partial \lambda} \nabla \lambda
$$

na qual as derivadas parciais são dadas por [70,72]

$$
\begin{aligned}
& \frac{\partial U_{g}}{\partial r}=-\frac{\mu_{T}}{r^{2}} \sum_{n=2}^{\infty} \sum_{m=0}^{n}\left(\frac{R_{T}}{r}\right)^{n}(n+1) P_{n}^{m}(\operatorname{sen} \lambda)\left(C_{n}^{m} \cos m \phi+S_{n}^{m} \operatorname{sen} m \phi\right) \\
& \frac{\partial U_{g}}{\partial \phi}=\frac{\mu_{T}}{r} \sum_{n=2}^{\infty} \sum_{m=0}^{n}\left(\frac{R_{T}}{r}\right)^{n}\left(P_{n}^{m+1}(\operatorname{sen} \lambda)-m \operatorname{tg} \lambda P_{n}^{m}(\operatorname{sen} \lambda)\right)\left(C_{n}^{m} \cos m \phi\right. \\
& \left.\quad+S_{n}^{m} \operatorname{sen} m \phi\right) \quad \text { e } \\
& \frac{\partial U_{g}}{\partial \lambda}=\frac{\mu_{T}}{r} \sum_{n=2}^{\infty} \sum_{m=0}^{n}\left(\frac{R_{T}}{r}\right)^{n} m P_{n}^{m}(\operatorname{sen} \lambda)\left(S_{n}^{m} \cos m \phi-C_{n}^{m} \operatorname{sen} m \phi\right) .
\end{aligned}
$$

Representado no GEI e substituindo o ponto qualquer $P$ pelo veículo, a aceleração devido à não homogeneidade da Terra é expressa por

$$
\begin{aligned}
& \mathbf{a}_{g}^{i}=\left[\left(\frac{1}{r_{v}} \frac{\partial U_{g}}{\partial r_{v}}-\frac{z}{r_{v}^{2} \sqrt{x^{2}+y^{2}}} \frac{\partial U_{g}}{\partial \lambda_{v}}\right) x-\left(\frac{1}{x^{2}+y^{2}} \frac{\partial U_{g}}{\partial \phi_{v}}\right) y\right] \hat{\mathbf{i}}^{i} \\
& +\left[\left(\frac{1}{r_{v}} \frac{\partial U_{g}}{\partial r_{v}}-\frac{z}{r_{v}^{2} \sqrt{x^{2}+y^{2}}} \frac{\partial U_{g}}{\partial \lambda_{v}}\right) y+\left(\frac{1}{x^{2}+y^{2}} \frac{\partial U_{g}}{\partial \phi_{v}}\right) x\right] \hat{\mathbf{j}}^{i} \\
& +\left[\frac{\sqrt{x^{2}+y^{2}}}{r^{2}} \frac{\partial U_{g}}{\partial \lambda_{v}}+\left(\frac{1}{r_{v}} \frac{\partial U_{g}}{\partial r_{v}}\right) z\right] \hat{\mathbf{k}}^{i},
\end{aligned}
$$

na qual $x, y$ e $z$ são as componentes do vetor posição do satélite no GEI, isto é, $\mathbf{r}_{v}^{i}=\left[\begin{array}{lll}x & y & z\end{array}\right]^{\top}$ e $r_{v}$ é o módulo de $\mathbf{r}_{v}$.

Para calcular numericamente $\mathbf{a}_{g}$ faz-se necessário truncar a série em um determinado grau $m$ e ordem $n$. A implementação mais comum é realizada com $m=0$ e $n=2$, (ilustrada anteriormente na Figura 23). É o equivalente a considerar a Terra como uma esfera achatada nos polos e a região próxima ao equador com maior distribuição de massa. 
Esse truncamento é justificado por se tratar de uma situação de maior influência no campo gravitacional, o que exige menor esforço computacional quando comparado ao truncamento em graus e ordens mais elevadas [68].

Em [70] são comparadas as perturbações de diversos satélites em diferentes órbitas devido ao arrasto atmosférico, à pressão da radiação solar, ao efeito de um terceiro corpo e à não homogeneidade da Terra com o truncamento em $m=0$ e $n=2, m=n=12, m=n=24$, e $m=n=70$. Vallado ressalta que apesar do truncamento em $m=0$ e $n=2$ ser de uma a duas ordens de magnitude mais influente que o truncamento em ordens superiores, a parcela da perturbação relativa às ordens superiores é da mesma ordem de grandeza que a perturbação devido à pressão da radiação solar e devido ao efeito de um terceiro corpo. Sendo assim, para um modelo de alta fidelidade matemática, faz-se necessário considerar o truncamento em, ao menos, $m=n=24$.

O modelo gravitacional de maior capacidade é o Earth Gravitational Model 2008 (EGM2008) publicado pela U.S. National Geospatial-Intelligence Agency (NGA) que permite o truncamento até o grau 2190 e ordem 2159 [91]. Neste trabalho foi utilizado o EGM2008 e as simulações foram realizadas com truncamento em $m=n=70$.

\subsubsection{Aceleração Devido ao Efeito de um Terceiro Corpo}

A Órbita de Kepler, apresentada na Equação (4.17), leva em consideração a interação gravitacional entre dois corpos. Tal situação é frequentemente denominada de Problema dos Dois Corpos [70]. Entretanto, outros corpos celestes, como a Lua e o Sol, também irão interagir gravitacionalmente com o veículo. Essa interação pode ser considerada como uma perturbação e modelada como um sistema de três corpos [72].

Considere a situação em que a interação gravitacional ocorre entre três corpos quaisquer, 1, 2 e 3, conforme ilustrado na Figura 24, na qual $m_{1}, m_{2}$ e $m_{3}$ são as respectivas massas, $\mathbf{F}_{i j}$ é a força gravitacional em $i$ exercida pelo corpo $j$, e $\mathbf{R}_{1}, \mathbf{R}_{2}$ e $\mathbf{R}_{3}$ são os respectivos vetores posição em relação à origem do sistema inercial. Essa situação é denominada de Problema dos Três Corpos, ou Problema de $n$ Corpos, pois pode ser facilmente generalizado para $n$ corpos [68].

Aplicando-se a Lei da Gravitação Universal (Eq. (4.16)),

$$
\begin{aligned}
& \mathbf{F}_{12}=-\mathbf{F}_{21}=\frac{G m_{1} m_{2}\left(\mathbf{R}_{2}-\mathbf{R}_{1}\right)}{\left\|\mathbf{R}_{2}-\mathbf{R}_{1}\right\|^{3}} \\
& \mathbf{F}_{13}=-\mathbf{F}_{31}=\frac{G m_{1} m_{3}\left(\mathbf{R}_{3}-\mathbf{R}_{1}\right)}{\left\|\mathbf{R}_{3}-\mathbf{R}_{1}\right\|^{3}} \mathrm{e} \\
& \mathbf{F}_{23}=-\mathbf{F}_{32}=\frac{G m_{2} m_{3}\left(\mathbf{R}_{3}-\mathbf{R}_{2}\right)}{\left\|\mathbf{R}_{3}-\mathbf{R}_{2}\right\|^{3}}
\end{aligned}
$$


Figura 24 - Problema dos Três Corpos.

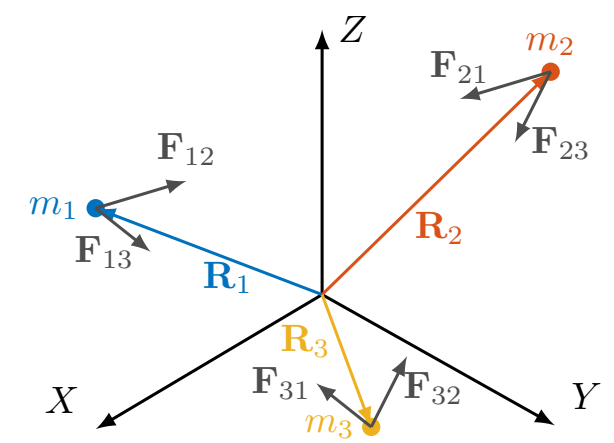

Fonte: Autor.

E, aplicando-se a segunda Lei de Newton $\left(\sum \mathbf{F}=m \mathbf{a}\right)$ resulta em

$$
\begin{aligned}
& \mathbf{a}_{1}=\frac{\mathbf{F}_{12}+\mathbf{F}_{13}}{m_{1}}=\frac{G m_{2}\left(\mathbf{R}_{2}-\mathbf{R}_{1}\right)}{\left\|\mathbf{R}_{2}-\mathbf{R}_{1}\right\|^{3}}+\frac{G m_{3}\left(\mathbf{R}_{3}-\mathbf{R}_{1}\right)}{\left\|\mathbf{R}_{3}-\mathbf{R}_{1}\right\|^{3}}, \\
& \mathbf{a}_{2}=\frac{\mathbf{F}_{21}+\mathbf{F}_{23}}{m_{2}}=\frac{G m_{1}\left(\mathbf{R}_{1}-\mathbf{R}_{2}\right)}{\left\|\mathbf{R}_{1}-\mathbf{R}_{2}\right\|^{3}}+\frac{G m_{3}\left(\mathbf{R}_{3}-\mathbf{R}_{2}\right)}{\left\|\mathbf{R}_{3}-\mathbf{R}_{2}\right\|^{3}} \mathrm{e} \\
& \mathbf{a}_{3}=\frac{\mathbf{F}_{31}+\mathbf{F}_{32}}{m_{3}}=\frac{G m_{1}\left(\mathbf{R}_{1}-\mathbf{R}_{3}\right)}{\left\|\mathbf{R}_{1}-\mathbf{R}_{3}\right\|^{3}}+\frac{G m_{2}\left(\mathbf{R}_{2}-\mathbf{R}_{3}\right)}{\left\|\mathbf{R}_{2}-\mathbf{R}_{3}\right\|^{3}}
\end{aligned}
$$

As acelerações $\mathbf{a}_{1}, \mathbf{a}_{2}$ e $\mathbf{a}_{3}$ são em relação ao sistema inercial. A aceleração relativa do corpo 2 em relação a 1, por exemplo, é dada por

$$
\mathbf{a}_{2 / 1}=\mathbf{a}_{2}-\mathbf{a}_{1}=-\frac{G\left(m_{1}+m_{2}\right)\left(\mathbf{R}_{2}-\mathbf{R}_{1}\right)}{\left\|\mathbf{R}_{2}-\mathbf{R}_{1}\right\|^{3}}+G m_{3}\left(\frac{\mathbf{R}_{3}-\mathbf{R}_{2}}{\left\|\mathbf{R}_{3}-\mathbf{R}_{2}\right\|^{3}}-\frac{\mathbf{R}_{3}-\mathbf{R}_{1}}{\left\|\mathbf{R}_{3}-\mathbf{R}_{1}\right\|^{3}}\right) .
$$

Considerando então o corpo 1 como sendo a Terra $(T)$, o corpo 2 o veículo $(v)$, o corpo 3 a Lua $(l)$ e o sistema inercial como o GEI $(i)$, a Equação (4.63) torna-se a aceleração do veículo em relação à Terra expressa por

$$
\mathbf{a}_{v}^{i}=-\frac{\mu_{T} \mathbf{r}_{v}^{i}}{r_{v}^{3}}+\mu_{l}\left(\frac{\mathbf{r}_{l / v}^{i}}{r_{l / v}^{3}}-\frac{\mathbf{r}_{l}^{i}}{r_{l}^{3}}\right)
$$

na qual $\mu_{T} \equiv G m_{T}=398600 \mathrm{~km}^{3} \mathrm{~s}^{2}$ (ver Eq. (4.17)), $\mu_{l} \equiv G m_{l}=4903 \mathrm{~km}^{3} \mathrm{~s}^{2}, \mathbf{r}_{l / v}$ é o vetor posição da Lua em relação ao veículo, $\mathbf{r}_{l}$ é o vetor posição da Lua em relação à origem do GEI, isto é, a Terra. O primeiro termo da Equação (4.64) é a própria Equação (4.17), isto é, a aceleração orbital sem perturbação. Portanto, o segundo termo da equação,

$$
\mathbf{a}_{t c_{l}}^{i}=\mu_{l}\left(\frac{\mathbf{r}_{l / v}^{i}}{r_{l / v}^{3}}-\frac{\mathbf{r}_{l}^{i}}{r_{l}^{3}}\right)
$$

é a perturbação causada pela influência da gravidade lunar. 
O mesmo processo pode ser realizado com a Equação (4.63), porém considerando o corpo 3 como o Sol $(s)$, resultando em

$$
\mathbf{a}_{t c_{s}}^{i}=\mu_{s}\left(\frac{\mathbf{r}_{s / v}^{i}}{r_{s / v}^{3}}-\frac{\mathbf{r}_{s}^{i}}{r_{s}^{3}}\right)
$$

na qual $\mu_{s} \equiv G m_{s}=132712 \times 10^{9} \mathrm{~km}^{3} \mathrm{~s}^{2}, \mathbf{r}_{s / v}$ é o vetor posição do Sol em relação ao veículo e $\mathbf{r}_{s}$ é o vetor posição do Sol em relação à origem do GEI.

Sendo assim, a aceleração devido ao efeito de um terceiro corpo é dada por

$$
\mathbf{a}_{t c}^{i}=\mu_{l}\left(\frac{\mathbf{r}_{l / v}^{i}}{r_{l / v}^{3}}-\frac{\mathbf{r}_{l}^{i}}{r_{l}^{3}}\right)+\mu_{s}\left(\frac{\mathbf{r}_{s / v}^{i}}{r_{s / v}^{3}}-\frac{\mathbf{r}_{s}^{i}}{r_{s}^{3}}\right) .
$$

Por fim, pode-se representar as perturbações de atitude e órbita, para fins didáticos, como na Figura 25.

Figura 25 - Diagrama das perturbações de atitude e órbita.
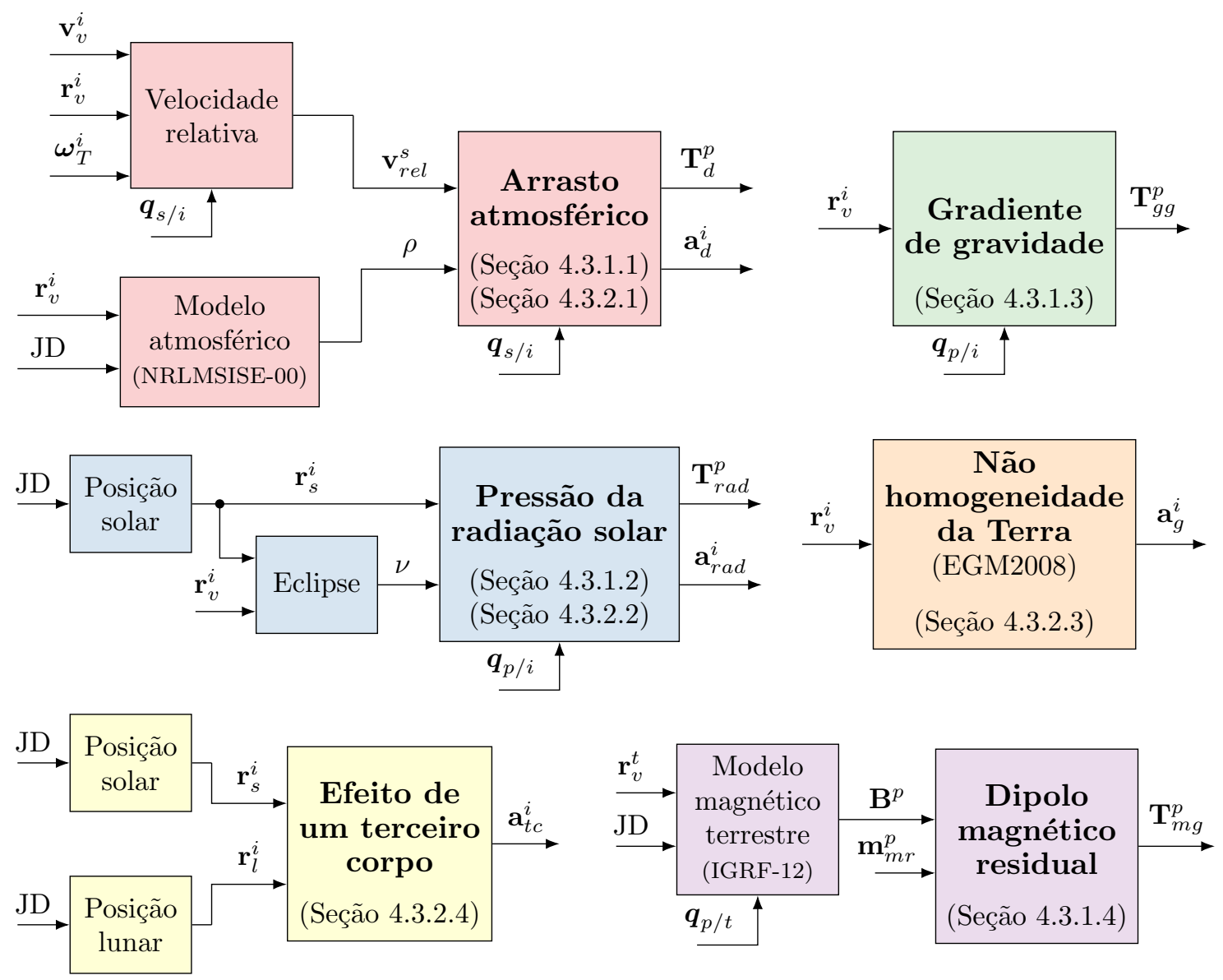

No diagrama as constantes foram suprimidas e estão ilustrados apenas os termos variantes no tempo. Lembra-se que $\boldsymbol{q}_{a / b}$ representa a atitude do sistema de coordenadas $a$ em relação à $b$ e JD é a informação de tempo em dias julianos.

Fonte: Autor. 



\section{RESULTADOS DE SIMULAÇÃO DA MODELA- GEM MATEMÁTICA}

Ao longo do Capítulo 4, foram apresentados modelos matemáticos: (i) da dinâmica e cinemática do satélite; (ii) da dinâmica orbital; (iii) dos atuadores; (iv) e das perturbações. Neste capítulo, apresentam-se os resultados de simulação desses modelos.

\subsection{Nanossatélites Hipotéticos}

Conforme anteriormente mencionado, o simulador tem a proposta de ser configurável e servir para diferentes estruturas de nanossatélites e trajetórias em LEO. Entretanto, para apresentar os resultados dos modelos matemáticos é preciso definir as características dos satélites e das órbitas utilizadas.

Visando aproveitar o momento de testes do simulador e contribuir com resultados preliminares às equipes do IMT e IAG, seria oportuno utilizar nanossatélites com características que atendam às respectivas missões. Todavia, no início desse projeto não existia uma definição última das características dos veículos. Sendo assim, fez-se necessário propor um nanossatélite hipotético com as informações disponíveis.

A equipe do IMT, trabalhando há mais tempo e com diferentes frentes de tarefa, concentrava esforços na concepção dos subsistemas de suprimento elétrico, telemetria, processamento de dados e estrutura de um CubeSat de 1U. O ACS, naquele momento, testava a possibilidade de utilizar 3 atuadores magnéticos e 3 rodas de reação. O projeto do IAG, por sua vez, era bastante recente e estava em fase de concepção.

Por conta da similaridade de objetivos, características e condições de desenvolvimento, o nanossatélite AAUSAT-II [92], também serviu como referência. Trata-se de um CubeSat de 1 U lançado em 2008, desenvolvido por alunos da Aalborg University, cujos objetivos eram estabelecer comunicação de duas vias e detectar explosões de raio gama oriundas do espaço. No referido nanossatélite, o ACS contava com 3 atuadores magnéticos e 3 rodas de reação.

Dessa forma, utilizando as informações da equipe do IMT e o AAUSAT-II como referência, foi estabelecido o nanossatélite hipotético. Trata-se de um CubeSat de 1U com 3 atuadores magnéticos e 3 rodas de reação, denominado de fooSAT-A1*.

*O acrônimo é formado pela combinação dos termos: foo, que em programação computacional, é utilizado para denominar uma variável, função ou comando genérico, com o intuito de apenas demonstrar um conceito; SAT, referente à palavra satélite; A, primeira letra do alfabeto como referência à primeira versão; e 1, referente à dimensão do CubeSat. 
A equipe do IMT já havia desenvolvido um protótipo de atuadores magnéticos, porém as características técnicas não estavam disponíveis. Os atuadores comerciais Cube Torquer Small [93] têm dimensões similares à descrição do protótipo e, portanto, foram adotados no fooSAT-A1. Suas principais características estão apresentadas na Tabela 2.

Tabela 2 - Características do atuador magnético.

\begin{tabular}{ll}
\hline Parâmetro & Valor \\
\hline Indutância $\left(L_{a m}\right)$ & $150 \times 10^{-3} \mathrm{H}$ \\
Resistência $\left(R_{a m}\right)$ & $30 \Omega$ \\
Número de espiras $\left(N_{a m}\right)$ & 36670 \\
Área média da bobina $\left(A_{a m}\right)$ & $7,85 \times 10^{-5} \mathrm{~m}^{2}$ \\
Momento magnético máximo & $1,5 \mathrm{~A} \mathrm{~m}^{2}$ \\
Altura & $60 \times 10^{-3} \mathrm{~m}$ \\
Massa & $27,5 \times 10^{-3} \mathrm{~kg}$ \\
\hline
\end{tabular}

Fonte: Autor.

No que se refere às rodas de reação, a equipe do IMT já havia adquirido algumas unidades do BLDC da Maxon modelo EC 9.2 Flat. Sendo assim, foram considerados esses motores acoplados a um disco de inércia. Os dados do fabricante estão disponíveis no Apêndice A e as principais características do conjunto são apresentadas na Tabela 3.

Tabela 3 - Características da roda de reação.

\begin{tabular}{ll}
\hline Parâmetro & Valor \\
\hline Indutância da armadura $\left(L_{a}\right)$ & $2,35 \times 10^{-3} \mathrm{H}$ \\
Resistência da armadura $\left(R_{a}\right)$ & $23,9 \Omega$ \\
Constante de torque $\left(k_{t}\right)$ & $11,3 \times 10^{-3} \mathrm{~N} \mathrm{~m} / \mathrm{A}$ \\
Constante elétrica $\left(k_{e}\right)$ & $11,3 \times 10^{-3} \mathrm{~V} \mathrm{~s} / \mathrm{rad}$ \\
Coeficiente de atrito viscoso $(b)$ & $291,8 \times 10^{-9}$ \\
Tensão máxima & $12 \mathrm{~V}$ \\
Corrente máxima & $0,503 \mathrm{~A}$ \\
Torque máximo & $5,67 \times 10^{-3} \mathrm{~N} \mathrm{~m}$ \\
Massa do conjunto & $32,75 \times 10^{-3} \mathrm{~kg}$ \\
Momento de inércia do conjunto $\left(I_{r r}\right)$ & $1,66 \times 10^{-6} \mathrm{~kg} \mathrm{~m}^{2}$ \\
\hline
\end{tabular}

Fonte: Autor.

A massa de um CubeSat de $1 \mathrm{U}$ deve ser, no máximo, $1,33 \mathrm{~kg}$ [94] e foi tida como $m_{v}=1,33 \mathrm{~kg}$, por se tratar da condição limite. A matriz de inércia foi obtida por 
meio da soma das matrizes de inércia de cada elemento do satélite (ver Seção A.1). O centro de massa de um CubeSat de $1 \mathrm{U}$ pode estar deslocado do centro geométrico em, no máximo, 2,0 cm em cada um dos eixos [94]. E, de forma similar à massa, foi tido como $C M^{s}=\left[\begin{array}{llll}2,0 & 2,0 & -2,0\end{array}\right]^{\top} \mathrm{cm}$. Os coeficientes de arrasto e superfícies, bem como o dipolo magnético residual, foram adotados conforme mencionado anteriormente nas subseções 4.3.1.1, 4.3.1.2 e 4.3.1.4, respectivamente. Essas características são apresentadas na Tabela 4.

Tabela 4 - Características do fooSAT-A1.

\begin{tabular}{|c|c|}
\hline Parâmetro & Valor \\
\hline Dimensão & $1 \mathrm{U}(10 \mathrm{~cm} \times 10 \mathrm{~cm} \times 10 \mathrm{~cm})$ \\
\hline $\operatorname{massa}\left(m_{v}\right)$ & $1,33 \mathrm{~kg}$ \\
\hline Matriz de inércia $\left(\left[\mathbf{I}_{v}\right]^{s}\right)$ & {$\left[\begin{array}{ccc}218,75 & -7,29 & -6,87 \\
-7,29 & 220,14 & -6,47 \\
-6.87 & -6,47 & 219,87\end{array}\right] 10^{-5} \mathrm{~kg} \mathrm{~m}^{2}$} \\
\hline Centro de massa $\left(C M^{s}\right)$ & {$\left[\begin{array}{llll}2,0 & 2,0 & -2,0\end{array}\right]^{\top} 10^{-2} \mathrm{~m}$} \\
\hline Coeficiente de arrasto $\left(C_{d}\right)$ & 2,1 \\
\hline Coeficientes da superfície $\left(c_{r a}, c_{r r}\right.$ e $\left.c_{r d}\right)$ & $0,79,0,04$ e 0,17 \\
\hline Dipolo magnético residual $\left(\mathbf{m}_{m r}^{s}\right)$ & {$[-0,14-0,12-19,32]^{\top} 10^{-3} \mathrm{~A} \mathrm{~m}^{2}$} \\
\hline
\end{tabular}

Fonte: Autor.

Alguns fenômenos da dinâmica do corpo rígido são mais facilmente observados quando o satélite possui dimensões distintas de altura, largura e profundidade. Além do mais, os movimentos causados exclusivamente pelos atuadores são mais facilmente observados quando não há deslocamento entre o centro de massa e o centro geométrico. Por conta disso, foram definidos outros dois nanossatélites "ideais": fooSAT-I1 e fooSAT-I6, CubeSats de $1 \mathrm{U}$ e $6 \mathrm{U}$, respectivamente. Eles foram utilizados pontualmente nesse capítulo e suas características estão apresentadas na Tabela 5 .

Os sistemas de coordenadas dos nanossatélites estão ilustrados na Figura 26 e seguem conforme o estabelecido nas seções 3.4 e 3.5 .

\section{2 Órbitas Hipotéticas}

Os nanossatélites são, majoritariamente, lançados como cargas secundárias ou da Estação Espacial Internacional, em inglês International Space Station (ISS), em uma órbita de $51,66^{\circ}$ em relação ao equador [5,9]. Como carga secundária, a órbita depende da missão principal, sendo a órbita heliossíncrona, do inglês Sun-synchronous orbit (SSO), a mais comum. Trata-se de um caso particular da órbita polar, com inclinação de 
Tabela 5 - Características do fooSAT-I1 e fooSAT-I6.

\begin{tabular}{|c|c|c|}
\hline \multirow[t]{2}{*}{ Parâmetro } & \multicolumn{2}{|c|}{ Valor } \\
\hline & fooSAT-I1 & fooSAT-I6 \\
\hline Dimensão & $1 \mathrm{U}(10 \mathrm{~cm} \times 10 \mathrm{~cm} \times 10 \mathrm{~cm})$ & $6 \mathrm{U}(10 \mathrm{~cm} \times 20 \mathrm{~cm} \times 30 \mathrm{~cm})$ \\
\hline $\operatorname{Massa}\left(m_{v}\right)$ & $1 \mathrm{~kg}$ & $6 \mathrm{~kg}$ \\
\hline Matriz de inércia $\left(\left[\mathbf{I}_{v}\right]^{s}\right)$ & $\operatorname{diag}[1,7 \quad 1,7 \quad 1,7] 10^{-3} \mathrm{~kg} \mathrm{~m}^{2}$ & $\operatorname{diag}\left[\begin{array}{lll}5,0 & 6,5 & 2,5\end{array}\right] 10^{-2} \mathrm{~kg} \mathrm{~m}^{2}$ \\
\hline Centro de massa $\left(C M^{s}\right)$ & {$\left[\begin{array}{lll}0 & 0 & 0\end{array}\right]^{\top} \mathrm{m}$} & {$\left[\begin{array}{lll}0 & 0 & 0\end{array}\right]^{\top} \mathrm{m}$} \\
\hline Coef. ar. $\left(C_{d}\right)$ & 2,1 & 2,1 \\
\hline Coef. sup. $\left(c_{r a}, c_{r r}\right.$ e $\left.c_{r d}\right)$ & $0,33,0,33$ e 0,33 & $0,33,0,33$ e 0,33 \\
\hline Dipolo mag. res. $\left(\mathbf{m}_{m r}\right)$ & {$\left[\begin{array}{lll}0 & 0 & -20\end{array}\right]^{\top} 10^{-3} \mathrm{~A} \mathrm{~m}^{2}$} & {$\left[\begin{array}{lll}0 & 0 & -20\end{array}\right]^{\top} 10^{-3} \mathrm{~A} \mathrm{~m}^{2}$} \\
\hline
\end{tabular}

Fonte: Autor.

Figura 26 - Sistema de coordenadas do fooSAT-A1, fooSAT-I1 e fooSAT-I6.

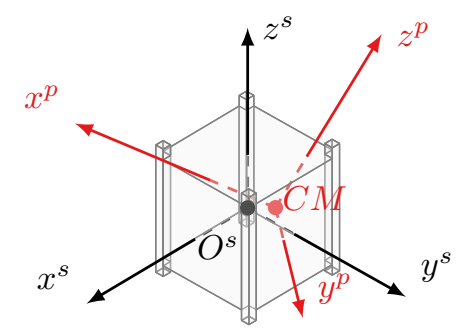

fooSAT-A1

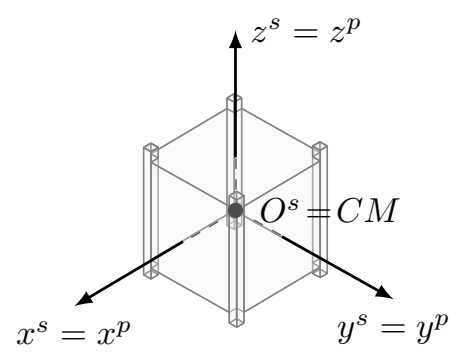

fooSAT-I1

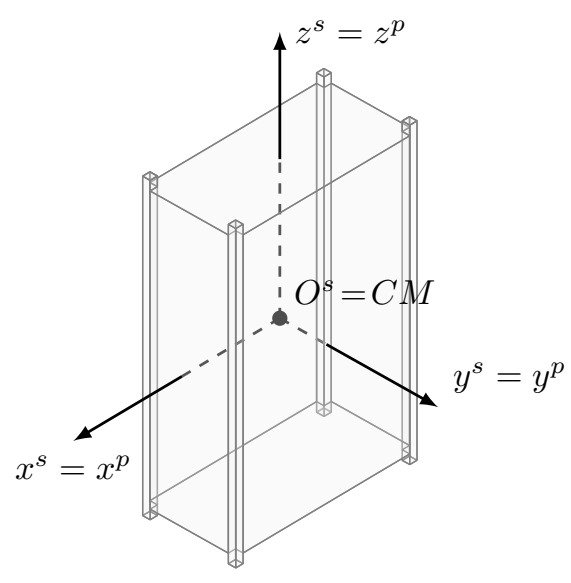

fooSAT-I6

Fonte: Autor.

aproximadamente $98^{\circ}$ em relação ao equador, mantendo o plano orbital direcionado para o Sol. A SSO é procurada pelas missões principais que desejam monitorar todo o globo terrestre e ainda garantir uma fonte de energia solar constante [70]. Por conta da diferença de inclinação entre a ISS e a SSO, ambas serão utilizadas nesse trabalho, permitindo avaliar suas características e influências. As condições iniciais de propagação foram extraídas da própria ISS e do PicSat no dia 03/01/2019† e estão acomodadas na Tabela 6 .

\footnotetext{
†Esses dados servem apenas para condições iniciais realistas. A propagação se dará por meio dos modelos propostos.
} 
Tabela 6 - Características das órbitas ISS e SSO.

\begin{tabular}{|c|c|c|}
\hline \multirow[t]{2}{*}{ Parâmetro } & \multicolumn{2}{|c|}{ Valor } \\
\hline & ISS & $\mathrm{SSO}$ \\
\hline Tempo inicial $(t(0))$ & 03/01/2019 12:41:22 UT1 & 03/01/2019 21:49:23 UT1 \\
\hline Posição inicial $\left(\mathbf{r}_{v}^{i}(0)\right)$ & {$\left[\begin{array}{lll}-1,19 & 6,68 & 0,01\end{array}\right]^{\top} 10^{3} \mathrm{~km}$} & {$\left[\begin{array}{lll}2,17 & 6,53 & 0,00\end{array}\right]^{\top} 10^{3} \mathrm{~km}$} \\
\hline Velocidade inicial $\left(\mathbf{v}_{v}^{i}(0)\right)$ & {$\left[\begin{array}{llll}-4,67 & -0,85 & 6,02\end{array}\right]^{\top} \mathrm{km} / \mathrm{s}$} & {$\left[\begin{array}{lll}0,96 & -0,33 & 7,54\end{array}\right]^{\top} \mathrm{km} / \mathrm{s}$} \\
\hline Altitude (mín. × máx.) & $406,17 \mathrm{~km} \times 418,56 \mathrm{~km}$ & $488,15 \mathrm{~km} \times 517,43 \mathrm{~km}$ \\
\hline Inclinação & $51,66^{\circ}$ & $97,51^{\circ}$ \\
\hline Período & $92,81 \mathrm{~min}$ & $94,67 \mathrm{~min}$ \\
\hline
\end{tabular}

Fonte: Autor.

\subsection{Configurações de Simulação}

As simulações foram realizadas no software Simulink, com passo fixo e método RungeKutta de quarta ordem de integração numérica (ode4). A constante de tempo mais rápida dos modelos implementados é proveniente da roda de reação, $300 \mathrm{~ms}$. Sendo assim, o passo de integração foi adotada como 30 vezes mais rápido, isto é, $10 \mathrm{~ms}$. No mais, as simulações rodaram em um processador Intel Core i7-7500U com frequência de 2,90 GHz.

\subsection{Simulação da Dinâmica do Satélite}

Movimentos como nutação, precessão e consequência da ação dos atuadores são frequentemente explorados nas literaturas que tratam da dinâmica de veículos espaciais (e.g. [68], [18], [69]) e os resultados são bem conhecidos. Sendo assim, para fins de comparação, a dinâmica do veículo, apresentada na Equação (4.15), foi submetida às mesmas condições.

\subsubsection{Movimento de Nutação}

Para avaliar o movimento de nutação e precessão, foi utilizado o fooSAT-I6, pois possui dimensões distintas em largura, profundidade e altura, o que permite observar melhor a diferença de rotação em cada um dos eixos.

Espera-se que, quando o satélite rotacione em torno de um eixo diferente de um dos eixos principais de inércia, ele realize um movimento cônico, chamado de nutação. Quando o eixo de rotação é próximo do eixo principal de maior ou menor inércia, esse movimento de rotação é estável, porém, quando próximo do eixo principal intermediário, o movimento de rotação é instável. Sendo assim, o fooSAT-I6 foi submetido à tais situações e os resultados 
são apresentados na Figura 27.

Os gráficos ilustrados em três dimensões representam como o sistema de coordenadas fixo ao satélite, REP, se comporta em relação ao sistema de coordenadas inerciais, GEI. Isso permite visualizar a propagação da atitude no tempo.

No instante inicial REP é coincidente à GEI. As cores seguem o padrão das velocidades angulares, isto é, eixo $\mathbf{x}^{p}$ azul, eixo $\mathbf{y}^{p}$ vermelho e eixo $\mathbf{z}^{p}$ amarelo. O tom de cor mais claro é próximo do início, enquanto o tom de cor mais escuro é próximo do fim. A rotação próxima do eixo principal de maior inércia é apresentada na Figura 27a, cuja condição inicial era $\omega_{p / i}^{p}=\left[\begin{array}{llll}0,05 & 1,0 & 0,05\end{array}\right]^{\top} \mathrm{rad} / \mathrm{s}$. Na Figura 27b, o satélite rotacionou próximo do eixo principal intermediário de inércia com condição inicial $\omega_{p / i}^{p}=\left[\begin{array}{lll}1,0 & 0,05 & 0,05\end{array}\right]^{\top} \mathrm{rad} / \mathrm{s}$, e a rotação próxima do eixo principal de menor inércia é apresentada na Figura 27c, cuja condição inicial era $\boldsymbol{\omega}_{p / i}^{p}=\left[\begin{array}{lll}0,05 & 0,05 & 1,0\end{array}\right]^{\top} \mathrm{rad} / \mathrm{s}$.

Note que, conforme ilustrado na Figura 27a, quando a rotação é próxima do eixo principal de maior inércia, $\mathbf{y}^{p}$ (vermelho), o satélite realiza um movimento cônico estável. O mesmo ocorre quando a rotação é próxima do eixo principal de menor inércia, $\mathbf{z}^{p}$ (amarelo), conforme ilustrado na Figura 27c. Entretanto, conforme é possível observar na Figura 27b, o satélite realiza um movimento instável quando a rotação inicial é próxima do eixo principal intermediário. Observa-se que o eixo $\mathbf{x}^{p}$ inicia um movimento cônico em torno eixo $\mathrm{x}^{i}$ (entre (0-10)s), porém, com o tempo, a velocidade angular é distribuída nos outros eixos (entre (10-15) s) e, então, passa a rotacionar em torno de $-\mathrm{x}^{i}$ (entre $(15-25) \mathrm{s})$.

\subsubsection{Movimento de Precessão}

Quando o satélite, inicialmente em repouso, é submetido à um torque externo constante, espera-se que o veículo rotacione em torno desse eixo. Entretanto, quando o satélite está rotacionando em torno de um eixo principal de inércia e é submetido à um torque não paralelo à essa velocidade angular, espera-se que o veículo realize um movimento em que o vetor da velocidade angular tenda a se aproximar do vetor de torque. Esse movimento é chamado de precessão ou efeito giroscópico. O fooSAT-I6 foi submetido à tal situação e os resultados são apresentados na Figura 28.

De forma similar à simulação do movimento de nutação, os gráficos ilustrados em três dimensões representam como o REP se propaga em relação ao GEI. As cores seguem o mesmo padrão e, nesse caso, a posição final do REP foi destacada para facilitar a interpretação do leitor. Em ambos os casos, REP é coincidente à GEI no instante inicial e o torque externo aplicado foi $\mathbf{T}_{e x t}^{i}=\left[\begin{array}{lll}1 & 0 & 0\end{array}\right]^{\top} 10^{-4} \mathrm{Nm}$, isto é, na direção de $\mathbf{x}^{i}$. Na Figura 28a o veículo está inicialmente em repouso, enquanto na Figura 28b a velocidade inicial é dada por $\boldsymbol{\omega}_{p / i}^{p}=\left[\begin{array}{lll}0,0 & 0,0 & 0,6\end{array}\right]^{\top} \mathrm{rad} / \mathrm{s}$, isto é, em torno do eixo $\mathbf{z}^{p}$. 
Figura 27 - Movimento de nutação.

(a) Rotação próxima do eixo principal de maior inércia.
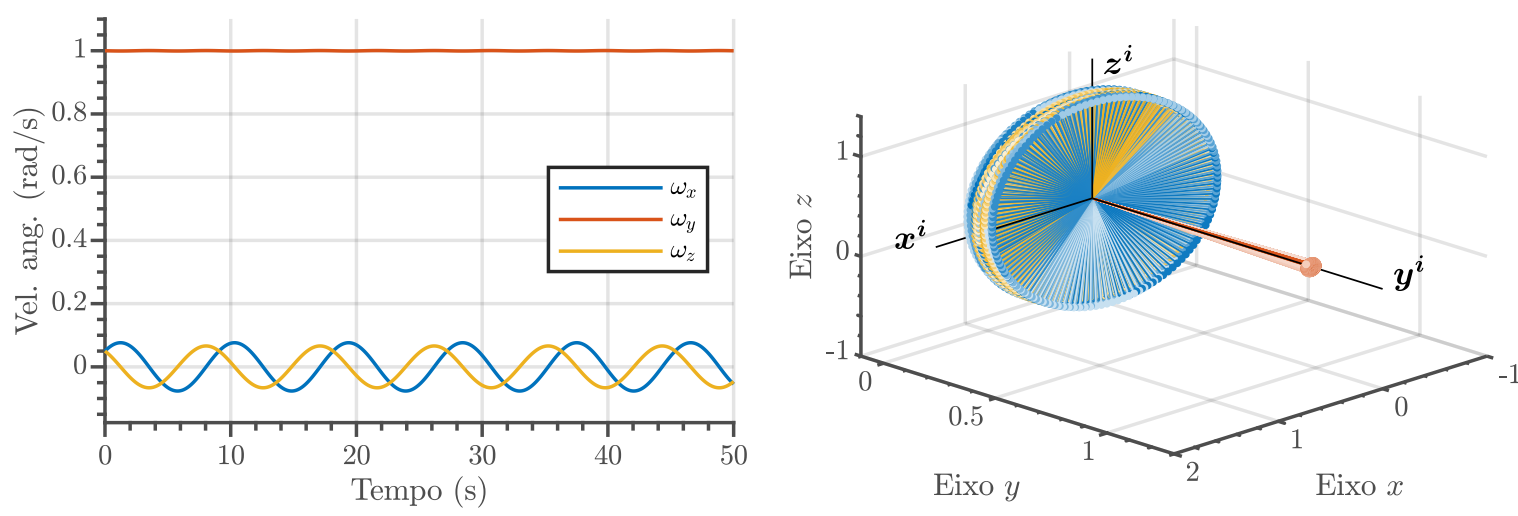

(b) Rotação próxima do eixo principal intermediário de inércia.
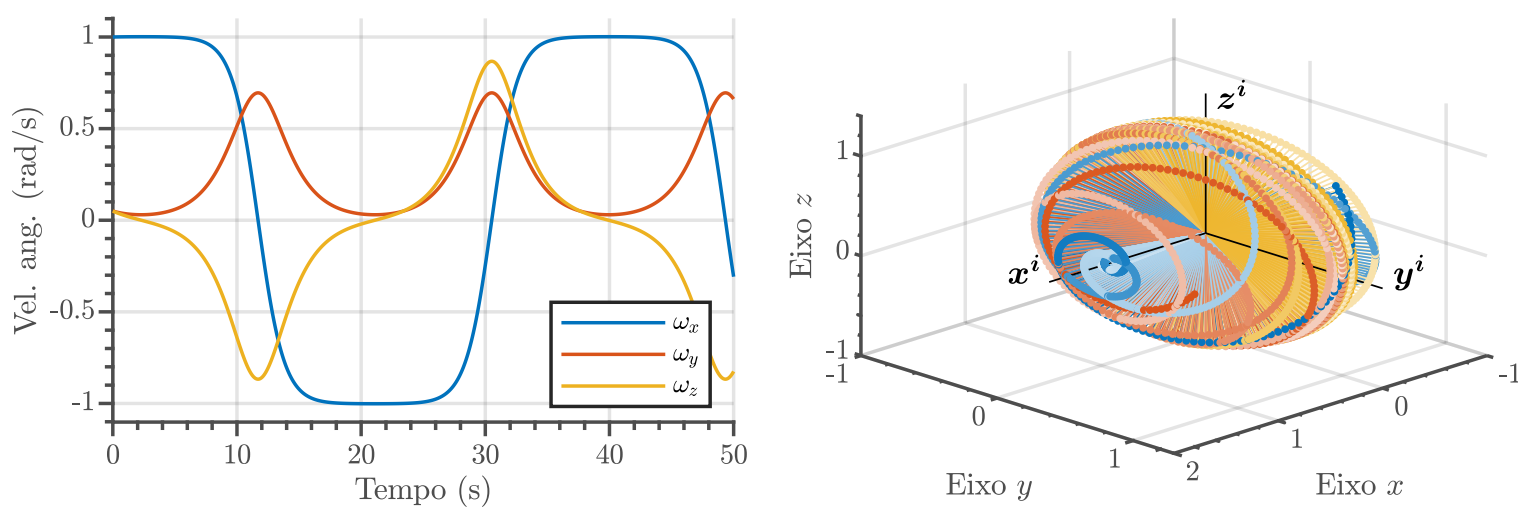

(c) Rotação próxima do eixo principal de menor inércia.
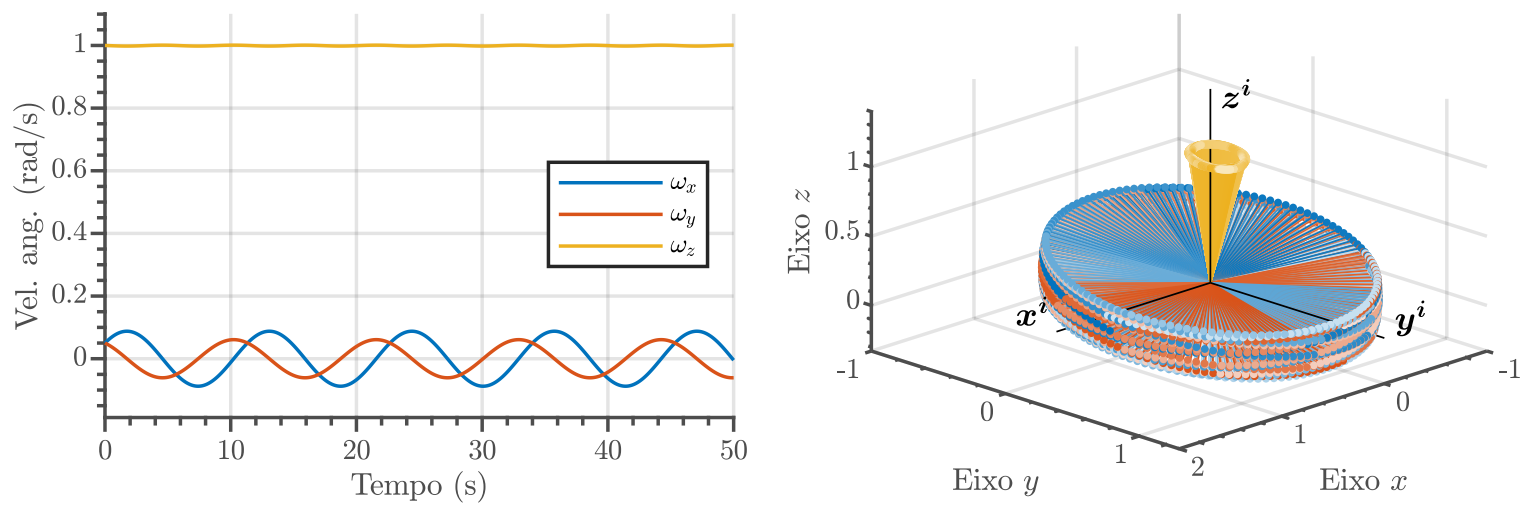

Fonte: Autor.

É possível observar que quando a velocidade inicial é nula (Figura 28a) o veículo passa a rotacionar em torno do eixo onde o torque foi aplicado, isto é $\mathbf{x}^{i}$, seguindo a regra da mão direita. Neste caso, como o torque externo é constante, a velocidade angular aumentará indefinidamente. Entretanto, quando o satélite está inicialmente rotacionando em torno de um dos eixos principais de inércia (Figura 28b), o eixo $\mathbf{z}^{p}$ (amarelo), inicialmente coincidente ao eixo $\mathbf{z}^{i}$, tende a se aproximar do vetor de torque externo, $\mathbf{T}_{\text {ext }}$, coincidente ao eixo $\mathbf{x}^{i}$. 
Figura 28 - Movimento de precessão.

(a) Inicialmente em repouso.
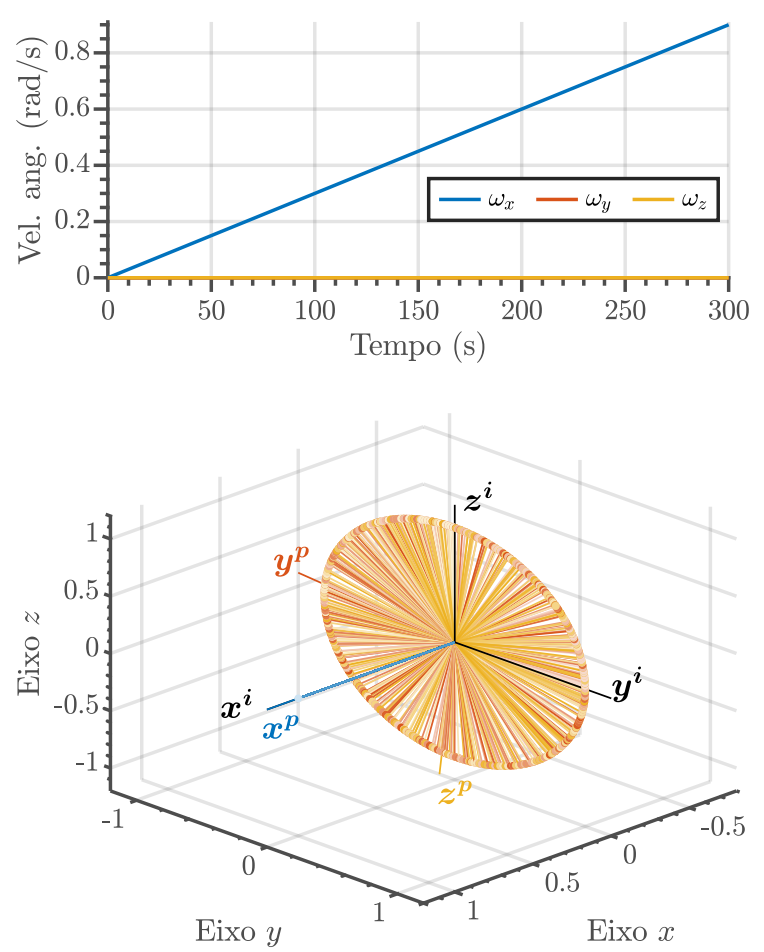

Fonte: Autor. (b) Inicialmente em rotação.
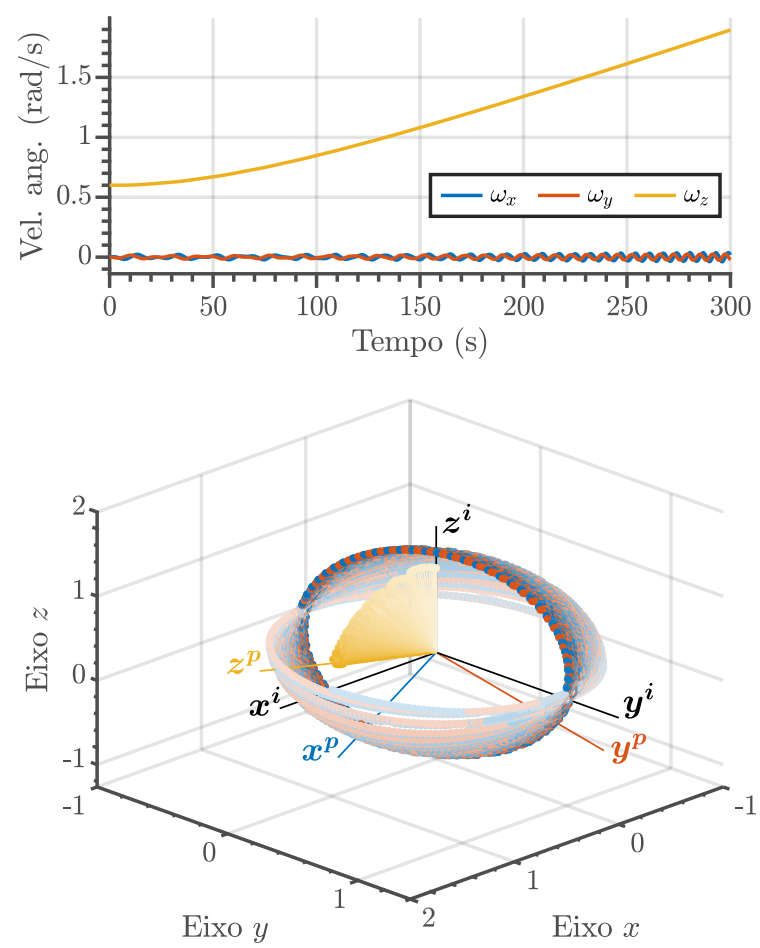

\subsubsection{Movimento Devido ao Atuador Magnético}

Para avaliar o movimento devido aos atuadores, utilizou-se o fooSAT-I1 pois, neste caso, não há vantagem em utilizar um satélite com dimensões distintas, mas há vantagem em utilizar um satélite "ideal".

Conforme apresentado na Subseção 4.1.2.1.1, quando não paralelo ao campo magnético terrestre, o atuador magnético gera um torque no satélite no sentido normal ao plano formado pelo momento do dipolo e o campo magnético (Eq. (4.6)). Portanto, o fooSAT-I1 foi submetido à condição em que o atuador magnético alinhado com o eixo $\mathbf{x}^{p}$ foi acionado com $10 \%$ do momento máximo, isto é, $\mathbf{m}_{a m}^{p}=\left[\begin{array}{lll}1,5 & 0 & 0\end{array}\right]^{\top} 10^{-1} \mathrm{~A} \mathrm{~m}^{2}$, e o campo magnético terrestre era $\mathbf{B}^{i}=\left[\begin{array}{lll}0 & 1 & 1\end{array}\right]^{\top} 10^{-4} \mathrm{~T}$, isto é, no plano $\mathbf{z}^{i} \mathbf{y}^{i}$ entre esses dois eixos. De forma similar às simulações de nutação e precessão, o gráfico em três dimensões representa como o REP se propaga em relação ao GEI e as cores seguem o mesmo padrão. No instante inicial REP é coincidente à GEI. Os resultados são apresentados na Figura 29.

Note que o eixo $\mathbf{x}^{p}$, inicialmente coincidente com o eixo $\mathbf{x}^{i}$, tende a se aproximar do vetor campo magnético $\mathbf{B}^{i}$ e então passa por ele e vai até $-\mathbf{x}^{i}$. Trata-se de um movimento 
Figura 29 - Movimento devido ao atuador magnético.

Torque aplicado ao satélite, $\mathbf{T}_{a m}^{p}$.

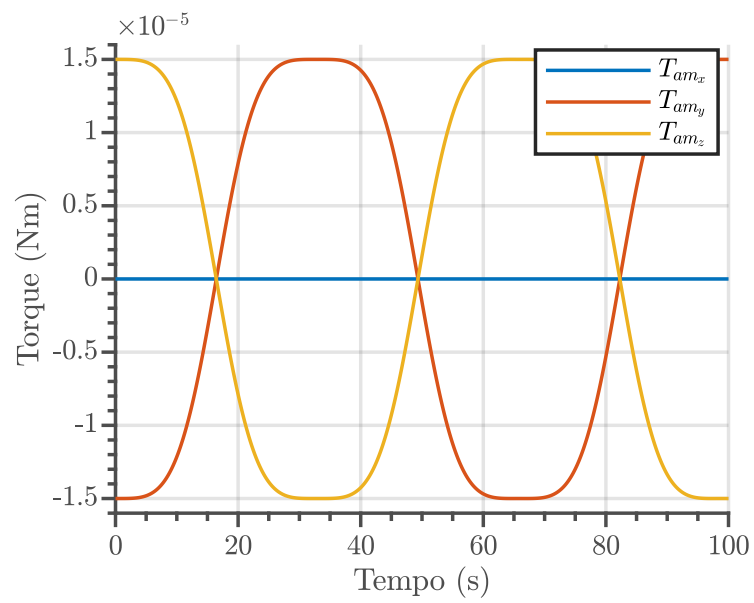

Propagação da atitude no tempo.

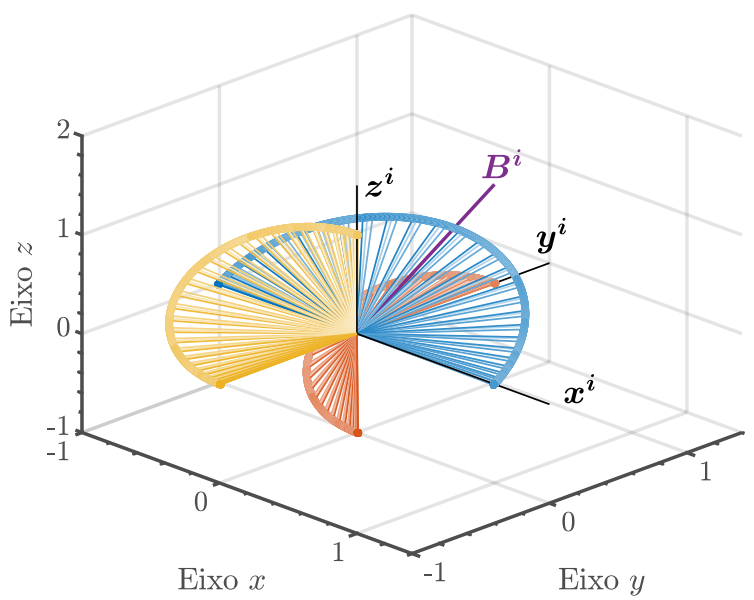

Fonte: Autor.

similar a de um pêndulo sem amortecimento ${ }^{\ddagger}$. Conforme esperado, nos instantes em que o dipolo e o campo magnético estão paralelos $(t \approx 18 \mathrm{~s}, 50 \mathrm{~s}$ e $82 \mathrm{~s})$ o torque resultante é nulo e quando estão perpendiculares $(t \approx 0 \mathrm{~s}, 32 \mathrm{~s}, 65 \mathrm{~s}$ e $98 \mathrm{~s})$ o torque resultante é máximo.

\subsubsection{Movimento Devido à Roda de Reação}

Conforme apresentado na Subseção 4.1.2.1.2, a roda de reação é capaz de gerar dois tipos de torque no veículo: um de controle $\left(\dot{\mathbf{H}}_{r r}^{p}\right)$,por conta da variação de sua velocidade angular, e o outro de perturbação $\left(\boldsymbol{\omega}_{p / i}^{p} \times \mathbf{H}_{r r}^{p}\right)$, em decorrência do efeito giroscópico (Eq. (4.9)). Sendo assim, o fooSAT-I1 foi submetido à duas condições permitindo observar ambos os fenômenos.

Em ambos os casos foram aplicadas as mesmas entradas de tensão na roda de reação alinhada ao eixo $\mathbf{z}^{p}$ do satélite. Trata-se de uma rampa de (0 a 5 ) V por $40 \mathrm{~s}$, seguido de uma rampa de $(5 \mathrm{a}-5) \mathrm{V}$ por $80 \mathrm{~s}$ e tensão constante em $-5 \mathrm{~V}$ nos instantes finais. Uma vez mais, os gráficos em três dimensões representam como o REP se propaga em relação ao GEI e as cores seguem o mesmo padrão. No instante inicial REP é coincidente à GEI. Na Condição 1 o veículo estava inicialmente em repouso, enquanto na Condição 2 $\boldsymbol{\omega}_{p / i}^{p}=\left[\begin{array}{lll}0.1 & 0 & 0\end{array}\right]^{\top} \mathrm{rad} / \mathrm{s}$. Os resultados são apresentados na Figura 30.

Observa-se que na Condição 1 , a roda de reação aplica um torque no eixo $\mathbf{z}^{p}$ fazendo com que o veículo inicie a rotação em torno desse eixo. Nessa situação o momento angular da roda de reação, $\mathbf{H}_{r r}$, está paralelo à velocidade do veículo, $\boldsymbol{\omega}_{p / i}^{p}$, por isso não há perturbação e alteração de sentido do movimento. Entretanto, na Condição 2, o satélite

\footnotetext{
$\ddagger$ O controle de atitude magnético passivo utiliza-se de ímã permanente, o que produz a mesma característica da simulação, porém também utiliza barra de histerese para dissipar energia, o que produz um efeito similar ao atrito no pêndulo. Dessa forma o controle de atitude passivo funcionará como um seguidor do campo magnético.
} 
Figura 30 - Movimento devido à roda de reação.

Condição 1.
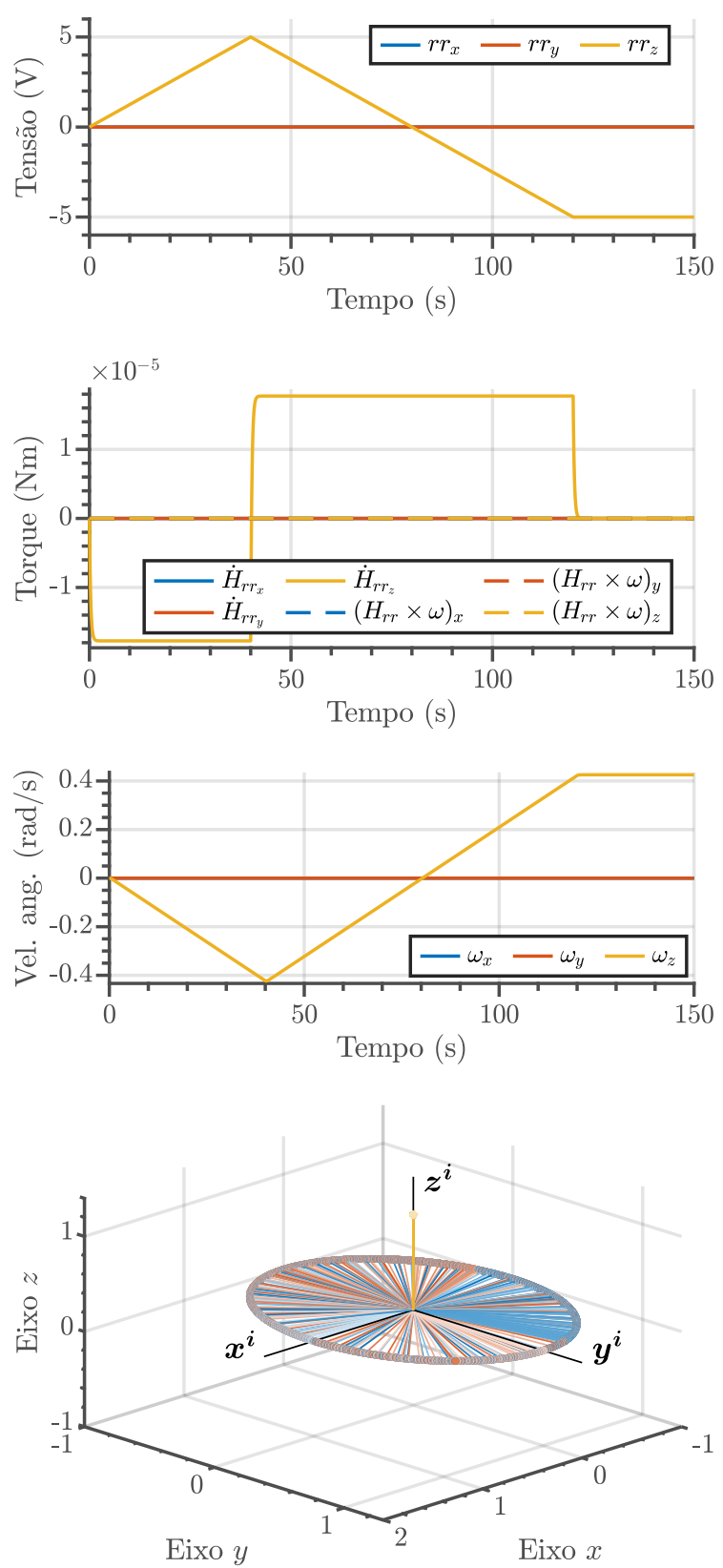

Condição 2.
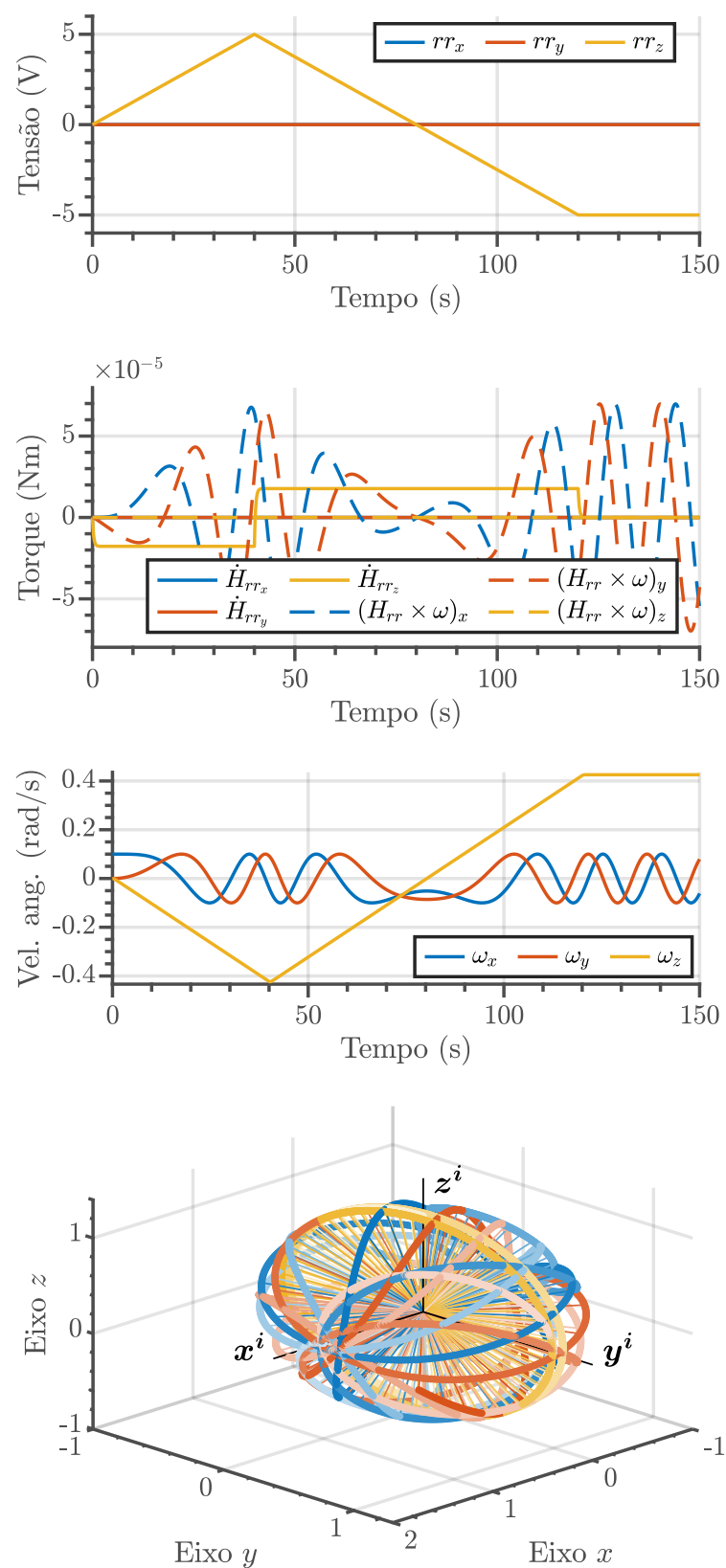

Fonte: Autor.

está inicialmente rotacionando em torno de $\mathbf{x}^{p}$ de forma que a velocidade angular não é mais paralela ao momento angular da roda de reação. Nessa situação o satélite está sujeito ao torque do efeito giroscópico.

\subsection{Simulação da Órbita do Satélite}

A dinâmica orbital foi apresentada na Seção 4.2 e, pelo mesmo princípio da conservação do momento angular (Eq.(A.1)), quando não há perturbações, não há variação na órbita. 
Sendo assim, a posição e velocidade do veículo são periódicas e dependem apenas das condições iniciais. Para avaliar esse movimento, considerou-se o fooSAT-A1 nas órbitas ISS e SSO, apresentadas na Tabela 6. Por questões didáticas, ao invés de apresentar a propagação do vetor posição no tempo, ilustra-se a propagação do equivalente à latitude e longitude no sistema de coordenadas inerciais (GEI), isto é, declinação e ascensão reta. Os resultados são apresentados na Figura 31.

Figura 31 - Simulação do movimento orbital.

(a) ISS.
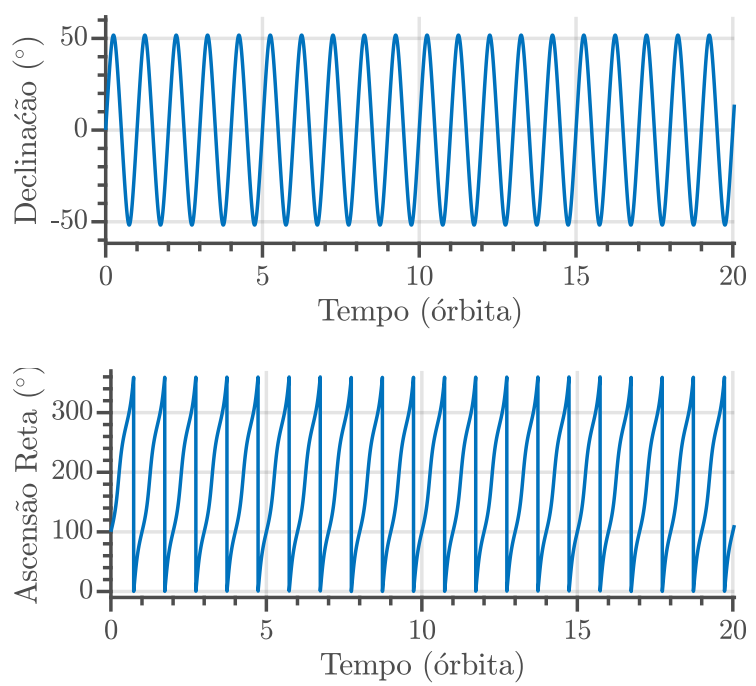

Propagação da órbita no tempo.

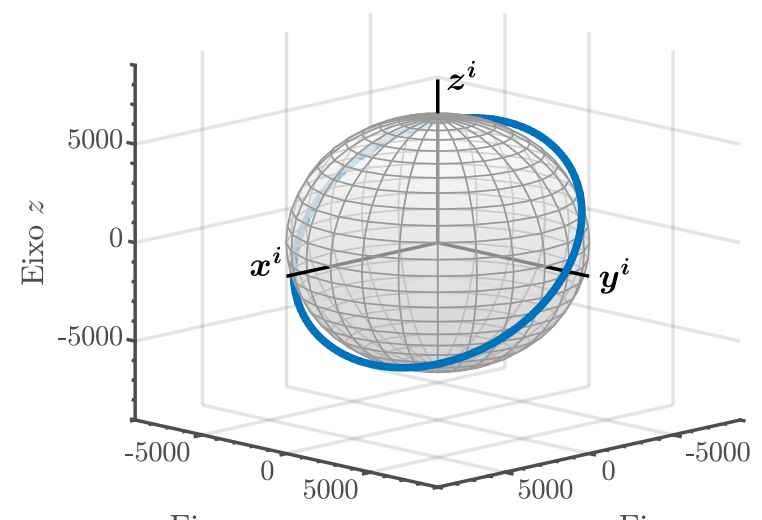

Eixo $y$

Eixo $x$
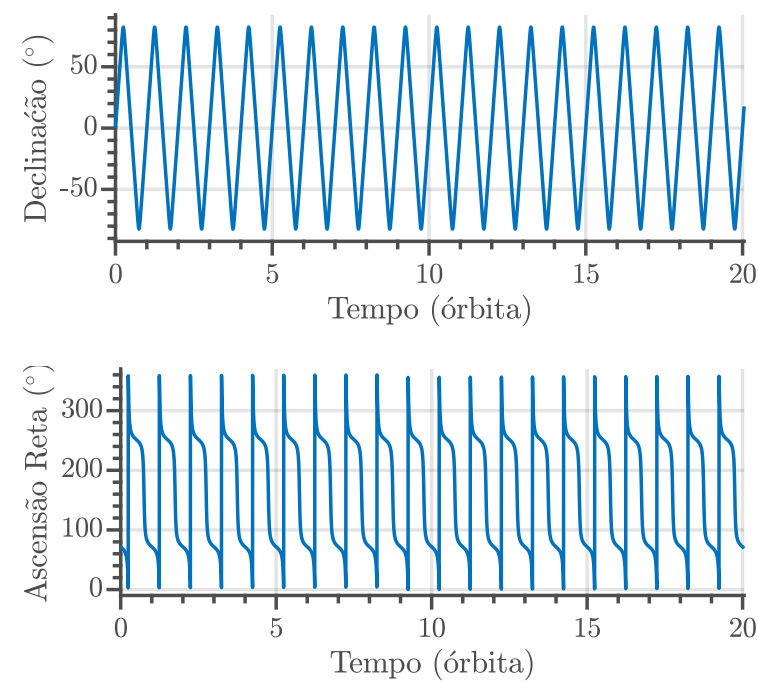

Propagação da órbita no tempo.

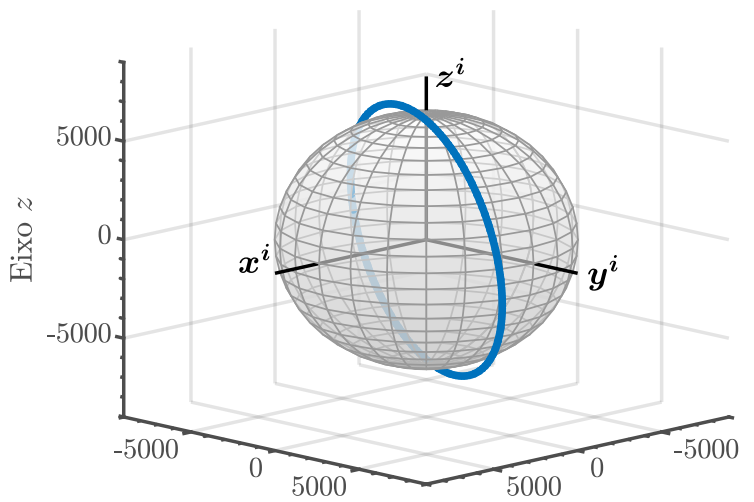

Eixo $y$

Eixo $x$

Fonte: Autor.

Observa-se que, assim como esperado, a declinação e a ascensão reta seguem um regime cíclico a cada órbita. Pela ascensão reta também identifica-se que a órbita ISS é prógrada, isto é, no sentido de rotação da Terra, enquanto a órbita SSO é retrógrada, isto é, no sentido contrário de rotação da Terra. Ademais, na ilustração em três dimensões é possível notar a diferença de inclinação das órbitas. 


\subsection{Simulação das Perturbações}

Para avaliar a influência das perturbações de atitude e órbita, foi utilizado o fooSAT-A1 nas órbitas ISS e SSO. Para que fosse possível observar a variação dos parâmetros que dependem da orientação do veículo, as simulações foram realizadas com velocidade inicial não nula, no caso, $\boldsymbol{\omega}_{p / i}^{p}=\left[\begin{array}{lll}1 & 1 & 1\end{array}\right]^{\top} 10^{-3} \mathrm{rad} / \mathrm{s}$.

A Figura 32 ilustra diversos parâmetros e elementos presentes nos modelos matemáticos das perturbações. Tais elementos são apresentados de antemão, uma vez que auxiliam a avaliar e compreender o comportamento de cada uma das perturbações no tempo, ilustradas posteriormente.

Figura 32 - Elementos presentes nas perturbações.

(a) Ascensão Reta.

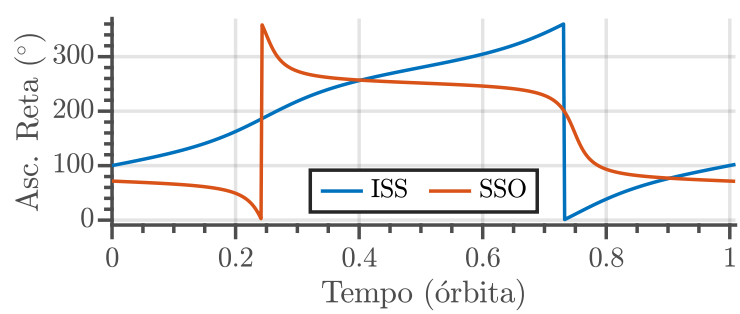

(c) Altitude.

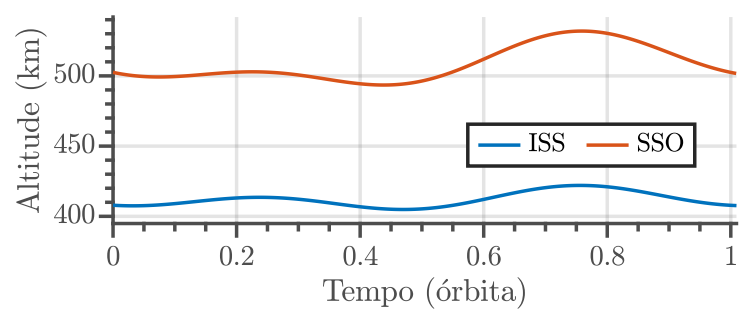

(e) Intensidade do campo magnético, $B$.

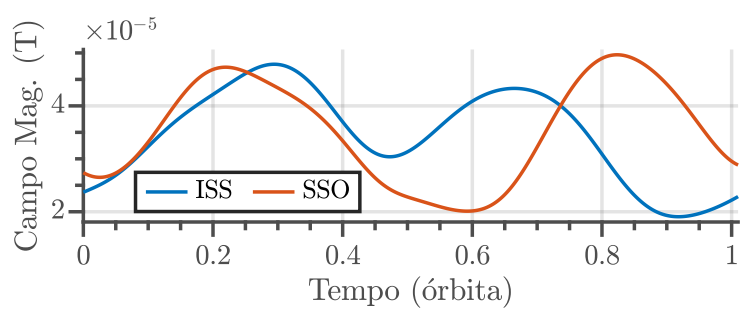

(g) Área atingida, $A_{d}$.

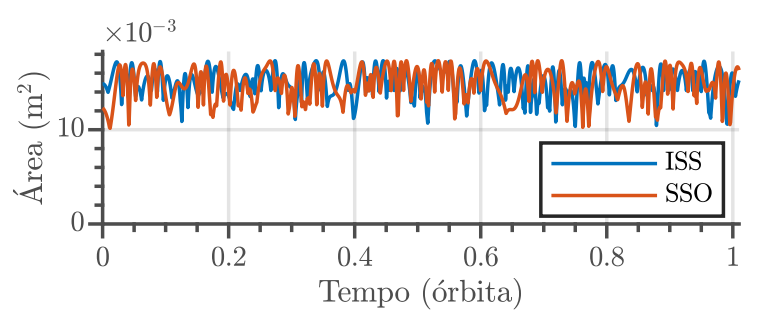

Fonte: Autor. (b) Declinação.

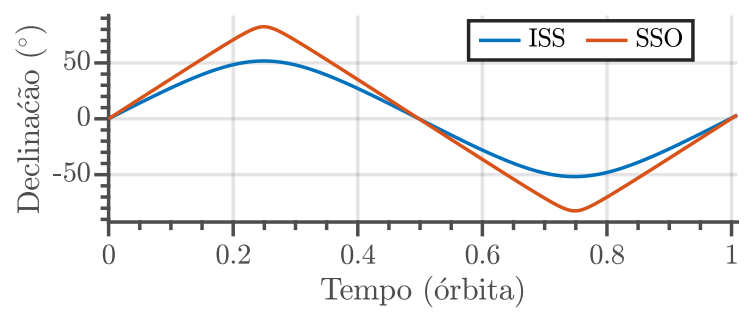

(d) Densidade atmosférica, $\rho$.

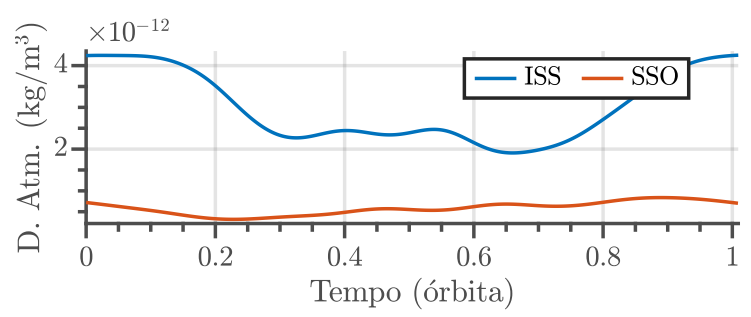

(f) Situação de eclipse, $\nu$.

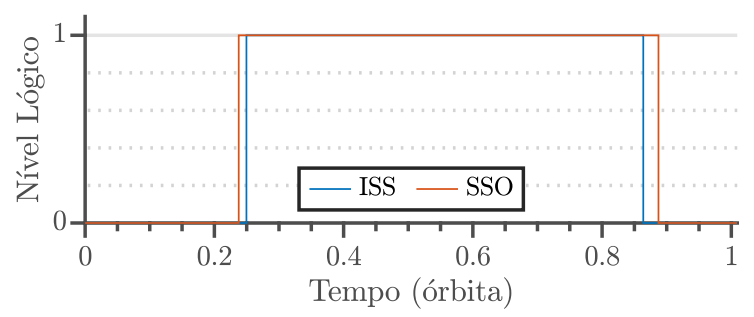

(h) Área atingida, $A_{\text {rad }}$.

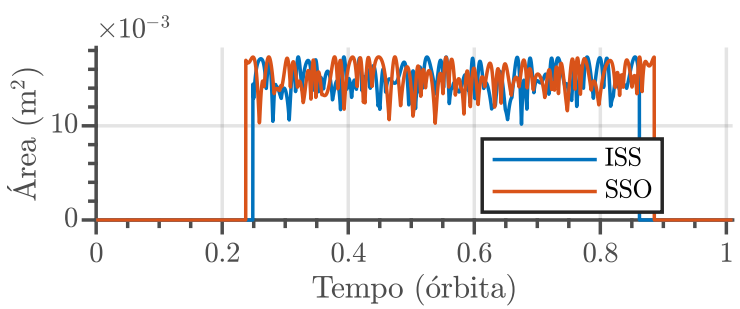


Conforme esperado, verifica-se que a altitude tem forte influência na densidade atmosférica que, por sua vez, influenciará o torque e a aceleração devidos ao arrasto atmosférico. Entretanto, a intensidade do campo magnético tem a mesma ordem de grandeza nas duas órbitas. Coincidentemente, a situação de eclipse tem uma faixa bastante similar.

Esse fator é interessante, pois espera-se que uma órbita heliossíncrona tenha contato com a radiação solar durante toda órbita ou, ao menos, durante a maior parte do tempo. Entretanto, pelos nanossatélites frequentemente serem lançados como cargas secundárias e não terem controle de órbita, tal situação pode não ocorrer. No mais, as áreas atingidas variam, conforme a rotação do satélite, do menor valor possível $100 \mathrm{~cm}^{2}$, que ocorre quando apenas uma das faces é atingida, até o valor máximo $173,2 \mathrm{~cm}^{2}$, quando três faces são atingidas parcialmente.

As perturbações de atitude foram apresentadas na Subseção 4.3 .1 e os resultados de simulação estão ilustrados na Figura 33.

Figura 33 - Torques de perturbação aplicados ao satélite, $T_{p r t}$.

(a) Torque devido ao arrasto atmosférico, $T_{d}$.

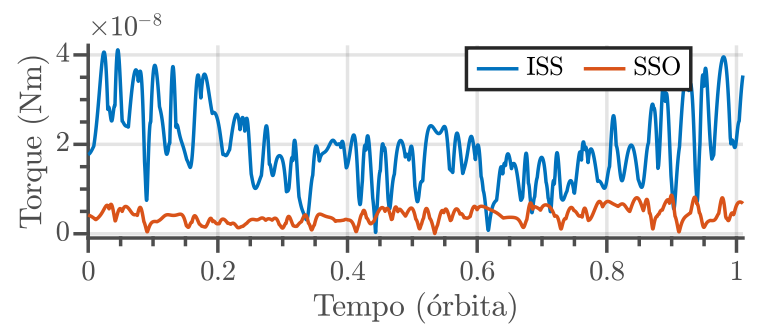

(c) Torque devido ao gradiente de gravidade, $T_{g g}$.

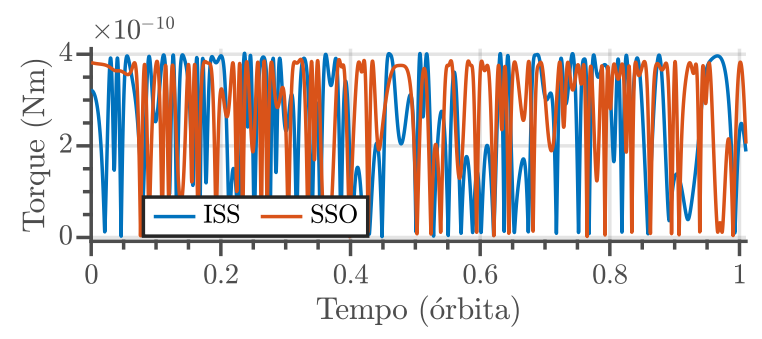

(b) Torque devido à pressão da radiação solar, $T_{\text {rad }}$.

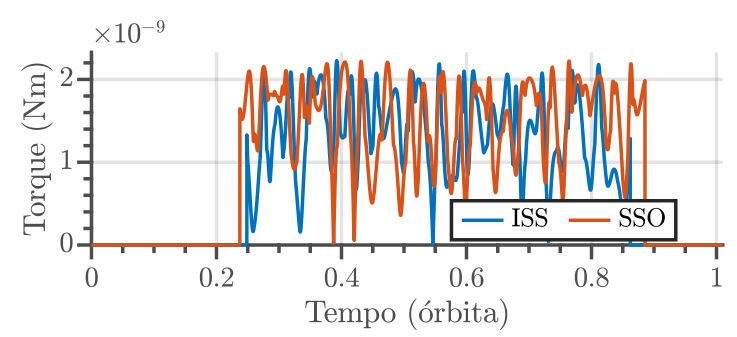

(d) Torque devido ao dipolo magnético residual, $T_{m r}$.

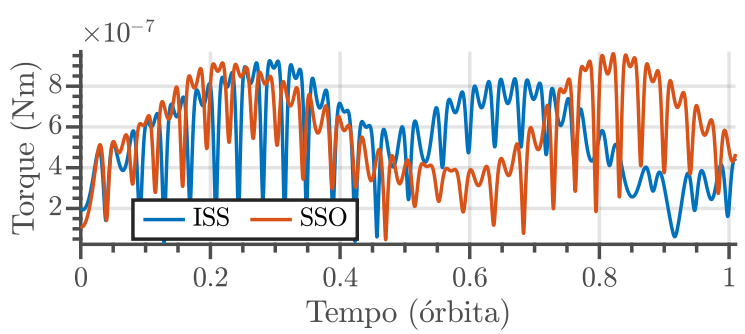

Fonte: Autor.

Em consequência da rotação do fooSAT-A1, todos os torques de perturbação podem, por um instante de tempo, serem nulos ou ao menos próximos de zero.

No caso dos torques devidos ao arrasto atmosférico, $T_{d}$, e à pressão da radiação solar, $T_{\text {rad }}$, isso ocorre quando há um equilíbrio entre os torques aplicados em cada uma das faces, como em uma balança mecânica. No caso do torque devido ao gradiente de gravidade, $T_{g g}$, ocorre quando o produto vetorial $\hat{\mathbf{r}}_{v}^{p} \times\left(\left[\mathbf{I}_{v}\right]^{p} \hat{\mathbf{r}}_{v}^{p}\right)$ é nulo. E, no caso do torque devido ao dipolo magnético residual, $T_{m r}$, ocorre quando o dipolo fica paralelo ao campo magnético.

Ademais, o valor médio do torque devido ao arrasto atmosférico tende a acompanhar a 
densidade atmosférica e, conforme esperado, é mais intenso na órbita ISS. A média do torque devido à pressão da radiação solar tende a ser constante e similar nas duas órbitas, já que não depende da distância para o Sol. A média do torque devido ao gradiente de gravidade tende à ser constante pelo fato de ambas as órbitas serem aproximadamente circulares. E a média do torque devido ao dipolo magnético residual, conforme esperado, tende a acompanhar a intensidade do campo magnético, sendo que na órbita SSO é mais fácil de observar os picos de intensidade sobre os polos magnéticos da Terra.

Para facilitar a comparação das magnitudes dos torques, para cada órbita, os torques foram ilustradas na Figura 34 em escala logarítmica.

Figura 34 - Comparação das magnitudes dos torques de perturbação.

(a) Torques na órbita ISS.

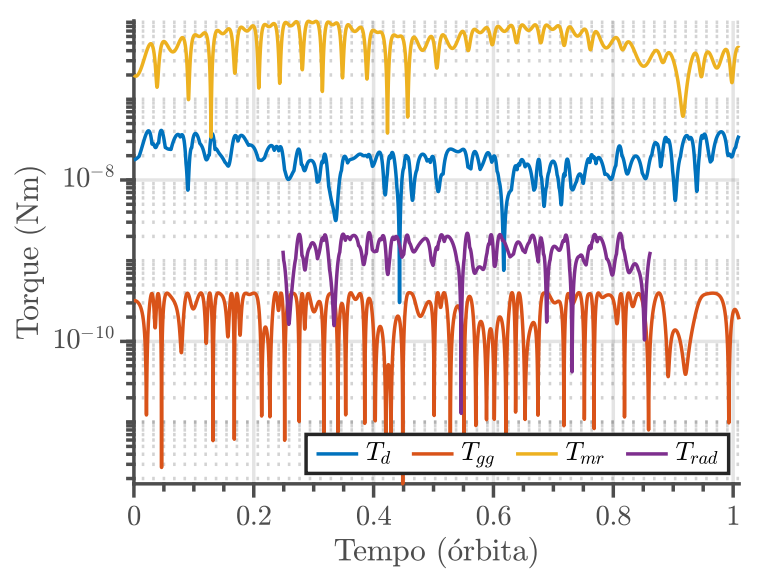

(b) Torques na órbita SSO.

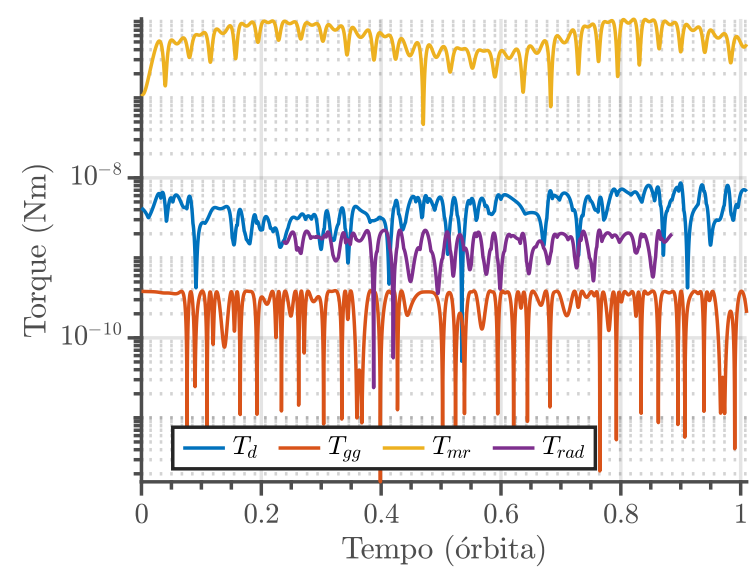

Fonte: Autor.

Nota-se que o torque devido ao dipolo magnético residual, $T_{m r}$, tem a maior intensidade em ambas as órbitas. Esse fator é relevante, pois em satélites de grande porte, ainda que em LEO, espera-se que essa perturbação tenha pouca relevância [18,69,70,77]. Isso ocorre porque, para uma mesma órbita, os torques de perturbação tendem a ser proporcionais ao volume do veículo. Entretanto, o mesmo não ocorre com o dipolo magnético residual.

Como no caso de nanossatélites o dipolo é proveniente, majoritariamente, de ímãs permanentes das rodas de reação e das antenas, é comum que CubeSats de $1 \mathrm{U}$ e $3 \mathrm{U}$ tenham a mesma intensidade de dipolo magnético residual, ainda que um tenha três vezes o volume do outro $[95,96]$. No mais, é possível notar que na órbita ISS o torque devido ao arrasto atmosférico, $T_{d}$, é uma ordem de grandeza maior do que o torque devido à pressão da radiação solar, $T_{\text {rad }}$, enquanto na órbita SSO são de mesma ordem.

As perturbações orbitais foram apresentadas na Subseção 4.3.2 e os resultados de simulação estão ilustrados na Figura 35.

Verifica-se que as acelerações devidas ao arrasto atmosférico, $a_{d}$, e à pressão da radiação solar, $a_{\text {rad }}$, possuem características similares às respectivas perturbações de atitude, $T_{d}$ e 
Figura 35 - Acelerações de perturbação aplicadas ao satélite, $a_{p r t}$.

(a) Devido ao arrasto atmosférico, $a_{d}$.

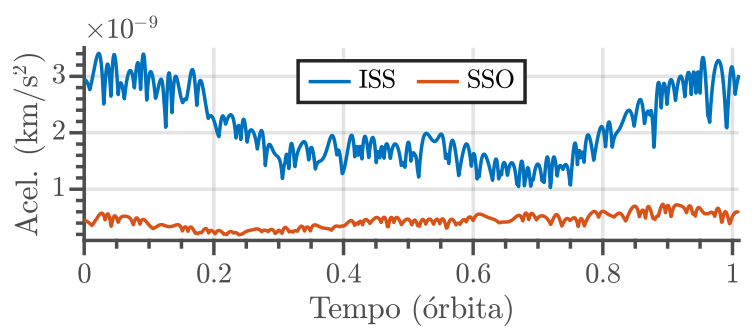

(c) Devido à não homogeneidade da Terra, $a_{g}$.

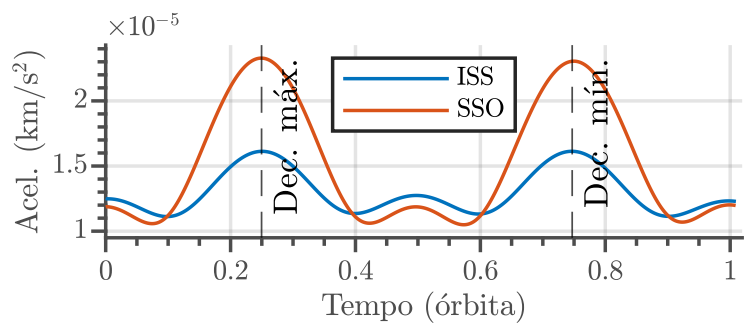

(b) Devido à pressão da radiação solar, $a_{\text {rad }}$.

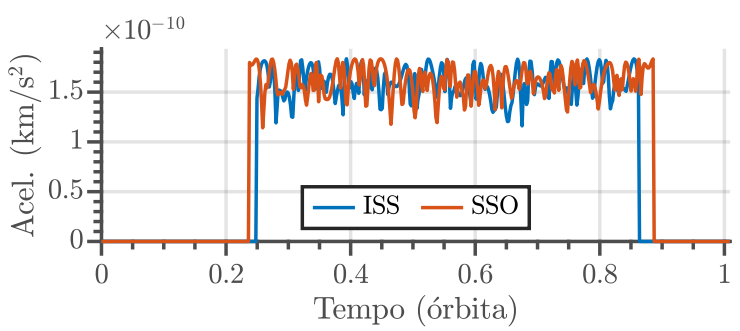

(d) Devido ao efeito de um terceiro corpo, $a_{t c}$.

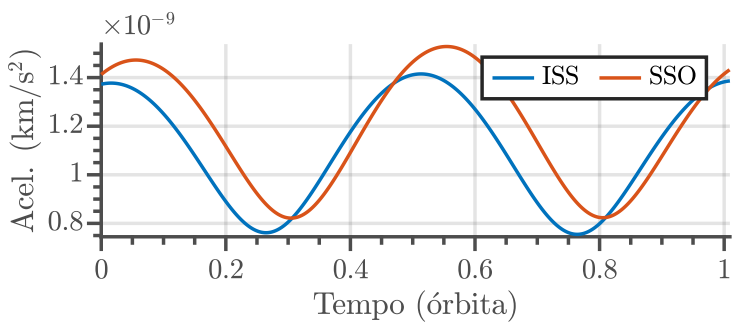

Fonte: Autor.

$T_{\text {rad }}$. Ainda, é possível observar que a aceleração devida à não homogeneidade da Terra, $a_{g}$, é mais intensa quando o fooSAT-A1 passa próximo aos polos geográficos, em razão da região de maior diferença de volume no geoide. E, a aceleração devida ao efeito de um terceiro corpo, $a_{t c}$, é mais intensa na órbita SSO em decorrência da diferença de altitude.

Uma vez mais, para facilitar a comparação das magnitudes das acelerações, para cada órbita, as acelerações foram ilustras na Figura 36 em escala logarítmica.

Figura 36 - Comparação das magnitudes das acelerações de perturbação.

(a) Acelerações na órbita ISS.

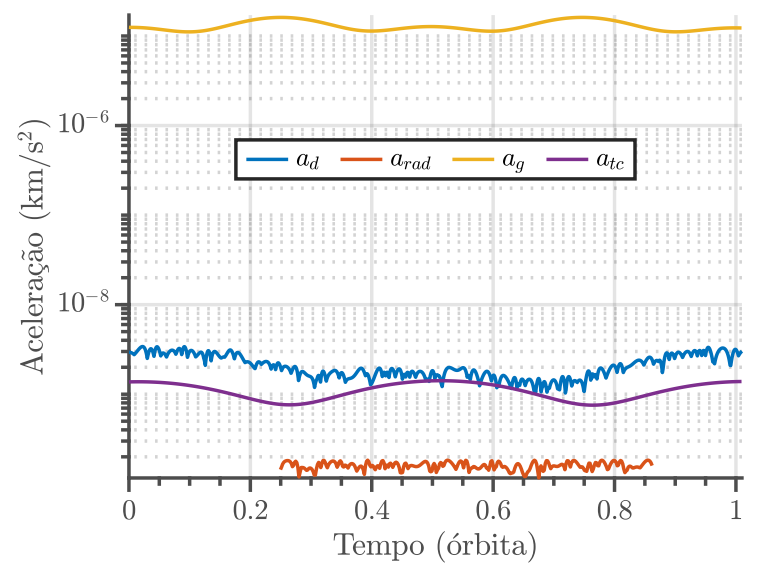

(b) Acelerações na órbita SSO.

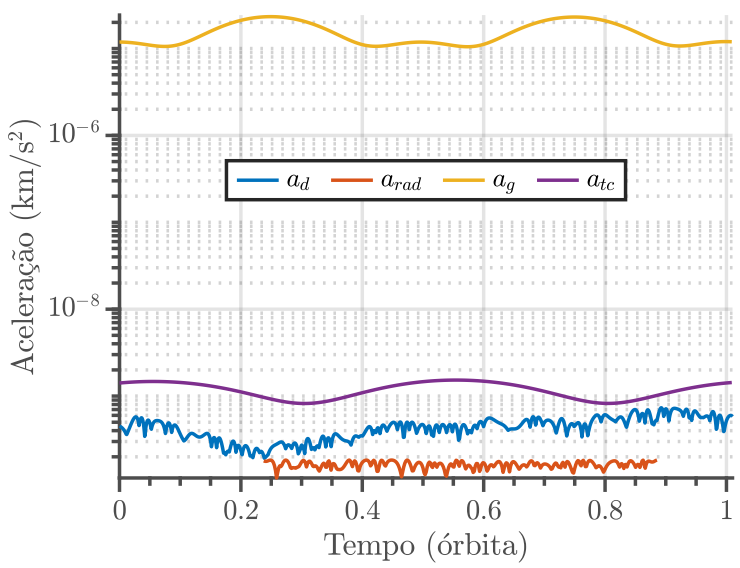

Fonte: Autor.

Em ambas as órbitas, a aceleração devida à não homogeneidade da Terra, $a_{g}$, é aproximadamente $10^{4}$ vezes mais intensa que as outras perturbações. E, assim como a aceleração devida ao efeito de um terceiro corpo, $a_{t c}$, são originárias de uma força 
conservativa, portanto influenciarão apenas na variação da inclinação e formato da órbita. Entretanto, as acelerações devida ao arrasto atmosférico e pressão da radiação solar são de origem não conservativa e influenciarão no decaimento de altitude.

Por fim, a Figura 37 ilustra a predição de reentrada do fooSAT-A1 nas órbitas ISS e SSO.

Figura 37 - Tempo em órbita.

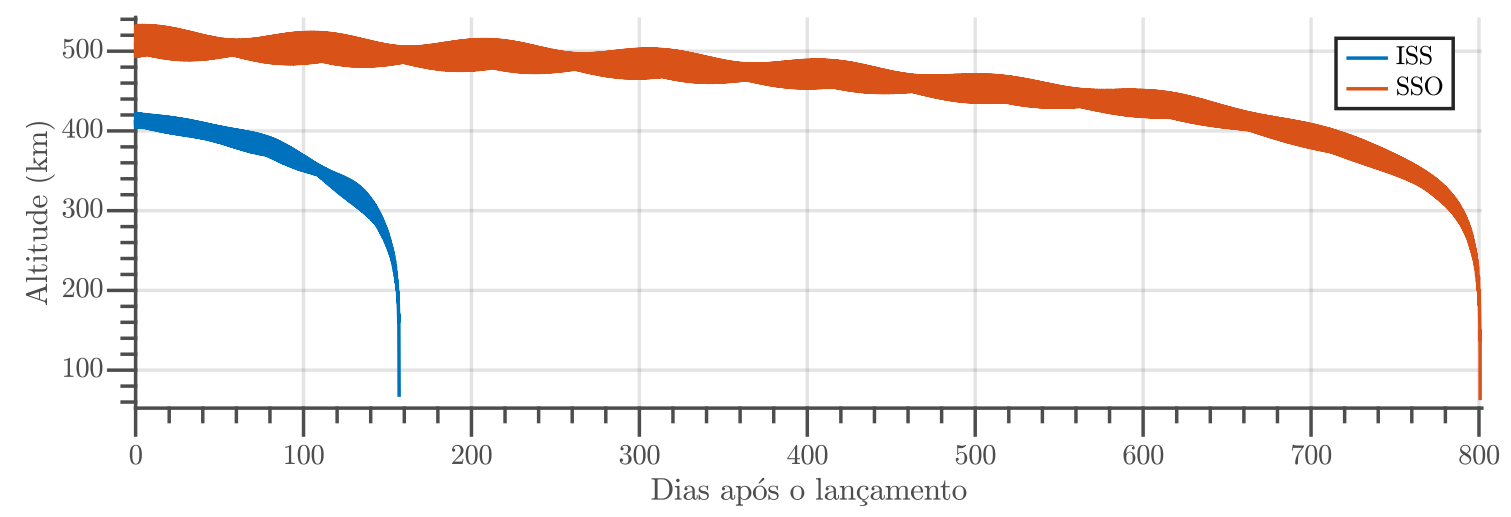

Fonte: Autor

Na órbita ISS a reentrada deve ocorrer em 157 dias após o lançamento, enquanto na órbita SSO deve ocorrer em 800 dias. A perturbação de maior influência no tempo de reentrada é a aceleração devida ao arrasto atmosférico $[68,70]$, na qual a densidade atmosférica aumenta exponencialmente conforme a altitude da órbita decresce. Note que, na órbita SSO o fooSAT-A1 leva aproximadamente 650 dias para chegar na altitude inicial da órbita ISS. Ademais, lembra-se que a aceleração devida ao arrasto atmosférico (Eq. (4.51)) é inversamente proporcional à massa do veículo $m_{v}$. Sendo assim, um nanossatélite de massa mais elevada tende a ter um tempo maior de vida em órbita. 


\section{RESULTADOS DE VALIDAÇÃO DA MODELA- GEM MATEMÁTICA}

Neste capítulo, são apresentados os resultados e procedimentos de validação dos modelos dinâmicos de atitude e órbita utilizando dados de voo.

\subsection{O nanossatélite PicSat}

PicSat é um CubeSat de 3U, desenvolvido pelo grupo de Astronomia de Alta Resolução Angular do Laboratório de Estudos Espaciais e Instrumentação em Astrofísica do Observatório de Paris (LESIA). A missão do PicSat era observar o transiente do exoplaneta Beta Pictoris b em torno de sua estrela Beta Pictoris [67].

Conforme ilustrado na Figura 38, a unidade superior do PicSat comporta o subsistema de energia (EPS), os subsistemas de comunicação (TRXVU e HDRM), as antenas VHF (VHF antennas) e o computador de bordo (OBC). A unidade intermediária comporta as antenas UHF (UHF antennas), o subsistema de controle e determinação de atitude (ADCS), a carga útil eletrônica (Eletronic payload) e o fotodiodo (Photodiode). As cargas úteis optomecânicas (Piezo-stage e Telescope) e o sensor de estrelas (Star tracker) estão acomodados na unidade inferior.

Com exceção das cargas úteis, todos os outros subsistemas foram subcontratados [97]. O ADCS, que é de interesse desse trabalho, foi desenvolvido pela empresa Hyperion Technologies [98] e o modelo selecionado é o iADCS 100. Esse modelo é composto por:

- Três atuadores magnéticos, sendo o modelo MTQ 200.20 para os eixos X e Y e o modelo MTQ 200.10S para o eixo Z;

- Três rodas de reação modelo RW 210.60;

- Um sensor de estrelas modelo ST 200;

- Um magnetômetro de 3 eixos;

- Um girômetro de 3 eixos.

As características dos atuadores magnéticos são apresentadas nas Tabelas 7 e 8, e das rodas de reação na Tabela 9.

Outras características disponíveis do ADCS são referentes ao sensor de estrelas, cuja acurácia é de $30^{\prime \prime}(3 \sigma)$ e a taxa de amostragem é de $5 \mathrm{~Hz}$. A estrutura e os demais subsistemas foram subcontratados da empresa Innovative Solutions In Space. 
Figura 38 - Ilustração e imagem do PicSat.

(a) Vista detalhada.

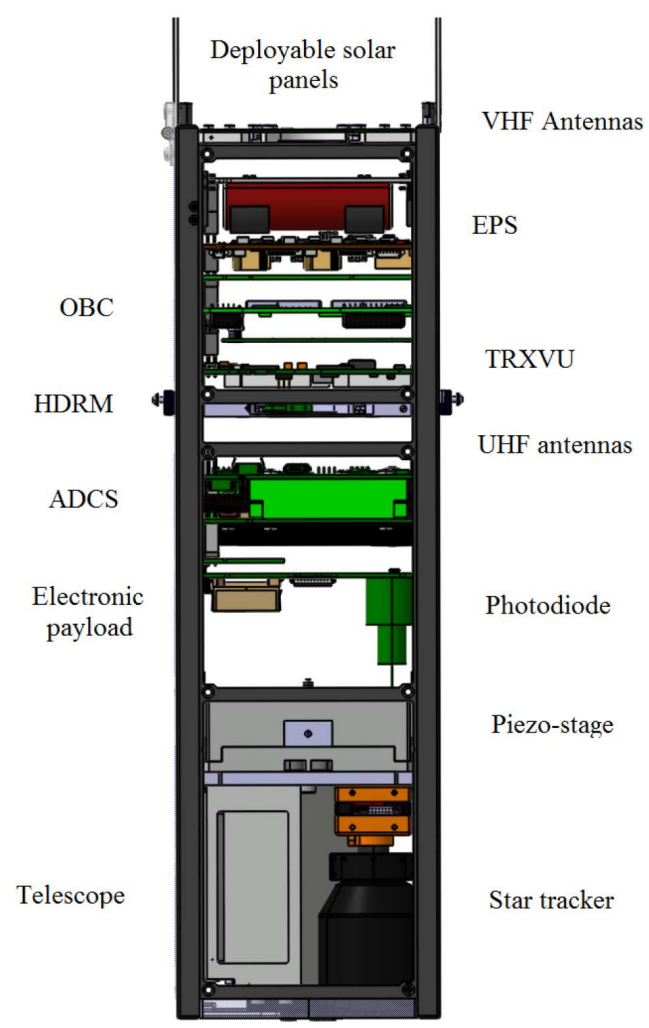

(b) Modelo de voo.

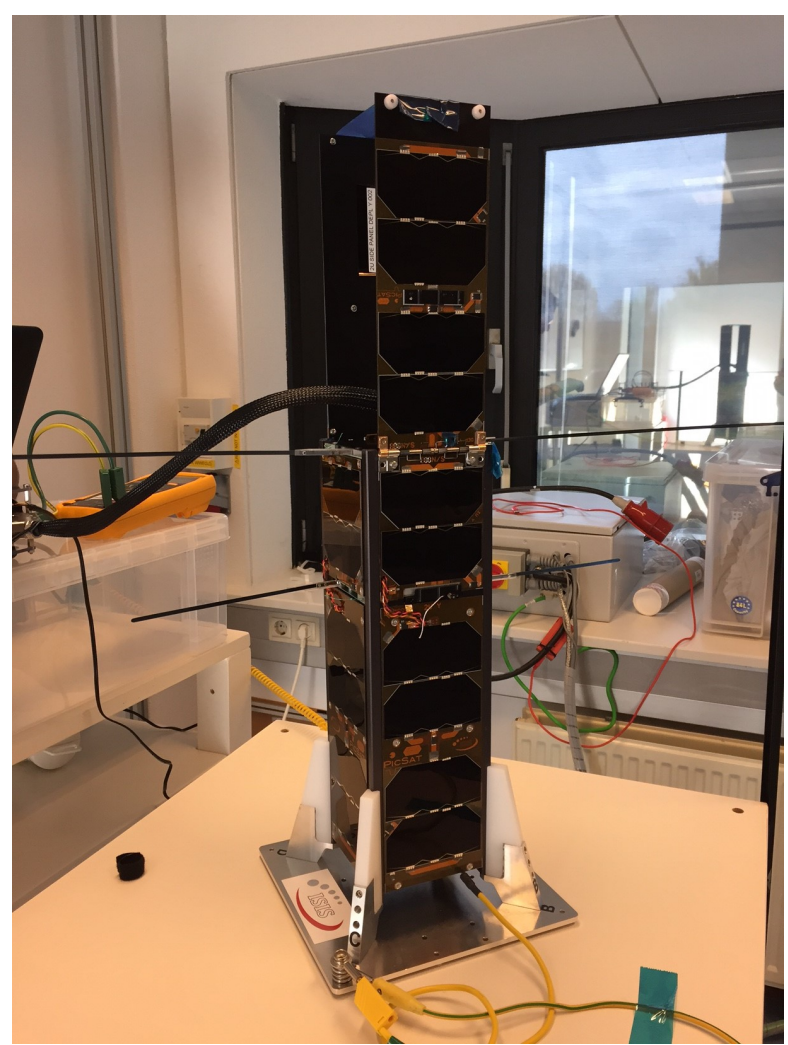

Fonte: Equipe PicSat.

Tabela 7 - Características do atuador magnético MTQ 200.20.

\begin{tabular}{ll}
\hline Parâmetro & Valor \\
\hline Área média da bobina $\left(A_{a m}\right)$ & $90,0 \times 10^{-6} \mathrm{~m}^{2}$ \\
Momento magnético máximo & $0,2 \mathrm{~A} \mathrm{~m}^{2}$ \\
Altura & $80,0 \times 10^{-3} \mathrm{~m}$ \\
Massa & $39,6 \times 10^{-3} \mathrm{~kg}$ \\
\hline
\end{tabular}

Fonte: Hyperion Technologies [98]

Também foi disponibilizado o modelo $\mathrm{CAD}^{*}$ do PicSat, o que permitiu extrair as informações de massa total, $m_{v}$, matriz de inércia, $\left[\mathbf{I}_{v}\right]$, e centro de massa, $C M$, em relação ao centro geométrico ${ }^{\dagger}$.

O PicSat foi lançado no dia 12 de janeiro de 2018, às 03:58 UTC, como carga útil secundária a bordo do veículo PSLV-C40 da Agência Espacial Indiana, em inglês Indian Space Research Organisation (ISRO). O satélite foi colocado em uma órbita polar heliossíncrona

* A versão do modelo CAD disponibilizado era anterior à montagem final, sem os cabos e conexões.

†Os valores foram omitidos por questões de sigilo. 
Tabela 8 - Características do atuador magnético MTQ 200.10S.

\begin{tabular}{ll}
\hline Parâmetro & Valor \\
\hline Área média da bobina $\left(A_{a m}\right)$ & $283,5 \times 10^{-6} \mathrm{~m}^{2}$ \\
Momento magnético máximo & $0,1 \mathrm{~A} \mathrm{~m}^{2}$ \\
Altura & $25,0 \times 10^{-3} \mathrm{~m}$ \\
Massa & $44,8 \times 10^{-3} \mathrm{~kg}$ \\
\hline
\end{tabular}

Fonte: Hyperion Technologies [98]

Tabela 9 - Características da roda de reação RW 210.60.

\begin{tabular}{ll}
\hline Parâmetro & Valor \\
\hline Torque máximo & $0,1 \times 10^{-3} \mathrm{~N} \mathrm{~m}$ \\
Massa do conjunto & $48,0 \times 10^{-3} \mathrm{~kg}$ \\
Momento angular máximo & $6,0 \times 10^{-3} \mathrm{~N} \mathrm{~m} \mathrm{~s}$ \\
\hline
\end{tabular}

Fonte: Hyperion Technologies [98]

com $505 \mathrm{~km}$ de altitude e período de 95 min aproximadamente.

O primeiro contato foi realizado na primeira passagem do veículo sobre a estação de solo da equipe. Porém, no dia 20 de março de 2018, após dez semanas, o contato com o PicSat foi perdido e no dia 05 de abril de 2018 a missão foi oficialmente encerrada. Durante este período ocorreram severos problemas com o ADCS, que chegou a reiniciar uma vez a cada três dias. O modo de redução da velocidade angular era realizado, mas o apontamento para a Beta Pictoris não foi possível [97].

Os dados de voo disponibilizados, do período entre 22/01/2018 e 20/03/2018, estão divididos em seis pacotes. O primeiro contém informações de atitude do satélite, produzidas pelo ADCS do veículo. O segundo também contém informações de atitude, porém fornecidas por meio de Beacons. Essas informações foram coletadas por diversos radioamadores e estações de solo espalhadas pelo globo e enviadas para a equipe do LESIA. O terceiro pacote contém dados dos sensores magnéticos e girômetros. O quarto e o quinto pacote contêm, respectivamente, os dados de corrente elétrica e setpoint dos atuadores. Por fim, o sexto pacote contém os comandos enviados para o PicSat.

Importante mencionar que, em razão do mau funcionamento do ADCS e da cobertura de comunicação limitada, parte desses dados estão ausentes ou com valores não condizentes, (como é o caso dos quatérnios que apresentam valores nulos ou maiores do que um). Nos trechos em que há dados, a taxa de amostragem máxima é de $0,1 \mathrm{~Hz}$ e existem problemas de sincronização de tempo. Isso se deve aos dados do primeiro pacote serem oriundos do 
ADCS do PicSat, enquanto os dados do segundo pacote serem provenientes de estações de solo distintas e datados em seus respectivos horários locais, não sincronizados em relação a uma referência única de tempo.

\subsection{Validação da Dinâmica do Satélite}

A evolução da velocidade angular do satélite no tempo pode ser obtida por meio dos girômetros presentes no PicSat e disponíveis nos pacotes de dados um e dois. A Figura 39 ilustra a velocidade angular do PicSat durante todo o tempo disponível, isto é, de 22/01/2018 a 20/03/2018.

Figura 39 - Velocidade angular do PicSat entre 22/01/2018 e 20/03/2018.

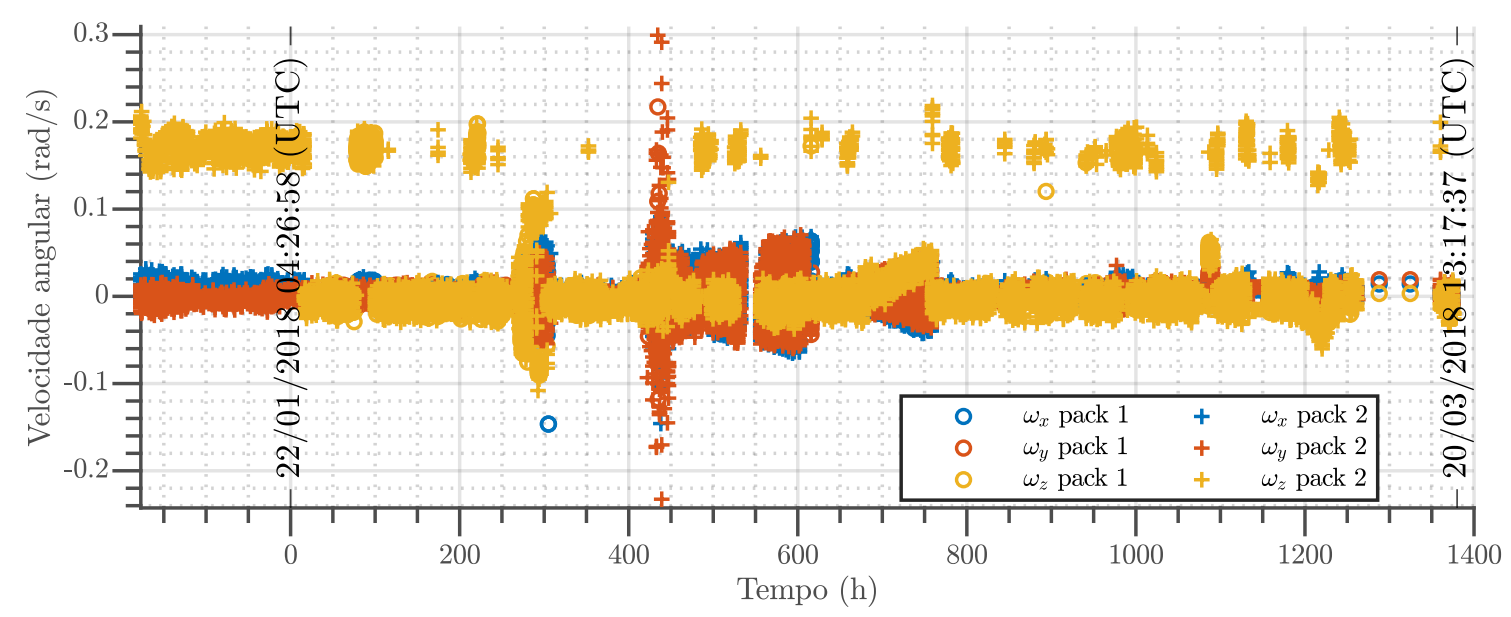

Fonte: Autor.

É possível observar que a velocidade angular do eixo z (amarela), em diversos instantes, apresenta um deslocamento vertical. Segundo a Equipe da LESIA, trata-se de um offset dos girômetros. Os instantes inciais, isto é, anteriores a $0 \mathrm{~h}$, foram utilizados para calibrar os sensores e o offset foi estimado em 0,1694 rad/s. Durante o voo, o ADCS apresentava falha e era possível observar novamente o offset dos girômetros. Em tais situações, a equipe de solo enviava um comando para reiniciar o ADCS.

Para realizar a validação da dinâmica de atitude, comparando os dados de voo com os dados de simulação, foi realizada uma varredura nos dados de voo selecionando trechos que continham, ao menos, 10 amostras consecutivas. Tal procedimento permitiu identificar 22 trechos distintos. O sexto pacote de dados, que contém os comandos enviados da equipe de solo para o PicSat, permitiu identificar as situações em que alguma ação de controle foi solicitada. Dos 22 trechos identificados, 12 estão em situações nas quais há atividade ou tentativa de atividade dos atuadores. Dessa forma, em 10 dos 22 trechos identificados, a velocidade angular do satélite é resultado apenas da propagação da dinâmica do veículo sob influência das perturbações. 
A fim de identificar os parâmetros relacionados à estrutura do veículo e os parâmetros relacionados à perturbação, a validação de atitude foi realizada em duas etapas:

Etapa 1: validar a dinâmica do satélite sem perturbações; e

Etapa 2: validar a influência das perturbações.

Com o intuito de determinar a fronteira entre as etapas, o modelo dinâmico do satélite apresentando na Subseção 4.1.2.2.3 foi revisitado. E, por questões práticas, é reescrito nessa seção

$$
\dot{\boldsymbol{\omega}}_{p / i}^{p}=\left(\left[\mathbf{I}_{v}\right]^{p}\right)^{-1}\left[\mathbf{T}_{a m}^{p}-\dot{\mathbf{H}}_{r r}^{p}+\mathbf{T}_{p r t}^{p}-\boldsymbol{\omega}_{p / i}^{p} \times\left(\left[\mathbf{I}_{v}\right]^{p} \boldsymbol{\omega}_{p / i}^{p}+\mathbf{H}_{r r}^{p}\right)\right]
$$

A variação da velocidade angular, $\dot{\boldsymbol{\omega}}$, é dada pela influência dos torques dos atuadores magnéticos, $\mathbf{T}_{a m}$, das rodas de reação, $\dot{\mathbf{H}}_{r r}$, das perturbações, $\mathbf{T}_{p r t}$ e do efeito giroscópico. Considerando a situação em que os atuadores não estão ativos, a Equação (4.15) torna-se

$$
\dot{\boldsymbol{\omega}}_{p / i}^{p}=\left(\left[\mathbf{I}_{v}\right]^{p}\right)^{-1}\left[\mathbf{T}_{p r t}^{p}-\boldsymbol{\omega}_{p / i}^{p} \times\left(\left[\mathbf{I}_{v}\right]^{p} \boldsymbol{\omega}_{p / i}^{p}\right)\right] .
$$

Suprimindo os termos de referência aos sistemas de coordenadas e aplicando a integral de um instante $t_{i}$ a $t_{f}$,

$$
\boldsymbol{\omega}_{f}=\boldsymbol{\omega}_{i}+\left[\mathbf{I}_{v}\right]^{-1} \int_{t_{i}}^{t_{f}} \mathbf{T}_{p r t} \mathrm{~d} t-\left[\mathbf{I}_{v}\right]^{-1} \int_{t_{i}}^{t_{f}} \boldsymbol{\omega} \times\left(\left[\mathbf{I}_{v}\right] \boldsymbol{\omega}\right) \mathrm{d} t
$$

isto é, a velocidade angular final de um trecho, $\boldsymbol{\omega}_{f}$, será a soma da velocidade angular inicial do trecho, $\boldsymbol{\omega}_{i}$, com as velocidades angulares provenientes, respectivamente, das perturbações e do efeito giroscópico do próprio veículo. A Equação (6.2) pode ser expressa como sendo a soma de duas expressões. A primeira, denominada velocidade angular de livre movimento, é dada por

$$
\boldsymbol{\omega}_{\text {free }}=\boldsymbol{\omega}_{i}-\left[\mathbf{I}_{v}\right]^{-1} \int_{t_{i}}^{t_{f}} \boldsymbol{\omega} \times\left(\left[\mathbf{I}_{v}\right] \boldsymbol{\omega}\right) \mathrm{d} t .
$$

A segunda, denominada velocidade angular de perturbação, é dada por

$$
\boldsymbol{\omega}_{p r t}=\left[\mathbf{I}_{v}\right]^{-1} \int_{t_{i}}^{t_{f}} \mathbf{T}_{p r t} \mathrm{~d} t
$$

Dos 10 trechos disponíveis, a norma da velocidade angular média é de 0,045 rad/s, sendo o menor valor $0,028 \mathrm{rad} / \mathrm{s}$ e o maior $0,056 \mathrm{rad} / \mathrm{s}$. Utilizando a matriz de inércia fornecida pela equipe do LESIA, a Figura 40 ilustra o comportamento de $\omega_{\text {free }}$ no tempo.

Nota-se que

$$
\omega_{\text {free }} \approx \omega_{i}
$$

Para a velocidade angular de perturbação, $\boldsymbol{\omega}_{p r t}$, o pior caso se dá quando o torque, $\mathbf{T}_{p r t}$, é constante e no valor máximo. Dessa forma,

$$
\boldsymbol{\omega}_{p r t} \approx\left[\mathbf{I}_{v}\right]^{-1} \mathbf{T}_{p_{\text {rttax }}} t
$$


Figura 40 - Comportamento de $\omega_{\text {free }}$.

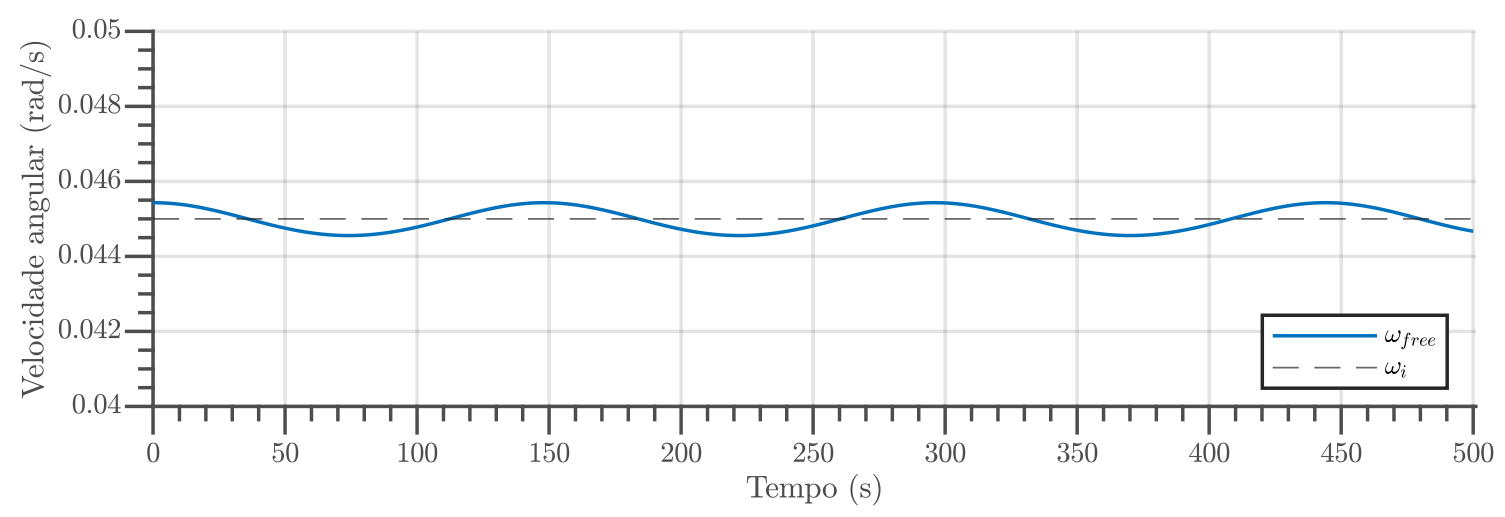

Fonte: Autor.

Utilizando os dados do PicSat e os modelos apresentados na Seção 4.3, a norma da velocidade angular de perturbação é dada por

$$
\omega_{p r t} \approx 4,15 \times 10^{-5} t
$$

Dessa forma, a relação entre a norma da velocidade angular de livre movimento e de perturbação é expressa por

$$
\frac{\omega_{\text {free }}}{\omega_{\text {prt }}} \approx \frac{\omega_{i}}{4,15 \times 10^{-5} t}
$$

Para que a influência da perturbação seja, ao menos, dez vezes menor que do livre movimento, isto é, $\omega_{\text {prt }} / \omega_{\text {free }} \leq 1 / 10$, e considerando a velocidade angular média dos trechos disponíveis, é necessário que

$$
t \leq 107,91 \mathrm{~s}
$$

Portanto, a Etapa 1 de validação deve ser feita com trechos de até 107,91 s.

\subsubsection{Primeira Etapa de Validação da Dinâmica}

Os dez trechos identificados possuem, nessa ordem, $290 \mathrm{~s}, 680 \mathrm{~s}, 570 \mathrm{~s}, 300 \mathrm{~s}, 770 \mathrm{~s}$, 600 s, 690 s, 750 s, 720 s e 620 s. Para realizar a Etapa 1 de validação, os trechos foram fracionados em subtrechos de $100 \mathrm{~s}$. Quando necessário, utilizou-se de dados da fração anterior para completar o tempo restante e compor o último subtrecho. Ao todo são 63 subtrechos.

A versão do modelo CAD disponibilizado era anterior a montagem final. Dessa forma, a matriz de inércia e o centro de massa obtidos devem ser diferentes do modelo de voo. Também não foram fornecidas informações de viés e erro estatístico do girômetro. Sendo assim, foram utilizados 32 subtrechos para estimar a matriz de inércia e viés do girômetro, bem como a condição inicial de velocidade de cada subtrecho. 
Os subtrechos foram selecionados de forma alternada. Neste caso, para estimar foram utilizados os de índice impar. Para evitar conflito com a numeração original e auxiliar a compreensão do leitor, para cada caso os subtrechos foram denominados de experimentos, numerados conforme sua utilização e acrescidos da letra $a$ quando se trata de estimação e da letra $b$ quando se trata de validação. Por exemplo: o Experimento 1a utiliza o primeiro dos 63 subtrechos e o Experimento 2a utiliza o terceiro dos 63 subtrechos para estimar os parâmetros; o Experimento 1b utiliza o segundo dos 63 subtrechos e o Experimento 2b utiliza o quarto dos 63 subtrechos para validar os parâmetros estimados.

A estimação foi realizada por meio dos softwares MATLAB e Simulink, utilizando um método de mínimos quadrados não linear (lsqnonlin), no qual o quadrado dos resíduos entre os dados reais e os dados simulados foi minimizado. Tal função custo é expressa por

$$
J\left(\left[\mathbf{I}_{v}\right], \boldsymbol{\omega}_{\text {viés }}, \boldsymbol{\omega}_{0_{i a}}\right)=\sum_{i=1 a}^{32 a} \sum_{k=1}^{N}\left(\boldsymbol{\omega}_{\text {real }_{i}}(k)-\boldsymbol{\omega}_{\text {sim }_{i}}(k)\right)^{2},
$$

na qual, $i$ é o índice de cada um dos experimentos, $k$ é o instante dentro de cada experimento e $N$ é o número de instantes disponíveis, em média $N=10$.

A Figura 41 ilustra, de forma ampliada, os dados reais e os dados de simulação do Experimento 1a após a estimação, bem como os resíduos ${ }^{\ddagger}$, isto é, a diferença entre os dados reais e os dados de simulação. Os resultados dos outros 31 experimentos estão ilustrados de forma reduzida nas Figuras B.1, B.2, B.3, B.4, B.5 e B.6, acomodadas no Apêndice B. Para facilitar a visualização dos resultados, a Figura 42 ilustra as médias e desvios padrões dos resíduos para cada um dos experimentos realizados ${ }^{\S}$.

Nos resultados destacam-se duas características relevantes: os erros médios distribuemse em torno do eixo das abscissas, indicando uma característica de aleatoriedade; e as magnitudes das médias dos resíduos são de uma a duas ordens menores do que os valores nominais das velocidades angulares iniciais.

A validação dos parâmetros estimados foi realizada com os outros 31 subtrechos, neste caso, como pressuposto, os de índice par.

Os resultados do Experimento 1b de validação estão ilustrados de forma ampliada na Figura 43. Os resultados dos outros 30 experimentos estão ilustrados de forma reduzida nas Figuras B.7, B.8, B.9, B.10 e B.11, também acomodadas no Apêndice B.

Novamente, para facilitar a visualização, a Figura 44 ilustra as médias e desvios padrões dos resíduos para cada um dos experimentos realizados.

\footnotetext{
${ }^{\ddagger} \mathrm{O}$ espectro de potência dos resíduos seria relevante para avaliar se alguma dinâmica não está sendo contemplada no modelo proposto. Entretanto, não foi realizado nesta etapa em virtude do baixo número de amostras, (no máximo 11 por experimento).

$\S$ Por questões de sigilo, a matriz de inércia e o viés do girômetro, obtidos como resultado do processo de estimação, foram suprimidos do texto.
} 
Figura 41 - Estimação de parâmetros da matriz de inércia, viés e condições iniciais Experimento 1a.

(a) Dados reais e simulação.

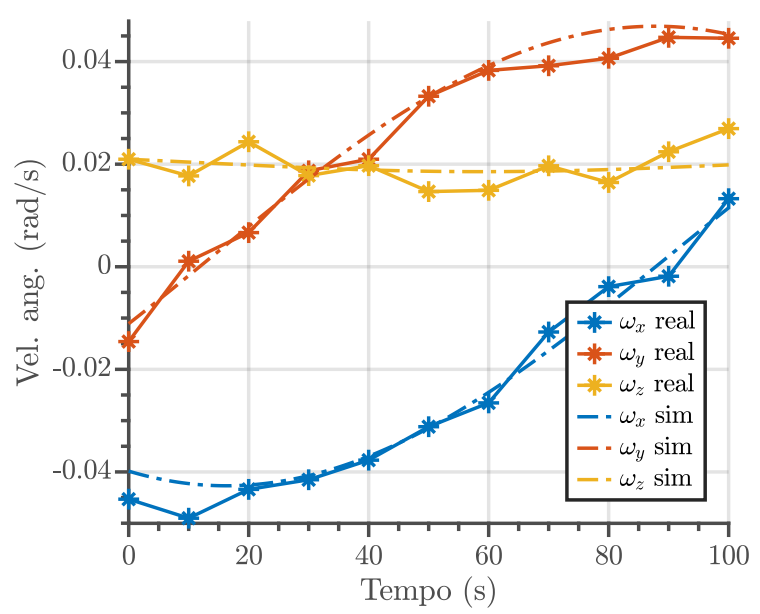

(b) Resíduos.

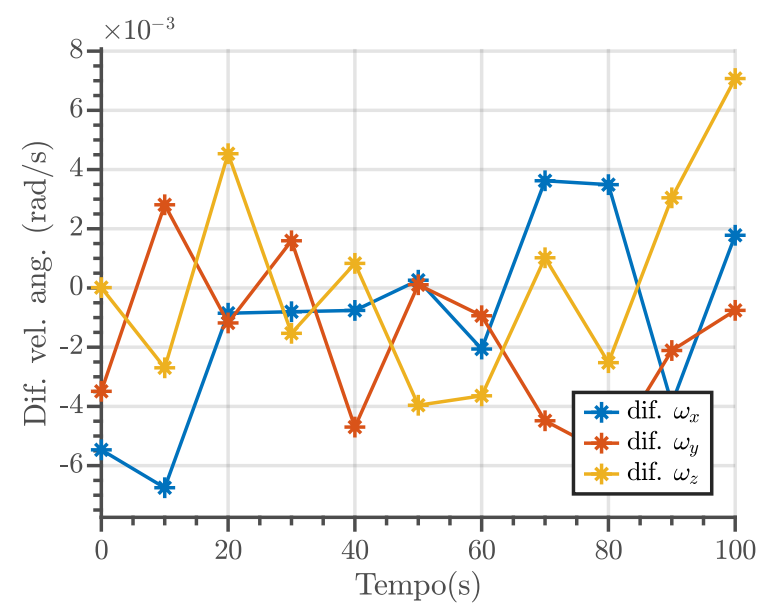

Fonte: Autor.

Figura 42 - Médias e desvios padrões dos resíduos dos experimentos utilizados para estimar os parâmetros da matriz de inércia, viés e condições iniciais.

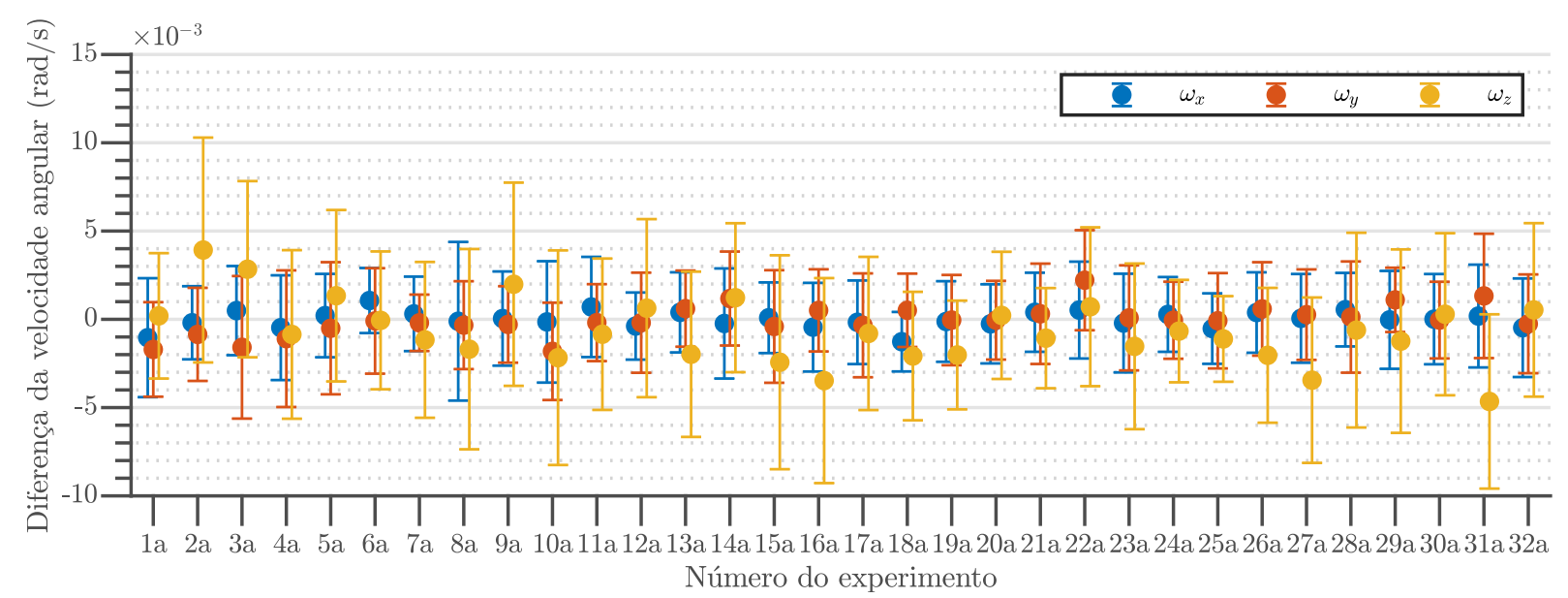

Fonte: Autor.

Similar aos resultados da estimação, é possível notar que os erros médios são de uma a duas ordens de magnitude menores do que os valores nominais das velocidades angulares iniciais, bem como a distribuição em torno do eixo das abscissas.

\subsubsection{Segunda Etapa de Validação da Dinâmica}

Para realizar a Etapa 2 de validação, foram utilizados, inicialmente, 5 dos 10 trechos disponíveis, bem como a matriz de inércia e viés do girômetro estimados na Etapa 1.

Parâmetros relevantes dos modelos de perturbação não foram disponibilizados ou foram parcialmente disponibilizados como: centro de massa, coeficiente de arrasto, composição da superfície e dipolo magnético residual. Ademais, imprecisões nas condições iniciais de 
Figura 43 - Validação de parâmetros da matriz de inércia, viés e condições iniciais Experimento 1b.

(a) Dados reais e simulação.

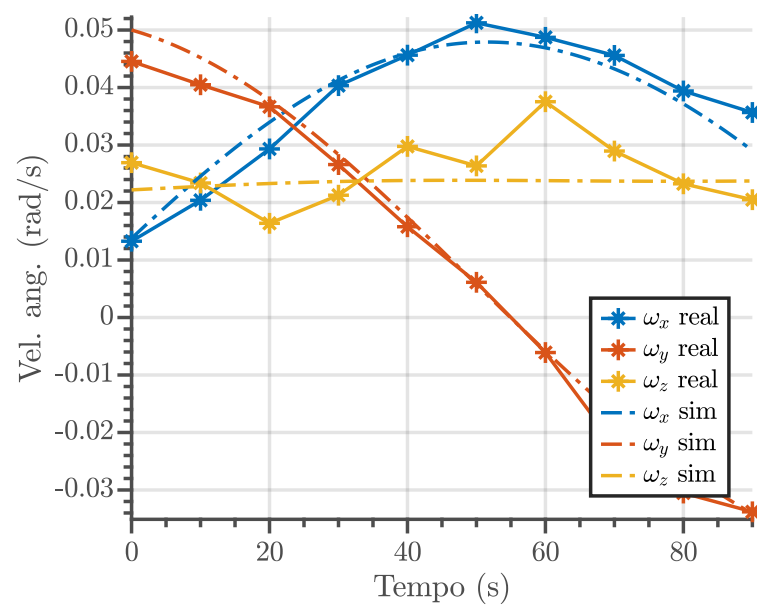

(b) Resíduos

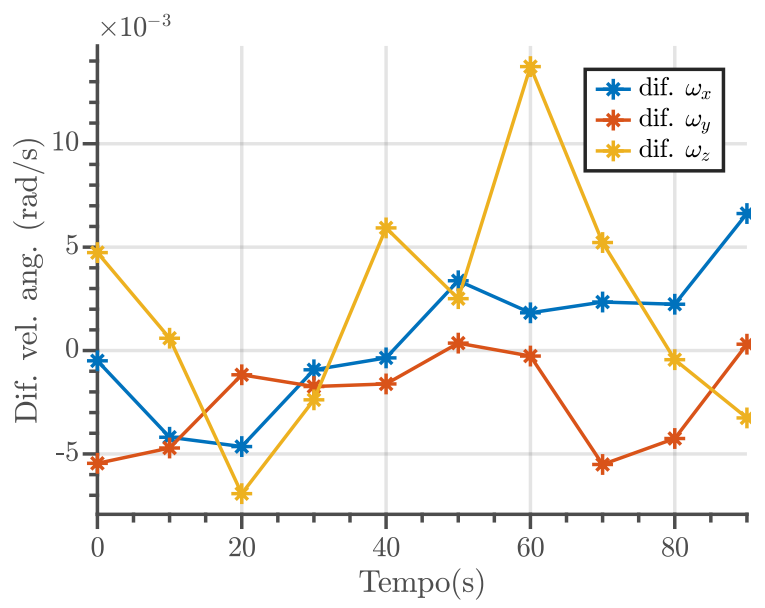

Fonte: Autor.

Figura 44 - Médias e desvios padrões dos resíduos dos experimentos utilizados para validar os parâmetros da matriz de inércia e viés.

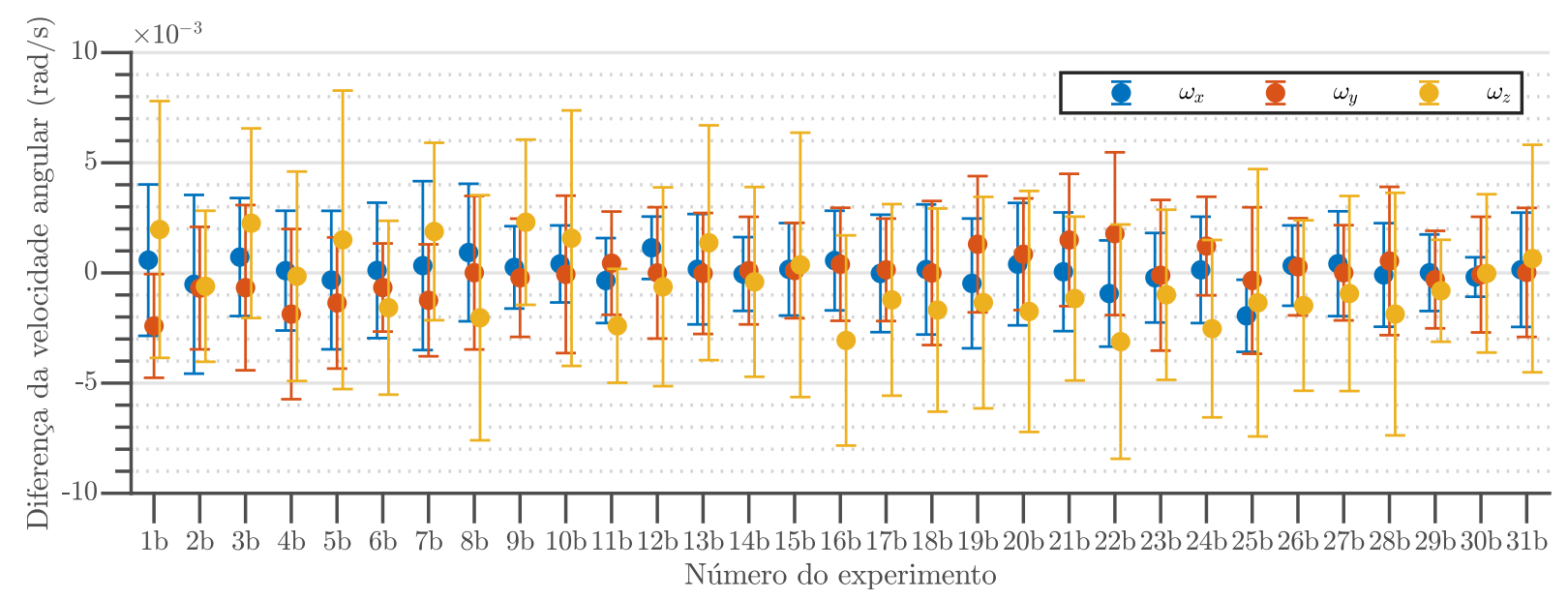

Fonte: Autor.

orientação do satélite e posição orbital geram desvios nos modelos de densidade atmosférica, campo magnético terrestre e gravitacional. E, conforme mencionando anteriormente, os dados de voo podem apresentar problemas de datação por conta da sua origem.

Diante deste cenário, foram estimados: o dipolo magnético residual, $\mathbf{m}_{m r}$, pois, conforme apresentado na Seção 5.6, está relacionado ao torque de maior intensidade; o centro de massa, $C M$, visto que foi parcialmente disponibilizado e está relacionado aos torques devidos ao arrasto atmosférico e à pressão da radiação solar; e um ganho de perturbação, $\mathbf{K}_{p r t}$, para acomodar todas as outras possíveis divergências supracitadas.

O procedimento para estimação também foi realizado por meio dos softwares MATLAB e Simulink, utilizando um método de mínimos quadrados não linear. De forma similar à 
Etapa 1, os trechos foram selecionados de forma alternada, denominados de experimentos e ordenados conforme sua utilização. Neste caso, a função custo é expressa por

$$
J\left(\mathbf{m}_{m r}, C M, \mathbf{K}_{p r t}\right)=\sum_{i=1 a}^{5 a} \sum_{k=1}^{N}\left(\boldsymbol{\omega}_{\text {real }_{i}}(k)-\boldsymbol{\omega}_{\text {sim }}(k)\right)^{2},
$$

na qual, $i$ é o índice de cada um dos experimentos, $k$ é o instante dentro de cada experimento e $N$ é o número de instantes disponíveis.

A Figura 45 ilustra de forma ampliada os dados reais e os dados de simulação do Experimento 1a, assim como os resíduos e seu respectivo espectro de potência. Os resultados dos outros 4 experimentos estão ilustrados de forma reduzida na Figura B.12, acomodada no Apêndice B. De forma similar à etapa anterior, a Figura 46 ilustra as médias e desvios padrões dos resíduos para cada um dos experimentos realizados.

Figura 45 - Estimação dos parâmetros de perturbação - Experimento 1a.

(a) Dados reais e simulação.

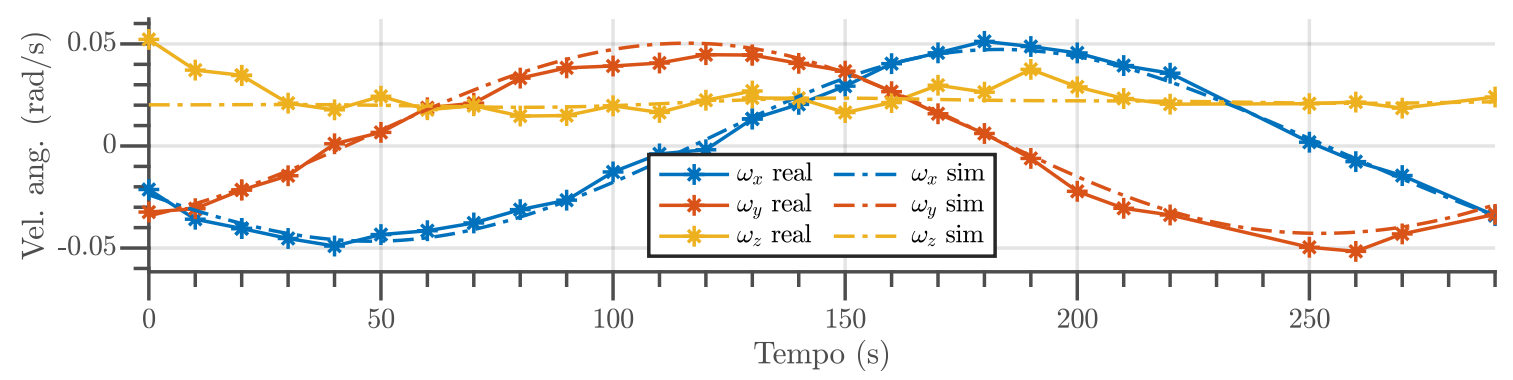

(b) Resíduos.

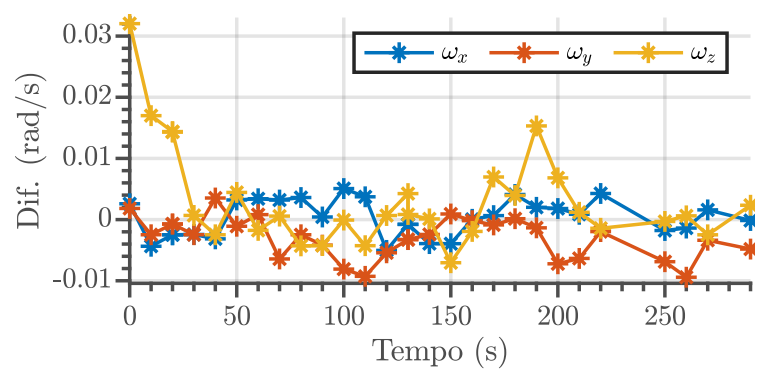

(c) Espectro de potência

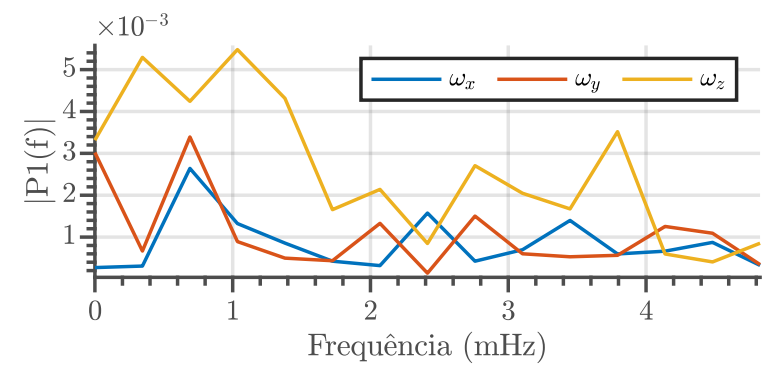

Fonte: Autor.

Na Etapa 2 há um número menor de experimentos quando comparado à Etapa 1, dessa forma a avaliação quanto à distribuição em torno do eixo das abscissas fica comprometida. Entretanto, é possível observar que as magnitudes das médias dos resíduos são de, ao menos, uma ordem de grandeza menores do que os valores nominais das velocidades angulares iniciais. Também é possível notar que há maior densidade espectral em baixa frequência, porém de amplitude não muito superior à de alta frequência. Dado que esse modelo será utilizado para projetar o controle em malha fechada, que será robusto a pequenos erros de modelagem, é possível considerar que se trata de uma diferença desprezível.

Os outros 5 trechos foram utilizados para validar os parâmetros de perturbação. O resultado do Experimento 1b está ilustrado de forma ampliada na Figura 47 e dos outros 
Figura 46 - Médias e desvios padrões dos resíduos dos experimentos utilizados para estimar os parâmetros de perturbação.

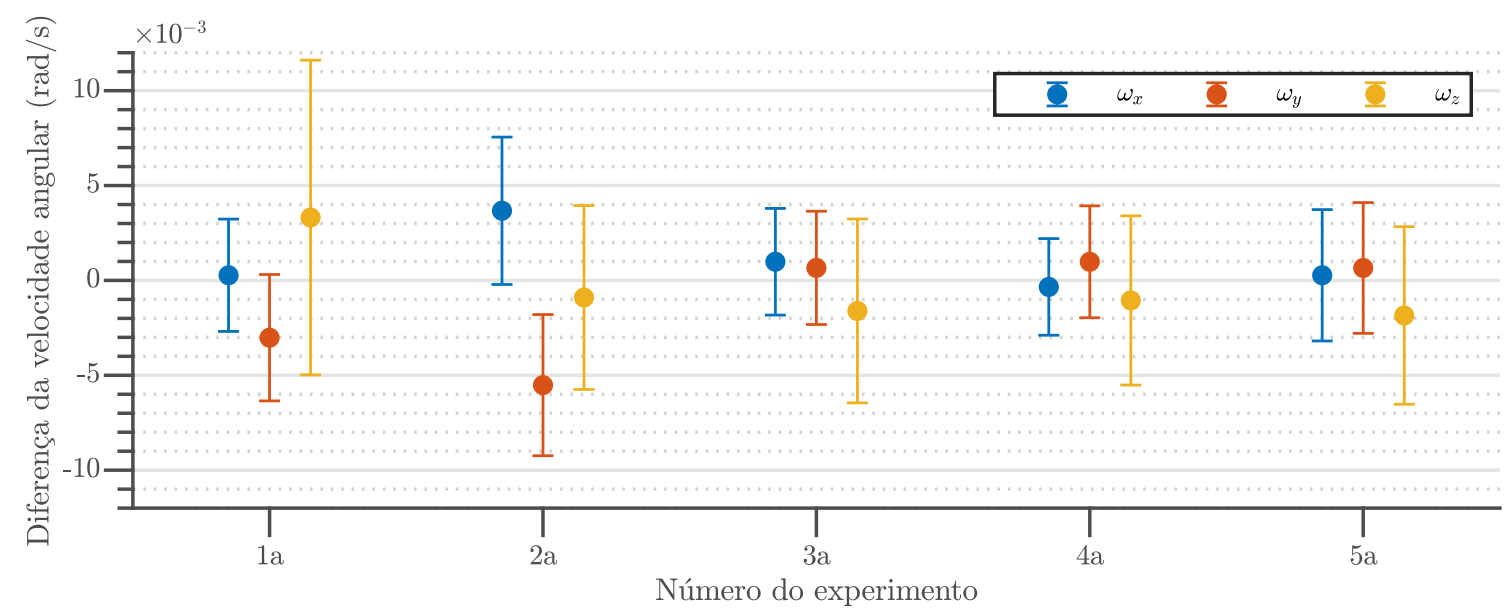

Fonte: Autor.

4 experimentos está ilustrado na Figura B.13. Mais uma vez, as médias e desvios padrões dos resíduos estão ilustrados na Figura 48.

Figura 47 - Validação dos parâmetros de perturbação - Experimento 1b.

(a) Dados reais e simulação.

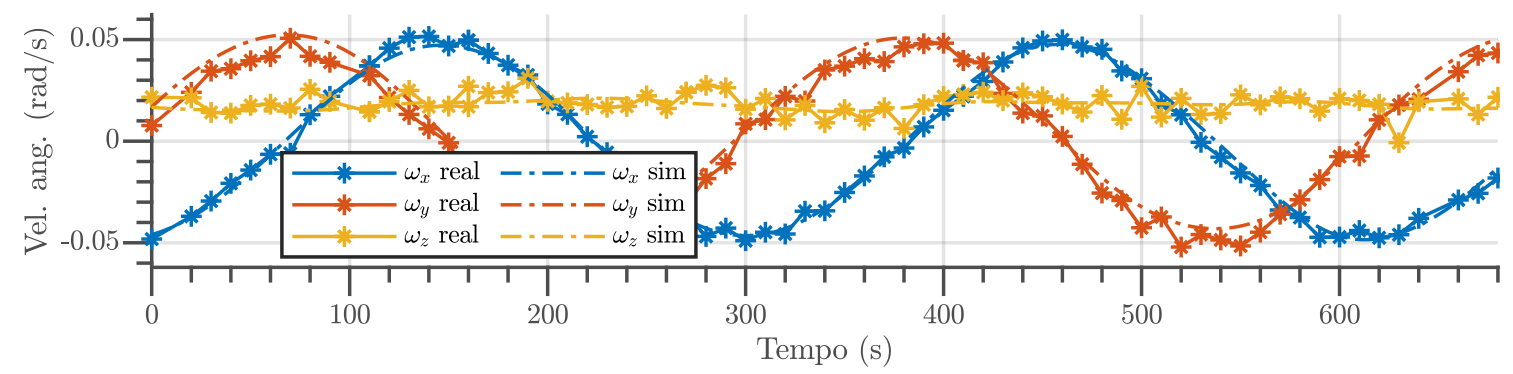

(b) Resíduos.

(c) Espectro de potência
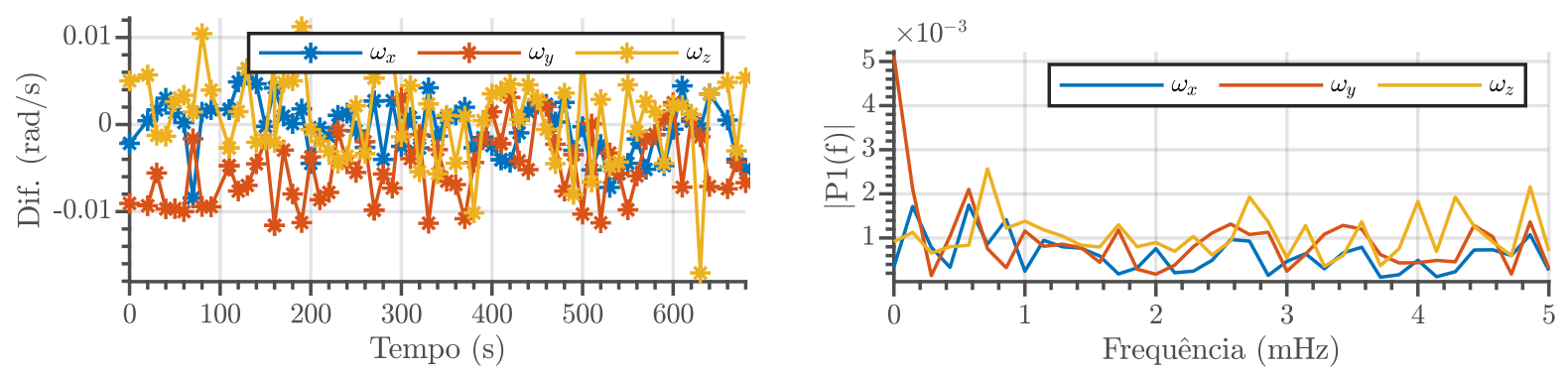

Fonte: Autor.

Assim como nos resultados da estimação, os erros médios são de, ao menos, uma ordem de magnitude menor do que os valores nominais das velocidades angulares, e, neste caso, a densidade espectral não está concentrada em uma frequência.

Como resultado do processo de estimação, o dipolo magnético residual obtido é dado 
Figura 48 - Médias e desvios padrões dos resíduos dos experimentos utilizados para validar os parâmetros de perturbação.

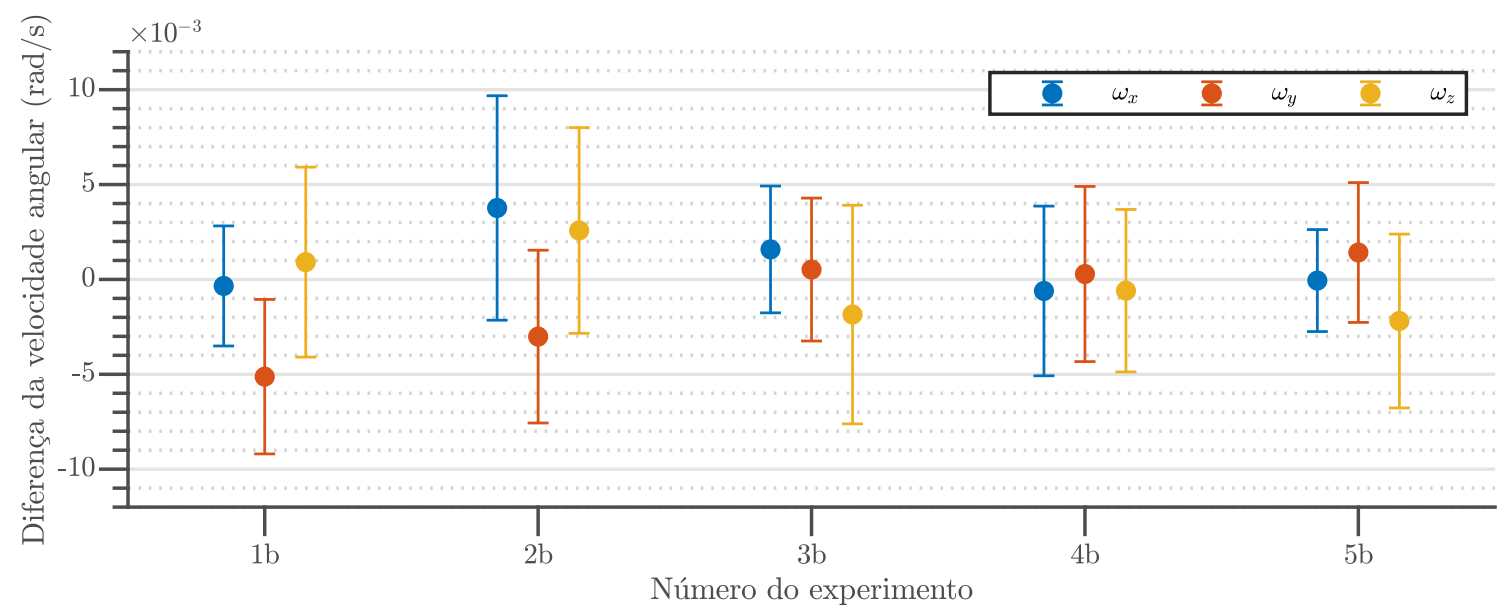

Fonte: Autor.

por

$$
\mathbf{m}_{m r}^{s}=\left[\begin{array}{lll}
(1,86 \pm 0,04) & (8,47 \pm 0,08) & (33,02 \pm 0,65)
\end{array}\right]^{\top} 10^{-3} \mathrm{~A} \mathrm{~m}^{2}
$$

o centro de massa é dado por

$$
C M^{s}=\left[\begin{array}{lll}
(-19,98 \pm 0,39) & (19,80 \pm 0,27) \quad(-69,75 \pm 1,23)
\end{array}\right]^{\top} 10^{-3} \mathrm{~m}
$$

e o ganho de perturbação é dado por

$$
\mathbf{K}_{p r t}=\left[\begin{array}{lll}
(1,08 \pm 0,01) & (0,95 \pm 0,01) & (1,06 \pm 0,03)
\end{array}\right]^{\top}
$$

No início da Seção 6.2, utilizando-se de valores teóricos e nominais, foi inferido que em simulações com tempo inferior a 107,91 s, no pior caso, a influência da perturbação seria dez vezes menor do que a dinâmica de livre movimento. Para verificar essa premissa, em cada um dos dez experimentos utilizados foi calculada a razão percentual entre as normas das velocidades angulares de perturbação, $\omega_{p r t}$, e de livre movimento, $\omega_{\text {free }}$, ao longo do tempo. A Figura 49 destaca os resultados do Trecho 1 e os demais trechos estão ilustrados nas Figuras B.14 e B.15, acomodados no Apêndice B. As médias e desvios padrões das frações de influência das perturbações, em relação ao tempo de simulação, estão ilustrados na Figura 50.

Observando os resultados apresentados, o tempo inferido de 107,91s apresenta-se coerente, pois a fração média de influência da perturbação a 100 s foi de $5,3 \%$. E, conforme mencionado anteriormente, o modelo dinâmico será utilizado para projetar o controle em malha fechada, mitigando esse erro de modelagem. Também é possível notar que, ao passar do tempo, a média e o desvio padrão aumentam progressivamente, indicando um aumento da influência da perturbação e espalhamento da diferença em relação à média. Ademais, é possível notar que, conforme esperado, o torque devido ao dipolo magnético 
Figura 49 - Influência das perturbações no tempo - Trecho 1.

(a) Dados reais e simulação.

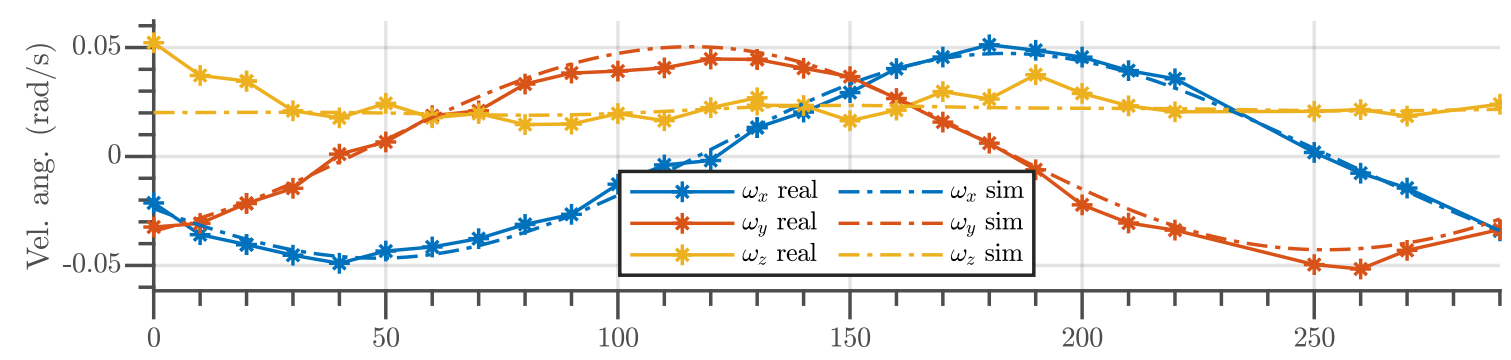

(b) Relação entre $\omega_{\text {prt }}$ e $\omega_{\text {free }}$.

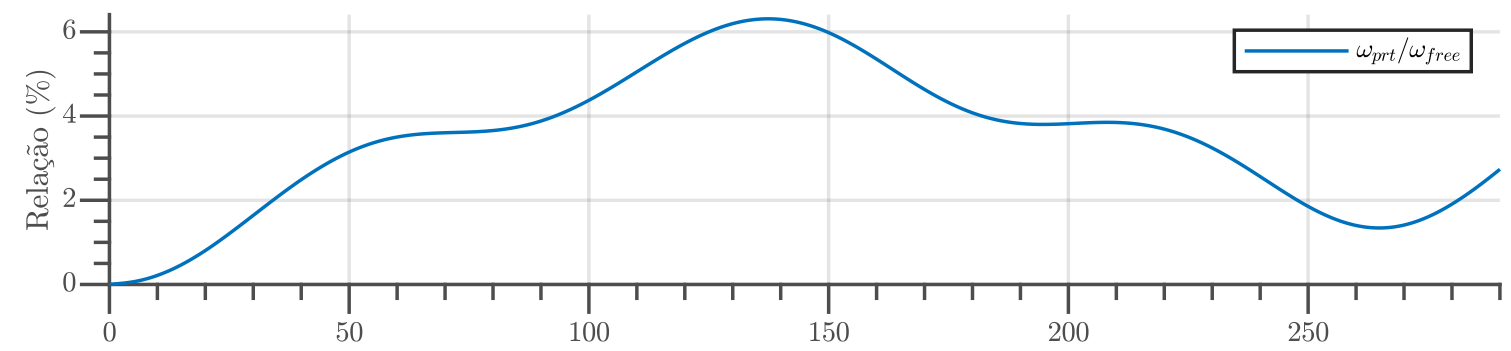

(c) Perturbações.

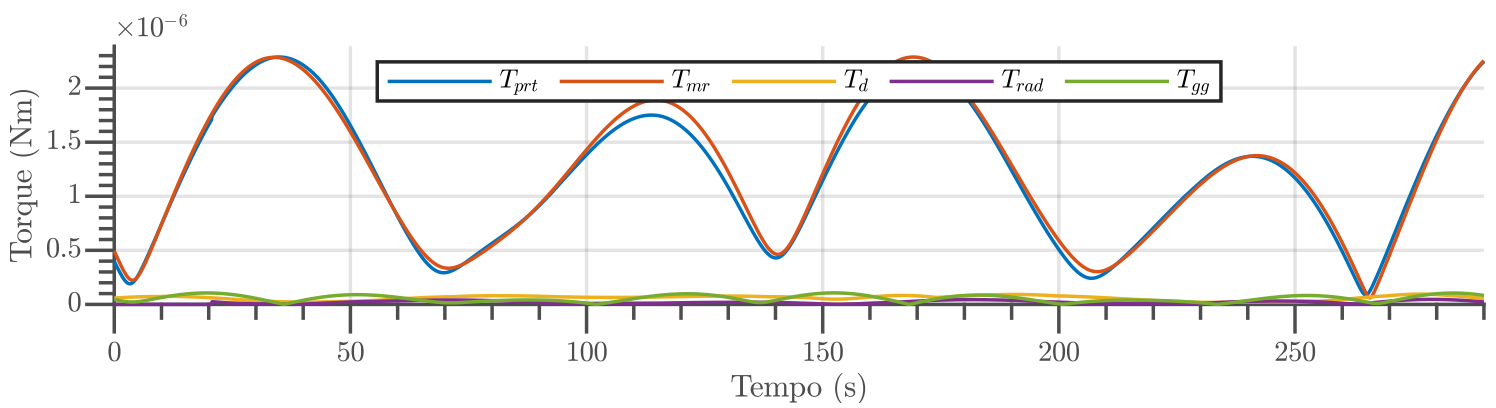

Fonte: Autor.

Figura 50 - Médias e desvios padrões das frações de influência da perturbação.

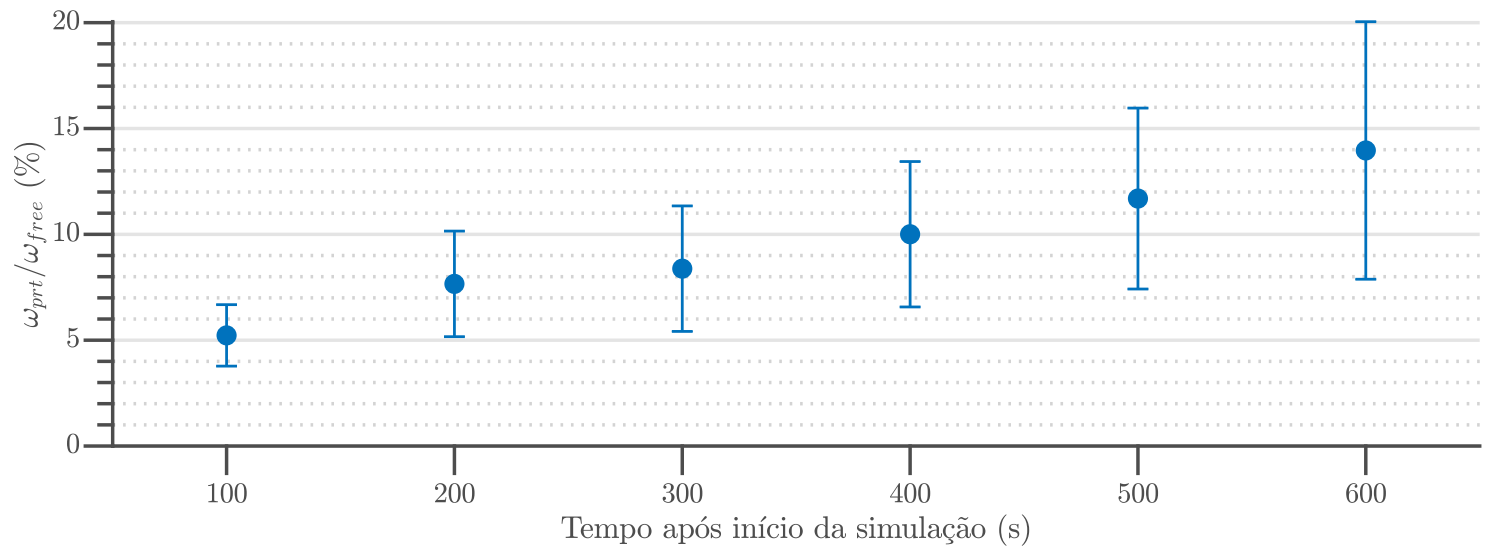

Fonte: Autor.

residual, $T_{m r}$, é o mais influente no PicSat, enquanto o torque devido à pressão da radiação solar, $T_{\text {rad }}$, tem a menor influência no tempo. 
Por fim, são apresentadas simulações comparando a presença e ausência das perturbações no modelo dinâmico do satélite. De forma destacada para o Trecho 1, a Figura 51 ilustra os dados de voo, dados de simulação com e sem perturbação, bem como a diferença entre eles. Os resultados dos demais trechos estão ilustrados nas Figuras B.16 e B.17, acomodadas no Apêndice B.

Figura 51 - Comparação da presença e ausência das perturbações no tempo - Trecho 1.

(a) Dados reais e simulação com (c/) e sem (s/) perturbações.

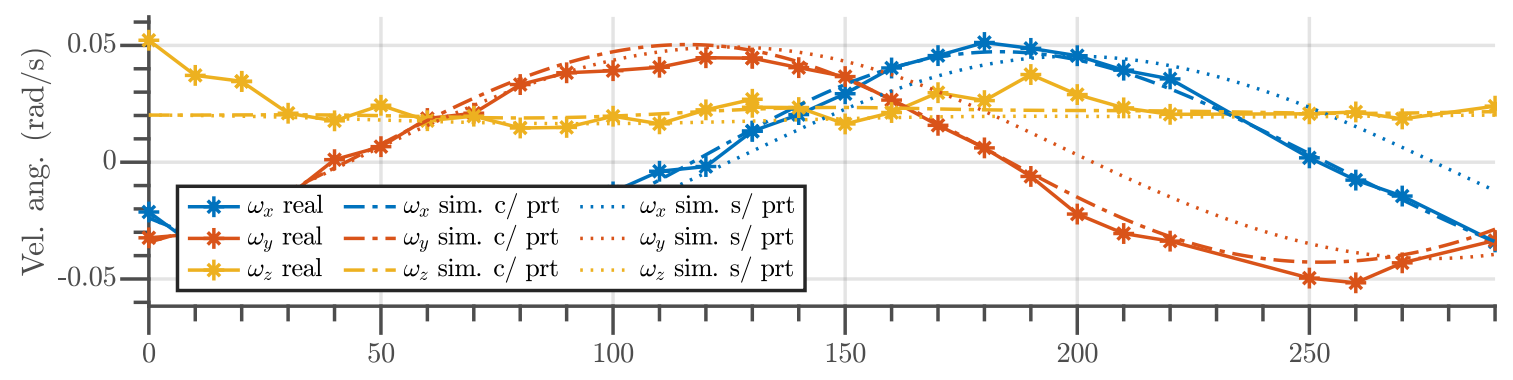

(b) Módulo da diferença das simulações com e sem perturbações.

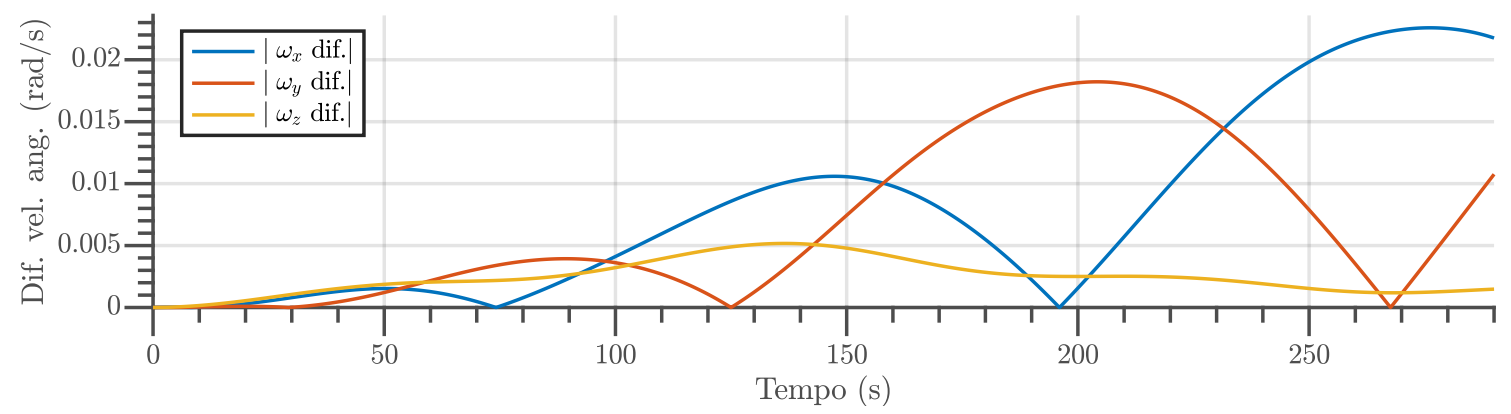

Fonte: Autor.

Conforme esperado, a diferença em relação aos dados de voo aumenta rapidamente quando a simulação não considera as perturbações. E, como $\omega_{x}$ (azul) e $\omega_{y}$ (vermelho) realizam um movimento oscilatório, o módulo da diferença tem o comportamento de onda cuja amplitude aumenta a cada ciclo.

\subsection{Validação da Órbita do Satélite}

A posição orbital de um satélite pode ser obtida por meio de um dispositivo de GPS embarcado no veículo, ou por rastreamento de radares em solo. O PicSat não possui um módulo GPS e nem um sistema de estimação de posição via estação de solo. Entretanto, o Sistema de Vigilância Espacial dos EUA, (U.S. Space Surveillance System), rastreia todos os objetos em órbita terrestre (satélites artificiais e detritos) e mantém uma base de dados catalogada [82]. Esses dados são publicados pelo Joint Space Operations Center (JSpOC) no portal < https://www.space-track.org > em um formato denominado Two-Line Element (TLE). 
O tempo entre atualizações do TLE, para um mesmo objeto não é constante e pode variar de uma órbita (tempo mínimo) até vários dias. A Figura 52 ilustra o histograma e o diagrama de caixa ${ }^{\llbracket}$ do tempo de atualização entre os TLEs do PicSat de 12/01/2018 a 29/09/2019\|. Ao todo foram 1166 atualizações nesse período.

Figura 52 - Atualizações dos TLEs do PicSat disponíveis de 12/01/2018 até 29/09/2019.

(a) Histograma.

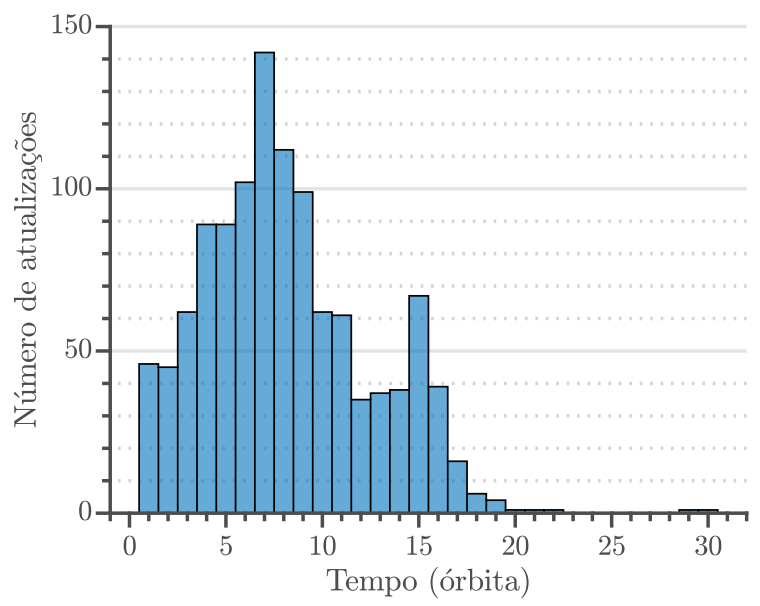

(b) Diagrama de caixa.

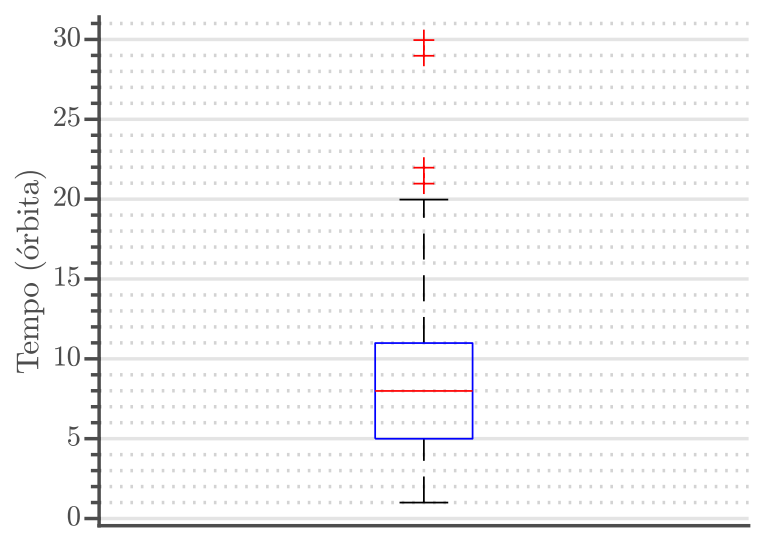

Fonte: Autor.

Nota-se que o maior intervalo entre TLEs foi de 30 órbitas, o equivalente à $47,4 \mathrm{~h}$, e que $75 \%$ das atualizações ocorreram em menos de $11 \mathrm{~h}$.

Os TLEs são publicados sem informação de acurácia associada. Entretanto, em [100] utilizou-se da constelação de CubeSats Flock 1B da empresa Planet, dotados de um módulo de GPS, para determinar a exatidão dos TLEs desses veículos. Tratam-se de CubeSats de 3Us, similares ao PicSat, lançados da ISS. Foram examinados 10 satélites durante o mês de setembro de 2014, com 634 atualizações de TLEs nesse período. Como resultado, o erro estatístico de posição foi menor que 2,01 km em $25 \%$ dos casos (primeiro quartil), menor que $4,52 \mathrm{~km}$ em $50 \%$ dos casos (mediana) e menor que 10,60 km em $75 \%$ dos casos (terceiro quartil).

Sendo assim, a validação da propagação orbital do simulador foi realizada utilizando os TLEs disponíveis do PicSat e o erro estatístico obtido em [100]. Para isso, foi realizado o seguinte procedimento: inserir no simulador as condições iniciais do TLE no instante $t_{i}$, propagar os estados e, então, comparar com o novo TLE no instante $t_{f}$. A diferença entre $t_{i}$ e $t_{f}$ foi do menor tempo disponível, isto é, uma órbita, até cerca de um dia, isto é, 15

IDiagrama de caixa, ou box plot é uma forma de representar a dispersão dos dados em função do limite inferior, primeiro quartil, i.e., $25 \%$ dos dados estão abaixo desse valor, mediana, terceiro quartil, i.e., $75 \%$ dos dados estão abaixo desse valor, e limite superior. Os valores atípicos, ou outliers são plotados como pontos individuais. Essa forma de representação é preferível em relação à média e desvio padrão, quando a distribuição dos dados não é simétrica [99].

" Apesar do contato com o PicSat ter-se interrompido no dia 20 de março de 2018, os TLEs continuam sendo disponibilizados até que o satélite reentre na atmosfera terrestre. 
órbitas. A Figura 53 ilustra quantas detecções havia entre 1 e 15 órbitas de diferença** entre os TLEs disponíveis de 12/01/2018 a 29/09/2019.

Figura 53 - Quantidade de detecções com diferença de tempo entre TLEs de 1 à 15 órbitas.

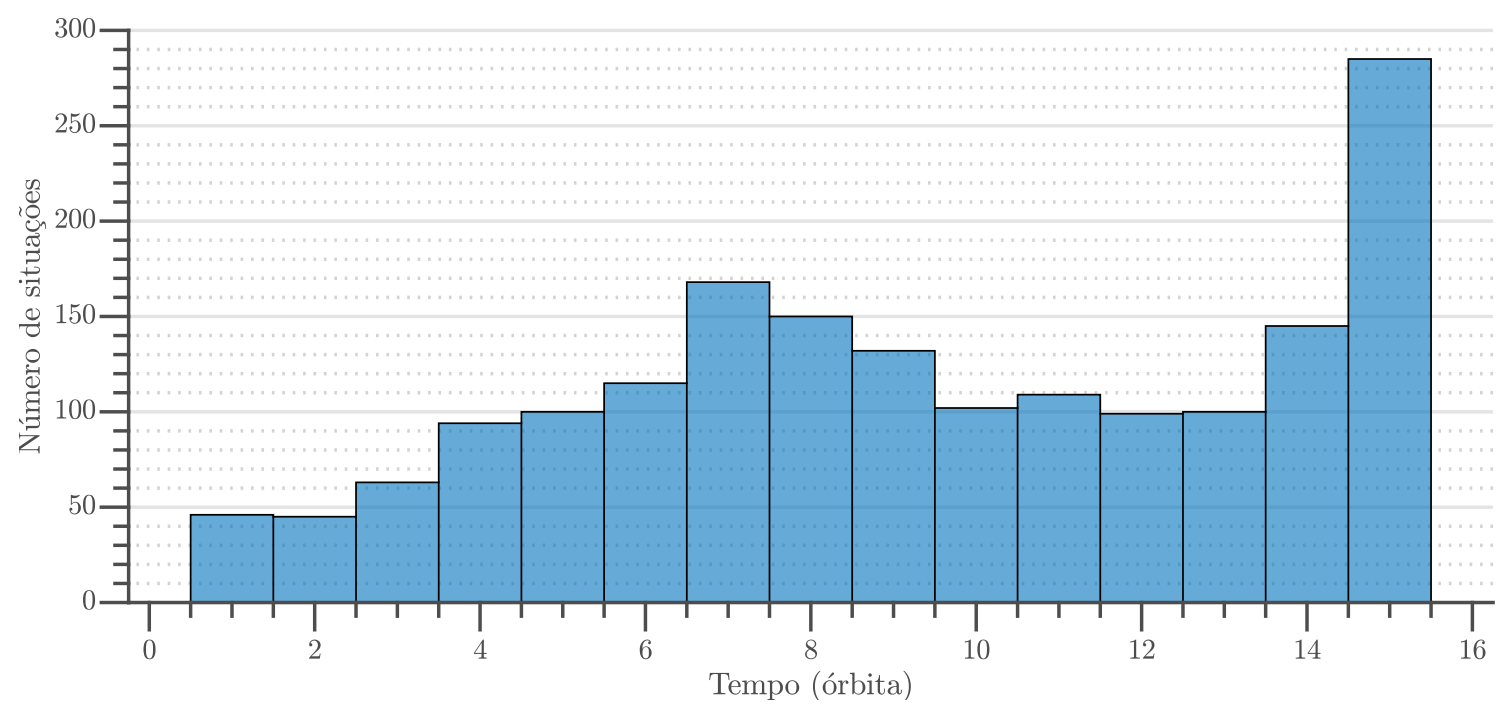

Fonte: Autor.

Os resultados do erro de propagação são apresentados na Figura 54. As linhas tracejadas horizontais representam os erros estatísticos obtidos em [100].

Figura 54 - Resultados do erro de propagação orbital.

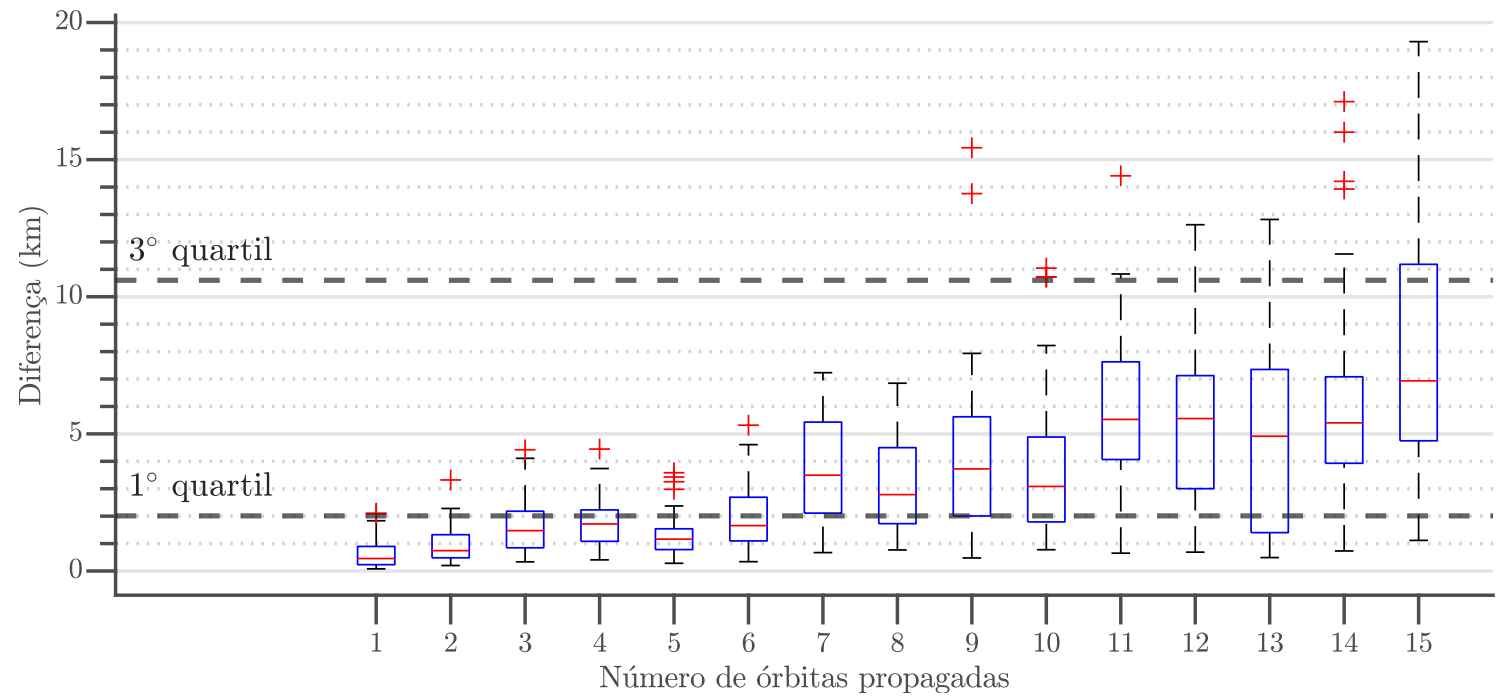

Fonte: Autor.

Nota-se que o erro do modelo deriva em função do tempo de propagação. Entretanto, após 15 órbitas, o erro mediano do modelo é de 7,1 km e menor do que 11,2 km em 75\% das simulações. Para um observador em solo, esse erro mediano é o equivalente a $3,5^{\prime}$ de diferença no apontamento para o veículo.

\footnotetext{
**As detecções não são de TLEs necessariamente consecutivos.
} 
Como resultado do processo de validação, os modelos da dinâmica do satélite e das perturbações de atitude apresentaram erro de, ao menos, uma ordem de grandeza menor do que os valores nominais de velocidade angular inicial. Ademais, foi possível notar a influência das perturbações na propagação da atitude, que foi de 5,3\% após $100 \mathrm{~s}$. O modelo da dinâmica orbital, por sua vez, apresentou erro mediano de $7,1 \mathrm{~km}$ após 15 órbitas.

Sendo assim, considerando que o simulador servirá como ferramenta de desenvolvimento, por exemplo, do controle de atitude em malha fechada, os erros de modelagem serão mitigados e os resultados podem ser considerados satisfatórios. 



\section{SISTEMA DE CONTROLE DE ATITUDE}

O Sistema de controle de atitude é responsável, como o próprio nome sugere, por controlar a orientação do veículo. Tal sistema pode ser realizado de forma passiva, ativa, ou em uma combinação de ambos. Gradiente de gravidade, vento solar, rotação em torno do eixo principal de inércia ou ímã permanente interagindo com o campo magnético terrestre, são exemplos de controles passivos. Por sua vez, o controle ativo faz uso de atuadores, alguns deles mencionados e modelados na Subseção 4.1.2.1. Tal controle pode ser em torno de um, dois ou três eixos de rotação do veículo.

Além disso, CubeSats são, geralmente, colocados em órbita por meio de lançadores, denominados de Picosatellite Orbital Deployers (POD). Tais lançadores ejetam os CubeSats por meio de uma mola comprimida de forma que imprimem nos satélites uma velocidade angular inicial. Como exemplo, o CubeSat de 1U, UWE3, registrou uma velocidade angular inicial de $0,4 \mathrm{rad} / \mathrm{s}$ [56]. Isto faz com que seja comum o ACS ter um controlador responsável por reduzir a velocidade angular do CubeSat, visando o bom funcionamento de alguns subsistemas e melhorando a capacidade de comunicação com as estações de solo. O mencionado controlador é chamado de detumbling, em tradução literal, "decapotamento". Outros objetivos comuns em uma missão são que o satélite seja capaz de observar um corpo celeste, orientar os painéis solares para o Sol e orientar as antenas para a Terra, isto é, seja capaz de realizar manobras, apontamentos ou seguir alguma referência. O controlador utilizado para essas funções é chamado de apontamento.

Nesse capítulo apresentam-se o projeto e os resultados de simulação de um controlador de detumbling e um controlador de apontamento.

\subsection{Modos de Operação}

Novamente, com o intuito de contribuir para os projetos do IMT e IAG, seria oportuno projetar os controladores de forma que atendam aos modos de operação e requisitos de desempenho das respectivas missões. Entretanto, no início desse projeto não havia uma definição última dos requisitos de atitude. Dessa forma, para estabelecer modos de operação e requisitos hipotéticos realistas, utilizou-se novamente como referência o nanossatélite AAUSAT-II, em virtude da semelhança de objetivos. Recordando-os: estabelecer comunicação de duas vias, similar ao projeto do IMT; e detectar explosões de raio gama oriundos do espaço, similar ao projeto do IAG.

O primeiro modo é de inatividade. Logo após ser projetado em órbita, o veículo deve permanecer inativo por 30 min. Conforme mencionado, a projeção imprime no nanossatélite uma velocidade angular inicial, portanto o segundo modo é o de detumbling. Após a 
velocidade angular ser reduzida é acionado o modo de apontamento. Por fim, caso necessário, deve existir um modo de contingência, o qual retoma para o modo de detumbling. A Figura 55 ilustra o diagrama de transição de estados dos modos do ACS.

Figura 55 - Diagrama de transição de estados do ACS.

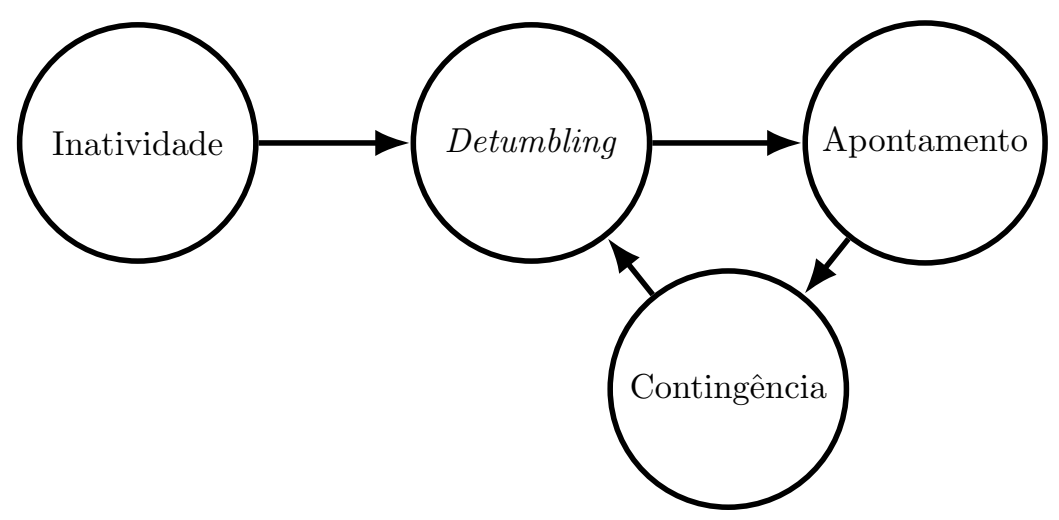

Fonte: Autor.

\subsection{Requisitos e Características}

Para facilitar a compreensão do leitor ao longo do texto, os requisitos de desempenho serão identificados por Ri, sendo i o número do requisito.

O controle de detumbling deve ser capaz de:

R1) reduzir a velocidade angular do satélite de $0,4 \mathrm{rad} / \mathrm{s}$ para $0,02 \mathrm{rad} / \mathrm{s}$ em até 3 órbitas;e

R2) reduzir a velocidade angular de $1,2 \mathrm{rad} / \mathrm{s}$ para $0,02 \mathrm{rad} / \mathrm{s}$ em até 6 órbitas, considerando uma situação de falha do ACS.

O controle de apontamento deve ser capaz de:

R3) apontar e manter o veículo em uma direção fixa do GEI (essa situação simula a observação de um corpo celeste ou orientação de painéis solares para o Sol);

R4) apontar e manter as antenas apontadas na direção Nadir, isto é, para o centro da Terra;

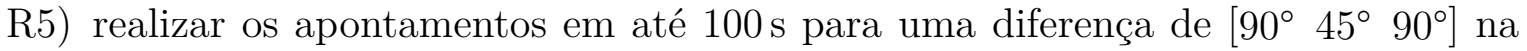
sequência ZYX, em relação à condição inicial; e

R6) manter os apontamentos com erro de $\pm 5^{\circ}$.

O controle das rodas de reação deve:

R7) apresentar erro em regime nulo para referência de torque do tipo impulso; 
R8) apresentar erro em regime constante máximo de $2 \%$ para referência de velocidade do tipo rampa;e

R9) apresentar tempo de acomodação máximo de 0,1s para referência de velocidade do tipo degrau.

O controle de dessaturação das rodas de reação deve ser capaz de:

R10) reduzir o momento angular da roda de reação de $90 \%$ para uma faixa entre $10 \%$ e $30 \%$ do valor máximo em até 1 órbita.

Conforme mencionando anteriormente, o desenvolvimento do ADS não faz parte desse trabalho. Entretanto, com o intuito de promover maior fidelidade às simulações do ACS, foram consideradas as características dos sensores e desempenhos dos ADSs de outros CubeSats desenvolvidos em ambiente universitários, com características similares e informações publicadas. São eles: (i) o AAUSAT3, sucessor do AAUSAT-II, que apresenta informações do girômetro com desvio padrão de $3,5 \times 10^{-3} \mathrm{rad} / \mathrm{s}$ e magnetômetro com desvio padrão de 36,14nT [28]; (ii) o próprio AUSAT-II que apresenta resultados de determinação de atitude com desvio padrão de 2,5 [26]; e, por fim, (iii) o MicroMAS-1 que apresenta resultados de determinação da referência Nadir com erro quadrático médio de $0,18^{\circ}[101]$.

Por fim, a taxa de atualização dos controladores depende de diversos fatores, em especial da capacidade de processamento do computador de bordo e da restrição de consumo energético. Utilizando como referência os nanossatélites citados, $1 \mathrm{~Hz}, 10 \mathrm{~Hz}$ e $100 \mathrm{~Hz}$ são, respectivamente, taxas de atualização realistas para as malhas de controle de apontamento, detumbling e roda de reação.

\subsection{Detumbling}

Apresentado inicialmente por Stickler e Alfriend[102], o algorítimo conhecido como Bdot tem sido amplamente utilizado como controlador de detumbling em CubeSats [103-107]. Isso se dá por sua simplicidade, robustez e eficiência, utilizando apenas a medida de campo magnético terrestre e os atuadores magnéticos.

\subsubsection{Controlador B-dot}

Sabe-se que a energia cinética em razão da rotação de um corpo rígido, adaptada aos termos do veículo, é dada por [68]

$$
\mathbf{E}_{c}^{p}=\frac{1}{2} \boldsymbol{\omega}_{p / i}^{p}{ }^{\top}\left[\mathbf{I}_{v}\right]^{p} \boldsymbol{\omega}_{p / i}^{p}
$$

e, portanto, a variação da energia cinética é expressa por

$$
\dot{\mathbf{E}}_{c}^{p}=\boldsymbol{\omega}_{p / i}^{p}\left[\mathbf{I}_{v}\right]^{p} \dot{\boldsymbol{\omega}}_{p / i}^{p}
$$


Essa formulação é relevante, pois implica que reduzir a energia cinética do veículo é o equivalente a reduzir a velocidade angular. Resta, portanto, identificar uma forma de realizar tal feito por meio do atuador magnético.

Considerando que durante o detumbling as rodas de reação estão inativas, isto é, $\mathbf{H}_{r r}=0 \Rightarrow \dot{\mathbf{H}}_{r r}=0$, e o torque de perturbação $\mathbf{T}_{p r t}$ é muito menor que o torque proveniente dos atuadores magnéticos $\mathbf{T}_{a m}$, substituindo a Equação (4.14) em (7.2)

$$
\dot{\mathbf{E}}_{c}^{p}=\boldsymbol{\omega}_{p / i}^{p}{ }^{\top}\left[\mathbf{T}_{a m}^{p}-\boldsymbol{\omega}_{p / i}^{p} \times\left(\left[\mathbf{I}_{v}\right]^{p} \boldsymbol{\omega}_{p / i}^{p}\right)\right]
$$

e, então, substituindo a Equação (4.6) em (7.3) resulta em

$$
\dot{\mathbf{E}}_{c}^{p}=\omega_{p / i}^{p}\left(\mathbf{m}_{a m}^{p} \times \mathbf{B}^{p}\right) .
$$

Portanto, reduzir a velocidade angular implica em $\dot{\mathbf{E}}_{c}<0$, isto é,

$$
\begin{array}{r}
\boldsymbol{\omega}_{p / i}^{p^{\top}}\left(\mathbf{m}_{a m}^{p} \times \mathbf{B}^{p}\right)<0 \\
\Rightarrow \mathbf{m}_{a m}^{p{ }^{\top}}\left(\boldsymbol{\omega}_{p / i}^{p} \times \mathbf{B}^{p}\right)>0 .
\end{array}
$$

É importante observar que a velocidade angular do veículo, $\boldsymbol{\omega}$, e o campo magnético terrestre, B, são elementos passivos enquanto o momento do atuador magnético, $\mathbf{m}_{a m}$, é o único elemento ativo da Equação (7.5). Uma possível solução para essa inequação é

$$
\mathbf{m}_{a m}^{p}=k\left(\boldsymbol{\omega}_{p / i}^{p} \times \mathbf{B}^{p}\right), \quad \text { se } \quad k>0 \quad \text { e } \quad \boldsymbol{\omega}_{p / i}^{p} \nVdash \mathbf{B}^{p} .
$$

O ganho $k$ do controlador pode ser adotado de forma que satisfaça a primeira condição, porém a condição em que a velocidade angular do veículo é paralela ao campo magnético terrestre não pode ser evitada, mas pode ser mitigada desde que a órbita do satélite não seja coplanar ao plano do equador magnético*. Deste modo a orientação do campo magnético irá variar ao longo da órbita [108].

A lei de controle apresentada na Equação (7.6) depende da medição ou estimativa do campo magnético terrestre e, também, da velocidade angular do veículo. Alternativamente, é possível relacionar esses termos com a derivada do campo magnético. A variação do campo magnético notada pelo satélite, $\dot{\mathbf{B}}^{p}$, é dada por

$$
\dot{\mathbf{B}}^{p}=\dot{\mathbf{B}}^{i}-\left(\boldsymbol{\omega}_{p / i}^{p} \times \mathbf{B}^{p}\right)
$$

na qual o termo $\dot{\mathbf{B}}^{i}$ é a variação do campo magnético em relação ao sistema de coordenadas inercial (GEI) e o termo $\left(\boldsymbol{\omega}_{p / i}^{p} \times \mathbf{B}^{p}\right)$ é consequência da velocidade angular do veículo em relação ao GEI. Dado que o detumbling ocorre apenas quando a velocidade angular

\footnotetext{
*Quando o campo magnético da Terra é aproximado por um dipolo, o plano do equador magnético dá-se pelo plano circular que divide esses dois polos. A inclinação entre o eixo geomagnético e o eixo de rotação da Terra era de 9,7 em 2015 e está estimado para ser de 9,4 em 2020 [89].
} 
do veículo é considerada elevada, pode-se dizer que $\dot{\mathbf{B}}^{i} \ll\left(\boldsymbol{\omega}_{p / i}^{p} \times \mathbf{B}^{p}\right)$ e, portanto, $\dot{\mathbf{B}}^{p} \approx-\boldsymbol{\omega}_{p / i}^{p} \times \mathbf{B}^{p}$. Sendo assim, reescrevendo a Equação (7.6)

$$
\mathbf{m}_{d}^{p}=-k_{d e t} \dot{\mathbf{B}}^{p}
$$

na qual a notação $\mathbf{m}_{d}$ é utilizada no local de $\mathbf{m}_{a m}$ para indicar que trata-se do momento magnético desejado pelo controlador e a notação $k$ foi acrecida do termo subscrito det apenas para evitar confusão ao longo do texto. A Equação (7.8) é conhecida como controlador B-dot [102].

Com esse algorítimo, a menor velocidade angular que o veículo alcançará é a velocidade de variação do campo magnético local. Portanto, para fins didáticos, pode-se dizer que essa estratégia de controle é equivalente a seguir o campo magnético Terrestre.

Conforme mencionado anteriormente, essa lei de controle é simples de ser implementada e depende apenas da medida de campo magnético e dos atuadores magnéticos. O ajusto do ganho $k_{d e t}$, porém, não é obtido de forma direta. Um valor elevado faz com que os atuadores atinjam os limites de saturação, enquanto uma valor baixo subutiliza os atuadores, aumentando o tempo que o veículo demora para reduzir a velocidade angular [109]. Avanzini e Giulietti[108] apresentam um critério para determinar $k_{\text {det }}$ resultando em um ganho estático sub-ótimo dado por

$$
k_{\text {det }}=2 \omega_{\text {orb }}\left(1+\operatorname{sen} \xi_{m}\right) I_{v_{\text {min }}},
$$

na qual $\omega_{\text {orb }}$ é a velocidade angular orbital, $\xi_{m}$ é a inclinação entre a órbita do veículo e o equador magnético e $I_{v_{m i n}}$ é o menor momento principal de inércia.

\subsubsection{Análise de Estabilidade}

A estabilidade do controlador B-dot, pode ser avaliada utilizando-se da definição de estabilidade segundo Lyapunov.

Considere a equação diferencial

$$
\dot{\mathbf{x}}=\mathbf{f}(\mathbf{x})
$$

na qual $\mathbf{f}: D \rightarrow \mathbb{R}^{n}$ é localmente Lipschitz contínua do domínio $D \subset \mathbb{R}^{n}$. Supondo $\mathbf{x}_{e q} \subset D$, é chamado de ponto de equilíbrio se $\mathbf{f}\left(\mathbf{x}_{e q}\right)=0$.

Por meio de translação de coordenadas é possível representar o ponto de equilíbrio em relação à origem de $\mathbb{R}^{n}$. Sendo assim, por conveniência e sem perder a generalidade, considera-se que o ponto de equilíbrio é a origem de $\mathbb{R}^{n}$, isto é, $\mathbf{x}_{e q}=0$ [110].

Definição. O ponto de equilíbrio $\mathbf{x}_{e q}$ da Equação (7.10) é denominado 
- estável se, para todo $\epsilon>0$, existe $\delta=\delta(\epsilon)>0$ tal que

$$
\|\mathbf{x}(0)\|<\delta \Rightarrow\|\mathbf{x}(t)\|<\epsilon, \quad \forall t \geq 0
$$

isto quer dizer que se os estados estão inicialmente em equilíbrio, permanecerão em equilíbrio por toda trajetória.

- assintoticamente estável se for estável e existir $\delta$ tal que

$$
\|\mathbf{x}(0)\|<\delta \Rightarrow \lim _{t \rightarrow \infty} \mathbf{x}(t)=0
$$

isto quer dizer que os estados, além de permanecerem em equilíbrio, tendem a 0 conforme $t \rightarrow \infty$.

- instável se não for estável.

Ademais, Lyapunov desenvolveu dois métodos para avaliar a estabilidade de um sistema. O Primeiro Método, também chamado de Método Indireto, permite investigar a estabilidade local de um sistema não linear por meio de sua aproximação linear. O Segundo Método, também conhecido como o Método Direto, é baseado em um conceito análogo ao de energia e pode ser aplicado para avaliar sistemas lineares e não lineares. Este último será utilizado para avaliar a estabilidade do controlador B-dot.

De forma intuitiva, o Método Direto relaciona a dimensão dos estados à uma função escalar que representa a energia total do sistema. Se não há alteração de energia, ou a energia é dissipada, o sistema deve ser estável ou assintoticamente estável.

Teorema. Teorema de Estabilidade de Lyapunov. [110] Seja $\mathbf{x}_{e q}$ um ponto de equilíbrio para Equação (7.10) e $D \subset \mathbb{R}^{n}$ um domínio contendo $\mathbf{x}_{e q}$. Seja $V: D \rightarrow \mathbb{R}$ uma função continua diferenciável tal que

$$
\begin{gathered}
V\left(\mathbf{x}_{e q}\right)=0, \\
V(\mathbf{x})>0, \quad \forall \mathbf{x} \in D-\{\mathbf{0}\} \\
e \quad \dot{V}(\mathbf{x}) \leq 0, \quad \forall \mathbf{x} \in D,
\end{gathered}
$$

então $\mathbf{x}_{e q}$ é estável. Ademais, se

$$
\dot{V}(\mathbf{x})<0, \quad \forall \mathbf{x} \in D-\{\mathbf{0}\}
$$

então $\mathbf{x}_{e q}$ é assintoticamente estável.

Denomina-se de Função de Lyapunov a função escalar $V$ que satisfaz uma das condições do teorema. Além disso, se uma das condições de estabilidade do teorema for verificada para um sistema definido em $D$, na qual $D \subset \mathbb{R}^{n}$ é um conjunto aberto, então o resultado é denominado de local. Porém, se $D=\mathbb{R}^{n}$, então o resultado é denominado de global. 
Aplicando, portanto, tais definições ao controlador de detumbling, B-dot será assintoticamente estável se $\boldsymbol{\omega}_{p / i}^{p} \rightarrow 0$ com $t \rightarrow \infty$ para todo $\boldsymbol{\omega}_{0} \neq 0$.

A energia cinética do veículo, $\mathbf{E}_{c}$, foi apresentada na Equação (7.1) e será candidata à Função de Lyapunov. Sendo assim, reescrevendo-a por conveniência,

$$
V(\boldsymbol{\omega})=\mathbf{E}_{c}^{p}=\frac{1}{2} \boldsymbol{\omega}_{p / i}^{p}{ }^{\top}\left[\mathbf{I}_{v}\right]^{p} \boldsymbol{\omega}_{p / i}^{p}
$$

Sabendo que a matriz de inércia do veículo, $\left[\mathbf{I}_{v}\right]^{p}$, é diagonal e com autovalores positivos (ver Apêndice A), então pode-se dizer que $V(\boldsymbol{\omega})$ é definida positiva, isto é, $V(0)=0$ e $V(\boldsymbol{\omega})>0$ para todo $\boldsymbol{\omega} \neq 0$. Essa condição atende à primeira parte do teorema. Por questões práticas de notação, os termos que indicam os sistemas de coordenadas são suprimidos até que exista necessidade de expressá-los.

A derivada de $V$ pode ser obtida por meio da derivada de $\mathbf{E}_{c}$, a qual já foi demonstrada durante a Subseção 7.3.1. Portanto, de forma similar à Equação (7.4),

$$
\begin{aligned}
\dot{V}(\boldsymbol{\omega}) & =\boldsymbol{\omega}^{\top}\left(\mathbf{m}_{a m} \times \mathbf{B}\right) \\
\Rightarrow & =-\mathbf{m}_{a m}^{\top}(\boldsymbol{\omega} \times \mathbf{B}) .
\end{aligned}
$$

Substituindo a lei de controle apresentada na Equação (7.8) na Equação (7.12) e reconsiderando que $\dot{\mathbf{B}} \approx-\boldsymbol{\omega} \times \mathbf{B}$

$$
\dot{V}(\boldsymbol{\omega})=-(\boldsymbol{\omega} \times \mathbf{B})^{\top} k_{\text {det }}(\boldsymbol{\omega} \times \mathbf{B}) .
$$

Sabendo que $k_{d e t}$ é uma constante positiva,

$$
\begin{aligned}
& \dot{V}=0 \quad \text { se } \quad \boldsymbol{\omega} \| \mathbf{B} \\
& \text { e } \dot{V}<0 \text { se } \boldsymbol{\omega} \nVdash \mathbf{B} \text {. }
\end{aligned}
$$

Portanto, uma vez que $\dot{V} \leq 0$, o controlador pode ser caracterizado apenas como estável. Conforme já discutido anteriormente, o veículo irá reduzir a energia cinética quando a velocidade angular do veículo e o campo magnético terrestre não forem paralelos. Do contrário, permanecerá constante.

Entretanto, o Teorema de Invariância de LaSalle permite definir o ponto de equilíbrio como assintoticamente estável se for possível encontrar uma Função de Lyapunov cuja derivada ao longo da trajetória do sistema é semi-definida negativa, isso é, $\dot{V} \leq 0$, e se for possível estabelecer que, com exceção da origem, não há trajetória que possa permanecer nos pontos onde $\dot{V}=0$ [110].

Teorema. Teorema de Invariância de LaSalle [110]. Seja $K \subset D$ um conjunto compacto invariante positivo em relação à Equação (7.10). Seja $V: D \rightarrow \mathbb{R}$ uma função diferenciável contínua tal que $\dot{V}(\mathbf{x}) \leq 0$ dentro de $K$. Seja $E=\{\mathbf{x} \in K \mid \dot{V}(\mathbf{x})=0\}$. Seja $M$ o maior conjunto invariante contido em E. Então, para toda condição inicial em $K$ a solução aproxima-se arbitrariamente de $M$ quando $t \rightarrow \infty$. 
Conforme mencionado na Subseção 7.3.1, desde que a órbita do veículo não seja coplanar ao equador magnético, o vetor campo magnético, B, não permanecerá constante. Sendo assim, é possível provar que o controlador B-dot é assintoticamente estável [111].

\subsubsection{Estimador da Derivada do Campo Magnético Terrestre}

A medida de variação do campo magnético terrestre, $\dot{\mathbf{B}}$, necessária para o controlador B-dot, não é possível de ser obtida de forma direta. Os magnetômetros fornecem apenas a medida de campo magnético, B. Sendo assim, faz-se necessário estimar $\dot{\mathbf{B}}$.

A derivada do campo magnético, na forma $\dot{\mathbf{B}}=s \mathbf{B}$, é não realizável e, para altas frequências, produz um ganho tendendo ao infinito. Uma alternativa é estimá-la utilizando um filtro de primeira ordem dado por

$$
\dot{\hat{\mathbf{B}}}(s)=\frac{s \omega_{c}}{s+\omega_{c}} \mathbf{B}(s),
$$

na qual $\omega_{c}$ é a frequência de corte do filtro. Para altas frequências (como os ruídos de medição), isto é, $s>>\omega_{c}$, o filtro se comporta como um ganho de valor $\omega_{c}$. E, para baixas frequências (como o campo magnético), isto é, $s<<\omega_{c}$, o filtro se comporta como um diferenciador.

Na prática, as leis de controle são implementadas em computadores de bordo, portanto em tempo discreto. Um dos métodos de discretização de uma função de transferência no domínio $s$ é o mapeamento casado de polos e zeros, no qual os polos e zeros finitos no plano $s$ são mapeados no plano $z$ como $z=e^{s T}$, sendo $T$ o tempo de amostragem da discretização [112]. Utilizando o método de mapeamento casado de polos e zeros na Equação (7.14)

$$
\dot{\hat{\mathbf{B}}}(z)=\frac{\left(1-e^{-\omega_{c} T}\right)(z-1)}{T\left(z-e^{-\omega_{c} T}\right)} \mathbf{B}(z),
$$

e substituindo na Equação (7.8), o controlador de detumbling pode ser escrito como

$$
\mathbf{m}_{a m}(z)=-k_{d e t} \frac{\left(1-e^{-\omega_{c} T}\right)(z-1)}{T\left(z-e^{-\omega_{c} T}\right)} \mathbf{B}(z)
$$

Para fins de simulação, a Figura 56 representa o controlador de detumbling proposto, na qual D/A e A/D representam, respectivamente, as conversões de digital para analógico e analógico para digital, e am representa o conjunto dos atuadores magnéticos.

\subsubsection{Resultados de Simulação do Controlador de Detumbling}

O controlador de detumbling foi projetado para o fooSAT-A1 nas órbitas ISS e SSO e os resultados de simulação são apresentados nessa seção.

Inicialmente foi avaliado o filtro de estimação da derivada de campo magnético terrestre, apresentado na Equação (7.15) em tempo discreto. 
Figura 56 - Diagrama do controlador de detumbling.

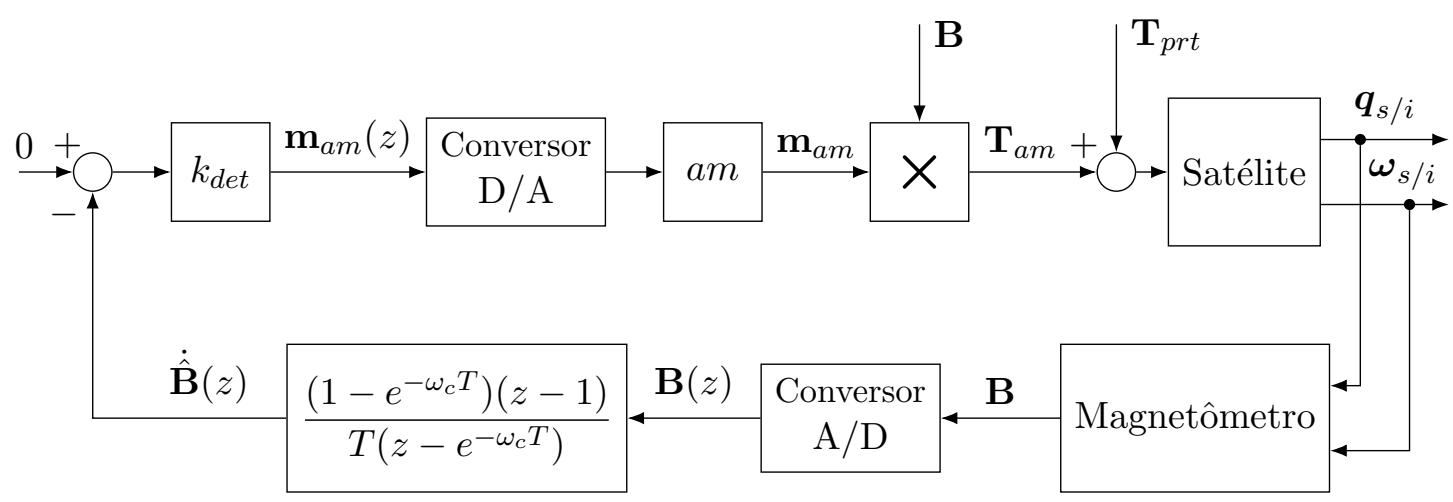

Fonte: Autor.

A frequência de corte do filtro, $\omega_{c}$, deve ser adotada de forma que a aproximação da derivada seja adequada dentro da faixa de interesse. A frequência de variação do campo magnético notada pelo satélite, $\mathbf{B}^{p}$, é proveniente, majoritariamente, da velocidade angular do veículo. Sendo assim, a região de interesse está entre a velocidade mínima e máxima do modo de detumbling, isto é, $\omega_{\min }=0,02 \mathrm{rad} / \mathrm{s}$ e $\omega_{\max }=1,2 \mathrm{rad} / \mathrm{s}$. Considerando $T=0,1 \mathrm{~s}$, conforme definido na Seção 7.2, a Figura 57 ilustra o diagrama de Bode do filtro para $\omega_{c}=1,2,5$ e 10 vezes $\omega_{\max }$, bem como a derivada continua, isto é, $s$, como referência das aproximações.

Figura 57 - Diagrama de Bode do filtro de estimação da derivada de campo magnético.
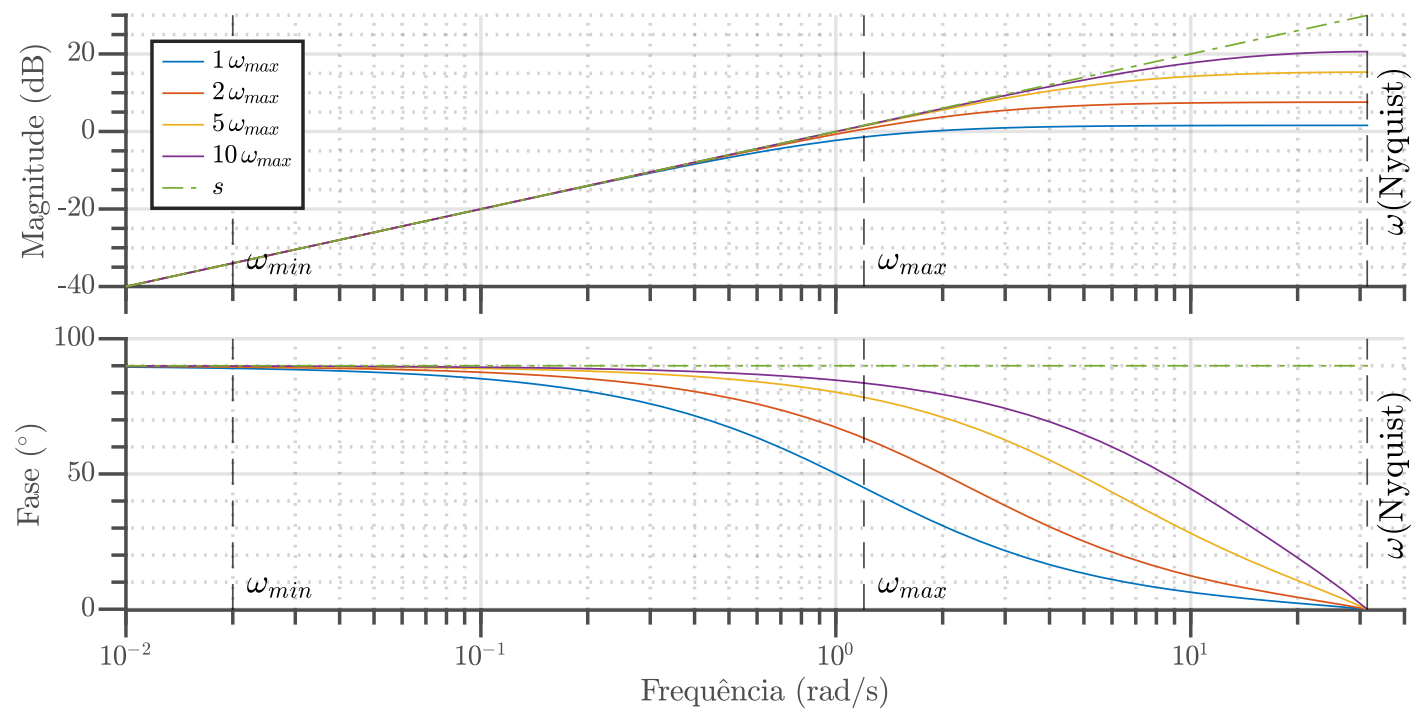

Fonte: Autor.

É possível notar no diagrama de magnitude que para $\omega_{c}=5 \omega_{\max }$ e $\omega_{c}=10 \omega_{\max }$, dentro da faixa de interesse, são imperceptíveis as diferenças das aproximações para a derivada contínua. Sendo que $\omega_{c}=10 \omega_{\max }$, conforme esperado, apresenta um ganho maior para frequências mais altas. 
Quando observado o diagrama de fase, é possível notar que em todos os casos há defasagem quando a frequência é máxima. As menores são $6,4^{\circ}$, referente à $\omega_{c}=10 \omega_{\text {max }}$, e $11,6^{\circ}$, referente à $\omega_{c}=5 \omega_{\max }$. Quando analisado na frequência de $0,4 \mathrm{rad} / \mathrm{s}$, outra frequência de interesse, tanto a defasagem de $\omega_{c}=5 \omega_{\max }$, quanto de $\omega_{c}=10 \omega_{\max }$ caem para $3^{\circ}$.

De fato, quanto maior a frequência de corte menor será a defasagem na frequência máxima, porém maior será o ganho em altas frequências. Ademais, por ser implementado em tempo discreto, outra fator relevante é a frequência em que o sistema se torna instável que, segundo o Teorema de Nyquist, ocorre quando for maior que a metade da frequência de amostragem, isto é, $\geq \pi / T$ [112]. Essa frequência está ilustrada na Figura 57 como $\omega$ (Nyquist) e tem o valor de $31,42 \mathrm{rad} / \mathrm{s}$.

Sendo assim, ponderando entre ganho em altas frequência, defasagem e distância da frequência de Nyquist, foi adotado $\omega_{c}=5 \omega_{\max }=6 \mathrm{rad} / \mathrm{s}$.

Os desempenhos do filtro quando a magnitude da velocidade angular do veículo é $0,02 \mathrm{rad} / \mathrm{s}, 0,4 \mathrm{rad} / \mathrm{s}$ e 1,2 rad/s nas órbitas ISS e SSO estão ilustrados na Figura 58. Para gerar o sinal de referência foi utilizado o bloco Derivative do Simulink, sem ruído de medição, que utiliza a função de transferência $s /(c s+1) \operatorname{com} c \rightarrow \infty$, para obter a derivada do sinal de entrada.

Conforme esperado, para velocidades angulares próximas da velocidade angular máxima (1,2 rad/s) o atraso é perceptível, enquanto para velocidades angulares próximas à mínima $(0,02 \mathrm{rad} / \mathrm{s})$ o ruído de medição é mais influente. A escolha de $\omega_{c}=5 \omega_{\max }$ foi considerada adequada, pois valores maiores de $\omega_{c}$ comprometeriam o desempenho em baixas velocidades, enquanto valores menores comprometeriam o desempenho em altas velocidades.

Após o filtro, foi avaliada a capacidade do controlador de detumbling em reduzir a velocidade angular do veículo. Aplicando a Equação (7.9) para o fooSAT-A1 na órbita ISS resultou em $k_{\text {det }}=2,18 \times 10^{-6}$ e na órbita SSO em $k_{\text {det }}=2,23 \times 10^{-6}$. A Figura 59 ilustra os resultados de simulação nas órbitas ISS e SSO para a condição inicial de $\boldsymbol{\omega}_{s / i}^{s}=1 / \sqrt{3}[0,4-0,40,4]^{\top} \mathrm{rad} / \mathrm{s}$, equivalente à $\omega=0,4 \mathrm{rad} / \mathrm{s}$.

O controlador de detumbling é capaz de reduzir a velocidade angular do satélite de 0,4 $\mathrm{rad} / \mathrm{s}$ para 0,02 rad/s em aproximadamente 1,6 e 0,9 órbita nas órbitas ISS e SSO, respectivamente, atingindo o requisito R1. Em alguns instantes é possível observar que a magnitude do momento magnético dos atuadores se aproxima de zero, como em $t=0,4$ órbitas em ISS e $t=0,3$ órbitas em SSO. Tal situação ocorre quando o vetor velocidade angular tende a ficar paralelo ao vetor campo magnético.

No mais, é possível notar que a inclinação da órbita tem forte influência no desempenho do controle de detumbling. Quanto maior a inclinação em relação ao equador magnético, que é o caso da SSO, maior a variação do campo e, portanto, maior a capacidade de 
Figura 58 - Desempenho do estimador da derivada do campo magnético terrestre. $\omega=0,02 \mathrm{rad} / \mathrm{s}$ (ISS).

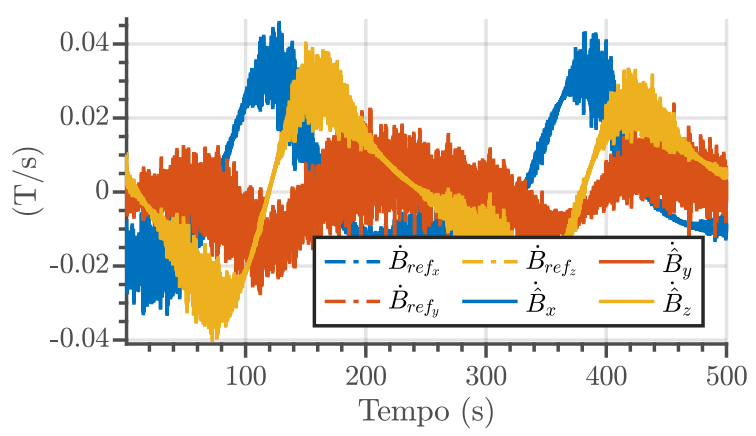
$\omega=0,4 \mathrm{rad} / \mathrm{s}(\mathrm{ISS})$.

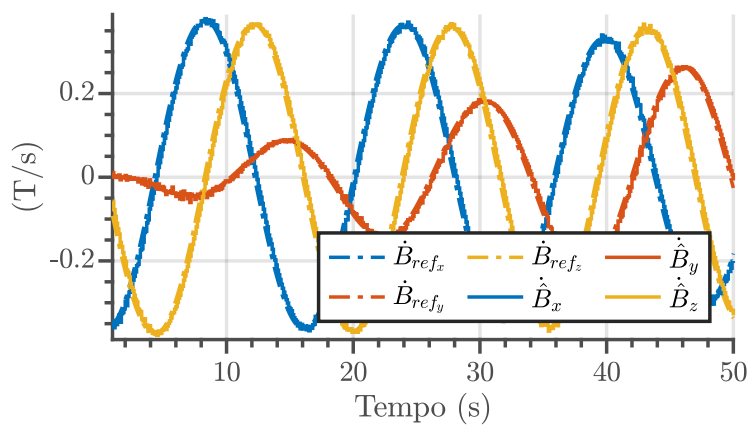

$\omega=1,2 \mathrm{rad} / \mathrm{s}$ (ISS).

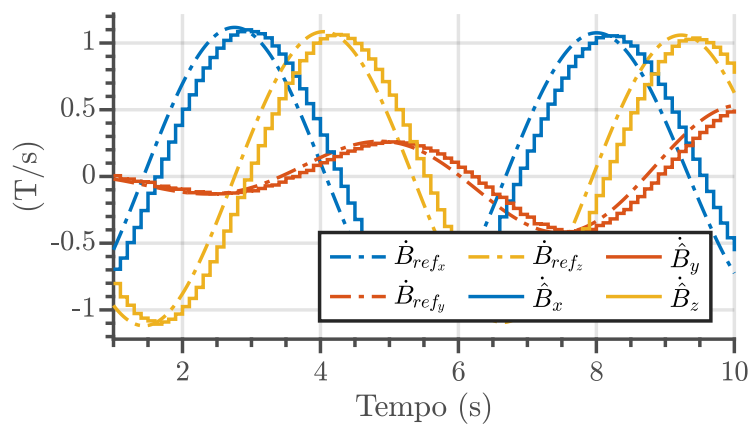
$\omega=0,02 \mathrm{rad} / \mathrm{s}(\mathrm{SSO})$.

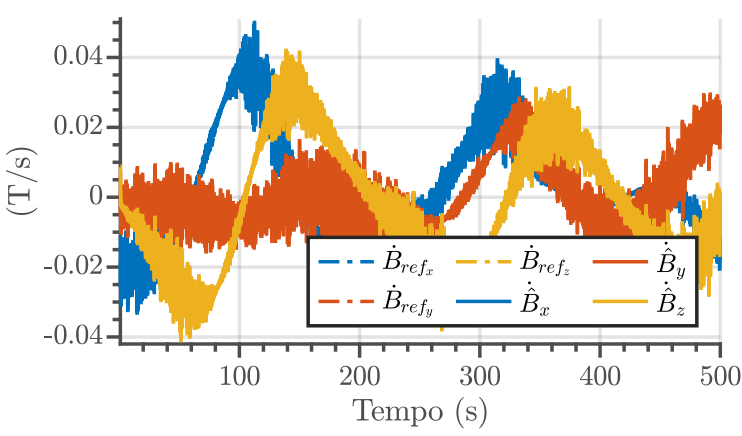

$\omega=0,4 \mathrm{rad} / \mathrm{s}(\mathrm{SSO})$.

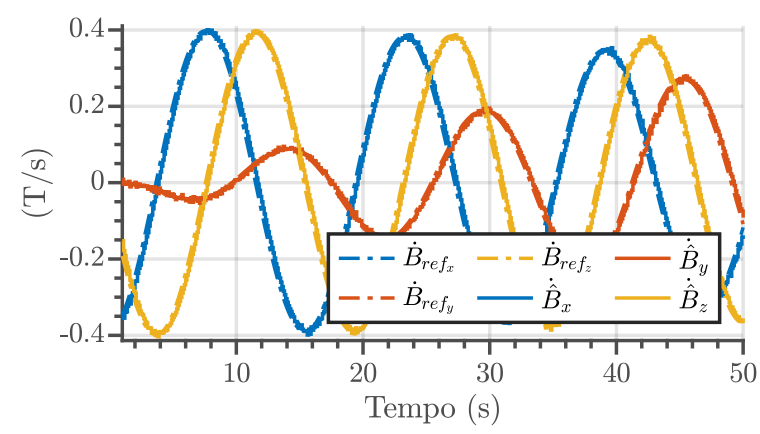

$\omega=1,2 \mathrm{rad} / \mathrm{s}(\mathrm{SSO})$.

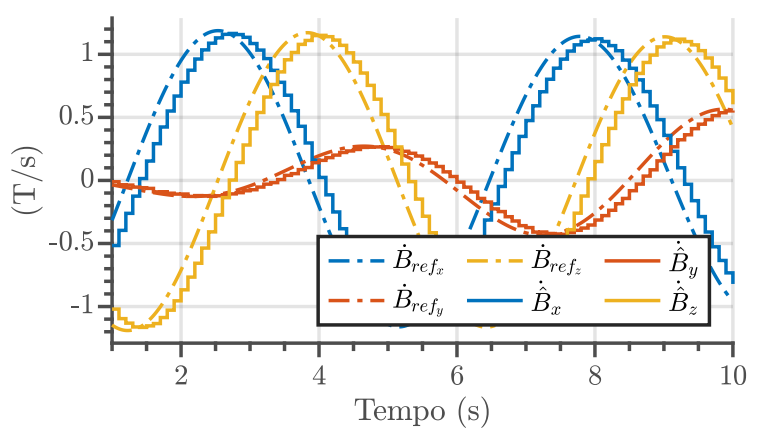

Fonte: Autor.

redução de velocidade.

Na sequência foi avaliada a capacidade do controlador para a condição inicial de $\boldsymbol{\omega}_{s / i}^{s}=$ $1 / \sqrt{3}[1,2-1,21,2]^{\top} \mathrm{rad} / \mathrm{s}$, equivalente à $\omega=1,2 \mathrm{rad} / \mathrm{s}$. Os resultados de simulação estão ilustrados na Figura 60.

Neste caso, o controlador de detumbling é capaz de reduzir a velocidade angular do satélite de 1,2 rad/s para 0,02 rad/s em aproximadamente 4,1 órbitas e 1,3 órbita nas órbitas ISS e SSO, respectivamente, atingindo o requisito R2. Quanto maior a magnitude da velocidade angular inicial, mais evidente é a influência da inclinação de cada órbita. Para a órbita ISS a redução de velocidade é acentuada até 1 órbita, entretanto, como é possível observar, passa a decair lentamente até atingir 0,02 rad/s. Isso se dá pela 
Figura 59 - Simulação do controlador de detumbling para velocidade angular inicial de $0,4 \mathrm{rad} / \mathrm{s}$.

Velocidade angular do satélite, $\boldsymbol{\omega}_{s / i}^{s}$ (ISS).

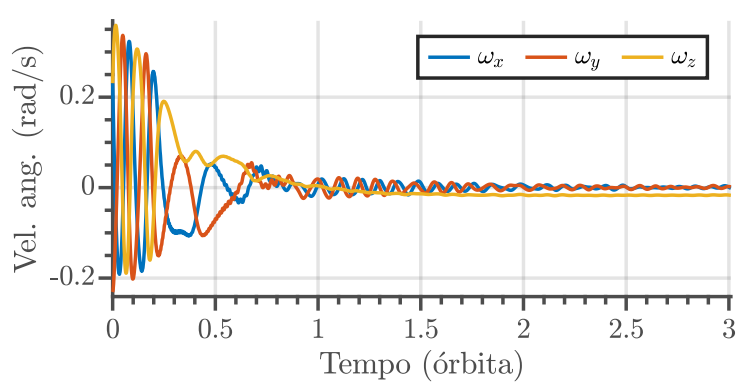

Norma da velocidade angular do satélite (ISS).

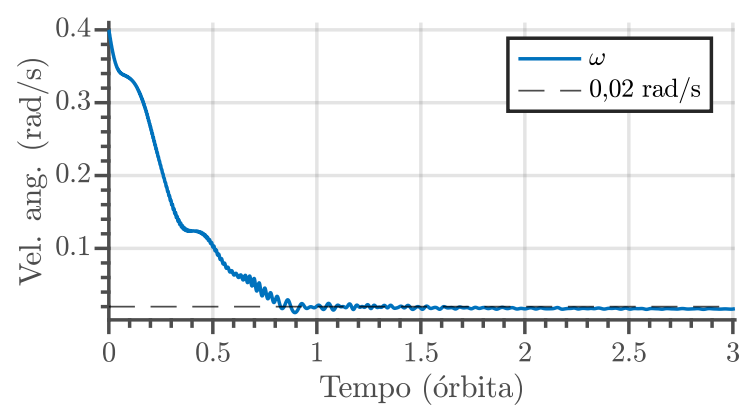

Momento do dipolo magnético, $\mathbf{m}_{a m}^{s}$ (ISS).

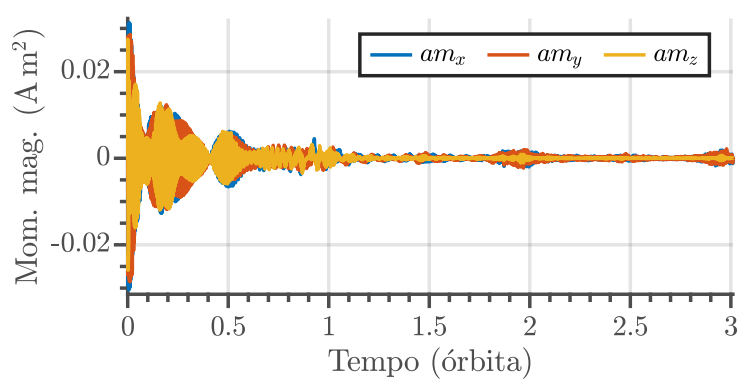

Velocidade angular do satélite, $\boldsymbol{\omega}_{s / i}^{s}(\mathrm{SSO})$.

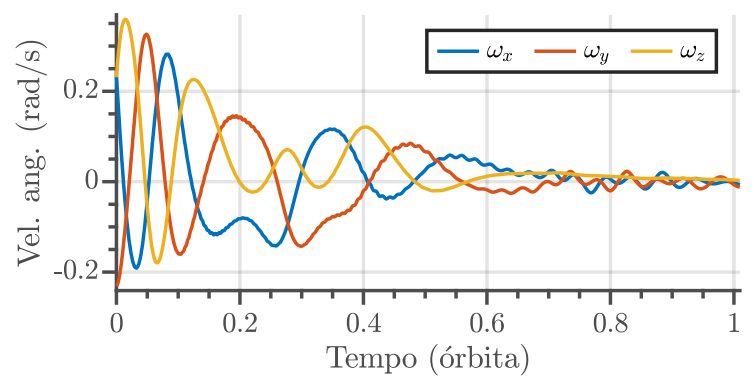

Norma da velocidade angular do satélite (SSO).

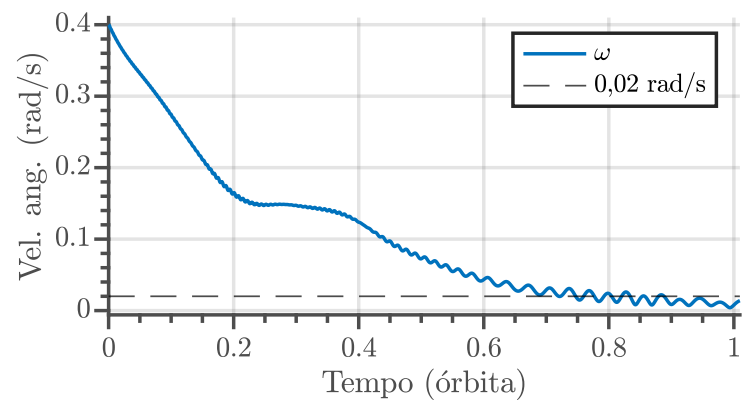

Momento do dipolo magnético, $\mathbf{m}_{a m}^{s}$ (SSO).

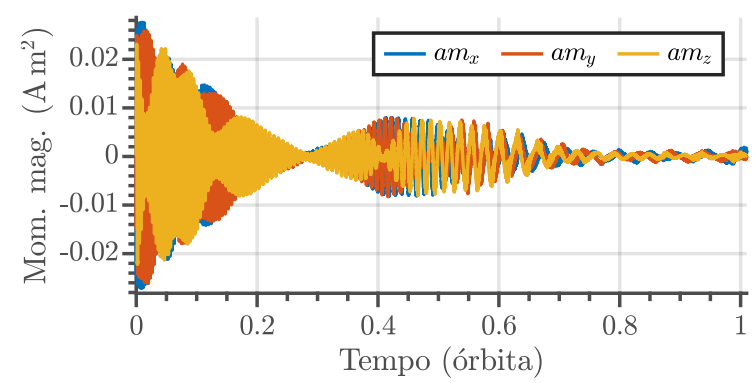

Fonte: Autor.

combinação de dois fatores: (i) em 1 órbita a velocidade angular do veículo está reduzida, na ordem de 0,04 rad/s, mas majoritariamente na direção do eixo de maior inercia, $\mathbf{z}^{p}$; e (ii) a variação do campo magnético terrestre é menor para órbitas próximas do equador terrestre.

\subsubsection{Resultados de Comparação com Dados de Voo}

Um dos modos do ADCS do PicSat é o detumbling. Para acioná-lo, a equipe do LESIA enviava um comando de início, bem como o tempo de duração que o controlador deveria atuar. A Figura 61 ilustra a norma da velocidade angular do PicSat durante todo o tempo de voo em que houve tentativas de acionamento, o que permite visualizar com mais facilidade as situações de redução da energia cinética do satélite. Os instantes em que foi solicitado o início do detumbling estão ilustrados com uma barra vertical tracejada, e o 
Figura 60 - Simulação do controlador de detumbling para velocidade angular inicial de $1,2 \mathrm{rad} / \mathrm{s}$.

Velocidade angular do satélite, $\boldsymbol{\omega}_{s / i}^{s}$ (ISS).

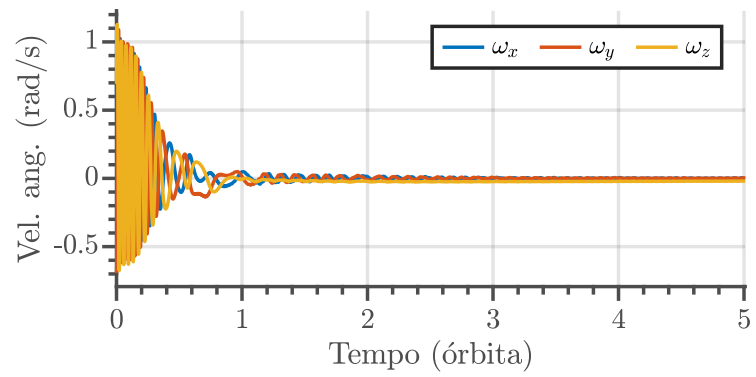

Norma da velocidade angular do satélite (ISS).

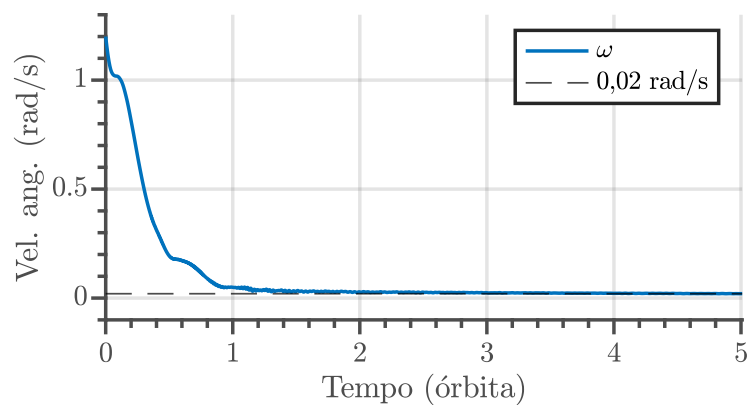

Momento do dipolo magnético, $\mathbf{m}_{a m}^{s}$ (ISS).

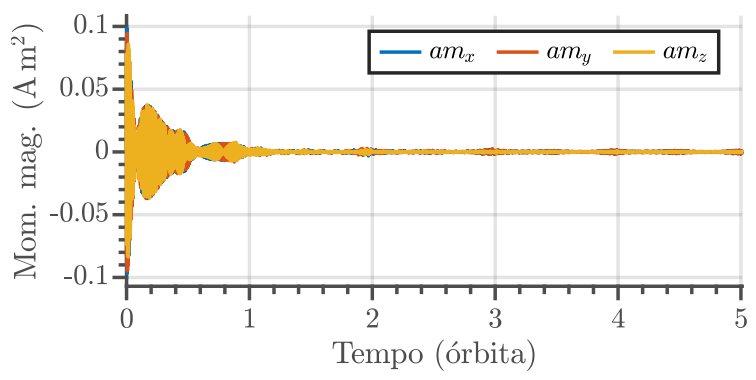

Fonte: Autor.
Velocidade angular do satélite, $\boldsymbol{\omega}_{s / i}^{s}(\mathrm{SSO})$.

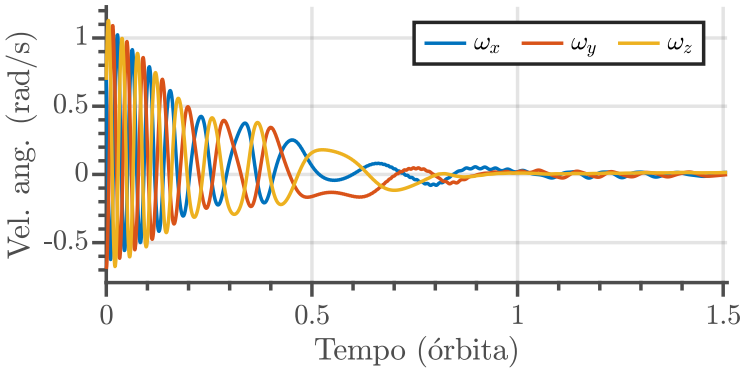

Norma da velocidade angular do satélite (SSO).

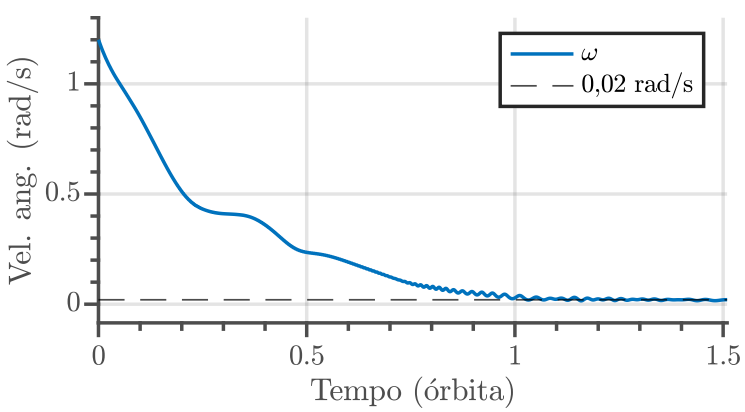

Momento do dipolo magnético, $\mathbf{m}_{a m}^{s}$ (SSO).

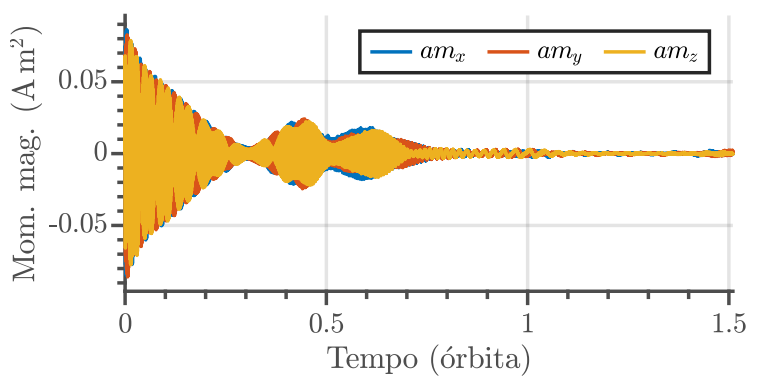

fim desses comandos estão ilustrados com uma barra vertical pontilhada de cor respectiva.

De todos os instantes de solicitação de detumbling, em apenas três é possível notar efetiva redução de velocidade angular. Tais situações estão destacadas na figura com as respectivas indicações. Nos outros instantes, os motivos pelos quais o controlador aparenta não funcionar são desconhecidos da equipe do PicSat. Algumas hipóteses podem ser levantadas: (i) a velocidade angular nesses instantes está próxima da velocidade mínima ao ponto de não ser visível a diferença; (ii) existe uma condição no algorítimo embarcado que não aciona o detumbling quando a velocidade angular está abaixo de certo valor; (iii) ocorreu um problema de comunicação e o satélite não recebeu tal comando. Entretanto, a ausência de informações disponibilizadas pelo ADCS não contribuiu para uma análise sobre essas e outras possíveis hipóteses. 
Figura 61 - Norma da velocidade angular do PicSat durante o voo.

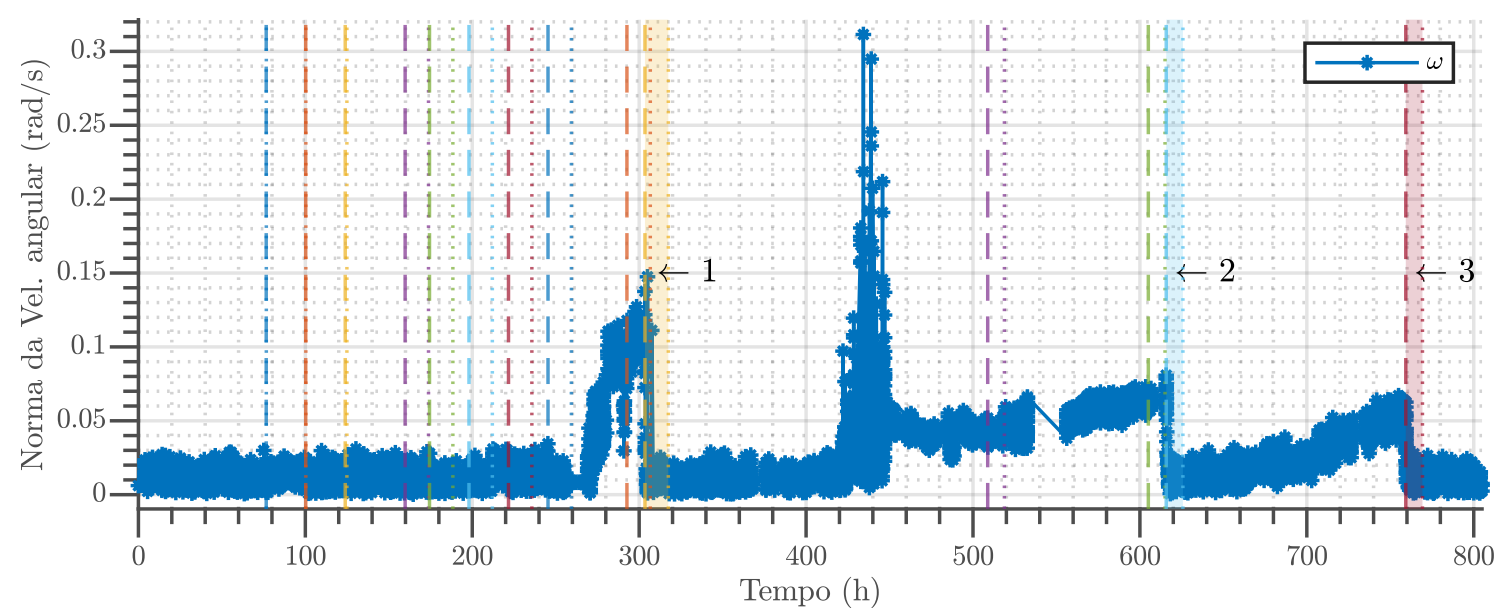

Fonte: Autor.

Outra informação ausente é a estrutura do controlador de detumbling utilizada pelo ADCS do PicSat. Conforme mencionado no início da Seção 7.3, o algorítimo B-dot é amplamente utilizado em CubeSats. Entretanto, pode ser implementando com algumas variações na estrutura: realimentação de velocidade angular ao invés de campo magnético, outra composição de filtro, etc [108]. Menos usual, mas também possível, é realizar o detumbling com um controlador Proporcional Integral, técnicas de controle moderno e não linear [109,113]. Também não estão disponíveis os dados dos atuadores durante os trechos identificados. Ademais, conforme também mencionado, os dados de velocidade angular possuem uma taxa de amostragem baixa $(0,1 \mathrm{~Hz})$, quando comparado à dinâmica do satélite, e diversas ausências entre o início e fim de cada trecho.

Por conta dos fatores supracitados, a validação do controlador de detumbling foi comprometida. Considerando a estrutura apresentada na Seção 7.3, foi proposto estimar o ganho $k_{\text {det }}$ e condições de velocidade inicial, de forma similar à validação da dinâmica realizada na Seção 6.2. Uma vez mais, o procedimento foi realizado por meio dos softwares MATLAB e Simulink, utilizando um método de mínimos quadrados não linear (Isqnonlin). O segundo trecho foi utilizado para estimar e os demais trechos foram utilizados para validar. Neste caso, a função custo é expressa por

$$
J\left(\boldsymbol{\omega}_{0_{i}}, k_{\text {det }}\right)=\sum_{k=1}^{N}\left(\boldsymbol{\omega}_{\text {real }}(k)-\boldsymbol{\omega}_{\text {sim }}(k)\right)^{2},
$$

na qual, $k$ é o instante dentro do trecho e $N$ é o número de instantes disponíveis.

Os resultados da estimação estão ilustrados na Figura 62 e os resultados da validação estão ilustrados na Figura 63.

Quando comparadas as normas das velocidades angulares, o controlador proposto com o ganho estimado apresenta resultado satisfatório, indicando que a redução da energia cinética é atingida de forma similar. Entretanto, quando comparadas as velocidades 
Figura 62 - Estimação do ganho do detumbling.

Dados reais e simulação.

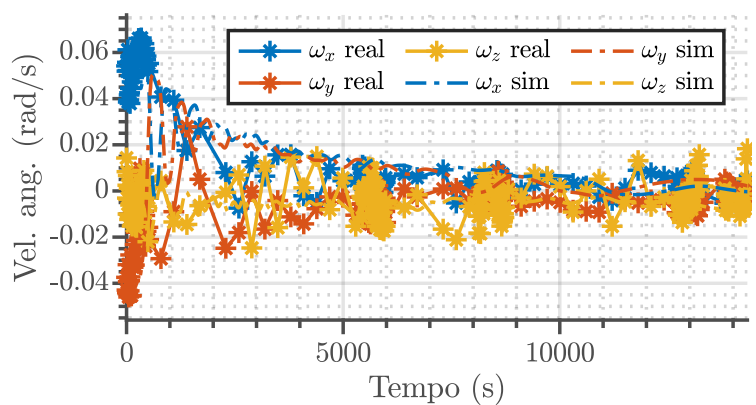

Resíduos.

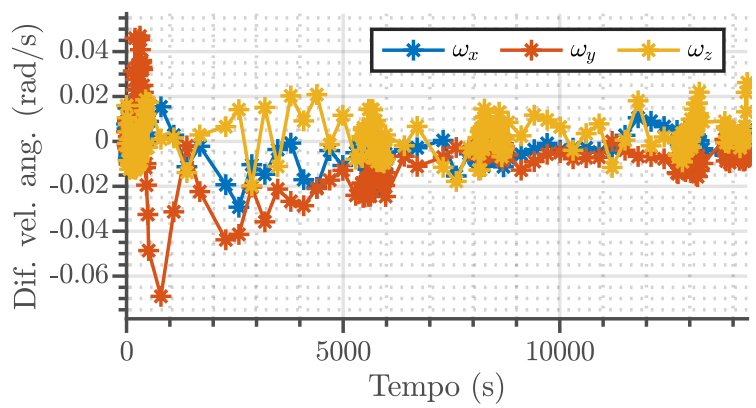

Norma dos dados reais e simulação.

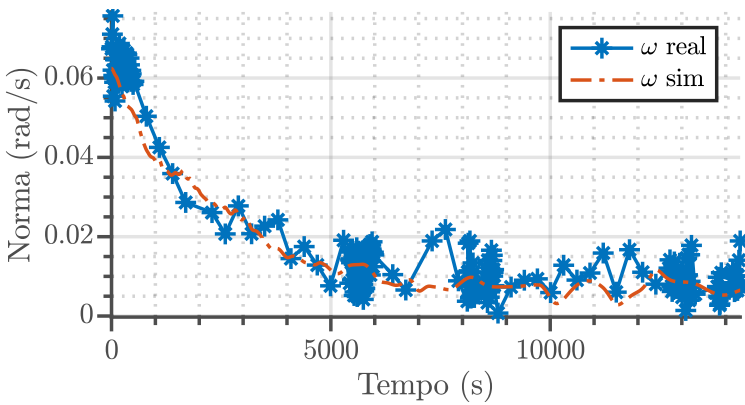

Resíduos da norma.

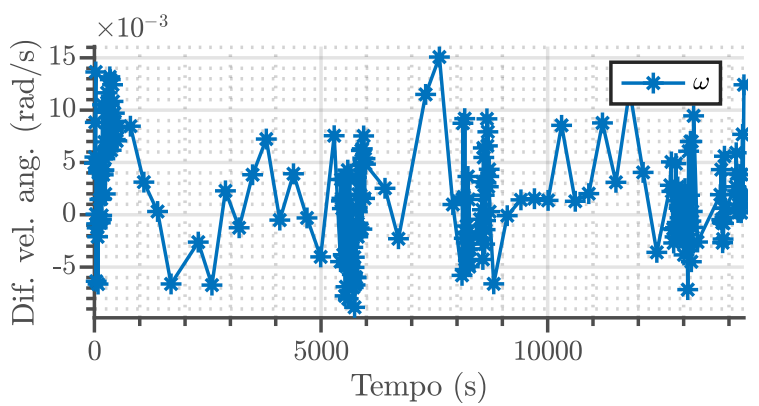

Fonte: Autor.

de forma independente, os resultados são insatisfatórios, sugerindo que a dinâmica do controlador utilizado no PicSat é diferente da dinâmica proposta.

\subsection{Apontamento}

A escolha do controlador leva em conta a complexidade, recurso computacional, gasto energético, confiabilidade e robustez da técnica de controle. Neste trabalho, propõe-se um Regulador Quadrático Linear, em inglês Linear-Quadratic Regulator (LQR), utilizando-se três rodas de reação.

\subsubsection{Regulador Quadrático Linear}

Um sistema dinâmico linear e invariante no tempo é expresso, em espaço de estados, por

$$
\begin{aligned}
& \dot{\mathbf{x}}=[\mathbf{A}] \mathbf{x}+[\mathbf{B}] \mathbf{u} \\
& \mathbf{y}=[\mathbf{C}] \mathbf{x}+[\mathbf{D}] \mathbf{u}
\end{aligned}
$$

Em controle moderno, isto é, por realimentação de estados, o vetor de controle pode ser expresso por

$$
\mathbf{u}=-[\mathbf{K}] \mathbf{x}
$$

na qual $[\mathbf{K}]$ é a matriz de ganho do controlador. 
Figura 63 - Validação do ganho do detumbling.

Dados reais e simulação (1).
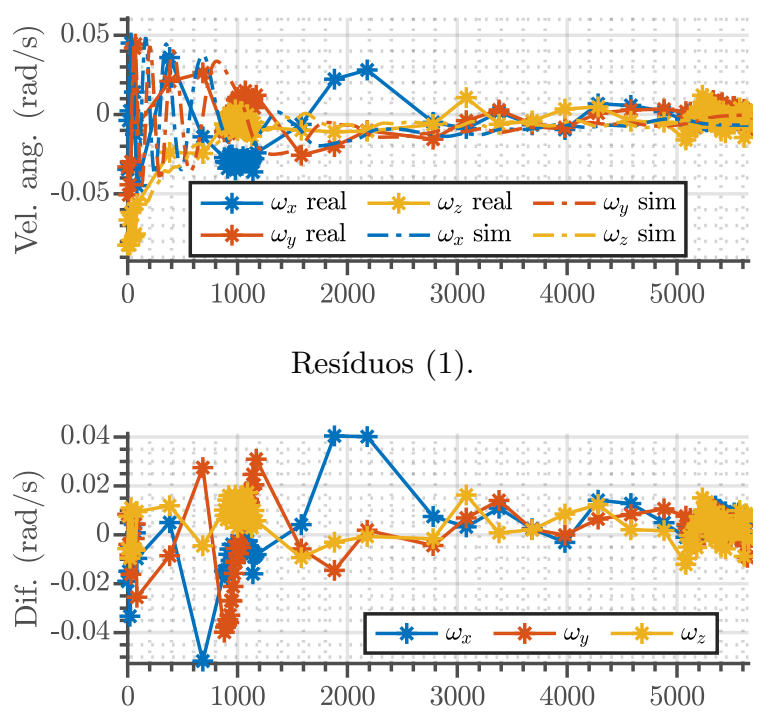

Dados reais e simulação (2).

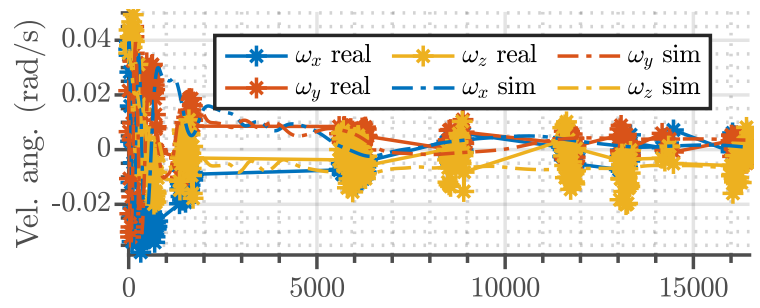

Resíduos (2).

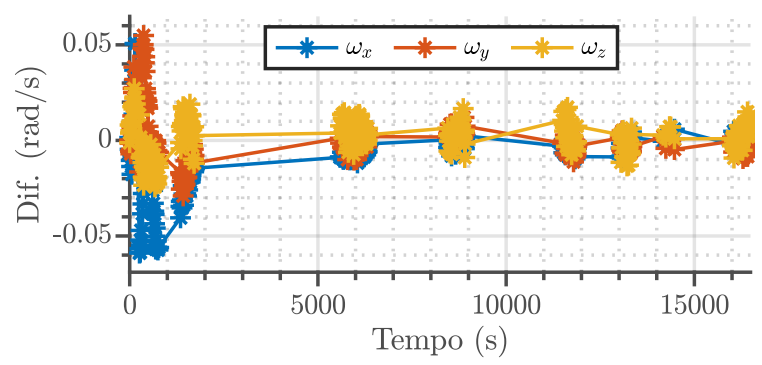

Norma dos dados reais e simulação (1).
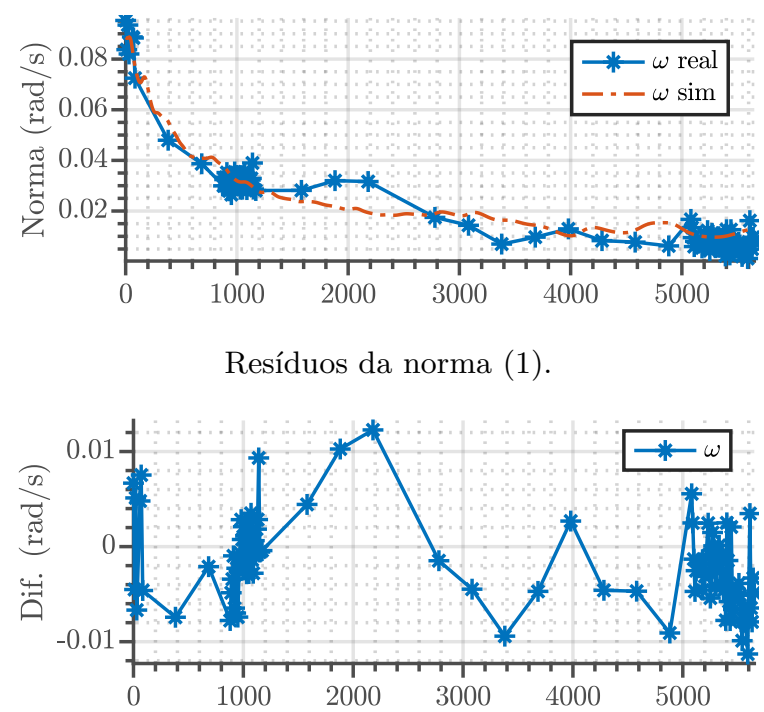

Norma dos dados reais e simulação (2).

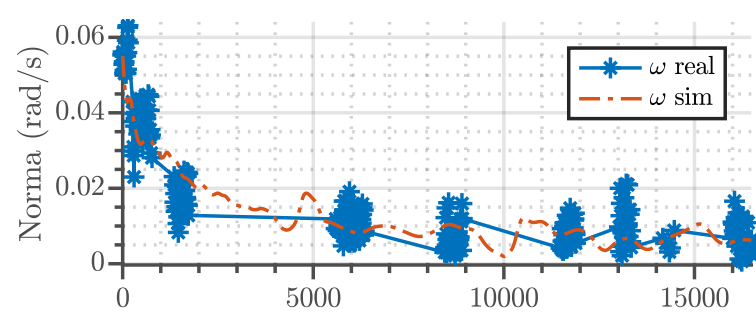

Resíduos da norma (2).

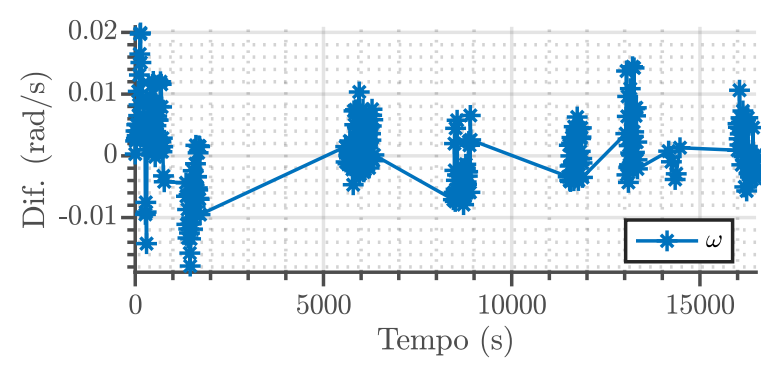

Fonte: Autor.

O LQR é uma técnica de controle ótimo, cujo objetivo é determinar a matriz de ganho $[\mathbf{K}]$ que minimize a função custo quadrático

$$
J=\int_{0}^{\infty}\left(\mathbf{x}^{\top}[\mathbf{Q}] \mathbf{x}+\mathbf{u}^{\top}[\mathbf{R}] \mathbf{u}\right) d t
$$

na qual $[\mathbf{Q}]$ e $[\mathbf{R}]$ são matrizes simétricas, positivas (semi)definidas que ponderam, respectivamente, os desvios dos estados, $\mathbf{x}$, e dos sinais de controle, $\mathbf{u}$.

[K] será a matriz de ganho ótimo quando

$$
[\mathbf{K}]=[\mathbf{R}]^{-1}[\mathbf{B}]^{\top}[\mathbf{P}]
$$


na qual $[\mathbf{P}]$ é uma matriz simétrica, positiva (semi)definida que, por sua vez, pode ser obtida ao se resolver a Equação Algébrica de Riccati [114], dada por

$$
[\mathbf{A}]^{\top}[\mathbf{P}]+[\mathbf{P}][\mathbf{A}]-[\mathbf{P}][\mathbf{B}][\mathbf{R}]^{-1}[\mathbf{B}]^{\top}[\mathbf{P}]+[\mathbf{Q}]=0
$$

\subsubsection{Modelo Linear}

Como se trata de uma técnica de controle linear, faz-se necessário linearizar o modelo cinemático e dinâmico do satélite. Uma alternativa é utilizar a expansão em séries de Taylor.

Seja uma função qualquer $f(x)$, na qual $\bar{x}$ é o ponto de operação (ou linearização) e $\delta x=x-\bar{x}$ é uma pequena variação em torno do ponto de operação, desprezando os termos de maior ordem, a expansão em série de Taylor de $f(x)$ é dada por

$$
f(x) \approx f(\bar{x})+\left.\frac{\partial f(x)}{\partial x}\right|_{x=\bar{x}} \delta x .
$$

Para as equações do satélite, a linearização é dada em torno de $\overline{\boldsymbol{q}}$ e $\overline{\boldsymbol{\omega}}$, referentes à atitude e velocidade angular do veículo. Sendo assim, utilizando a álgebra de quatérnios, pode-se dizer que a variação de atitude, $\delta \boldsymbol{q}$, é dada por

$$
\delta \boldsymbol{q}=\overline{\boldsymbol{q}}^{-1} \boldsymbol{q}_{p / i}
$$

sendo que, para pequenas variações de ângulo, $\delta q_{0} \approx 1$, portanto $\delta \boldsymbol{q} \approx[1, \delta \mathbf{q}]^{\top}[72]$.

E a variação de velocidade angular, $\delta \boldsymbol{\omega}$, é dada por

$$
\delta \boldsymbol{\omega}=\boldsymbol{\omega}_{p / i}^{p}-\overline{\boldsymbol{\omega}}
$$

O modelo linear da cinemática do veículo pode ser expresso por [79]

$$
\frac{\mathrm{d}}{\mathrm{d} t} \boldsymbol{q} \approx\left[\begin{array}{c}
0 \\
-\frac{1}{2}[\mathbf{S}(\overline{\boldsymbol{\omega}})] \delta \mathbf{q}
\end{array}\right]+\frac{1}{2}[\mathbf{1}]_{3 \times 3} \delta \boldsymbol{\omega}
$$

na qual $[1]_{3 \times 3}$ é uma matriz identidade de dimensão $3 \times 3$ e $[\mathbf{S}(\cdot)]$ é uma matriz antissimétrica equivalente ao produto vetorial, isto é, para um vetor qualquer a,

$$
[\mathbf{S}(\mathbf{a})] \triangleq\left[\begin{array}{ccc}
0 & -a_{3} & a_{2} \\
a_{3} & 0 & -a_{1} \\
-a_{2} & a_{1} & 0
\end{array}\right]
$$

Para a equação dinâmica considera-se que apenas as rodas de reação serão utilizadas no controle de apontamento e, para um curto intervalo de tempo, os torques em virtude 
das perturbações, $\mathbf{T}_{p r t}^{p}$ e $\left(\boldsymbol{\omega}_{p / i}^{p} \times \mathbf{H}_{r r}^{p}\right)$, são desprezíveis quando comparados ao torque dos atuadores $^{\dagger}$. Sendo assim, aplica-se a expansão em série de Taylor na Equação (4.15),

$$
\dot{\boldsymbol{\omega}} \approx\left(\left[\mathbf{I}_{v}\right]^{p}\right)^{-1}\left[\left[\mathbf{S}\left(\left[\mathbf{I}_{v}\right]^{p} \overline{\boldsymbol{\omega}}\right)\right]-[\mathbf{S}(\overline{\boldsymbol{\omega}})]\left[\mathbf{I}_{v}\right]^{p}\right] \delta \boldsymbol{\omega}-\left(\left[\mathbf{I}_{v}\right]^{p}\right)^{-1} \dot{\mathbf{H}}_{r r}
$$

Ademais, a dinâmica das rodas de reação também pode ser desprezada por ser de 10 a 15 vezes mais rápida que a dinâmica do veículo [74].

Para o vetor de estados $\mathbf{x}=[\delta \mathbf{q}, \delta \boldsymbol{\omega}]^{\top}$ e vetor de entrada $\mathbf{u}=\left[\dot{\mathbf{H}}_{r r}\right]$, as matrizes do modelo linear do veículo, em espaço de estados, são dadas por

$$
\begin{gathered}
{[\mathbf{A}]=\left[\begin{array}{cc}
-\frac{1}{2}[\mathbf{S}(\overline{\boldsymbol{\omega}})] & \frac{1}{2}[\mathbf{1}]_{3 \times 3} \\
{[\mathbf{0}]_{3 \times 3}} & \left(\left[\mathbf{I}_{v}\right]^{p}\right)^{-1}\left[\left[\mathbf{S}\left(\left[\mathbf{I}_{v}\right]^{p} \overline{\boldsymbol{\omega}}\right)\right]-[\mathbf{S}(\overline{\boldsymbol{\omega}})]\left[\mathbf{I}_{v}\right]^{p}\right]
\end{array}\right],} \\
{[\mathbf{B}]=\left[\begin{array}{c}
{[\mathbf{0}]_{3 \times 3}} \\
-\left(\left[\mathbf{I}_{v}\right]^{p}\right)^{-1}
\end{array}\right], \quad[\mathbf{C}]=\left[[\mathbf{1}]_{6 \times 6}\right] \quad \text { e } \quad[\mathbf{D}]=\left[[\mathbf{0}]_{6 \times 3}\right],}
\end{gathered}
$$

na qual [0] é uma matriz nula.

\subsubsection{Controlabilidade, Observabilidade e Estabilidade}

Para que seja possível determinar o ganho do controlador LQR, primeiramente se faz necessário que o sistema dinâmico linear seja completamente controlável. Isto é, que exista um sinal de controle $\mathbf{u}$ capaz de levar qualquer um dos estados de uma condição inicial desejada para uma condição final desejada. De forma similar, para que a realimentação seja possível, $\mathbf{u}=-[\mathbf{K}] \mathbf{x}$, faz-se necessário que as variáveis de estados sejam observáveis. Isto é, a partir da entrada u e saída y seja possível obter todos os estados do sistema ${ }^{\ddagger}$ [115].

Para o sistema apresentado na Equação (7.17) de ordem $n$, a controlabilidade e a observabilidade podem ser determinadas se, respectivamente, as matrizes

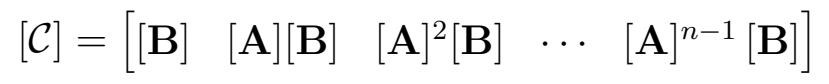

e

$$
[\mathcal{O}]=\left[\begin{array}{lllll}
{[\mathbf{C}]} & {[\mathbf{C}][\mathbf{A}]} & {[\mathbf{C}][\mathbf{A}]^{2}} & \cdots & {[\mathbf{C}][\mathbf{A}]^{n-1}}
\end{array}\right]^{\top}
$$

forem de posto também $n$.

Para sistemas lineares invariantes no tempo, a estabilidade pode ser definida no sentido de entrada limitada saída limitada, do inglês bounded input bounded output (BIBO). Isto é,

\footnotetext{
†Utilizando o fooSAT-A1 como exemplo, a magnitude do torque devido à roda de reação, $\dot{\mathbf{H}}_{r r}$, é da ordem de $10^{-3} \mathrm{Nm}$, enquanto a magnitude dos torques em razão do efeito giroscópico, $\left(\boldsymbol{\omega}_{p / i}^{p} \times \mathbf{H}_{r r}^{p}\right), \mathrm{e}$ perturbação de atitude, $\mathbf{T}_{p r t}^{p}$, são, respectivamente, da ordem de $10^{-5} \mathrm{~N} \mathrm{~m} \mathrm{e} 10^{-7} \mathrm{~N} \mathrm{~m}$.

†Essa informação é relevante para o desenvolvimento do ADS, no qual, eventualmente, nem todos os estados podem ser medidos, mas estimados.
} 
para qualquer sinal de entrada $\mathbf{u}$ de amplitude finita, uma saída y de amplitude também finita seja produzida [116]. Isto ocorre quando todos os polos do sistema estão localizados no semiplano esquerdo do plano $s$. No caso da representação em espaço de estados, pode-se avaliar se os autovalores da matriz $[\mathbf{A}]$, em malha aberta, ou de $([\mathbf{A}]-[\mathbf{B}][\mathbf{K}])$, em malha fechada, tem parte real negativa.

\subsubsection{Projeto do Controlador}

O objetivo do regulador é levar os estados do sistema, $\left(\mathbf{q}_{p / i}\right.$ e $\left.\boldsymbol{\omega}_{p / i}^{p}\right)$, para a origem. Porém, o vetor de estados do modelo linear, apresentado na Equação (7.28), é composto pelo desvio dos estados. Tal problema é similar ao chamado de seguidor de trajetória, cujo objetivo é levar o erro dos estados para a origem. De qualquer forma, conforme apresentado por Lewis, Vrabie e Syrmos[117], a dinâmica do erro, ou do desvio, é equivalente à dinâmica do sistema, isto é, $\delta \dot{\mathbf{x}}=[\mathbf{A}] \delta \mathbf{x}+[\mathbf{B}] \delta \mathbf{u}$. Sendo assim, ainda que o estado seja formado pelos desvios, pode-se utilizar a forma apresentada na Subseção 7.4.1 para determinar o ganho $[\mathbf{K}]$.

Para cumprir o requisito R3, o satélite deve permanecer orientado para uma posição fixa em relação ao eixo inercial. Portanto, as equações são linearizadas em torno de $\overline{\boldsymbol{q}}_{a}=[$ cte $]$ e $\overline{\boldsymbol{\omega}}_{a}=\left[\begin{array}{lll}0 & 0 & 0\end{array}\right]^{\top} \mathrm{rad} / \mathrm{s}$. Os desvios que formam o vetor de estados são dados por

$$
\delta \mathbf{q}_{a}=\mathbf{q}_{b / i}-\overline{\mathbf{q}}_{a} \quad \text { e } \quad \delta \boldsymbol{\omega}_{a}=\boldsymbol{\omega}_{b / i}^{p}-\left[\begin{array}{lll}
0 & 0 & 0
\end{array}\right]^{\top}
$$

por sua vez, o vetor de estados é dado por

$$
\delta \mathbf{x}_{a}=\left[\begin{array}{c}
\mathbf{q}_{b / i}-\overline{\mathbf{q}}_{a} \\
\boldsymbol{\omega}_{b / i}^{p}
\end{array}\right]
$$

Para cumprir o requisito R4, o RCS deve acompanhar o ROS. Portanto, as equações são linearizadas em torno de $\overline{\boldsymbol{q}}_{b}=\boldsymbol{q}_{o / i}$ e $\overline{\boldsymbol{\omega}}_{b}=[\mathbf{q}]_{p / s}\left[\boldsymbol{\omega}_{o / i}^{s} \boldsymbol{\omega}_{o / i}^{s} \boldsymbol{\omega}_{o / i}^{s}\right]^{\top}$. Neste caso, os desvios que formam o vetor de estados são dados por

$$
\delta \mathbf{q}_{b}=\mathbf{q}_{b / i}-\mathbf{q}_{o / i} \quad \text { e } \delta \boldsymbol{\omega}_{b}=\boldsymbol{\omega}_{b / i}^{p}-\boldsymbol{\omega}_{o / i}^{p},
$$

e o vetor de estados é dado por

$$
\delta \mathbf{x}_{b}=\left[\begin{array}{c}
\mathbf{q}_{b / i}-\mathbf{q}_{o / i} \\
\boldsymbol{\omega}_{b / i}^{p}-\boldsymbol{\omega}_{o / i}^{p}
\end{array}\right]
$$

As matrizes de ganho do LQR, $[\mathbf{Q}]$ e $[\mathbf{R}]$, podem ser determinadas por diferentes métodos. Um dos métodos é a Regra de Bryson [116] que consiste em definir as matrizes $[\mathbf{Q}]$ e $[\mathbf{R}]$ como diagonais principais, ponderando o valor máximo que os estados e as entradas podem alcançar, isto é,

$$
[\mathbf{Q}]=\rho_{Q} \operatorname{diag}\left[\frac{1}{x_{1_{\max }}^{2}}, \ldots, \frac{1}{x_{n_{\max }}^{2}}\right] \quad \text { e }[\mathbf{R}]=\rho_{R} \operatorname{diag}\left[\frac{1}{u_{1_{\max }^{2}}^{2}}, \ldots, \frac{1}{u_{n_{\max }}^{2}}\right],
$$


na qual $\rho_{Q}$ e $\rho_{R}$ são coeficientes de ponderação, inicialmente unitários.

Conforme ressalta Hespanha[118], esse método é especialmente útil quando há elevada diferença de magnitude entre os elementos do vetor de estado e/ou vetor de controle.

Utilizando o fooSAT-A1 como referência, os estados $x_{1}, x_{2}$ e $x_{3}$ são a parte vetorial do quatérnio, portanto, estando o quatérnio restrito à condição de ser unitário, o valor máximo desses termos é 1 . Os estados $x_{4}, x_{5}$ e $x_{6}$ são formados pela velocidade angular do satélite cujo valores máximos esperados, para uma manobra de $180^{\circ} \mathrm{em} 100 \mathrm{~s}$ partindo do repouso, são de aproximadamente $0,06 \mathrm{rad} / \mathrm{s}$. E, por fim, as entradas $u_{1}, u_{2}$ e $u_{3}$ são formadas pelo torque das rodas de reação e têm valor máximo de $5,7 \times 10^{-3} \mathrm{~N} \mathrm{~m}$. Sendo assim, dada a diferença de magnitude dos estados e dos sinais de controle, esse método será utilizado como forma de se obter as matrizes $[\mathbf{Q}]$ e $[\mathbf{R}]$ iniciais.

\subsubsection{Controle das Rodas de Reação}

A cada instante de tempo, a lei de controle do LQR (Eq. (7.18)) irá determinar o valor do sinal de controle, u. E, conforme apresentado na Subseção 7.4.1.1, o sinal de controle é composto pelo torque das rodas de reação, $\dot{\mathbf{H}}_{r r}$. Portanto, se faz necessário determinar um controlador para as rodas de reação capaz de fornecer tal torque, dentro das restrições físicas do motor.

Rememorando a Subseção 4.1.2.1.2, o torque do motor em relação à variação da velocidade angular é dado por

$$
T_{m}=I_{r r} \dot{\omega}_{m}
$$

Aplicando a transformada de Laplace na Equação (7.36) e isolando a velocidade angular do motor, resulta em

$$
\Omega_{m}(s)=\frac{1}{I_{r r} s} T_{m}(s)
$$

Sendo assim, é possível projetar um controle de velocidade para a roda de reação, no qual o sinal de referência de torque proveniente do LQR é transformado em sinal de referência de velocidade angular por meio da Equação (7.37).

A função de transferência da velocidade angular em relação à tensão aplicada no motor pode ser obtida aplicando a transformada de Laplace nas Equações (4.7) e (4.8), resultando, respectivamente, em

$$
L_{a} s I_{a}(s)+R_{a} I_{a}(s)=E_{a}(s)-k_{e} \Omega_{m}(s)
$$

$\mathrm{e}$

$$
I_{r r} s \Omega_{m}(s)=k_{t} I_{a}(s)-b \Omega_{m}
$$


Isolando $I_{a}(s)$ na Equação (7.39), substituindo na Equação (7.38) e rearranjando os termos

$$
\frac{\Omega_{m}(s)}{E_{a}(s)}=\frac{k_{t}}{s^{2} I_{r r} L_{a}+s\left(I_{r r} R_{a}+b L_{a}\right)+\left(b R_{a}+k_{e} k_{t}\right)} .
$$

Quando $I_{r r} L_{a}, b L_{a}$ e $b R_{a}$ são muito menores que $I_{r r} R_{a}$ e $k_{t} k_{e}$, (como é o caso da roda de reação da Tabela 3), a Equação (7.40) pode ser simplificada para

$$
\frac{\Omega_{m}(s)}{E_{a}(s)}=\frac{k_{e}^{-1}}{\left(\frac{I_{r r} R_{a}}{k_{e} k_{t}}\right) s+1} .
$$

Trata-se de uma função de transferência de primeira ordem cujo ganho, $k_{m}$, e constante de tempo, $\tau_{m}$, são dados por

$$
k_{m}=\frac{1}{k_{e}} \quad \text { e } \quad \tau_{m}=\frac{I_{r r} R_{a}}{k_{e} k_{t}} .
$$

Por conta do termo 1/s na Equação (7.37), sinais de referência de torque do tipo impulso se tornarão sinais de referência de velocidade do tipo degrau, enquanto sinais do tipo degrau se tornarão sinais do tipo rampa. A função de transferência de velocidade do motor em malha fechada é um sistema do tipo 0, isto é, não possui polos na origem. Portanto, apresentará erro constante para sinais de referência do tipo degrau e erro tendendo ao infinito para sinais de referência do tipo rampa. Sendo assim, para cumprir os requisitos $\mathrm{R} 7$ e R8, é proposto um controlador de velocidade da roda de reação do tipo PI, para que o erro em regime para entrada do tipo degrau seja nulo e o erro em regime para entrada do tipo rampa seja constante. A função de transferência do controlador PI, no domínio $s$, é dada por

$$
C(s)=k_{p}+\frac{k_{i}}{s}=\frac{k_{p} s+k_{i}}{s}
$$

na qual $k_{p}$ é o ganho proporcional e $k_{i}$ o ganho integrativo.

Isto posto, a função de transferência de malha fechada, com realimentação unitária, é dada por

$$
\frac{\Omega_{m}(s)}{\Omega_{r e f}(s)}=\frac{C(s) \frac{\Omega_{m}(s)}{E_{a}(s)}}{1+C(s) \frac{\Omega_{m}(s)}{E_{a}(s)}}=\frac{\frac{k_{p} k_{m} s}{\tau_{m}}+\frac{k_{i} k_{m}}{\tau_{m}}}{s^{2}+\left(\frac{1+k_{p} k_{m}}{\tau_{m}}\right) s+\frac{k_{i} k_{m}}{\tau_{m}}} .
$$

Trata-se de uma função de transferência de segunda ordem ${ }^{\S}$ cuja frequência natural, $\omega_{n}$, e coeficiente de amortecimento, $\xi$, são dados por

$$
\omega_{n}=\sqrt{\frac{k_{i} k_{m}}{\tau_{m}}} \quad \text { e } \quad \xi=\frac{1+k_{p} k_{m}}{2 \omega_{n} \tau_{m}} .
$$

$\S$ A função de transferência possui um zero adicional em $-k_{i} / k_{p}$. Quanto mais próximo esse zero estiver dos polos dominantes no plano $s$, maior será sua influência na resposta transitória. 
Os ganhos do controlador, $k_{p}$ e $k_{i}$, podem ser expressos em função do erro em regime para entrada do tipo rampa, $e_{r}(\infty)$, e tempo de acomodação, $t_{s}$.

O erro em regime, por sua vez, pode ser obtido por meio do teorema do valor final. Para uma entrada do tipo rampa, o erro da malha fechada de velocidade do motor é dado por $[115]$

$$
e_{r}(\infty)=\frac{1}{\lim _{s \rightarrow 0} s C(s) \frac{\Omega_{m}(s)}{E_{a}(s)}}=\frac{1}{k_{i} k_{m}}
$$

Portanto,

$$
k_{i}=\frac{1}{k_{m} e_{r}(\infty)} .
$$

Para um sistema de segunda ordem, o tempo de acomodação para uma faixa de $2 \%$ em torno do valor final é dado por

$$
t_{s} \approx \frac{4}{\xi \omega_{n}}
$$

Isolando $\xi \omega_{n}$ na Equação (7.44) e substituindo na Equação (7.47) resulta em

$$
k_{p}=\frac{8 \tau_{m}-t_{s}}{t_{s} k_{m}} .
$$

Conforme mencionado na Subseção 7.3.3, o controlador é implementado em tempo discreto. Um dos métodos de discretização da integral é o Tustin, também conhecido como método trapezoidal, pois a integral é aproximada pela área de um trapézio. Neste, a aproximação discreta é dada por [112]

$$
s=\frac{2}{T} \frac{(z-1)}{(z+1)},
$$

na qual $T$ é o período de amostragem. Utilizando o método de Tustin no controlador PI (Eq. (7.42)), resulta em

$$
C(z)=k_{p}+k_{i} \frac{T}{2} \frac{(z+1)}{(z-1)} .
$$

Adequando a notação e também discretizando a relação entre torque e velocidade angular (Eq. (7.37))

$$
\Omega_{r e f}(z)=\frac{T}{2 I_{r r}} \frac{(z+1)}{(z-1)} T_{r e f}(z)
$$

na qual $\Omega_{r e f}$ é o sinal de referência de velocidade angular e $T_{r e f}$ é o sinal de torque desejado pelo controlador LQR.

\subsubsection{Dessaturação das Rodas de Reação}

Conforme apresentado na Subseção 4.3.1, o satélite está sujeito a torques de perturbação. Assim sendo, o momento angular total do veículo tende a aumentar indefinidamente de 
forma que as rodas de reação podem saturar e não serem mais capazes de acomodar tais distúrbios. Portanto, faz-se necessário dessaturá-las.

Para tal, uma estratégia simples é apresentada por Sidi[69],

$$
\mathbf{T}_{d s t}=-k_{d s t}\left(\mathbf{H}_{r r}-\mathbf{H}_{d}\right)
$$

na qual $k_{d s t}$ é o ganho do controlador de dessaturação $\left(k_{d s t}>0\right), \mathbf{H}_{r r}$ é o momento angular total das rodas de reação e $\mathbf{H}_{d}$ é o momento angular desejado das rodas de reação. $\mathrm{O}$ princípio dessa estratégia é gerar torque (com outro atuador) de forma que pondere a diferença de momento angular das rodas de reação.

O torque de dessaturação, $\mathbf{T}_{d s t}$, pode ser gerado pelos atuadores magnéticos. Substituindo a Equação (4.6) em (7.51) e realizando algumas modificações para garantir a implementação, resulta em

$$
\mathbf{m}_{d s t}^{p}=\frac{-k_{d s t}}{B^{2}} S\left([\mathbf{B}]^{p}\right)[\mathbf{Q}]_{p / r r}\left[\begin{array}{c}
\operatorname{sgn}\left(H_{r r_{1}}\right)\left(\left|H_{r r_{1}}\right|-H_{d_{1}}\right) \\
\operatorname{sgn}\left(H_{r r_{2}}\right)\left(\left|H_{r r_{2}}\right|-H_{d_{2}}\right) \\
\operatorname{sgn}\left(H_{r r_{3}}\right)\left(\left|H_{r r_{3}}\right|-H_{d_{3}}\right)
\end{array}\right],
$$

Para fins de simulação, o controle de apontamento é representado na Figura 64.

Figura 64 - Diagrama do controlador de apontamento.

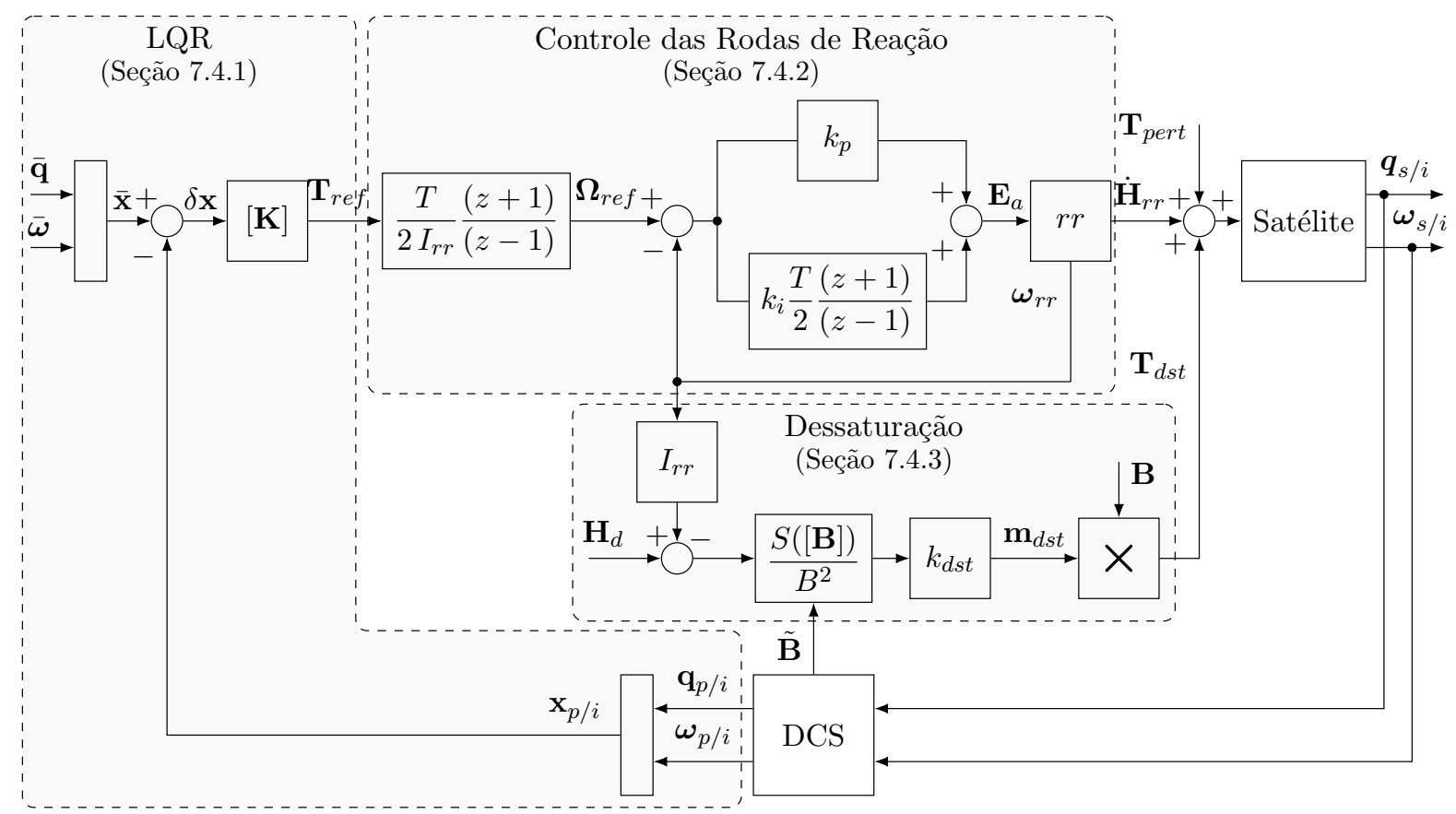

A notação $\tilde{\mathbf{B}}$ foi utilizada para indicar que se trata do campo magnético medido pelo satélite, enquanto que B se trata do campo magnético que o veículo está sujeito. $r r$ representa o conjunto das rodas de reação.

Fonte: Autor. 


\subsubsection{Resultados de Simulação do Controlador de Apontamento}

O controlador de apontamento foi projetado para o fooSAT-A1 nas órbitas ISS e SSO e os resultados de simulação são apresentados nessa seção.

Inicialmente, avaliou-se o controle das rodas de reação desenvolvido ao longo da Subseção 7.4.2. Substituindo os parâmetros da roda de reação apresentados na Tabela 3, $e_{r}(\infty)=0.02(\mathrm{R} 8)$ e $t_{s}=0,1 \mathrm{~s}(\mathrm{R} 9)$

$$
k_{p}=269,38 \times 10^{-3} \text { e } k_{i}=595,86 \times 10^{-3} .
$$

Considerando $T=0,01 \mathrm{~s}$, conforme definido na Seção 7.2, o controle da roda de reação foi submetido a uma entrada do tipo degrau de amplitude $35 \mathrm{rad} / \mathrm{s}$ e a uma entrada do tipo rampa de inclinação $400 \mathrm{rad} / \mathrm{s}^{2}$. Os resultados de simulação estão ilustrados na Figura 65.

Figura 65 - Desempenho do controle das rodas de reação.

Referência do tipo degrau.

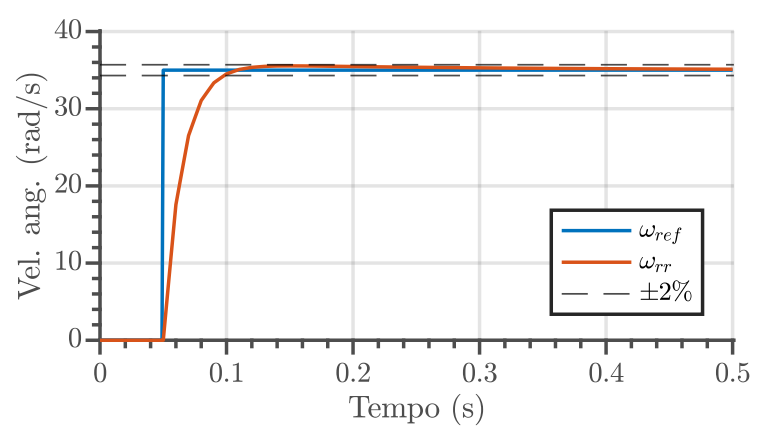

Sinal de controle.

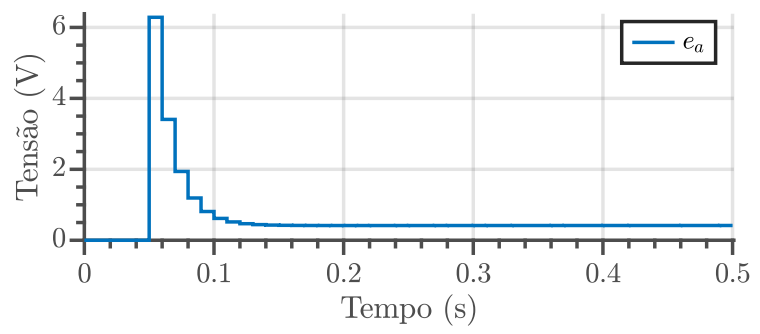

Referência do tipo rampa.

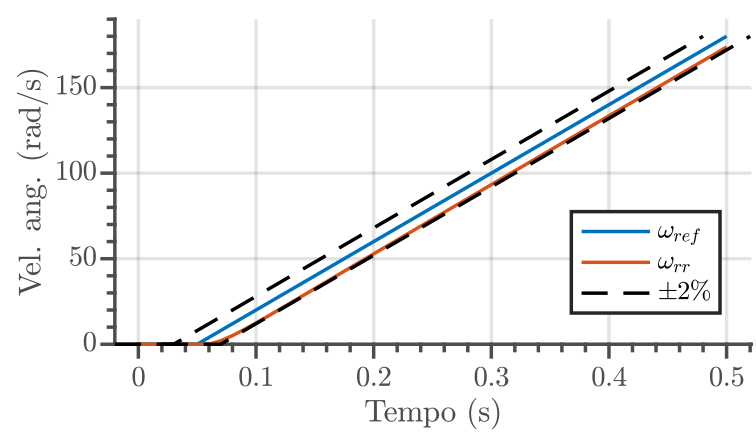

Sinal de controle.

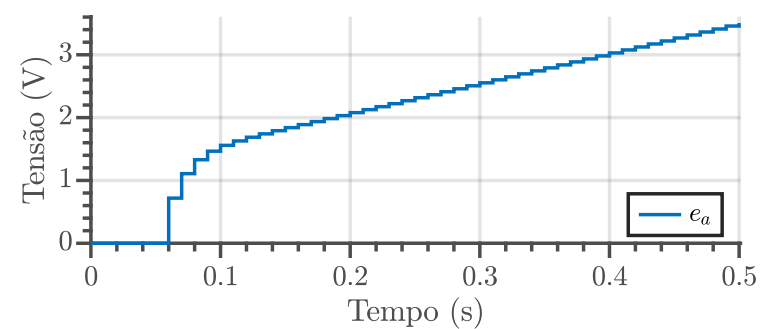

Fonte: Autor.

O tempo de acomodação, $t_{s}$, foi de $0,098 \mathrm{~s}$, atingindo o requisito R9 e o erro em regime para entrada rampa foi de $1,7 \%$, atingindo o requisito R8. Sendo assim, na sequência foi simulada uma situação completa, na qual o sinal de referência de torque proveniente do LQR é dado por uma sequência de degraus. Os resultados estão ilustrados na Figura 66.

É possível notar que a referência de torque na forma degrau, $T_{r e f}$, foi transforma em referência de velocidade, $\omega_{\text {ref }}$, na forma de rampa por meio da Equação (7.50). O controlador PI projetado, por sua vez, fez com que a velocidade da roda de reação, $\omega_{r r}$, seguisse essa referência de velocidade. Como resultado, o torque produzido pela roda de reação, $T_{r r}$, foi capaz de seguir a referência, $T_{r e f}$, com tempo de acomodação de $0,6 \mathrm{~s}$. No 
Figura 66 - Desempenho do controle das rodas de reação.

Referência de torque.

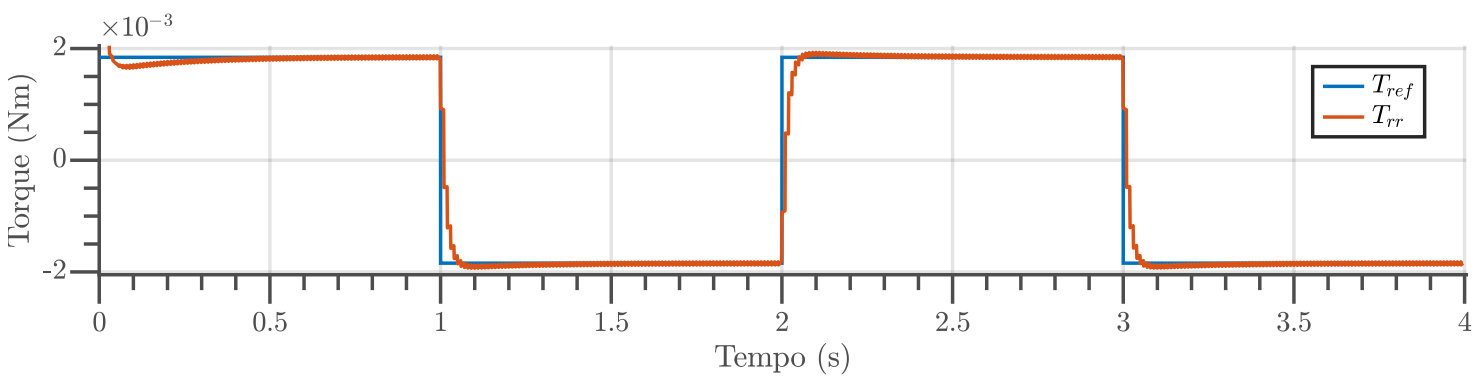

Referência de velocidade angular.

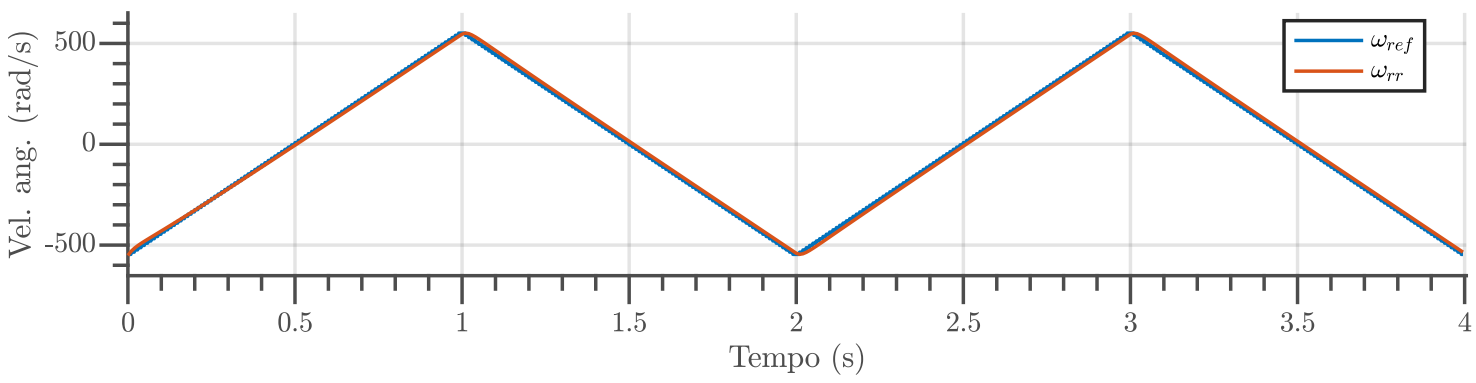

Sinal de Controle.

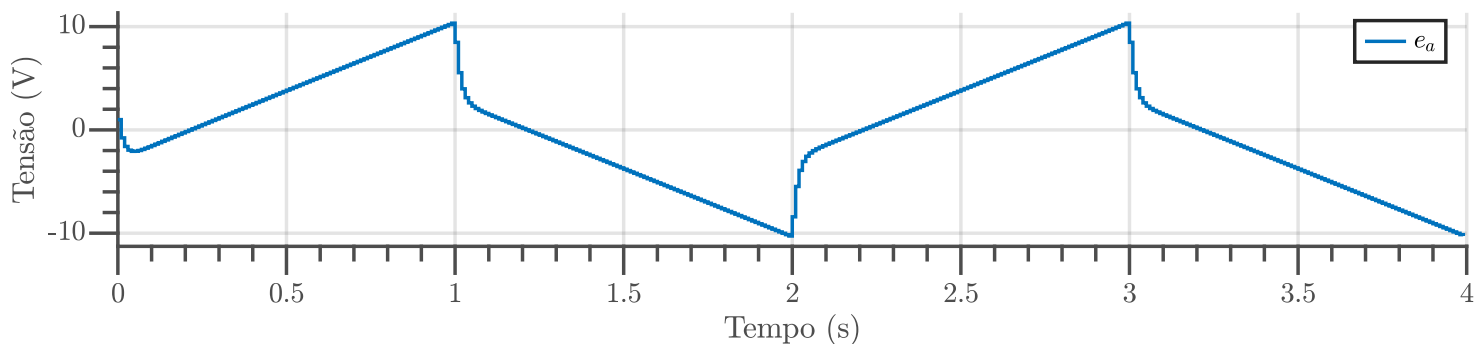

Fonte: Autor.

mais, lembra-se que as rodas de reação são capazes de produzir torque no veículo apenas enquanto for possível variar a velocidade angular. Dessa forma, a depender do tempo de duração do degrau de referência, as rodas de reação podem saturar. Note que, para um degrau de torque de amplitude $\approx 4 \mathrm{mN}$ e duração de $1 \mathrm{~s}$, a tensão do motor atingiu valores próximos da saturação $(12 \mathrm{~V})$.

Após o controle das rodas de reação, avaliou-se o controle de apontamento para uma direção fixa do GEI (requisito R3). Para esse caso, conforme explicado na Subseção 7.4.1.3, a linearização foi realizada em torno de $\overline{\boldsymbol{\omega}}_{a}=\left[\begin{array}{lll}0 & 0 & 0\end{array}\right]^{\top} \mathrm{rad} / \mathrm{s}$. O modelo linear (Eq. (7.28)) resultou em

$$
\begin{gathered}
{[\mathbf{A}]_{a}=\left[\begin{array}{cc}
{[\mathbf{0}]_{3 \times 3}} & 0,5\left([\mathbf{1}]_{3 \times 3}\right) \\
{[\mathbf{0}]_{3 \times 3}} & {[\mathbf{0}]_{3 \times 3}}
\end{array}\right], \quad[\mathbf{B}]_{a}=\left[\begin{array}{c}
{[\mathbf{0}]_{3 \times 3}} \\
\operatorname{diag}[-485,9-442,1-440,9]
\end{array}\right],} \\
{[\mathbf{C}]_{a}=\left[[\mathbf{1}]_{6 \times 6}\right] \quad \text { e }[\mathbf{D}]_{a}=\left[[\mathbf{0}]_{6 \times 3}\right] .}
\end{gathered}
$$


Para o sistema $a$, a matriz de controlabilidade, $[\mathcal{C}]_{a}$, e a matriz de observabilidade, $[\mathcal{O}]_{a}$, têm posto 6. Portanto, o sistema é totalmente controlável e observável. A estabilidade em malha aberta também foi avaliada e todos os autovalores de $[\mathbf{A}]_{a}$ são nulos. Sendo assim, o sistema é marginalmente estável em malha aberta.

Aplicando a Regra de Bryson (Eq. (7.35)), as matrizes $[\mathbf{Q}]_{a}$ e $[\mathbf{R}]_{a}$ resultaram em

$$
[\mathbf{Q}]_{a}=\left[\begin{array}{cc}
{[\mathbf{1}]_{3 \times 3}} & {[\mathbf{0}]_{3 \times 3}} \\
{[\mathbf{0}]_{3 \times 3}} & 277,8\left([\mathbf{1}]_{3 \times 3}\right)
\end{array}\right] \quad \text { e } \quad[\mathbf{R}]_{a}=\left[31,1 \times 10^{3}\left([\mathbf{1}]_{3 \times 3}\right)\right] .
$$

Ao observar os valores das matrizes $[\mathbf{Q}]_{a}$ e $[\mathbf{R}]_{a}$, pode-se intuir que os estados $x_{1}, x_{2}$ e $x_{3}$ têm menor relevância do que os estados $x_{4}, x_{5}$ e $x_{6}$ que, por sua vez, têm menor relevância que as entradas $u_{1}, u_{2}$ e $u_{3}$. Entretanto, conforme mencionado na Subseção 7.4.1.3, essa diferença se dá justamente para normalizar a divergência que há entre os valores máximos que cada estado e entrada podem assumir.

Deste modo, a matriz de ganho $[\mathbf{K}]_{a}$ obtida foi

$$
[\mathbf{K}]_{a}=\left[\begin{array}{cccccc}
-1,43 & 0 & 0 & -23,9 & 0 & 0 \\
0 & -1,55 & 0 & 0 & -25,9 & 0 \\
0 & 0 & -1,55 & 0 & 0 & -25,9
\end{array}\right] 10^{-3}
$$

Avaliou-se a estabilidade em malha fechada e os autovalores de $\left([\mathbf{A}]_{a}-[\mathbf{B}]_{a}[\mathbf{K}]_{a}\right)$ resultaram em

$$
-30,0 \times 10^{-3}, \quad-45,9, \quad-30,0 \times 10^{-3}, \quad-41,7, \quad-41,8 \text { e } \quad-30,0 \times 10^{-3} .
$$

E, como é possível notar, todos os polos são reais e estão localizados no semiplano esquerdo do plano s. Portanto, o sistema é estável em malha fechada.

O desempenho do LQR com a matriz de ganho $[\mathbf{K}]_{a}$ está ilustrado na Figura $67^{\Uparrow}$. No instante inicial o veículo estava alinhado com o GEI, isto é, $\boldsymbol{\Theta}_{s / i}=\left[\begin{array}{lll}0,0^{\circ} & 0,0^{\circ} & 0,0^{\circ}\end{array}\right]^{\top}$, a velocidade angular era de $\boldsymbol{\omega}_{s / i}^{s}=1 / \sqrt{3}\left[\begin{array}{lll}0,02 & 0,02 & 0,02\end{array}\right]^{\top} \mathrm{rad} / \mathrm{s}$, o equivalente à situação após o detumbling, e as rodas de reação estavam em $10 \%$ do valor máximo, isto é, $\mathbf{e}_{a}=\left[\begin{array}{lll}1,2 & 1,2 & 1,2\end{array}\right]^{\top} \mathrm{V}$. O apontamento foi realizado na direção $\boldsymbol{\Theta}_{s / i}=\left[\begin{array}{lll}-90^{\circ} & 45^{\circ}-90^{\circ}\end{array}\right]^{\top}$.

Neste caso, o erro atingiu o intervalo de $\pm 5^{\circ}$ em $108,2 \mathrm{~s}$, o que cumpre o requisito R6, mas não cumpre o requisito R5. Dessa forma, foi necessário ajustar a matriz de ganho. O parâmetro de ajuste $\rho_{Q}$ foi dividido em $\rho_{Q_{1}}$ referente aos estados $x_{1}, x_{2}$ e $x_{3}$, e $\rho_{Q_{2}}$ referente aos estados $x_{4}, x_{5}$ e $x_{6}$. A Figura 68 ilustra os resultados de simulação para $\rho_{Q_{1}}=1,3$ e $\rho_{Q_{1}}=100$, situação em que uma das rodas de reação atinge $90 \%$ do limite de saturação.

\footnotetext{
"Para facilitar a visualização, as simulações foram ilustradas apenas na órbita ISS, pois não existe diferença perceptível para os resultados obtidos na órbita SSO. Isso ocorreu porque no apontamento para uma direção fixa, a forma de obter o controlador não depende de informações orbitais.
} 
Figura 67 - Desempenho do controle de apontamento para direção fixa.

Atitude durante o apontamento.

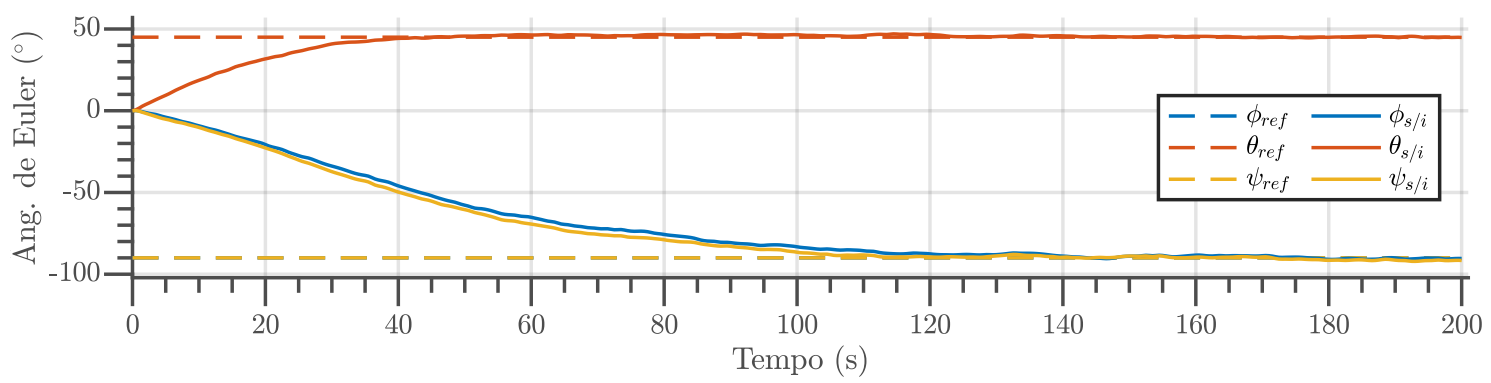

Erro de atitude durante o apontamento.

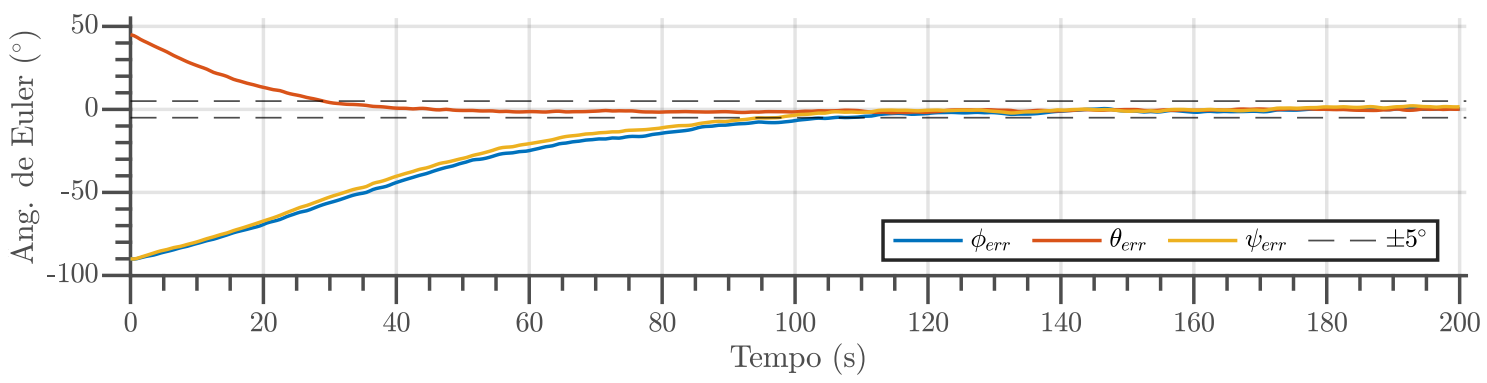

Tensão nas rodas de reação.

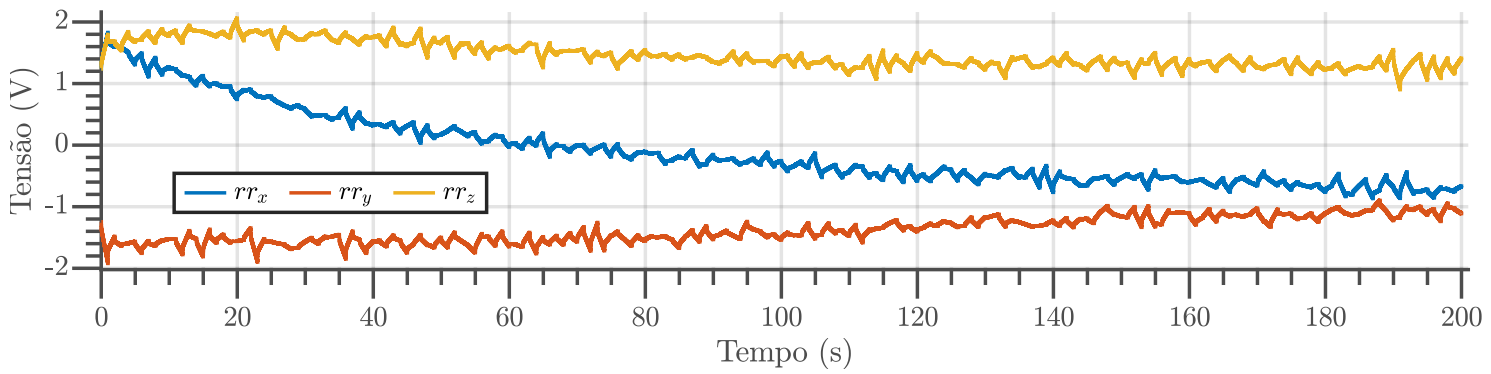

Velocidade angular das rodas de reação.

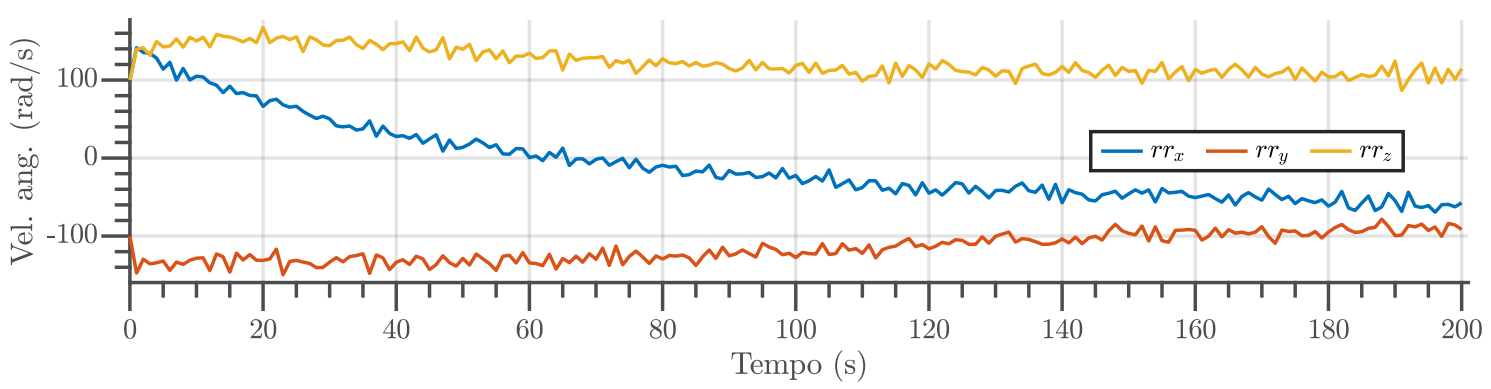

Fonte: Autor.

Com o ajustes de $\rho_{Q_{1}}=1,3$, o erro atingiu o intervalo de $\pm 5^{\circ}$ em $98,6 \mathrm{~s}$, cumprindo também o requisito R5. Note que, nesse caso, a tensão da roda de reação atinge valores próximos de $2 \mathrm{~V}$, o que equivale à aproximadamente $17 \%$ do limite de saturação.

Ajustando o $\rho_{Q_{1}}$ para 100, a roda de reação alinhada ao eixo $y$ do veículo atinge $10 \mathrm{~V}$, o que equivale a aproximadamente $90 \%$ do limite de saturação. Nesse caso, o erro atingiu 
Figura 68 - Desempenho do controle de apontamento para direção fixa com ajuste.

$$
\text { Para } \rho_{Q_{1}}=1,3 .
$$

Atitude durante o apontamento.

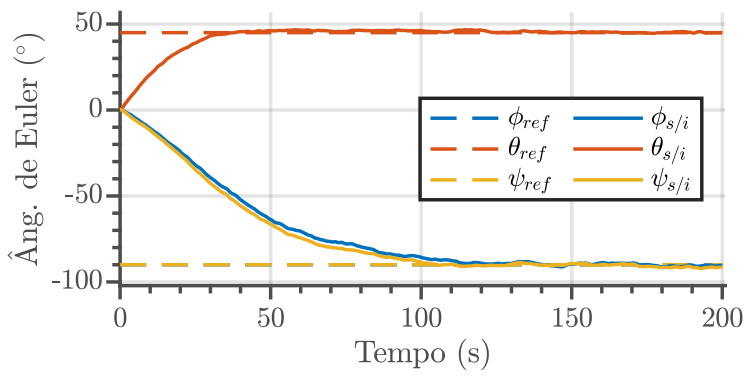

Erro de atitude durante o apontamento.

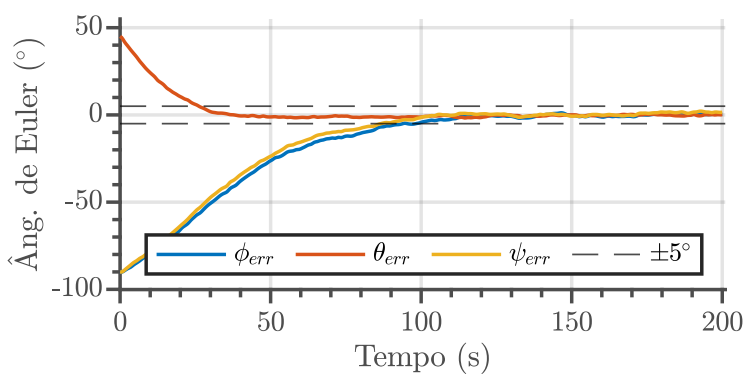

Tensão nas rodas de reação.

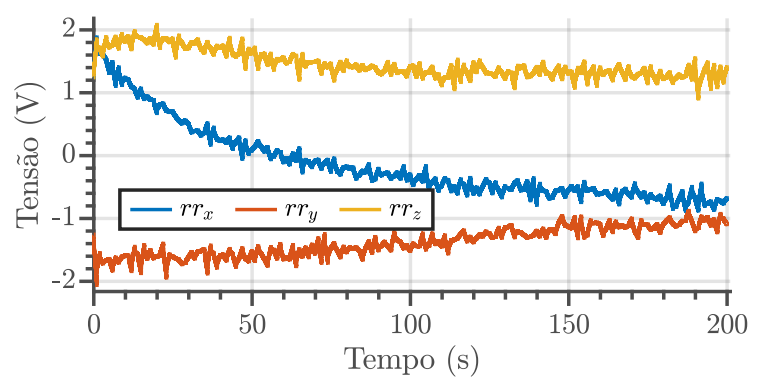

Velocidade angular das rodas de reação.

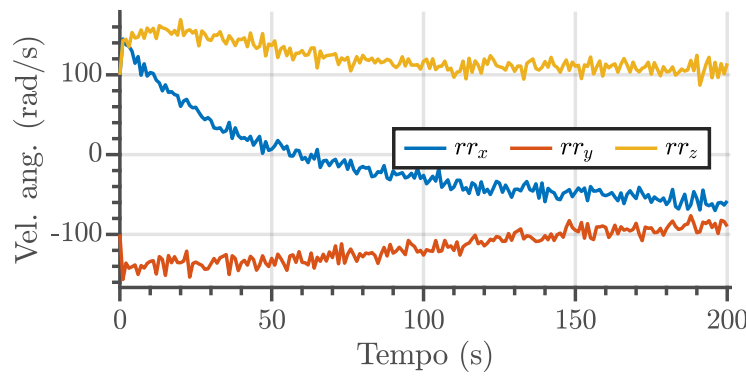

Para $\rho_{Q_{1}}=100$.

Atitude durante o apontamento.

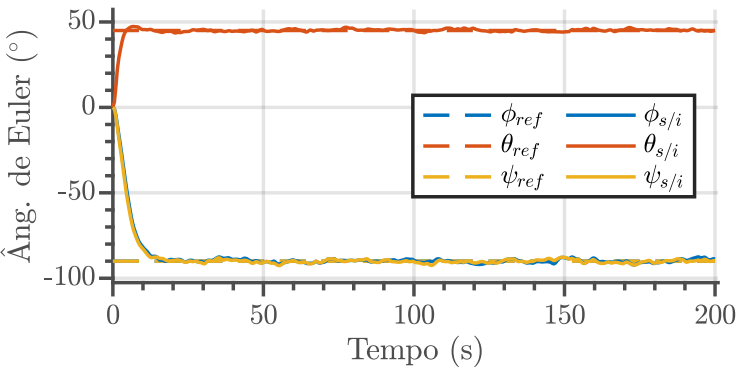

Erro de atitude durante o apontamento.

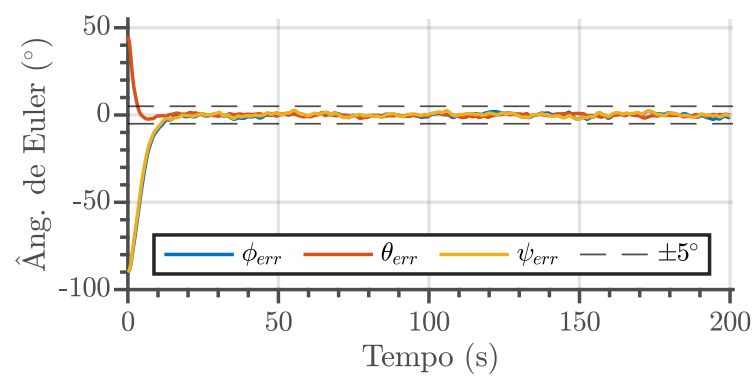

Tensão nas rodas de reação.

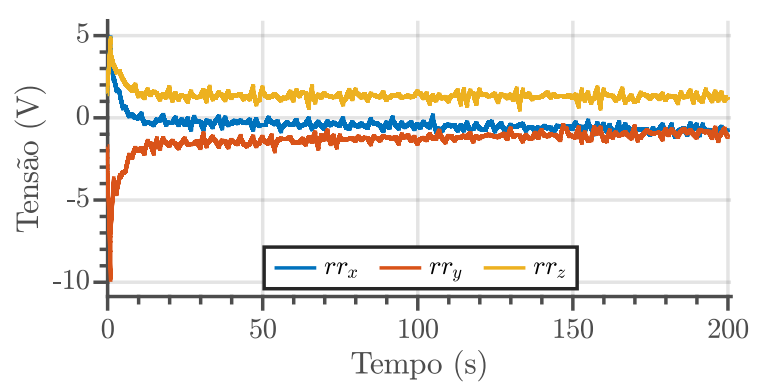

Velocidade angular das rodas de reação.

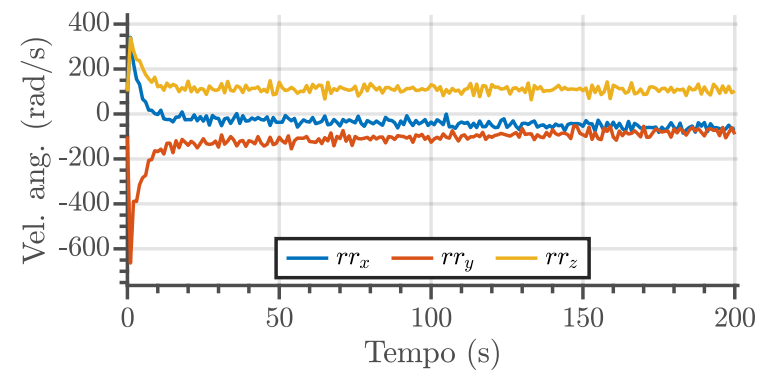

Fonte: Autor.

o intervalo de $\pm 5^{\circ}$ em $11,7 \mathrm{~s}$. Sendo assim, caso necessário, o requisito de tempo para o apontamento pode ser menor que $100 \mathrm{~s}$ ou pode-se adotar uma roda de reação de menor potência de modo que o consumo energético seja menor. Ademais, o sinal de tensão tem o perfil serrilhado, pois, conforme esperado, trata-se de uma sequência de rampas.

Na sequência, avaliou-se o controle de apontamento na direção Nadir (requisito R4). 
Para esse caso, conforme apresentado na Subseção 7.4.1.3, a linearização depende das características da órbita e deve ser realizada em torno de $\overline{\boldsymbol{\omega}}_{b}=\boldsymbol{\omega}_{o / i}^{p}$. Para a órbita ISS foi utilizada a notação $b_{1}$ e a linearização foi realizada em $\overline{\boldsymbol{\omega}}_{b_{1}}=\left[\begin{array}{lll}0,87 & 0,16 & 0,70\end{array}\right]^{\top} 10^{-3} \mathrm{rad} / \mathrm{s}$, resultando no modelo linear

$$
\begin{aligned}
& {[\mathbf{A}]_{b_{1}}=\left[\begin{array}{cccccc}
0 & 699,21 & -155,06 & 500000,00 & 0 & 0 \\
-699,21 & 0 & 873,74 & 0 & 500000,00 & 0 \\
155,06 & -873,74 & 0 & 0 & 0 & 500000,00 \\
0 & 0 & 0 & 0 & -2,12 & -0,47 \\
0 & 0 & 0 & 64,92 & 0 & 81,12 \\
0 & 0 & 0 & -13,93 & -78,49 & 0
\end{array}\right] 10^{-6}} \\
& {[\mathbf{B}]_{b_{1}}=[\mathbf{B}]_{a}, \quad[\mathbf{C}]_{b_{1}}=[\mathbf{C}]_{a} \quad \text { e } \quad[\mathbf{D}]_{b_{1}}=[\mathbf{D}]_{a}}
\end{aligned}
$$

Assim como o sistema $a$, o sistema $b_{1}$ é totalmente controlável e observável, pois as matrizes de controlabilidade, $[\mathcal{C}]_{b_{1}}$, e observabilidade, $[\mathcal{O}]_{b_{1}}$, também têm posto 6 . Ao avaliar a estabilidade em malha aberta, os autovalores de $[\mathbf{A}]_{b_{1}}$ foram dados por

$$
0, \quad 0,74 \times 10^{-6}, \quad(0,00 \pm 1129,76 \mathrm{i}) \times 10^{-6} \text { e }(-0,37 \pm 80,62 \mathrm{i}) \times 10^{-6} .
$$

Note que, o sistema $b_{1}$ tem um polo localizado no semiplano direito do plano $s$, portanto é instável em malha aberta.

As matrizes $[\mathbf{Q}]_{b_{1}}$ e $[\mathbf{R}]_{b_{1}}$ iniciais são idênticas às matrizes $[\mathbf{Q}]_{a}$ e $[\mathbf{R}]_{a}$ iniciais, pois não dependem de parâmetros orbitais. Deste modo, a matriz de ganho $[\mathbf{K}]_{b_{1}}$ obtida foi

$$
[\mathbf{K}]_{b_{1}}=\left[\begin{array}{cccccc}
-56700,00 & -0,90 & 0,20 & -95115,39 & -0,07 & 0,02 \\
0,99 & -56700,00 & -1,07 & -0,07 & -95176,10 & 0,00 \\
-0,22 & 1,07 & -0,06 & 0,02 & 0,00 & -95177,96
\end{array}\right] 10^{-6} \text {. }
$$

Ao avaliar a estabilidade de malha fechada, os autovalores de $\left([\mathbf{A}]_{b_{1}}-[\mathbf{B}]_{b_{1}}[\mathbf{K}]_{b_{1}}\right)$ resultaram em

$$
-300,01 \times 10^{-3}, \quad(-300,01 \pm 1,13 \mathrm{i}) \times 10^{-3}, \quad-41,67, \quad-41,78 \quad \text { e } \quad-45,92 .
$$

Dado que todos os polos têm parte real negativa, o sistema $b_{1}$ é estável em malha fechada.

Para a órbita SSO foi utilizada a notação $b_{2}$ e a linearização foi realizada em $\overline{\boldsymbol{\omega}}_{b_{2}}=$ $[1,0-0,35-0,15]^{\top} 10^{-3} \mathrm{rad} / \mathrm{s}$, resultando no modelo linear

$$
\begin{aligned}
& {[\mathbf{A}]_{b_{2}}=\left[\begin{array}{cccccc}
0 & -146,40 & 345,04 & 500000,00 & 0 & 0 \\
146,40 & 0 & 1040,77 & 0 & 500000,00 & 0 \\
-345,04 & -1040,77 & 0 & 0 & 0 & 500000,00 \\
0 & 0 & 0 & 0 & 0,44 & 1,04 \\
0 & 0 & 0 & -13,59 & 0 & 96,63 \\
0 & 0 & 0 & 31,00 & -93,50 & 0
\end{array}\right] 10^{-6}} \\
& {[\mathbf{B}]_{b_{2}}=[\mathbf{B}]_{a}, \quad[\mathbf{C}]_{b_{2}}=[\mathbf{C}]_{a} \quad \text { e } \quad[\mathbf{D}]_{b_{2}}=[\mathbf{D}]_{a}}
\end{aligned}
$$


O sistema $b_{2}$ também é totalmente controlável e observável, pois as matrizes de controlabilidade, $[\mathcal{C}]_{b_{2}}$, e observabilidade, $[\mathcal{O}]_{b_{2}}$, têm posto 6 . Uma vez mais, analisando a estabilidade em malha aberta, os autovalores de $[\mathbf{A}]_{b_{2}}$ foram dados por

$$
0, \quad 0,29 \times 10^{-6}, \quad(3,73 \pm 1106,20 \mathrm{i}) \times 10^{-6} \text { e }(-0,15 \pm 94,91 \mathrm{i}) \times 10^{-6} .
$$

E, similar ao sistema $b_{1}$, o sistema $b_{2}$ é instável em malha aberta, pois possui polos no semiplano direito do plano $s$.

Novamente, as matrizes $[\mathbf{Q}]_{b_{2}}$ e $[\mathbf{R}]_{b_{2}}$ iniciais são idênticas as matrizes $[\mathbf{Q}]_{a}$ e $[\mathbf{R}]_{a}$ iniciais. Sendo assim, a matriz de ganho $[\mathbf{K}]_{b_{2}}$ resultou em

$$
[\mathbf{K}]_{b_{2}}=\left[\begin{array}{cccccc}
-56700,00 & 0,19 & -0,44 & -95115,39 & 0,02 & -0,04 \\
-0,21 & -56700,00 & -1,27 & 0,01 & -95176,10 & 0,00 \\
0,49 & 1,28 & -0,06 & -0,03 & 0,00 & -95177,96
\end{array}\right] 10^{-6} .
$$

Ao avaliar a estabilidade de malha fechada, os autovalores de $\left([\mathbf{A}]_{b_{2}}-[\mathbf{B}]_{b_{2}}[\mathbf{K}]_{b_{2}}\right)$ resultaram em

$$
-300,01 \times 10^{-3}, \quad(-300,01 \pm 1,11 \mathrm{i}) \times 10^{-3}, \quad-41,66, \quad-41,78 \quad \text { e } \quad-45,92 .
$$

Dado que todos os polos têm parte real negativa, o sistema $b_{2}$ também é estável em malha fechada.

Note que os polos de malha fechada do sistema $b_{1}$ e $b_{2}$ são muito similares, o que caracterizará, inicialmente, em um desempenho similar. Isso se deve ao fato de que, apesar das órbitas ISS e SSO terem inclinações distintas, os módulos das velocidades angulares orbitais são próximos, em razão da altitude ser próxima.

A Figura 69 ilustra o desempenho do LQR para o apontamento na direção Nadir nas órbitas ISS e SSO, respectivamente. Em ambos os casos, no instante inicial, a velocidade angular era de $\boldsymbol{\omega}_{s / i}^{s}=1 / \sqrt{3}\left[\begin{array}{llll}0,02 & 0,02 & 0,02\end{array}\right]^{\top} \mathrm{rad} / \mathrm{s}$, o equivalente à situação após o detumbling, e as rodas de reação estavam em $10 \%$ do valor máximo, isto é, $\mathbf{e}_{a}=\left[\begin{array}{lll}1,2 & 1,2 & 1,2\end{array}\right]^{\top} \mathrm{V}$. Para que a diferença fosse, no instante inicial, de $\left[\begin{array}{ll}-90^{\circ} & 45^{\circ}-90^{\circ}\end{array}\right]^{\top}$, para a órbita ISS, o veículo iniciou em $\Theta_{s / i}=\left[61,97^{\circ}-26,03^{\circ}-29,08^{\circ}\right]^{\top}$ e para a órbita $\mathrm{SSO}$, o veículo iniciou em $\boldsymbol{\Theta}_{s / i}=\left[\begin{array}{lll}26,87^{\circ} & 5,35^{\circ} & 5,48^{\circ}\end{array}\right]^{\top}$.

Para a órbita ISS, o erro atingiu o intervalo de $\pm 5^{\circ}$ em 96,1 s contando com ajuste de $\rho_{Q_{1}}=1,5$, enquanto para a órbita SSO foi atingida em $73,1 \mathrm{~s}$ com ajuste de $\rho_{Q_{1}}=3.9$. O ajuste para SSO foi maior, pois, como é possível notar, nos primeiros $200 \mathrm{~s}$ de simulação a referência está se afastando rapidamente dos valores iniciais. Dessa forma, a manobra realizada em SSO acaba sendo mais longa do que a manobra realizada na órbita ISS. Em ambos os casos foi possível cumprir os requisitos R6 e R5.

Avaliou-se também o controle de dessaturação das rodas de reação, apresentado na Subseção 7.4.3. A tensão máxima da roda de reação do fooSAT-A1 (Tabela 3) é $12 \mathrm{~V}$, o que produzirá uma velocidade angular de 999,03 rad/s e momento angular de $1,66 \times 10^{-3} \mathrm{~kg} \mathrm{~m}^{2} / \mathrm{s}$. 
Figura 69 - Desempenho do controle de apontamento para direção Nadir.

Órbita ISS.

Atitude durante o apontamento.

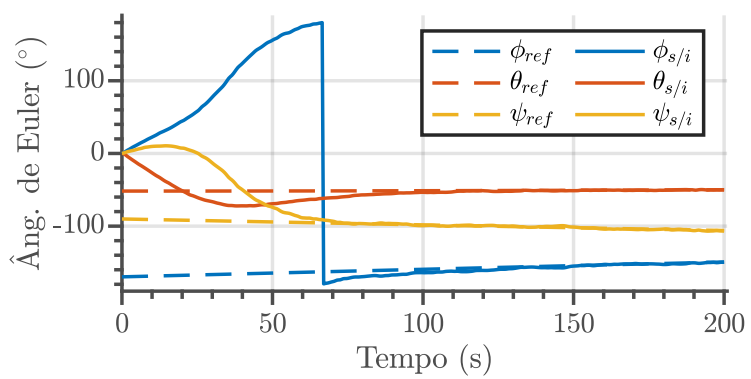

Erro de atitude durante o apontamento.

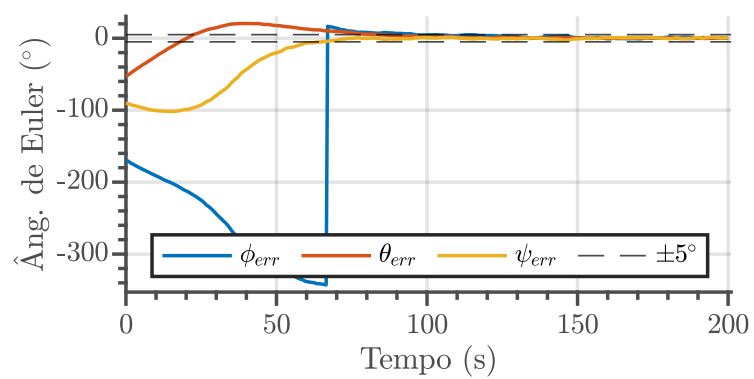

Tensão nas rodas de reação.

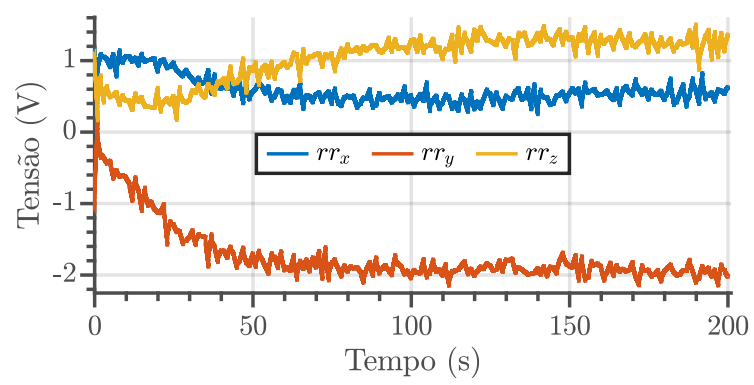

Velocidade angular das rodas de reação.

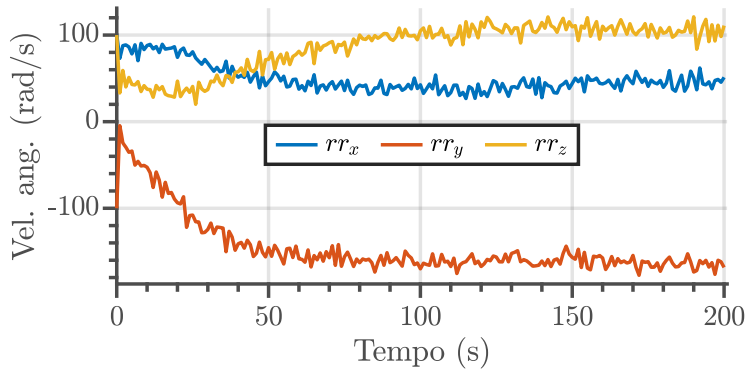

Órbita SSO.

Atitude durante o apontamento.

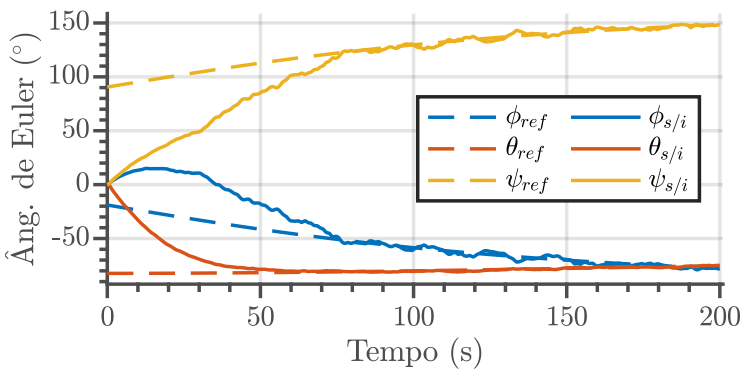

Erro de atitude durante o apontamento.

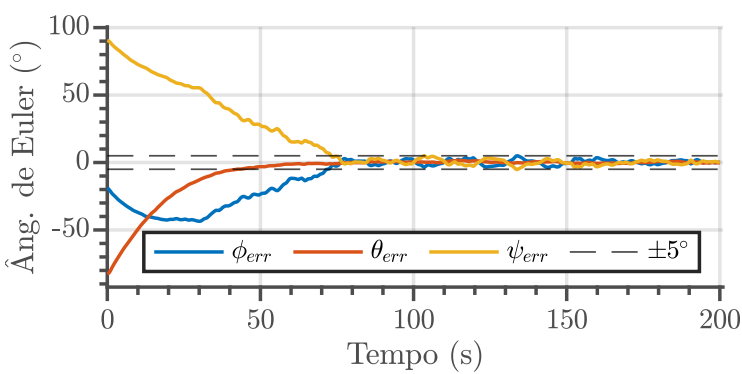

Tensão nas rodas de reação.

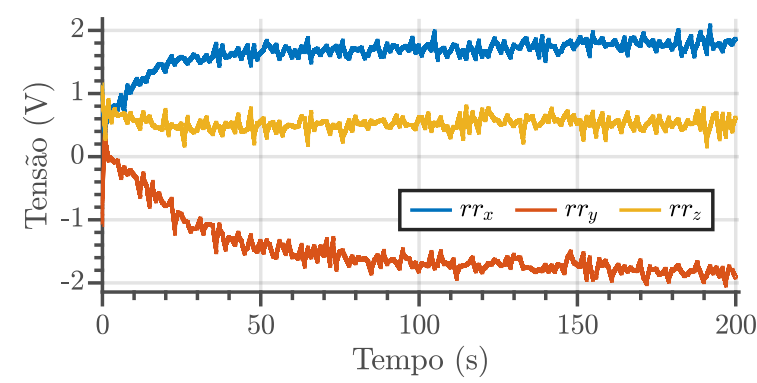

Velocidade angular das rodas de reação.

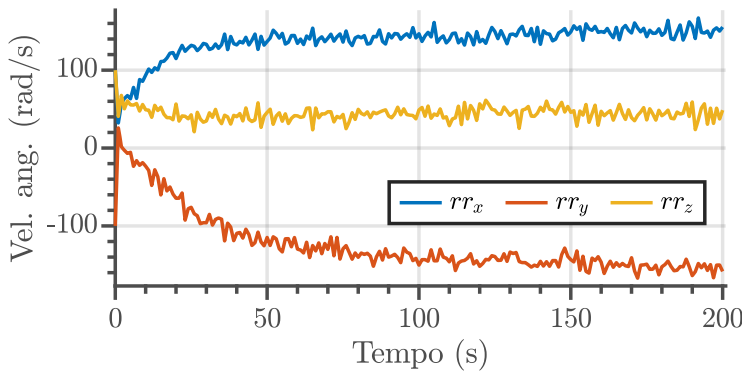

Fonte: Autor.

O controle de dessaturação deve reduzir o momento angular de $1,49 \times 10^{-3} \mathrm{~kg} \mathrm{~m}^{2} / \mathrm{s}(90 \%)$ para uma faixa de $0,50 \times 10^{-3} \mathrm{~kg} \mathrm{~m}^{2} / \mathrm{s}(30 \%)$ a $0,17 \times 10^{-3} \mathrm{~kg} \mathrm{~m}^{2} / \mathrm{s}(10 \%)$ em até 1 órbita para cumprir o requisito R10. Sendo assim, para a órbita ISS na condição de apontamento na direção fixa, $k_{d s t}$ deve ser ao menos $3,5 \times 10^{-3}$, e na condição de apontamento na direção Nadir, $k_{d s t}$ deve ser ao menos $2,2 \times 10^{-3}$. Já para a órbita SSO na condição de apontamento 
na direção fixa, $k_{d s t}$ deve ser ao menos $1,1 \times 10^{-3}$, e na condição de apontamento na direção Nadir, $k_{d s t}$ deve ser ao menos $2,4 \times 10^{-3}$. A Figura 70 ilustra o desempenho do controle de saturação para as respectivas condições limites supracitados.

Figura 70 - Desempenho do controle de dessaturação das rodas de reação.

Órbita ISS.

Direção fixa com $k_{d s t}=3,5 \times 10^{-3}$.

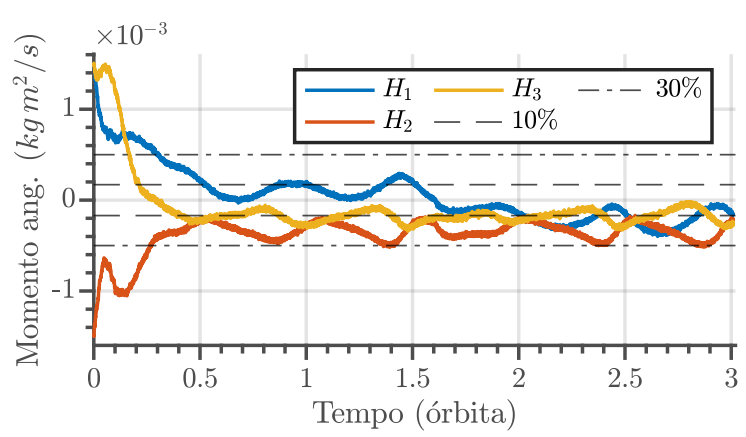

Direção Nadir com $k_{d s t}=2,2 \times 10^{-3}$.

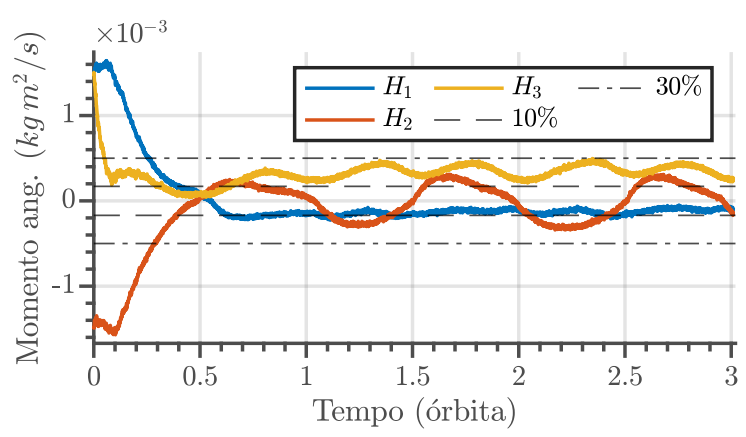

Órbita SSO.

Direção fixa com $k_{d s t}=1,1 \times 10^{-3}$.

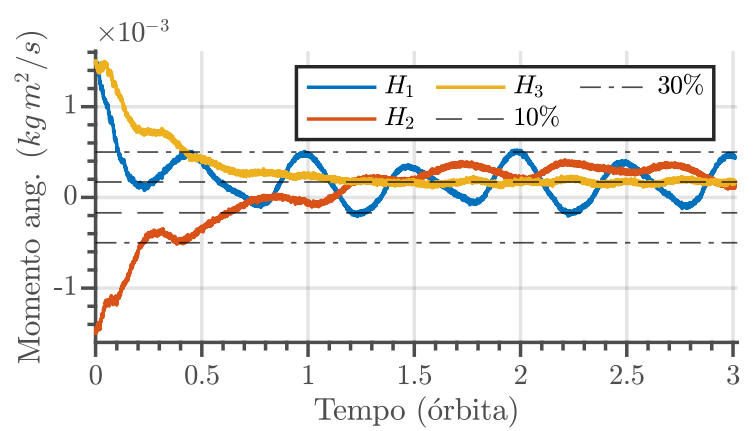

Direção Nadir com $k_{d s t}=2,4 \times 10^{-3}$.

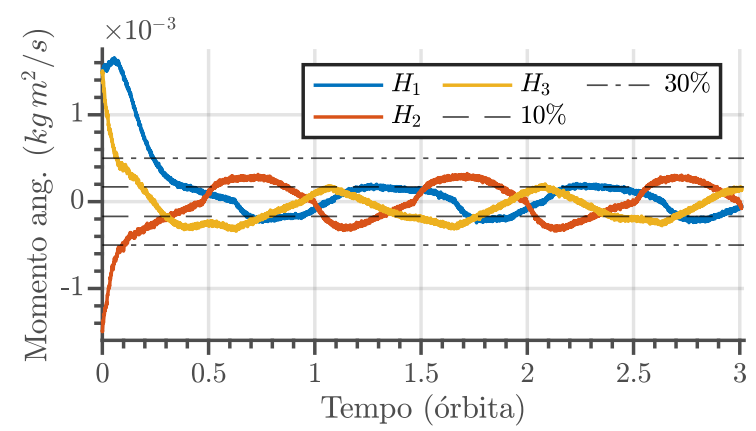

Fonte: Autor.

Em todos os casos a dessaturação atinge a faixa dos $30 \%$ em ao menos 0,5 órbita, cumprindo o requisito R10. Apesar de existir uma folga em relação ao tempo em que a dessaturação é atingida, reduzir o ganho $k_{d s t}$ para que o decaimento do momento angular seja mais lento, implicará em não permanecer no limite de $30 \%$. Note que, com exceção do apontamento na direção Nadir na órbita SSO, o momento angular de, ao menos, uma das rodas de reação oscila de forma que toca o limite superior ou inferior dos $30 \%$. No caso do apontamento na direção Nadir na órbita SSO, reduzir o ganho $k_{d s t}$ implica em permitir que a saturação ocorra nos instantes iniciais, antes mesmo de atingir a faixa desejada.

A Figura 71 ilustra o apontamento na direção fixa nas órbitas ISS com o controle de dessaturação ativado e desativado. No instante inicial o veículo estava alinhado com o GEI, isto é, $\boldsymbol{\Theta}_{s / i}=\left[\begin{array}{lll}0,0^{\circ} & 0,0^{\circ} & 0,0^{\circ}\end{array}\right]^{\top}$, a velocidade angular era de $\boldsymbol{\omega}_{s / i}^{s}=$ $1 / \sqrt{3}\left[\begin{array}{lll}0,02 & 0,02 & 0,02\end{array}\right]^{\top} \mathrm{rad} / \mathrm{s}$, o equivalente à situação após o detumbling, e as rodas de reação estavam em $10 \%$ do valor máximo, isto é, $\mathbf{e}_{a}=\left[\begin{array}{lll}1,2 & 1,2 & 1,2\end{array}\right]^{\top} \mathrm{V}$. O apontamento foi realizado na direção $\Theta_{s / i}=\left[\begin{array}{lll}-90^{\circ} & 45^{\circ}-90^{\circ}\end{array}\right]^{\top}$.

Como é possível notar, com o controle de dessaturação ativado, o erro em regime 
Figura 71 - Apontamento para direção fixa com o controle de dessaturação ativado e desativado.

Controle de dessaturação ativado.

Atitude durante o apontamento.

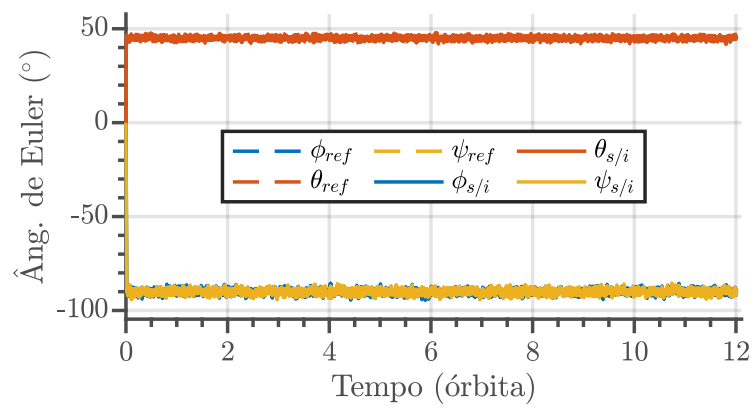

Erro de atitude durante o apontamento.

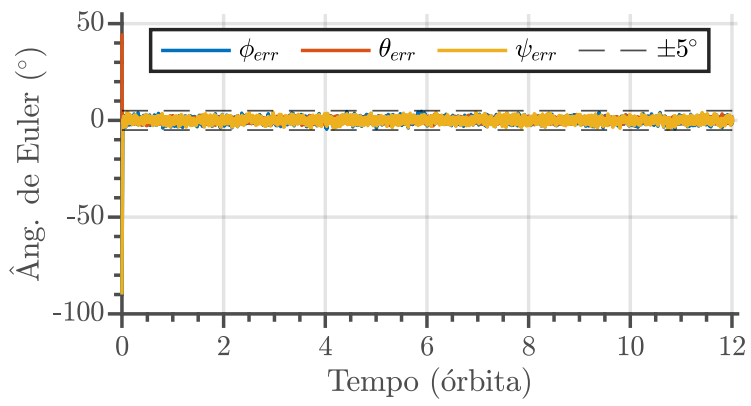

Tensão nas rodas de reação.

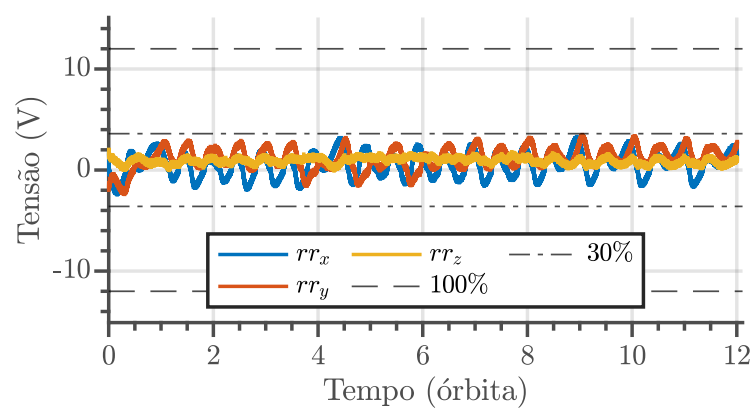

Controle de dessaturação desativado.

Atitude durante o apontamento.

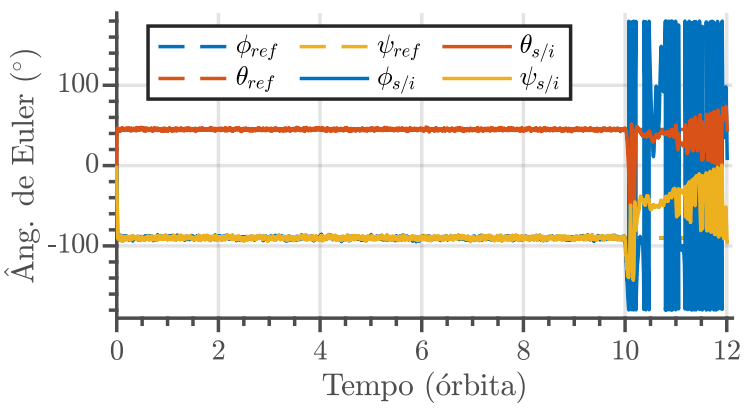

Erro de atitude durante o apontamento.

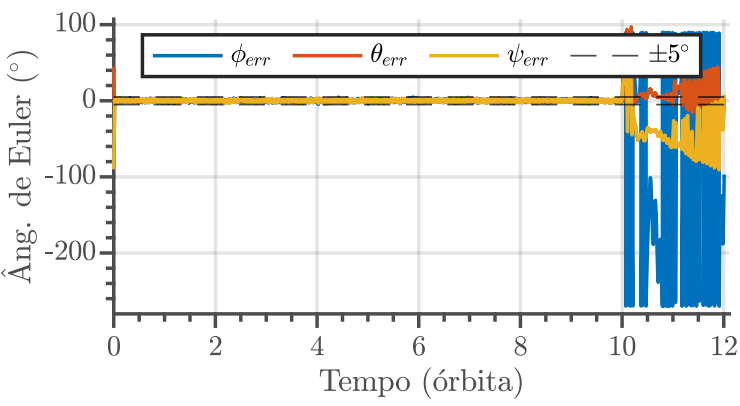

Tensão nas rodas de reação.

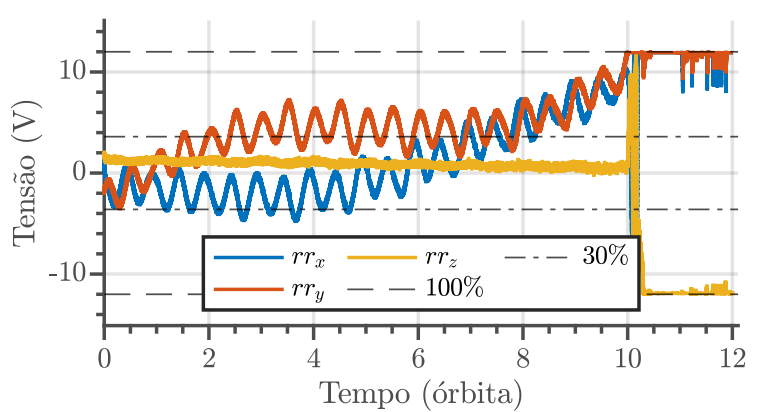

Fonte: Autor.

permanece dentro do intervalo de $\pm 5^{\circ}$ e a tensão das rodas de reação permanece dentro do intervalo de $\pm 3,5 \mathrm{~V}$ (30\%) durante todo o período de simulação. Entretanto, com o controle de dessaturação desativado, as rodas de reação saturam em aproximadamente 10 órbitas e, dessa forma, perdem a capacidade de manter o controle de apontamento.

Por fim, foi simulado um cenário com todos os modos do ACS (Seção 7.1), isto é, inatividade, detumbling, apontamento e contingência. Foi adotada a órbita SSO, pois permite ao leitor observar na ilustração as faixas com maior clareza. A simulação foi realizada na seguinte ordem:

1. o fooSAT-A1 é ejetado na órbita SSO com velocidade angular inicial de $\boldsymbol{\omega}_{s / i}^{s}=$ $1 / \sqrt{3}[0,4-0,40,4]^{\top} \mathrm{rad} / \mathrm{s}$ e permanece inativo durante $30 \mathrm{~min}$; 
2. ativa o modo de detumbling e permanece ativo até a velocidade angular atingir $0,02 \mathrm{rad} / \mathrm{s}$;

3. desativa o modo de detumbling, ativa o modo de apontamento na direção Nadir e permanece ativo por 1 órbita;

4. o ACS apresenta falha, permanece inativo por $30 \mathrm{~min}$ e a velocidade angular do veículo atinge $\boldsymbol{\omega}_{s / i}^{s}=1 / \sqrt{3}[1,2-1,21,2]^{\top} \mathrm{rad} / \mathrm{s}$;

5. ativa o modo de contingência que, por sua vez, ativa o modo de detumbling;

6. o modo de detumbling permanece ativo até a velocidade angular atingir novamente $0,02 \mathrm{rad} / \mathrm{s}$;

7. desativa o modo de detumbling, ativa o modo de apontamento na direção Nadir e permanece ativo por mais 1 órbita.

A atitude, a velocidade angular e os instantes de transição dos modos de controle ao longo de toda a simulação estão ilustrados na Figura 72. E, de forma destacada, as faixas onde ocorreram os modos de detumbling e apontamento estão ilustradas, respectivamente, nas figuras 73 e 74 .

Na faixa 1, o ACS está inativo e, portanto, o fooSAT-A1 está apenas sob influência dos torques de perturbação. Com isso, neste trecho de $30 \mathrm{~min}$, o momento angular do satélite aumentou em $2 \%$ do seu valor inicial.

Na sequência, na faixa 2, foi realizado o detumbling reduzindo a velocidade angular do veículo de $0,4 \mathrm{rad} / \mathrm{s}$ para $0,02 \mathrm{rad} / \mathrm{s}$ em aproximadamente 0,75 órbita.

Na faixa 3 foi realizado o apontamento na direção Nadir. E, na figura destacada (Figura 74) é possível observar que o erro se manteve dentro do intervalo de $5^{\circ}$.

Em seguida, o ACS apresenta falha e a velocidade angular do veículo atinge 1,2 rad/s.

Durante a faixa 4, o ACS permanece inativo e, após $30 \mathrm{~min}$, por meio do modo contingência, o detumbling é acionado novamente. Dessa vez, durante a faixa 5/6, a velocidade angular do fooSAT é reduzida de 1,2 rad/s para 0,02 rad/s em aproximadamente 1,64 órbita. Na faixa 7, mais uma vez, o apontamento na direção Nadir é realizado e permanece no intervalo de $5^{\circ}$ até o fim da simulação. 
Figura 72 - Simulação de um cenário com todos os modos do ACS.

Atitude do satélite.

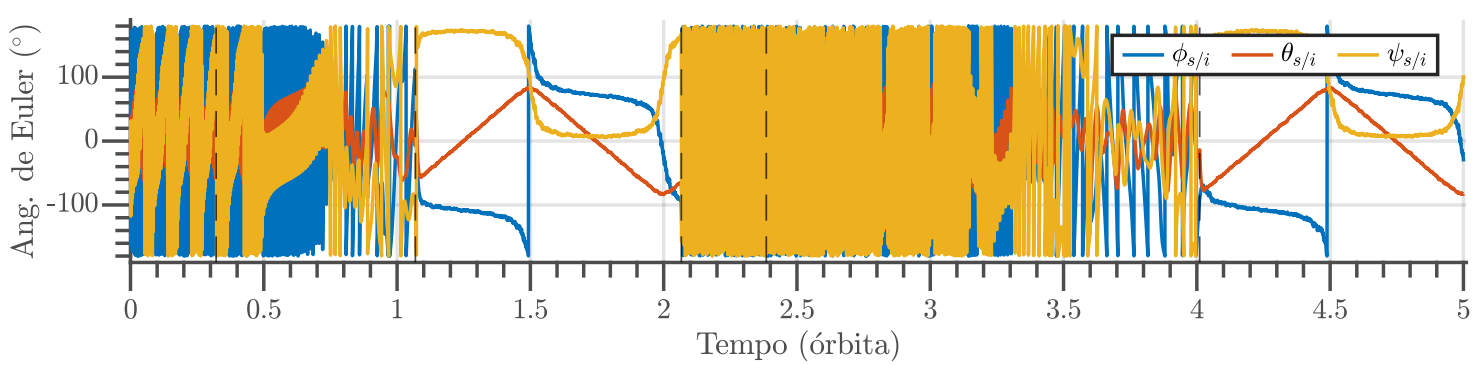

Velocidade angular do satélite.

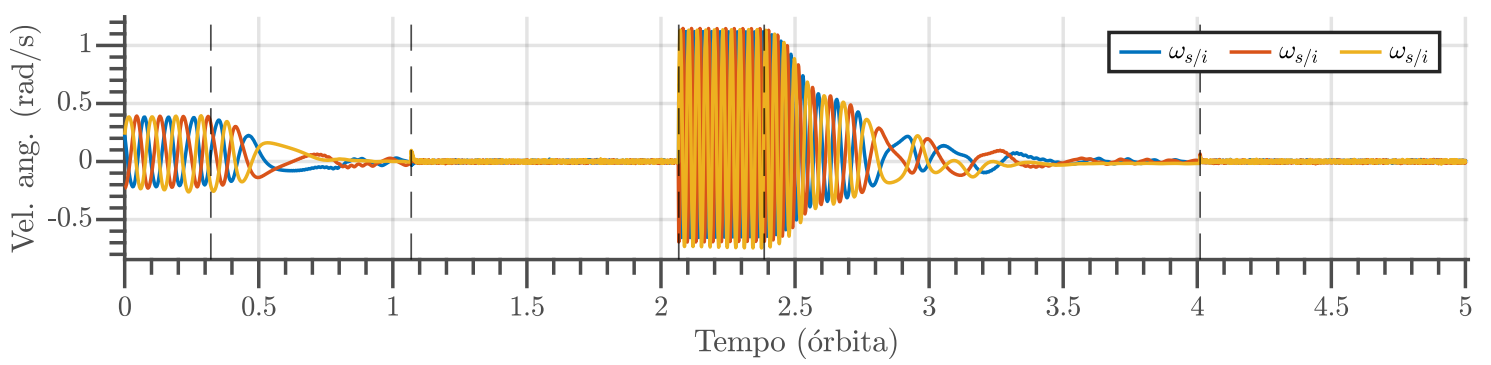

Atividade do ACS.

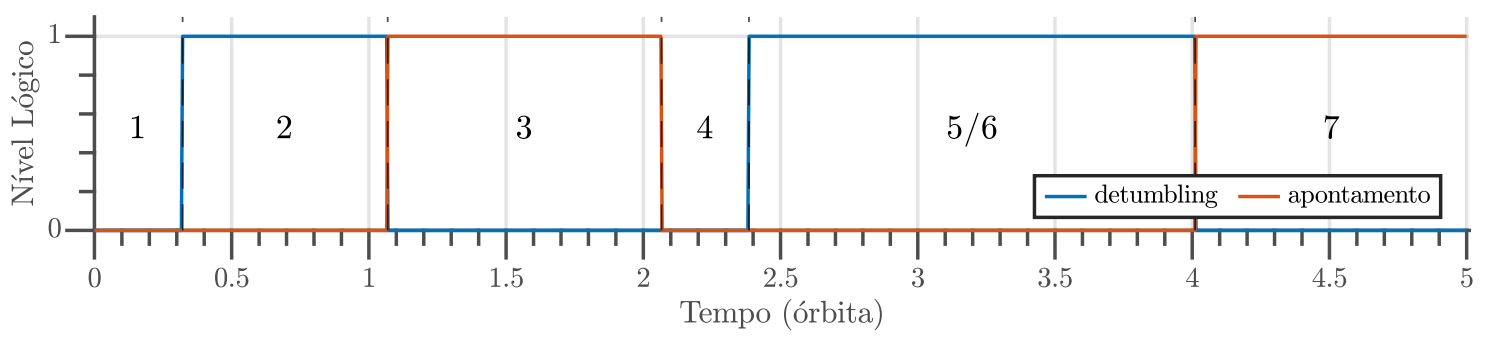

Fonte: Autor. 
Figura 73 - Destaque dos modos de detumbling (Faixas 2 e 6).

Faixa 2.

Velocidade angular do satélite.

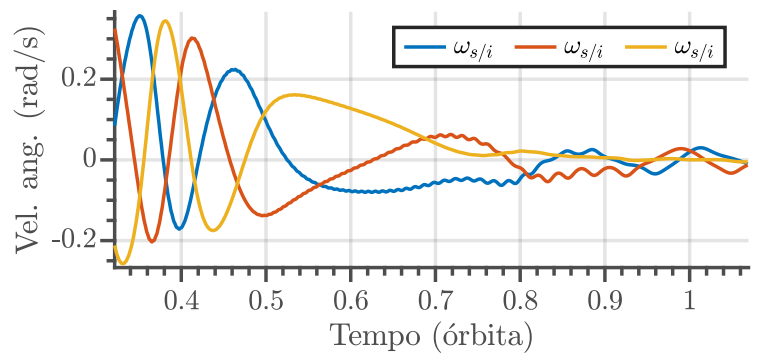

Norma da velocidade angular do satélite.

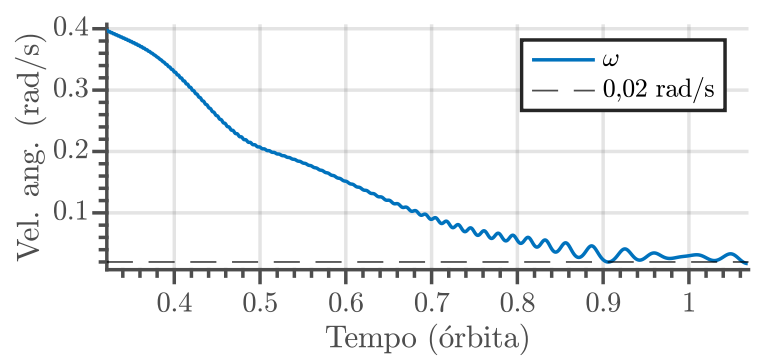

Momento do dipolo magnético.

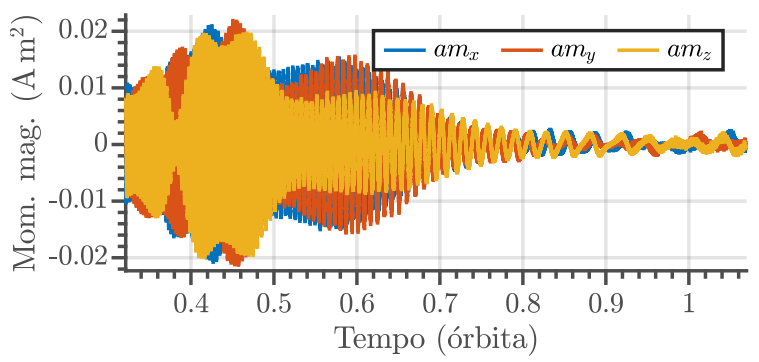

Fonte: Autor.
Faixa 6.

Velocidade angular do satélite.

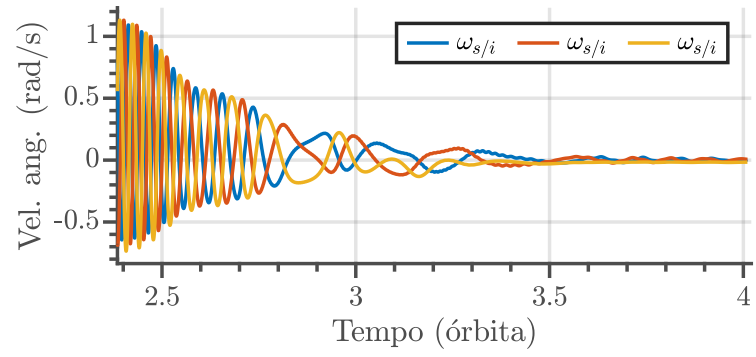

Norma da velocidade angular do satélite.

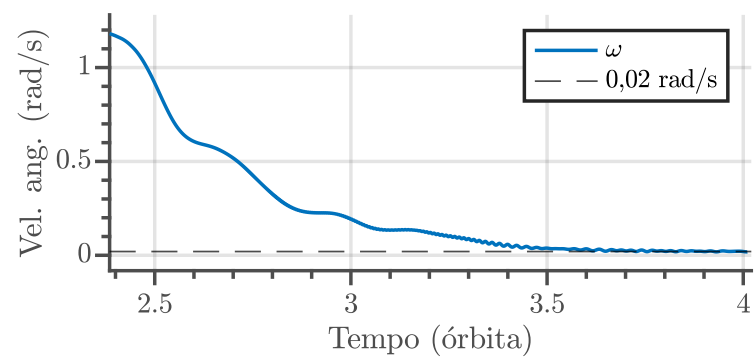

Momento do dipolo magnético.

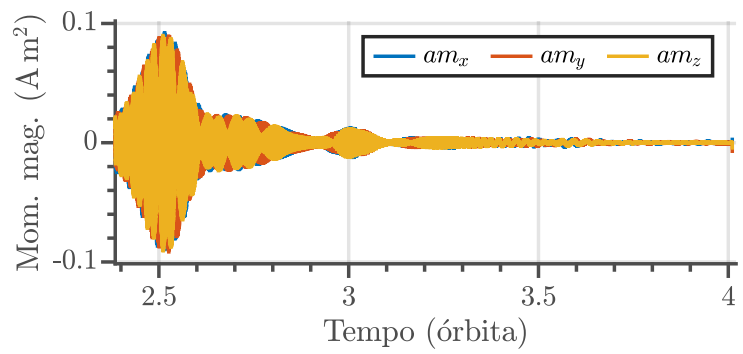


Figura 74 - Destaque dos modos de apontamento para direção Nadir (Faixas 3 e 7).

Faixa 3.

Atitude durante o apontamento.

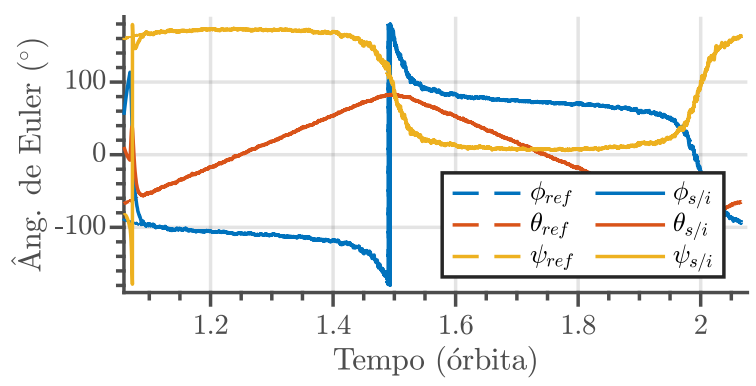

Erro de atitude durante o apontamento.

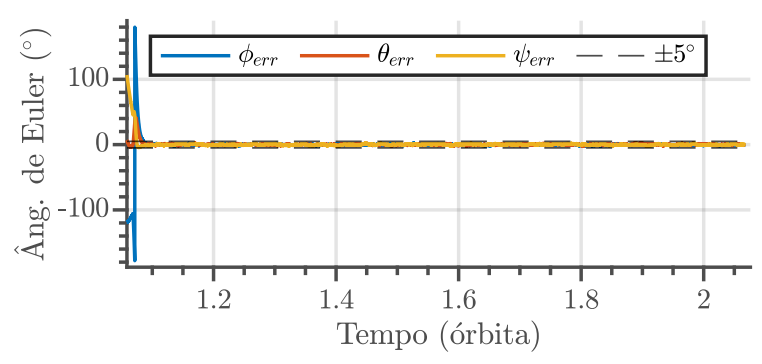

Tensão nas rodas de reação.

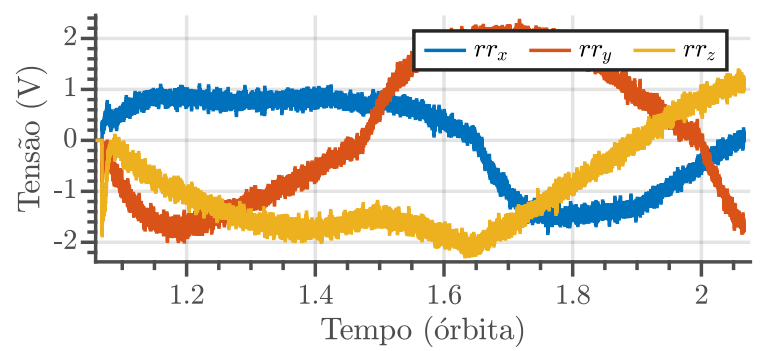

Fonte: Autor.
Faixa 7.

Atitude durante o apontamento.

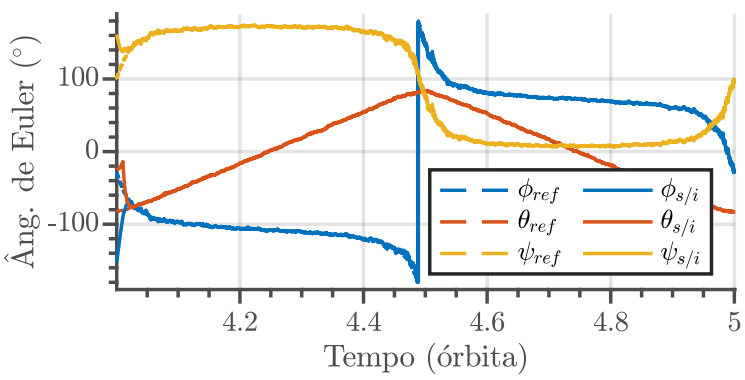

Erro de atitude durante o apontamento.

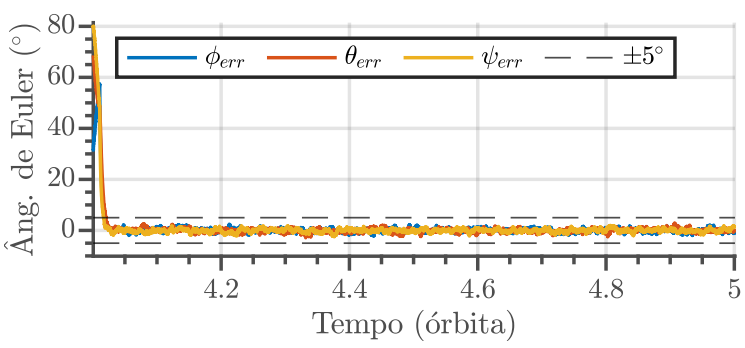

Tensão nas rodas de reação.

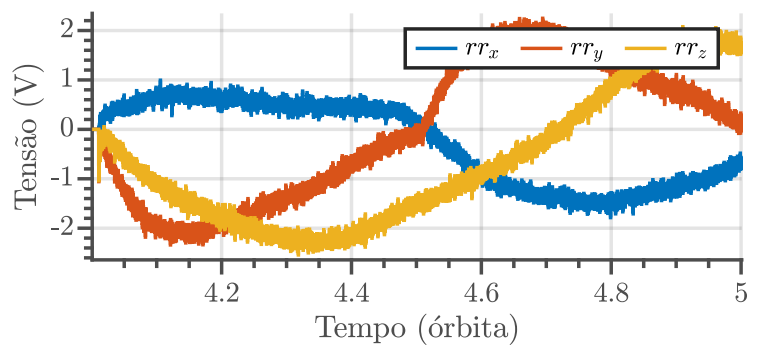





\section{DISCUSSÕES E CONCLUSÕES}

Com o intuito de contribuir com os projetos do IMT e IAG, este trabalho apresentou o desenvolvimento de um simulador de atitude e órbita para nanossatélites em LEO. Para isso, foram implementados em MATLAB e Simulink modelos de alta fidelidade matemática (segundo Sebestyen et al.[23]) da cinemática, dinâmica, propagação orbital e principais perturbações de atitude e órbita.

Como os nanossatélites do IMT e IAG ainda estavam em desenvolvimento no início desse trabalho, não existiam definições últimas quanto às características do veículo e da órbita. Entretanto, para que os resultados de simulação fossem compatíveis com os respectivos projetos, foi estabelecida uma família de nanossatélites hipotéticos, denominada de fooSAT, com características e missões similares às informações disponíveis, bem como duas órbitas hipotéticas, ISS e SSO.

As simulações dos modelos matemáticos foram apresentadas no Capítulo 5 e os resultados da dinâmica do satélite (Seção 5.4), propagação orbital (Seção 5.5) e principais perturbações (Seção 5.6) foram considerados coerentes, quando comparados às referências $[18,68-70]$. Também foi possível notar que a perturbação de atitude de maior influência foi o torque devido ao dipolo magnético residual, o qual é, ao menos, uma ordem de grandeza maior do que o torque devido ao arrasto atmosférico (a segunda perturbação de maior influência). Esse resultado é relevante, pois, para satélites de grande porte, espera-se que a perturbação devida ao dipolo magnético residual tenha pouca influência. No caso das perturbações orbitais, a aceleração devida à não homogeneidade da Terra foi a que apresentou maior influência, aproximadamente $10^{4}$ vezes mais intensa do que as outras perturbações.

Com a contribuição da equipe do LESIA, que disponibilizou os dados de voo do nanossatélite PicSat, foi realizada a validação da dinâmica de atitude e órbita do simulador.

A validação da dinâmica de atitude foi apresentada na Seção 6.2 e realizada em duas etapas. A primeira avaliou a propagação de atitude por 100 s, desconsiderando a influência das perturbações. Nesta etapa, 32 subtrechos de dados de voo foram utilizados para estimar a matriz de inércia, o viés do girômetro e as condições iniciais de velocidade angular. Outros 31 subtrechos de dados de voo foram utilizados para validar os parâmetros estimados. Como resultado, o modelo matemático apresentou erro de, ao menos, uma ordem de grandeza menor do que os valores nominais de velocidade angular inicial.

A segunda etapa, por sua vez, avaliou a influência das perturbações de atitude. Nesta etapa, 5 trechos de dados de voo foram utilizados para estimar o dipolo magnético residual, o centro de massa do veículo e um ganho de perturbação. Outros 5 trechos de dados de 
voo foram utilizados para validar os parâmetros estimados. De forma similar, o modelo da dinâmica do satélite considerando as perturbações de atitude apresentou erro de, ao menos, uma ordem de grandeza menor do que os valores nominais de velocidade angular inicial. Nesta etapa, também foi possível notar que, a influência das perturbações na propagação da atitude foi de $5,3 \%$ após 100 s.

A validação do modelo de propagação orbital foi apresentada na Seção 6.3 e realizada comparando as simulações com os TLEs disponíveis do PicSat entre os dias 12/01/2018 e 29/09/2019. Como resultado, o modelo apresentou erro mediano de 7,1 km após 15 órbitas. Para um observador em solo, esse erro equivale a $3,5^{\prime}$ de diferença no apontamento para o veículo.

Sendo assim, considerando que o simulador foi utilizado para desenvolver o controle de atitude em malha fechada, os erros de modelagem apresentados foram mitigados e os resultados são considerados satisfatórios.

Vale ressaltar que, após uma pesquisa bibliográfica extensa, até o desenvolvimento deste trabalho, não foi encontrada outra publicação brasileira que tenha realizado a validação de um simulador de atitude e/ou órbita com dados de voo.

Também foi apresentado neste trabalho o desenvolvimento de um sistema de controle de atitude passível de ser implementado nos projetos do IMT e IAG. Uma vez mais, para que o ACS desenvolvido fosse compatível com os respectivos projetos, foram estabelecidos requisitos de desempenho baseados em nanossatélites com características similares. Ainda que o sistema de determinação de atitude não fizesse parte desse trabalho, os ruídos de medição dos sensores e o erro de atitude foram emulados. E, ainda, as leis de controle foram implementadas em tempo discreto como forma de inserir realismo ao desempenho final do ACS.

Os resultados de simulação do controlador foram apresentados nas seções 7.3.4 e 7.4.4 e a Tabela 10 apresenta um resumo dos requisitos e seus respectivos resultados.

Por fim, o ACS proposto cumpriu todos os objetivos, bem como foi capaz de executar os seus modos de funcionamento em sequência.

\subsection{Recomendações para Trabalhos Futuros}

É possível que um aprofundamento nas técnicas de identificação de sistemas e tratamento de dados permita realizar a validação do controle de detumbling do PicSat, o que não foi possível de ser realizado nesse trabalho em razão das limitações e dificuldades mencionadas na Seção 6.1.

O simulador pode ter sua capacidade, complexidade e abrangência aumentada com trabalhos futuros. Entre eles, é possível desenvolver: (i) perturbações ainda não contempladas 
Tabela 10 - Resumo dos Requisitos Atingidos.

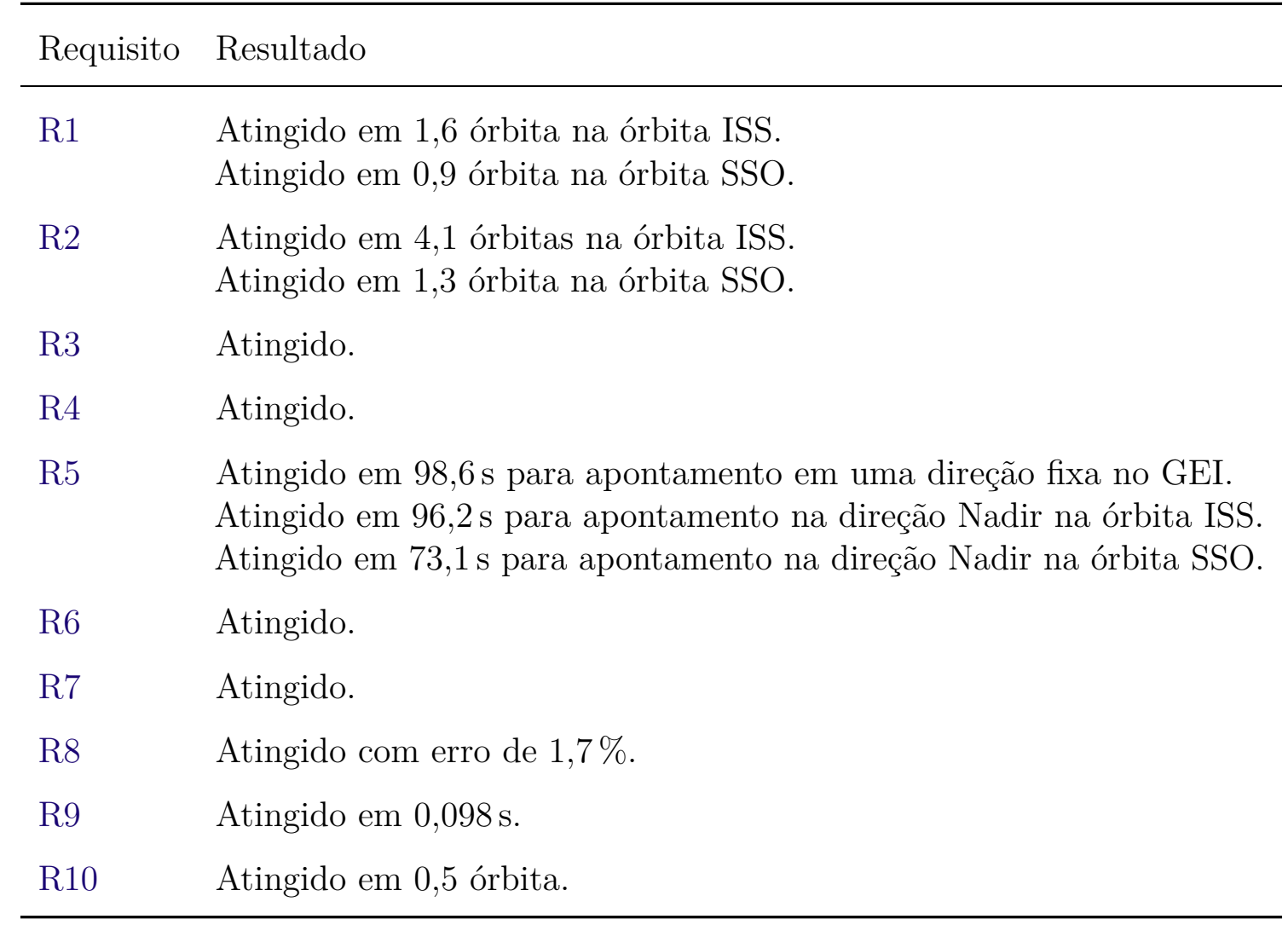

Fonte: Autor.

como efeito das marés, efeito do albedo, isto é, da reflexão da radiação solar na atmosfera, efeito do desalinhamento das rodas de reação, efeito da abertura de antenas e painéis solares e efeito da flexibilidade da estrutura do veículo; (ii) outros tipos de atuadores como ímã permanente, barra de histerese, mastro de gradiente de gravidade, propulsor e disco de inércia; (iii) outros tipos de controladores e modos de funcionamento do ACS; (iv) o sistema de determinação de atitude; (v) o sistema de determinação e controle de órbita; e (vi) uma interface gráfica para usuários com menor experiência de programação no software MATLAB e Simulink. Ademais, o simulador também pode ser utilizado como ferramenta de desenvolvimento de outros nanossatélites e subsistemas. 



\section{REFERÊNCIAS}

1 KEPLER, J. Mysterium cosmographicum (The Secret of the Universe). Translation by A. M. Duncan and notes by E. J. Aiton. New York: Abaris Books, 1981. v. 9. ISBN 9780913870648.

2 UNITED NATIONS OFFICE FOR OUTER SPACE AFFAIRS. Online index of objects launched into outer space. 2019. Disponível em: <http://www.unoosa.org $>$. Acesso em: 07 jan. 2019.

3 Botelho A. S., R. C.; Xavier Jr, A. L. A unified satellite taxonomy proposal based on mass and size. Advances in Aerospace Science and Technology, Scientific Research Publishing, Inc., v. 04, n. 04, p. 57-73, 2019. ISSN 2473-6724. Disponível em: < https: //www.scirp.org/journal/paperinformation.aspx?paperid=96030>. Acesso em: 25 maio 2020.

4 NANOSATS Database. Maintained by Erik Kulu. 2020. Disponível em: < https://www. nanosats.eu>. Acesso em: 20 abr. 2020.

5 WEKERLE, T. et al. Status and trends of smallsats and their launch vehicles - an up-to-date review. Journal of Aerospace Technology and Management, Institute of Aeronautics and Space, São José dos Campos, v. 7, n. 3, p. 269-286, aug 2017. Disponível em: <https://doi.org/10.5028/jatm.v9i3.853>. Acesso em: 13 maio 2020.

6 Centro de Gestão e Estudos Estratégicos - CGEE. CubeSats: Resumo executivo. Brasília, DF: CGEE, 2018. 46 p. ISBN 978-85-5569-142-3. Disponível em: <https://www. cgee.org.br/documents/10195/734063/CGEE_resumoexecutivo_CubeSats_Web.pdf $>$. Acesso em: 24 maio 2020.

7 PUIG-SUARI, J.; TURNER, C.; TWIGGS, R. CubeSat: the development and launch support infrastructure for eighteen different satellite customers on one launch. In: ANNUAL/USU CONFERENCE ON SMALL SATELLITES, 15., 2001, Logan. Proceedings... Logan: AIAA/USU, 2001. Disponível em: < https://digitalcommons.usu.edu/ smallsat/2001/All2001/59/>. Acesso em: 11 jun. 2019.

8 POGHOSYAN, A.; GOLKAR, A. CubeSat evolution: analyzing CubeSat capabilities for conducting science missions. Progress in Aerospace Sciences, Elsevier BV, v. 88, p. 59-83, jan. 2016. Disponível em: <http://dx.doi.org/10.1016/j.paerosci.2016.11.002>. Acesso em: 12 maio 2020.

9 VILLELA, T. et al. Towards the thousandth CubeSat: a statistical overview. International Journal of Aerospace Engineering, Hindawi Limited, v. 2019, p. 1-13, jan 2019. Disponível em: <https://doi.org/10.1155/2019/5063145>. Acesso em: 13 maio 2020.

10 PLANET LABS. 2020. Disponível em: < https://www.planet.com/>. Acesso em: 25 maio 2020.

11 MARS CUBE ONE (MarCO). [2020]. Disponível em: <https://www.jpl.nasa.gov/ cubesat/missions/marco.php>. Acesso em: 25 maio 2020. 
12 NANOSATC-BR1. [201-?]. Disponível em: < http://www.inpe.br/crs/nanosat/>. Acesso em: 25 maio 2020.

13 SERPENS. 2018. Disponível em: <http://www.aeb.gov.br/espaco-educacao-etecnologia/serpens/>. Acesso em: 25 maio 2020.

14 AESP-14. [2015?]. Disponível em: <http://www.ita.br/cubesat/aesp-14>. Acesso em: 25 maio 2020.

15 ITASAT-1. [2019]. Disponível em: <http://www.itasat.ita.br/>. Acesso em: 25 maio 2020.

16 FLORIPASAT-1. [2020]. Disponível em: < https://floripasat.ufsc.br/pt/home-br/>. Acesso em: 25 maio 2020.

17 BOUWMEESTER, J.; GUO, J. Survey of worldwide pico- and nanosatellite missions, distributions and subsystem technology. Acta Astronautica, Elsevier BV, v. 67, n. 7-8, p. 854-862, oct 2010. Disponível em: < https://doi.org/10.1016/j.actaastro.2010.06.004>. Acesso em: 04 ago. 2018.

18 WERTZ, J. R. (Ed.). Spacecraft attitude determination and control. Dordrecht, Holland: D. Reidel, 1978. v. 73. 858 p. ISBN 90-277-0959-9.

19 LANGER, M. et al. A reliability estimation tool for reducing infant mortality in CubeSat missions. In: AEROSPACE CONFERENCE, 2017, Big Sky, MT. Proceedings... Big Sky, MT: IEEE, 2017. Disponível em: < https://ieeexplore.ieee.org/document/ 7943598>. Acesso em: 25 maio 2020.

20 NAKASUKA, S. et al. Discussions on attitude determination and control system for micro/nano/pico-satellites considering survivability based on Hodoyoshi-3 and 4 experiences. Acta Astronautica, Elsevier BV, v. 145, p. 515-527, apr 2018. Disponível em: <https://doi.org/10.1016/j.actaastro.2018.02.006>. Acesso em: 14 maio 2020.

21 PASCOA, J. C.; TEIXEIRA, O.; FILIPE, G. A review of propulsion systems for CubeSats. In: INTERNATIONAL MECHANICAL ENGINEERING CONGRESS AND EXPOSITION, 1., 2018, Pittsburgh. Proceedings... Pittsburgh: ASME, 2018. (Advances in Aerospace Technology, Volume 1), p. 1-8. V001T03A039. Disponível em: < https: //doi.org/10.1115/IMECE2018-88174>. Acesso em: 25 maio 2020.

22 POLAT, H. C.; VIRGILI-LLOP, J.; ROMANO, M. Survey, statistical analysis and classification of launched CubeSat missions with emphasis on the attitude control method. Journal of Small Satellites, v. 5, n. 3, p. 513-530, 2016. Disponível em: <https: //jossonline.com/?page_id=1906>. Acesso em: 14 maio 2020.

23 SEBESTYEN, G. et al. Low earth orbit satellite design. Cham, Switzerland: Springer-Verlag GmbH, 2018. ISBN 978-3-319-68314-0.

24 GRAVERSEN, T.; FREDERIKSEN, M. K.; VEDSTESEN, S. V. Attitude control system for AAU CubeSat. 2002. Dissertação (Mestrado) - Aalborg University, Aalborg, 2002. GROUP: IAS-1031.

25 KROGH, K.; SCHREDER, E. Attitude determination for AAU CubeSat. Aalborg, 2002. 133 p. GROUP: IAS-1030. 
26 ANDRESEN, B. Ø. et al. Attitude control system for AAUSAT-II. Aalborg, 2005. 113 p.

27 GIESSELMANN, J. Development of an active magnetic attitude determination and control system for picosatellites on highly inclined circular low Earth orbits. 2006. Dissertação (Mestrado) - RMIT University, Melbourne, 2006. Disponível em: <http://researchbank.rmit.edu.au/view/rmit:6277>. Acesso em: 20 maio 2020.

28 JENSEN, K. F.; VINTHER, K. Attitude determination and control system for AAUSAT3. 2010. Dissertação (Mestrado) - Aalborg University, Aalborg, 2010.

29 FRANCOIS-LAVET, V. Study of passive and active attitude controlsystems for the OUFTI nanosatellites. 2010. Dissertação (Mestrado) - University of Liège, Liège, 2010.

30 OLIVEIRA, G. F. Um sistema de determinação e controle de atitude de baixo custo para o primeiro nonossatélite ucraniano, UYS-1. 2013. Dissertação (Mestrado) - Universidade de Brasília, Brasília, 2013. Departamento de Engenharia Elétrica. Disponível em: < https://repositorio.unb.br/handle/10482/14230>. Acesso em: 13 maio 2020.

31 HOLST, R. Satellite attitude control: using magnetorquers with magnetic dipole moment calcellation. 2014. Dissertação (Mestrado) - Aalborg University, Aalborg, 2014.

32 VUUREN, G. H. J. van. The design and simulation analysis of an attitude determination and control system for a small earth observation satellite. 2015 . Dissertação (Mestrado) - Stellenbosch University, Stellenbosch, 2015. Disponível em: <http://hdl.handle.net/10019.1/96979>. Acesso em: 17 maio 2020.

33 THOMSEN, B. G.; NIELSEN, J. CubeSat sliding mode attitude control - developing testbed for verification of attitude control algorithms. 2016. Dissertação (Mestrado) - Aalborg University, Aalborg, 2016.

34 RONDãO, D. O. d. M. A. Modeling and simulation of the ECOSat-III attitude determination and control system. 2016. Dissertação (Mestrado) - Técnico Lisboa, 2016. Disponível em: < https://fenix.tecnico.ulisboa.pt/cursos/meaer/dissertacao/ 283828618789559>. Acesso em: 13 maio 2020.

35 JUNIOR, A. F. de O. Projeto e simulação do sistema de validação e testes de controle de atitude com aplicação em micro-satélites. 2016. Dissertação (Mestrado) - Instituto Nacional de Pesquisas Espaciais, São José dos Campos, 2016. Disponível em: <http://urlib.net/sid.inpe.br/mtc-m21b/2016/07.14.00.14>. Acesso em: 13 maio 2020.

36 CAMPOS, E. L. Implementação de um simulador para ocontrole de atitude em nanossatélites. 2018. Dissertação (Mestrado) - Universidade Federal do Rio Grande do Norte, Natal, 2018. Disponível em: <https://repositorio.ufrn.br/jspui/handle/ 123456789/26344>. Acesso em: 13 maio 2020.

37 AVANZINI, G. et al. Attitude control of Low Earth Orbit satellites by reaction wheels and magnetic torquers. Acta Astronautica, Elsevier BV, v. 160, p. 625-634, jul. 2019. Disponível em: <https://doi.org/10.1016/j.actaastro.2019.03.013>. Acesso em: 12 maio 2020. 
38 JONSSON, L. Simulations of satellite attitude maneuvers : detumbling and pointing. 2019. Dissertação (Mestrado) — LuleåUniversity of Technology, Space Technology, 2019. Disponível em: < http://ltu.diva-portal.org/smash/record.jsf?pid=diva2: 1298491\&dswid=3150>. Acesso em: 20 maio 2020.

39 MENGES, B.; GUADIAMOS, C.; PERNICKA, H. Dynamic modeling of microsatellite Spartnik's attitude. In: AEROSPACE SCIENCES MEETING AND EXHIBIT, 36., 1998, Reno, NV. Proceedings... Reno, NV: AIAA, 1998. Disponível em: < https: //doi.org/10.2514/6.1998-9>. Acesso em: 14 maio 2020.

40 LOVERA, M. Modelling and simulation of spacecraft attitude dynamics. In: VIENNA CONFERENCE ON MATHEMATICAL MODELLING, 4., 2003, Vienna. Proceedings... Vienna: ARGESIM, 2003. p. 498-506. ISBN 978-3-901608-23-0. Disponível em: < https:// www.eurosim.info/publications/eurosim-pub-detail/mathmod-2003-proceedings $>$. Acesso em: 14 maio 2020.

41 NASIRIAN, M. et al. Design of a satellite attitude control simulator. In: INTERNATIONAL SYMPOSIUM ON SYSTEMS AND CONTROL IN AEROSPACE AND ASTRONAUTICS, 1., 2006, Harbin, China. Proceedings... Harbin, China: IEEE, 2006. p. 160-163. ISBN 0-7803-9395-3. Disponível em: < https://ieeexplore.ieee.org/document/1627602>. Acesso em: 13 maio 2020.

42 TRIHARJANTO, R. H. et al. Evaluation of attitude dynamic module on LAPAN-ITB micro-satellite simulator. In: IEEE INTERNATIONAL CONFERENCE ON AEROSPACE ELECTRONICS AND REMOTE SENSING TECHNOLOGY (ICARES), 2015, Bali. Proceedings... Bali: IEEE, 2015. p. 1-6. Disponível em: < https://ieeexplore.ieee.org/ document/7429815>. Acesso em: 20 maio 2020.

43 HABIBKHAH, S.; ARASI, J.; BOLANDI, H. SPACSSIM: simulation and analysis software for mathematical modeling of satellite position and attitude control systems. Computing in Science \& Engineering, Institute of Electrical and Electronics Engineers (IEEE), v. 19, n. 5, p. 38-48, 2017. Disponível em: < https://ieeexplore.ieee.org/document/ 8024145>. Acesso em: 20 maio 2020.

44 NAQVI, N. A.; RAZA, M. Simulator development of an attitude determination and control subsystem of an Earth observation satellite. In: INTERNATIONAL CONFERENCE ON RECENT ADVANCES IN SPACE TECHNOLOGIES, 3., 2007, Istanbul. Proceedings... IEEE, 2007. p. 448-452. Disponível em: < https://ieeexplore.ieee.org/ document/4284031>. Acesso em: 20 maio 2020.

45 ALSHAMY, H. M. I. et al. Flight dynamic model for low earth orbit satellites. IOP Conference Series: Materials Science and Engineering, IOP Publishing, v. 610, p. 012100, oct 2019. Disponível em: < https://iopscience.iop.org/article/10.1088/1757899X/610/1/012100>. Acesso em: 20 maio 2020.

46 LIU, Y. H. et al. Modeling and simulation of satellite attitude dynamics and control system using Modelica. In: ASIA CONFERENCE ON MECHANICAL AND AEROSPACE ENGINEERING, 9., 2018, Singapore. Proceedings... Singapore: IOP Publishing, 2019. v. 1215. Disponível em: <https://doi.org/10.1088/1742-6596/1215/1/012014>. Acesso em: 14 maio 2020. 
47 ODTBX. 2019. Disponível em: <https://opensource.gsfc.nasa.gov/projects/ODTBX/ >. Acesso em: 25 maio 2020.

48 OMAR, K. H. Simultaneous orbital and attitude propagation of satellites in low-Earth orbit using CUDA for aerodynamics simulation. In: AIAA AEROSPACE SCIENCES MEETING, 55., 2017, Grapevine, TX. Proceedings... Grapevine, TX: American Institute of Aeronautics and Astronautics, 2017. Disponível em: <https://doi.org/10.2514/6.20172005>. Acesso em: 13 maio 2020.

49 CARRARA, V. An open source satellite attitude and orbit simulator toolbox for Matlab. In: INTERNATIONAL SYMPOSIUM ON DYNAMIC PROBLEMS OF MECHANICS, 17., 2015, Natal. Proceedings... Natal: ABCM, 2015. Disponível em: <http://abcm.org.br/anais/diname/2015/proceedings.html>. Acesso em: 13 maio 2020.

50 RAWASHDEH, S. A. Attitude analysis of small satellites using model-based simulation. International Journal of Aerospace Engineering, Hindawi Limited, v. 2019, p. 1-11, apr 2019. Disponível em: <https://doi.org/10.1155/2019/3020581>. Acesso em: 19 maio 2020.

51 TURNER, A. J. An open-source, extensible spacecraft simulation and modeling environment framework. 2003. Dissertação (Mestrado) - Virginia Tech, Blacksburg, 2003. Disponível em: < http://hdl.handle.net/10919/34727>. Acesso em: 20 maio 2020 .

52 STK ODTK AGI. 2020. Disponível em: < https://www.agi.com/products>. Acesso em: 25 maio 2020.

53 MADS 3D. [2020]. Disponível em: < https://www.cubesatshop.com/product/mads3d-dynamic-simulator/>. Acesso em: 25 maio 2020.

54 SPACECRAFT Control Toolbox (SCT). 2020. Disponível em: < http://www.psatellite. com/products/sct/>. Acesso em: 25 maio 2020.

55 STERNBERG, D. C. et al. Jet Propulsion Laboratory Small Satellite Dynamics Testbed simulation: on-orbit performance model validation. Journal of Spacecraft and Rockets, American Institute of Aeronautics and Astronautics (AIAA), v. 55, n. 2, p. 322-334, mar 2018. Disponível em: <https://doi.org/10.2514/1.A33806>. Acesso em: 19 maio 2020 .

56 BANGERT, P.; BUSCH, S.; SCHILLING, K. Performance characteristics of the UWE-3 miniature attitude determination and control system. In: IAA CONFERENCE ON DYNAMICS AND CONTROL OF SPACE SYSTEMS (DYCOSS), 2., 2014, Rome. Proceedings... [S.l.], 2014.

57 SATO, Y. et al. Improvement and verification of satellite dynamics simulator based on flight data analysis. In: IEEE/SICE INTERNATIONAL SYMPOSIUM ON SYSTEM INTEGRATION (SII), 2017, Taipei. Proceedings... Taipei: IEEE, 2017. p. 686-691. ISSN 2474-2325. Disponível em: < https://ieeexplore.ieee.org/document/8279301>. Acesso em: 13 maio 2020.

58 SLAVINSKIS, A. et al. Flight results of ESTCube-1 attitude determination system. Journal of Aerospace Engineering, American Society of Civil Engineers (ASCE), 
v. 29, n. 1, p. 1-7, jan 2016. Disponível em: < https://doi.org/10.1061/(ASCE)AS.19435525.0000504>. Acesso em: 15 maio 2020.

59 SPRINGMANN, J. C.; CUTLER, J. W. Flight results of a low-cost attitude determination system. Acta Astronautica, Elsevier BV, v. 99, p. 201-214, jun 2014. Disponível em: <https://doi.org/10.1016/j.actaastro.2014.02.026>. Acesso em: 14 maio 2020.

60 TARABA, M. et al. Boeing's CubeSat TestBed 1 attitude determination design and on-orbit experience. In: ANNUAL/USU CONFERENCE ON SMALL SATELLITES, 23., 2009, Logan. Proceedings... AIAA/USU, 2009. Disponível em: < https://digitalcommons. usu.edu/smallsat/2009/all2009/64/>. Acesso em: 20 maio 2020.

61 SCHOLZ, A. et al. Flight results of the COMPASS-1 picosatellite mission. Acta Astronautica, Elsevier BV, v. 67, n. 9-10, p. 1289-1298, nov 2010. Disponível em: $<$ https://doi.org/10.1016/j.actaastro.2010.06.040>. Acesso em: 19 maio 2020.

62 XIANG, T. et al. Design and on-orbit performance of the attitude determination and control system for the ZDPS-1A pico-satellite. Acta Astronautica, Elsevier BV, v. 77, p. 182-196, aug 2012. Disponível em: < https://doi.org/10.1016/j.actaastro.2012.03.023>. Acesso em: 19 maio 2020.

63 SARDA, K. et al. On-orbit performance of the bright target explorer (BRITE) nanosatellite astronomy constellation. In: ANNUAL/USU CONFERENCE ON SMALL SATELliteS, 28., 2014, Logan. Proceedings... AIAA/USU, 2014. Disponível em: $<$ https://digitalcommons.usu.edu/smallsat/2014/YearReview/4/>. Acesso em: 19 maio 2020 .

64 DECHAO, R. et al. Attitude control system design and on-orbit performance analysis of nano-satellite - "Tian Tuo 1". Chinese Journal of Aeronautics, Elsevier BV, v. 27, n. 3, p. 593-601, jun 2014. Disponível em: < http://dx.doi.org/10.1016/j.cja.2013.11.001>. Acesso em: 15 maio 2020.

65 MASON, J. P. et al. MinXSS-1 CubeSat on-orbit pointing and power performance: the first flight of the Blue Canyon Technologies XACT 3-axis attitude determination and control system. Journal of Small Satellites, v. 6, p. 651-662, 2017. Disponível em: < https: //jossonline.com/letters/minxss-1-cubesat-on-orbit-pointing-and-power-performancethe-first-flight-of-the-blue-canyon-technologies-xact-3-axis-attitude-determination-andcontrol-system/>. Acesso em: 20 maio 2020.

66 PONG, C. On-orbit performance \& operation of the attitude \& pointing control subsystems on ASTERIA. In: ANNUAL/USU CONFERENCE ON SMALL SATELLITES, 32., 2018, Logan. Proceedings... AIAA/USU, 2018. Disponível em: < https: //digitalcommons.usu.edu/smallsat/2018/all2018/361/>. Acesso em: 20 maio 2020.

67 PICSAT TEAM. PicSat. 2019. Disponível em: < https://picsat.obspm.fr>. Acesso em: 07 jan. 2019.

68 CURTIS, H. Orbital mechanics for engineering students. 3. ed. Oxford: Butterworth-Heinemann, 2014. 768 p. (Aerospace Engineering). ISBN 0080977472.

69 SIDI, M. J. Spacecraft dynamics and control: a practical engineering approach. [S.l.]: Cambridge university press, 1997. v. 7. 432 p. (Cambridge aerospace series, v. 7). ISBN 978-0-521-78780-2. 
70 VALLADO, D. Fundamentals of astrodynamics and applications. Hawthorne, CA: Published by Microcosm Press, 2013. ISBN 9781881883203.

71 DIEBEL, J. Representing attitude: euler angles, unit quaternions, and rotation vectors. Matrix, Stuuttgart, Germany, v. 58, p. 35, 2006.

72 MARKLEY, F. L.; CRASSIDIS, J. L. Fundamentals of spacecraft attitude determination and control. New York: Springer, 2014. ISBN 978-1-4939-0801-1.

73 SEIDELMANN, P. K. (Ed.). Explanatory supplement to the astronomical almanac. Sausalito, CA: University Science Books, 2006. ISBN 978-1-891389-85-6.

74 BLANKE, M.; LARSEN, M. B. Satellite dynamics and control in a quaternion formulation. Technical University of Denmark, Department of Electrical Engineering, 2010. 50 p. Lecture note for course 31365. Disponível em: <https://orbit.dtu.dk/files/ 98594729/Satdyn_mb_2010f.pdf $>$. Acesso em: 12 jun. 2019.

75 YOST, B. State of the art of small spacecraft technology. 2020. NASA. Disponível em: <https://sst-soa.arc.nasa.gov>. Acesso em: 20 maio 2020.

76 XIA, C.-1. Permanent magnet brushless dc motor drives and controls. [S.l.]: Wiley, 2012. 282 p. ISBN 978-1-118-18833-0.

77 CENTRE NATIONAL D'ETUDES SPATIALES. Spacecraft techniques and technology. 4. ed. Toulouse: Cépaduès, 2005. v. 3. CNES. ISBN 978-2-85428-685-4.

78 NASA SPACE VEHICLE DESIGN CRITERIA. Spacecraft aerodynamic torques. Washington, DC, 1971. 38 p. Technical Report, NASA-SP-8058. Disponível em: <https: //ntrs.nasa.gov/archive/nasa/casi.ntrs.nasa.gov/19710016459.pdf $>$. Acesso em: 11 jul. 2019 .

79 CANUTO, E. et al. Spacecraft dynamics and control : the embedded model control approach. Cambridge, MA: Butterworth-Heinemann, 2018. ISBN 978-0-08100700-6.

80 REYNERSON, C. Aerodynamic disturbanceforce and torque estimation for spacecraft and simple shapes using finite plate elements - part I: drag coefficient. In: Advances in Spacecraft Technologies. [S.1.]: InTech, 2011.

81 PRIETO, D. M.; GRAZIANO, B. P.; ROBERTS, P. C. E. Spacecraft drag modelling. Progress in Aerospace Sciences, v. 64, p. 56-65, 2014. ISSN 0376-0421. Disponível em: < http://www.sciencedirect.com/science/article/pii/S0376042113000754>. Acesso em: 12 jul. 2019.

82 VALLADO, D. A.; FINKLEMAN, D. A critical assessment of satellite drag and atmospheric density modeling. Acta Astronautica, Colorado Springs, v. 95, p. 141-165, fev. 2014. ISSN 0094-5765. Disponível em: < http://www.sciencedirect.com/science/ article/pii/S0094576513003755>. Acesso em: 12 jun. 2019.

83 PICONE, J. M. et al. NRLMSISE-00 empirical model of the atmosphere: statistical comparisons and scientific issues. Journal of Geophysical Research: Space Physics, Washington, D.C., v. 107, n. A12, p. 1-16, 2002. Disponível em: <https://agupubs. onlinelibrary.wiley.com/doi/abs/10.1029/2002JA009430>. Acesso em: 12 jul. 2019. 
84 NASA SPACE VEHICLE DESIGN CRITERIA. Spacecraft magnetic torques. Washington, DC, 1969. 55 p. Technical Report, NASA-SP-8018. Disponível em: < https: //ntrs.nasa.gov/archive/nasa/casi.ntrs.nasa.gov/19690020961.pdf >. Acesso em: 11 jul. 2019.

85 NASA SPACE VEHICLE DESIGN CRITERIA. Spacecraft radiation torques. Washington, DC, 1969. 41 p. Technical Report, NASA-SP-8027. Disponível em: < https: //ntrs.nasa.gov/archive/nasa/casi.ntrs.nasa.gov/19710014836.pdf $>$. Acesso em: 11 jul. 2019.

86 U.S. NAUTICAL ALMANAC OFFICE. The astronomical almanac for the year 2014. Washington, D.C., 2013. 618 p. (Astronomical Almanac For the Year).

87 NASA SPACE VEHICLE DESIGN CRITERIA. Spacecraft gravitational torques. Washington, DC, 1969. 51 p. Technical Report, NASA-SP-8024. Disponível em: < https: //ntrs.nasa.gov/archive/nasa/casi.ntrs.nasa.gov/19700014113.pdf > . Acesso em: 11 jul. 2019.

88 SPRINGMANN, J.; CUTLER, J.; BAHCIVAN, H. Magnetic sensor calibration and eesidual dipole characterization for application to nanosatellites. In: AIAA/AAS ASTRODYNAMICS SPECIALIST CONFERENCE, 2010, Toronto. Proceedings... Toronto: American Institute of Aeronautics and Astronautics, 2010. Disponível em: <https://doi.org/10.2514/6.2010-7518>. Acesso em: 12 abr. 2019.

89 THÉBAULT, E. et al. International geomagnetic reference field: the 12th generation. Earth, Planets and Space, Springer, v. 67, n. 1, p. 79, maio 2015. ISSN 1880-5981. Disponível em: <https://doi.org/10.1186/s40623-015-0228-9>. Acesso em: 12 jul. 2019.

90 CHULLIAT, A. et al. The US/UK world magnetic model for 2015-2020. [S.l.], 2015. 112 p. National Geophysical Data Center, NOAA. Disponível em: <https://doi.org/ 10.7289/V5TB14V7>. Acesso em: 12 jul. 2019.

91 PAVLIS, N. K. et al. The development and evaluation of the Earth Gravitational Model 2008 (EGM2008). Journal of Geophysical Research: Solid Earth, American Geophysical Union (AGU), v. 117, n. B4, apr 2012. Disponível em: <https://doi.org/10. 1029/2011JB008916>. Acesso em: 19 jun. 2020.

92 AAUSAT-II. [2013?]. Disponível em: < http://www.space.aau.dk/aausatii/>. Acesso em: 25 maio 2020.

93 CUBETORQUER. 2018. Disponível em: < https://www.cubespace.co.za/products/ adcs-components/cubetorquer/>. Acesso em: 29 mar. 2018.

94 MEHRPARVAR, A. et al. Cubesat design specification rev. 13. [S.l.], 2014.

95 INAMORI, T.; SAKO, N.; NAKASUKA, S. Magnetic dipole moment estimation and compensation for an accurate attitude control in nano-satellite missions. Acta Astronautica, Elsevier BV, v. 68, n. 11-12, p. 2038-2046, jun 2011. Disponível em: <https://doi.org/10.1016/j.actaastro.2010.10.022>. Acesso em: 12 maio 2020.

96 LASSAKEUR, A. Investigation of the magnetic characteristics of CubeSats and on-orbit determination and mitigation of their dynamic magnetic moment disturbances. 2019. Tese (Doutorado) - University of Surrey, Surrey, UK, 2019. Disponível em: <http://epubs.surrey.ac.uk/id/eprint/853107>. Acesso em: 15 jun. 2020. 
97 NOWAK, M. et al. Short life and abrupt death of PicSat, a small 3U CubeSat dreaming of exoplanet detection. Space Telescopes and Instrumentation 2018: Optical, Infrared, and Millimeter Wave, SPIE, v. 10698, jul. 2018. Disponível em: $<$ http://dx.doi.org/10.1117/12.2313242>.

98 HIPERION Technologies. 2019. Disponível em: < https://hyperiontechnologies.nl/>. Acesso em: 07 jan. 2019.

99 ILLOWSKY, B.; DEAN, S. Introductory statistics. 1. ed. OpenStax College, 2019. 905 p. ISBN 1938168208. Disponível em: < https://openstax.org/details/books/ introductory-statistics $>$.

100 RIESING, K. Orbit determination from two line element sets of ISS-deployed CubeSats. In: CONFERENCE ON SMALL SATELLITES, 29., 2015, Logan. Proceedings... Logan: AIAA/USU, 2015. Disponível em: < https://digitalcommons.usu.edu/smallsat/ 2015/all2015/58/>. Acesso em: 05 out. 2019.

101 NGUYEN, T.; CAHOY, K.; MARINAN, A. Attitude determination for small satellites with infrared Earth horizon sensors. Journal of Spacecraft and Rockets, American Institute of Aeronautics and Astronautics (AIAA), v. 55, n. 6, p. 1466-1475, nov 2018. Disponível em: <https://doi.org/10.2514/1.A34010>. Acesso em: 06 jun 2020.

102 STICKLER, A. C.; ALFRIEND, K. T. Elementary magnetic attitude control system. Journal of spacecraft and rockets, Washington D.C., v. 13, n. 5, p. 282-287, 1976. Disponível em: <https://doi.org/10.2514/3.57089>. Acesso em: 12 jul. 2019.

103 WISNIEWSKI, R. Satellite attitude control using only electromagnetic actuation. 1997. 147 p. Tese (Doutorado) - Aalborg University, Aalborg, 1996. Department of Control Engineering.

104 GRAVDAHL, J. T. Magnetic attitude control for satellites. In: IEEE CONFERENCE ON DECISION AND CONTROL, 43., 2004, Nassau, Bahamas. Proceedings... Nassau, Bahamas: IEEE, 2004. p. 261-266. ISBN 0-7803-8682-5. ISSN 0191-2216. Disponível em: <http://ieeexplore.ieee.org/document/1428640/>. Acesso em: 12 jul. 2019.

105 ARMSTRONG, J. et al. Pointing control for low altitude triple CubeSat space darts. In: CONFERENCE ON SMALL SATELLITES, 23., 2009, Logan. Proceedings... Logan: AIAA/USU, 2009. Disponível em: <https://digitalcommons.usu.edu/smallsat/2009/ all2009/63/>. Acesso em: 11 jun. 2019.

106 PIGNÈDE, A. Prediction algorithms for the NUTS attitude estimator and robust spacecraft attitude stabilization using magnetorquers. 2014. 160 p. Dissertação (Mestrado) - Norwegian University of Science and Technology, Trondheim, 2014. Department of Engineering Cybernetics. Disponível em: <http://hdl.handle.net/11250/ $2352421>$. Acesso em: 12 jun. 2019.

107 CARRARA, V. et al. The ITASAT CubeSat development and design. Journal of Aerospace Technology and Management, São José dos Campos, v. 9, n. 2, p. 147-156, 2017. ISSN 2175-9146. Disponível em: <http://www.scielo.br/scielo.php?script= sci_arttext\&pid=S2175-91462017000200147\&nrm=iso $>$. Acesso em: 12 jul. 2019. 
108 AVANZINI, G.; GIULIETTI, F. Magnetic detumbling of a rigid spacecraft. Journal of Guidance, Control, and Dynamics, American Institute of Aeronautics and Astronautics (AIAA), v. 35, n. 4, p. 1326-1334, jul 2012.

109 FONOD, R.; GILL, E. Magnetic detumbling of fast-tumbling picosatellites. In: INTERNATIONAL ASTRONAUTICAL CONGRESS, 69., 2018, Bremen, Germany. Proceedings... Bremen, Germany: International Astronautical Federation, 2018. p. 1-11. Disponível em: < http://resolver.tudelft.nl/uuid:aedf23cb-a2d4-49e7-8244-1524aa6e0de3>. Acesso em: 12 jul. 2019.

110 KHALIL, H. K. Nonlinear systems. 3. ed. New Jersey: Prentice Hall, 2002. ISBN 978-0-13-067389-3.

111 LOVERA, M. Magnetic satellite detumbling: the b-dot algorithm revisited. In: AMERICAN CONTROL CONFERENCE (ACC), 2015, Chicago, IL. Proceedings... Chicago, IL: IEEE, 2015. p. 1867-1872. Disponível em: <https://ieeexplore.ieee.org/ document/7171005>. Acesso em: 12 jul. 2019.

112 FRAnKLin, G. F.; POWELL, J. D.; WORKMAN, M. L. Digital control of dynamic systems. Menlo Park, Calif: Addison-Wesley, 1998. ISBN 0201820544.

113 WIŚNIEWSKI, R. Sliding mode attitude control for magnetic actuated satellite. IFAC Proceedings Volumes, Elsevier BV, Seoul, Korea, v. 31, n. 21, p. 179-184, ago. 1998. Disponível em: <https://doi.org/10.1016/S1474-6670(17)41076-7>. Acesso em: 03 mar. 2020.

114 KWAKERNAAK, H.; SIVAN, R. Linear optimal control systems. 1. ed. New York: Wiley-Interscience, 1972. 575 p. ISBN 0-471-51110-2.

115 NISE, N. S. Engenharia de sistemas de controle. 7. ed. Rio de Janeiro: LTC, 2018. 751 p. ISBN 978-85-216-3435-5.

116 FRANKLIN, G. F.; POWELL, J. D.; Emami-Naeini, A. Sistemas de controle para engenharia. 6. ed. Porto Alegre: Bookman, 2013. ISBN 978-85-8260-067-2.

117 LEWIS, F. L.; VRABIE, D. L.; SYRMOS, V. L. Optimal control. 3. ed. New Jersey: Wiley \& Sons, 2012. 540 p. ISBN 978-0-470-63349-6.

118 HESPANHA, J. P. Lecture notes on lqr/lqg controller design. Lecture Notes, 2005.

119 GOLDSTEIN, H.; POOLE, C. P.; SAFKO, J. L. Classical mechanics. 3. ed. San Francisco, CA: Addison Wesley, 2002. 638 p. ISBN 0-201-65702-3.

120 BATE, R. R.; MUELLER, D. D.; WHITE, J. E. Fundamentals of astrodynamics. New York: Dover Publications, 1971. 480 p. ISBN 0-486-60061-0. 


\section{APÊNDICE A - DINÂMICA DO CORPO RÍGIDO}

Considerando um corpo rígido em movimento de rotação pura, o Teorema da Conservação do Momento Angular (2a Lei de Newton) fornece [119]

$$
\mathbf{T}_{\text {total }}^{i}=\frac{\mathrm{d} \mathbf{H}^{i}}{\mathrm{~d} t} \equiv \dot{\mathbf{H}}^{i}
$$

no qual $\mathbf{T}_{\text {total }}$ é a soma de todos os torques aplicados ao corpo, internos e externo, e $\mathbf{H}$ é o momento angular desse corpo, ambos expressos em um sistema de coordenadas inercial.

Porém, algumas propriedades são expressas com mais facilidade em um sistema de coordenadas móvel. Sendo assim, utilizando-se do Teorema de Coriolis [120], o torque total expresso no sistema de coordenadas móvel é dado por

$$
\mathbf{T}^{m}=\dot{\mathbf{H}}^{m}+\boldsymbol{\omega}_{m / i}^{m} \times \mathbf{H}^{m}
$$

na qual $\boldsymbol{\omega}_{m / i}$ é a velocidade angular do eixo móvel em relação ao eixo inercial.

A Equação (A.2) é comumente conhecida como Equação de Euler para o Movimento [69].

Por sua vez, o momento angular pode ser definido pelo produto escalar da matriz de inércia $[\mathbf{I}]$ e o vetor velocidade angular $\boldsymbol{\omega}$, isto é,

$$
\mathbf{H}=[\mathbf{I}] \boldsymbol{\omega}
$$

A matriz de inércia, algumas vezes chamada de tensor de inércia [69], é uma grandeza física vetorial que expressa a resistência à mudança de velocidade angular de um corpo. Quantitativamente, depende da distribuição de massa em torno de um eixo de rotação. O interesse nessa propriedade justifica-se pelo fato de ser possível relaciona-la com o momento e velocidade angular, conforme apresentado na Equação (A.3). Além do que, para geometrias conhecidas, seu valor quantitativo é de fácil obtenção, sem contar os inúmeros softwares de desenho CAD com a capacidade de oferecer esses mesmos valores.

Tratando-se de um corpo tridimensional, a matriz de inércia é expressa por

$$
[\mathbf{I}]=\left[\begin{array}{ccc}
I_{x} & I_{x y} & I_{x z} \\
I_{x y} & I_{y} & I_{y z} \\
I_{x z} & I_{y z} & I_{z}
\end{array}\right],
$$

na qual os termos com apenas um subscrito se referem ao eixo e os termos com dois subscritos se referem ao plano. Por exemplo, $I_{x}$ se refere ao momento de inércia do corpo 
em relação ao eixo $x$ e $I_{x y}$ se refere ao momento de inércia do corpo em relação ao plano $x y$.

É importante observar que a matriz I é simétrica e, no caso específico, quando os planos $x y, x z$ e $y z$ são planos de simetria do corpo, a matriz de inércia é, também, diagonal [68]. Neste caso, os eixos são chamados de eixos principais de inércia.

Na situação em que o eixo móvel é também o eixo principal de inércia, a Equação (A.2) pode ser expressa por

$$
\mathbf{T}^{p}=\left[\mathbf{I}^{p}\right] \dot{\boldsymbol{\omega}}_{p / i}^{p}+\boldsymbol{\omega}_{p / i}^{p} \times\left(\left[\mathbf{I}^{p}\right] \boldsymbol{\omega}_{p / i}^{p}\right)
$$

\section{A.1 Teorema de Steiner}

O Teorema dos Eixos Paralelos, ou Teorema de Steiner, permite calcular o momento de inércia de um corpo rígido em relação a qualquer eixo de rotação.

Pelo teorema, o momento de inércia de um corpo $a$ em relação a um ponto arbitrário $P,\left[\mathbf{I}_{a}\right]_{P}$, é expresso por

$$
\left[\mathbf{I}_{a}\right]_{P}=\left[\mathbf{I}_{a}\right]_{C M}+\left[\mathbf{I}_{m_{a}}\right]_{P}
$$

na qual $\left[\mathbf{I}_{a}\right]_{C M}$ é o momento de inércia do corpo $a$ em relação ao seu próprio centro de massa, $C M$, e $\left[\mathbf{I}_{m_{a}}\right]_{P}$ é o momento de inércia da massa do corpo $a$, concentrada no ponto $C M$, em relação ao ponto $P[119]$. 


\section{APÊNDICE B - ILUSTRAÇÕES DE VALIDAÇÃO}


Figura B.1 - Estimação de parâmetros da matriz de inércia, bias e condições iniciais Experimentos 2a a $7 \mathrm{a}$.

Dados reais e simulação.
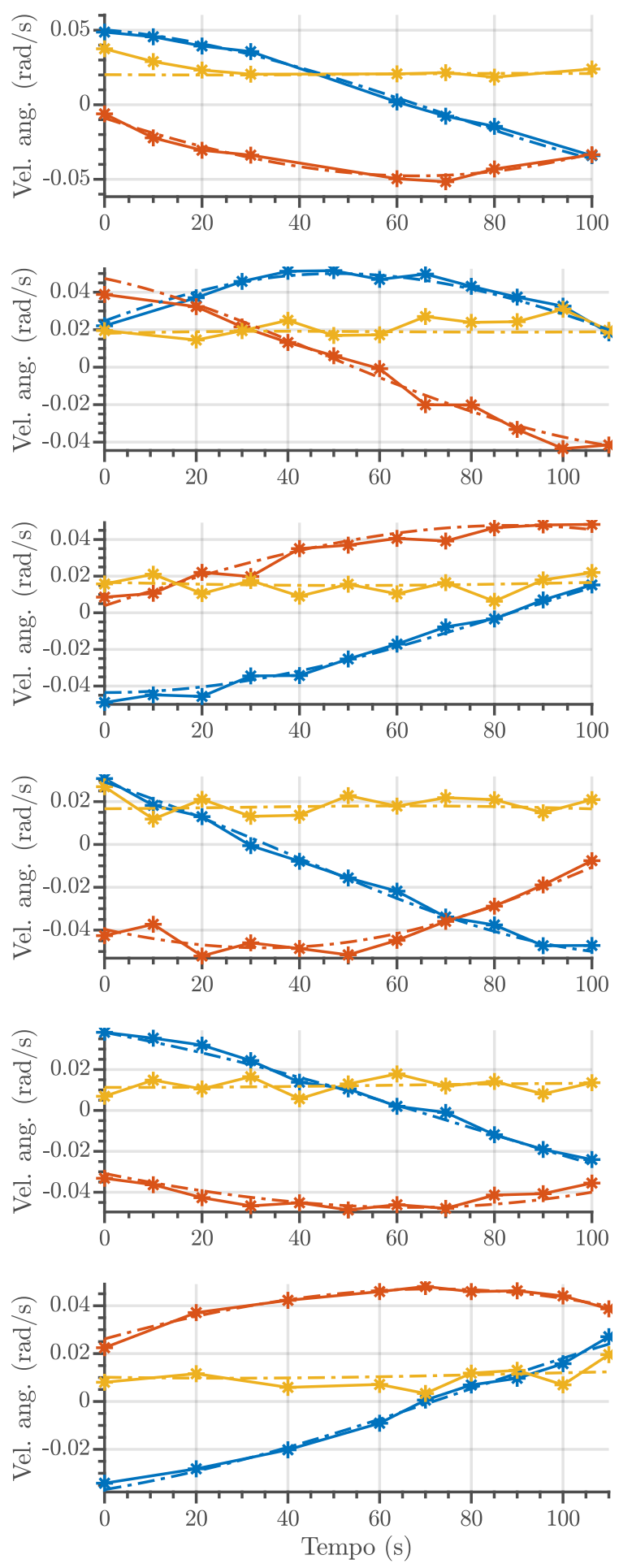

$* \omega_{x}$ real $-\cdot \omega_{x} \operatorname{sim}$

$* \omega_{y}$ real $-\omega_{y} \operatorname{sim}$

$* \omega_{z}$ real $-\omega_{z} \operatorname{sim}$
Resíduos.
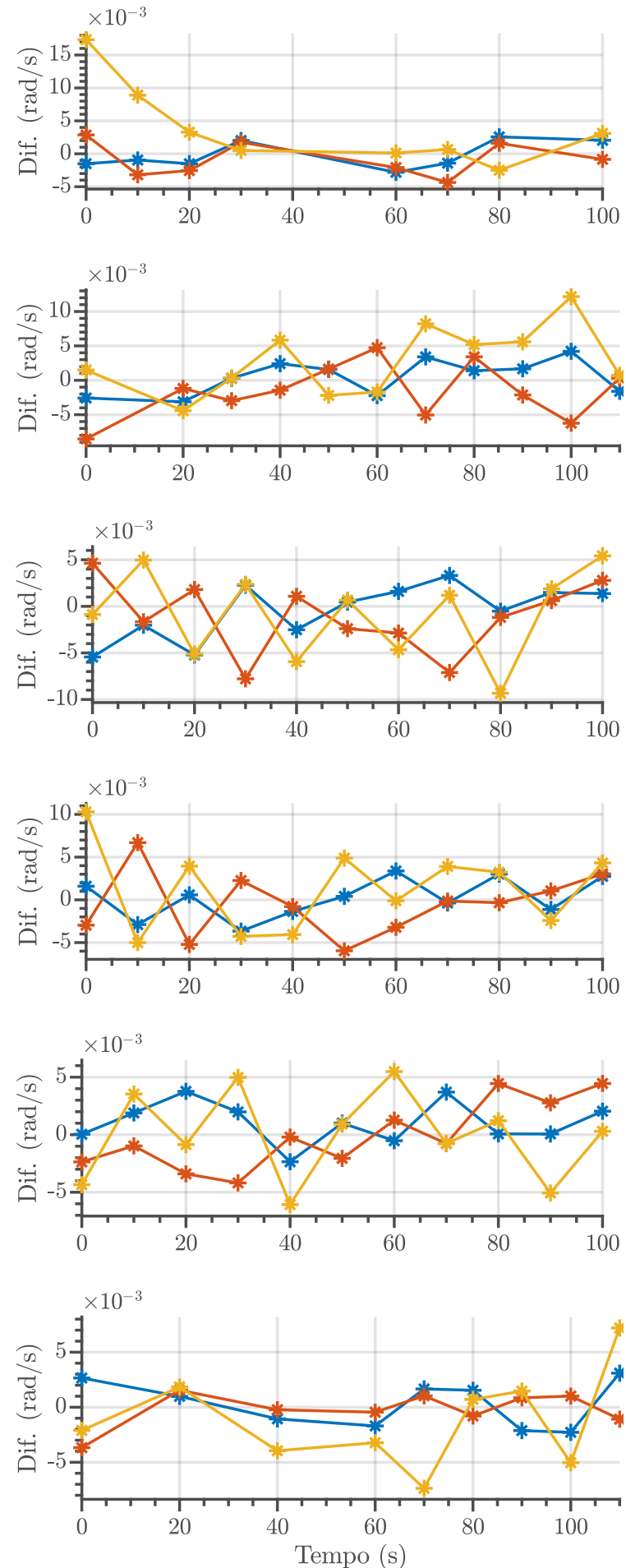

* dif. $\omega_{x}$

* dif. $\omega_{y}$

* dif. $\omega_{z}$

Fonte: Autor. 
Figura B.2 - Estimação de parâmetros da matriz de inércia, viés e condições iniciais Experimentos 8a a 13a.

Dados reais e simulação.
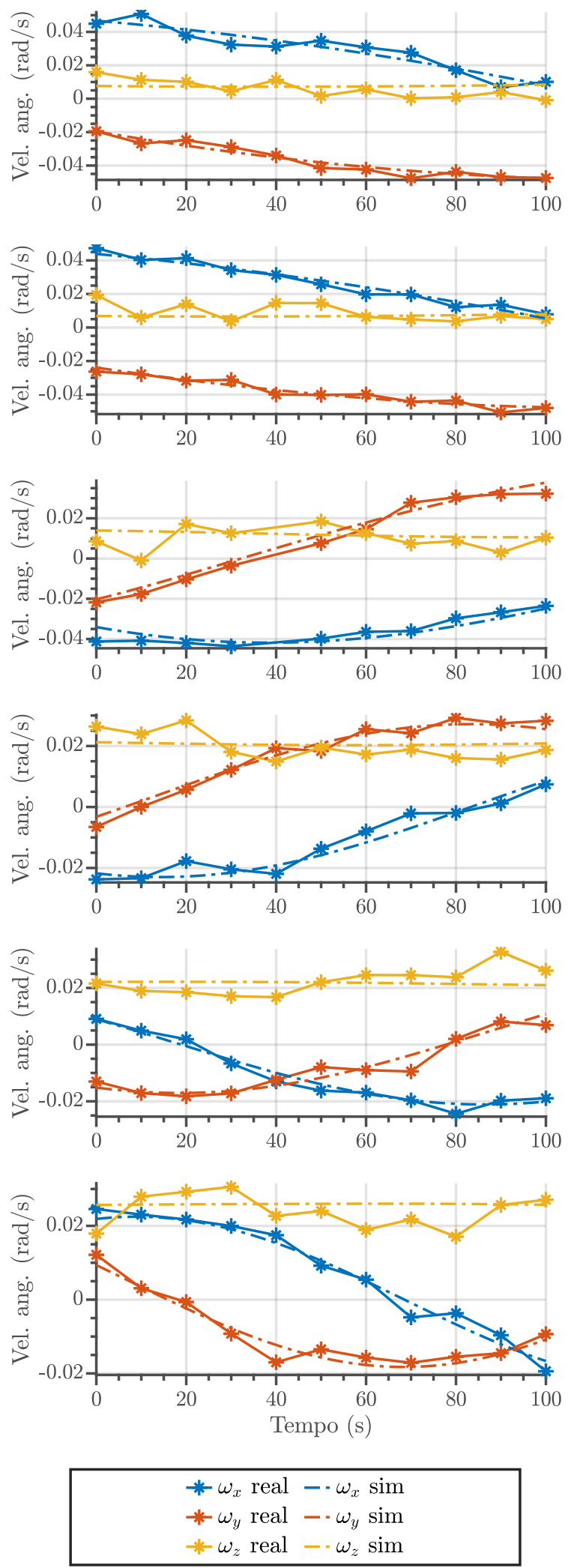

Resíduos.
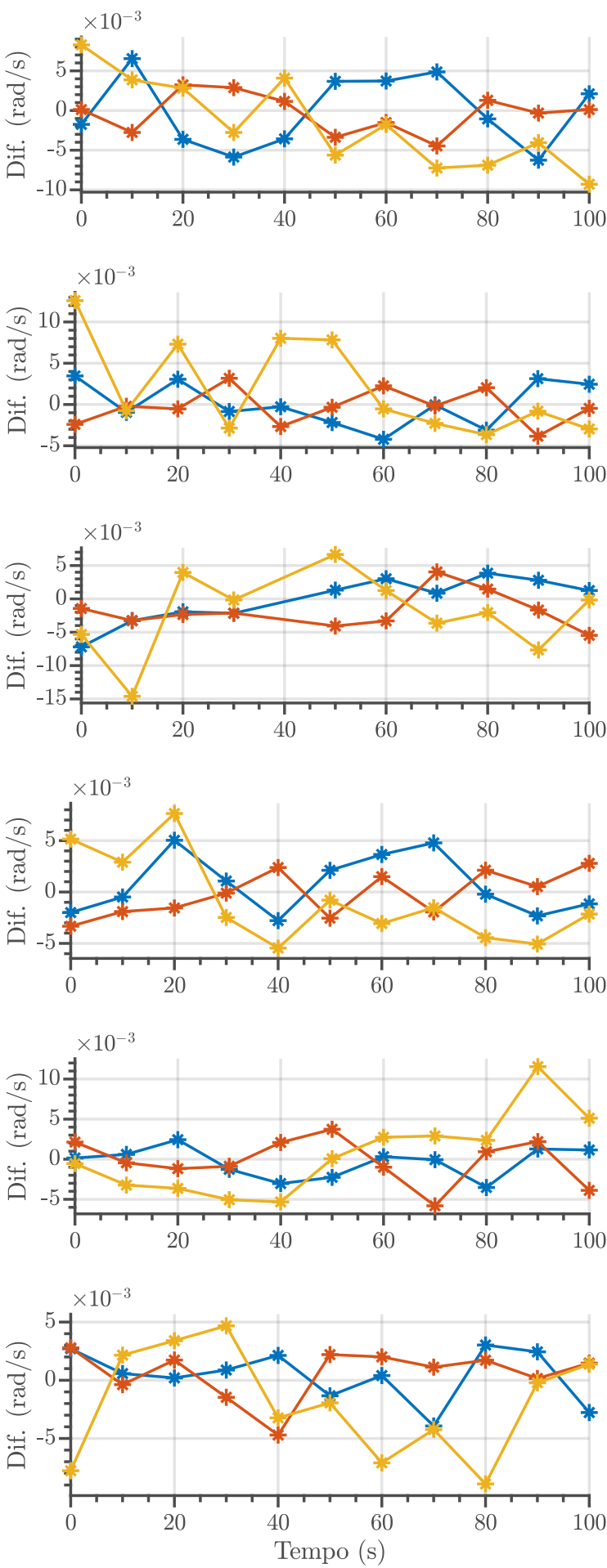

* dif. $\omega_{x}$

* dif. $\omega_{y}$

$*$ dif. $\omega_{z}$

Fonte: Autor. 
Figura B.3 - Estimação de parâmetros da matriz de inércia, viés e condições iniciais Experimentos 14a a 19a.

Dados reais e simulação.
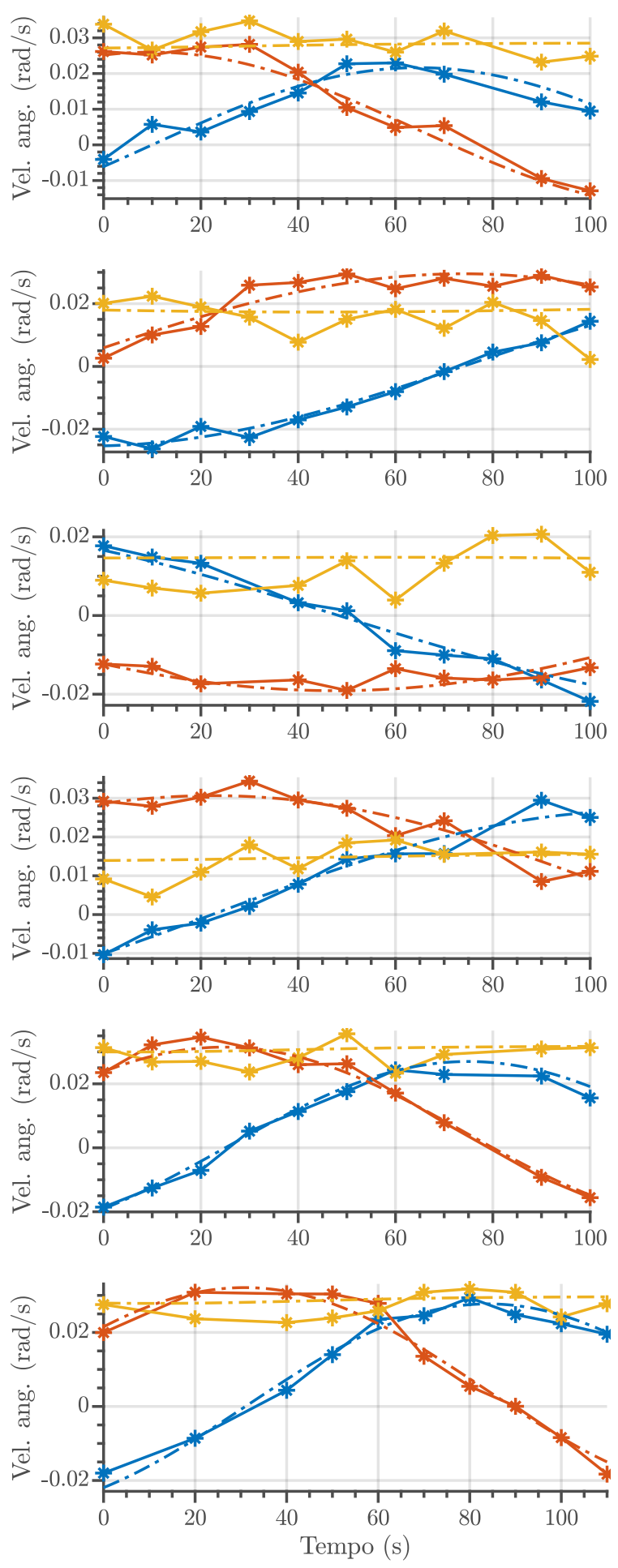

$* \omega_{x}$ real $-\cdot \omega_{x} \operatorname{sim}$

$* \omega_{y}$ real $-\omega_{y} \operatorname{sim}$

$* \omega_{z}$ real $-\omega_{z} \operatorname{sim}$
Resíduos.
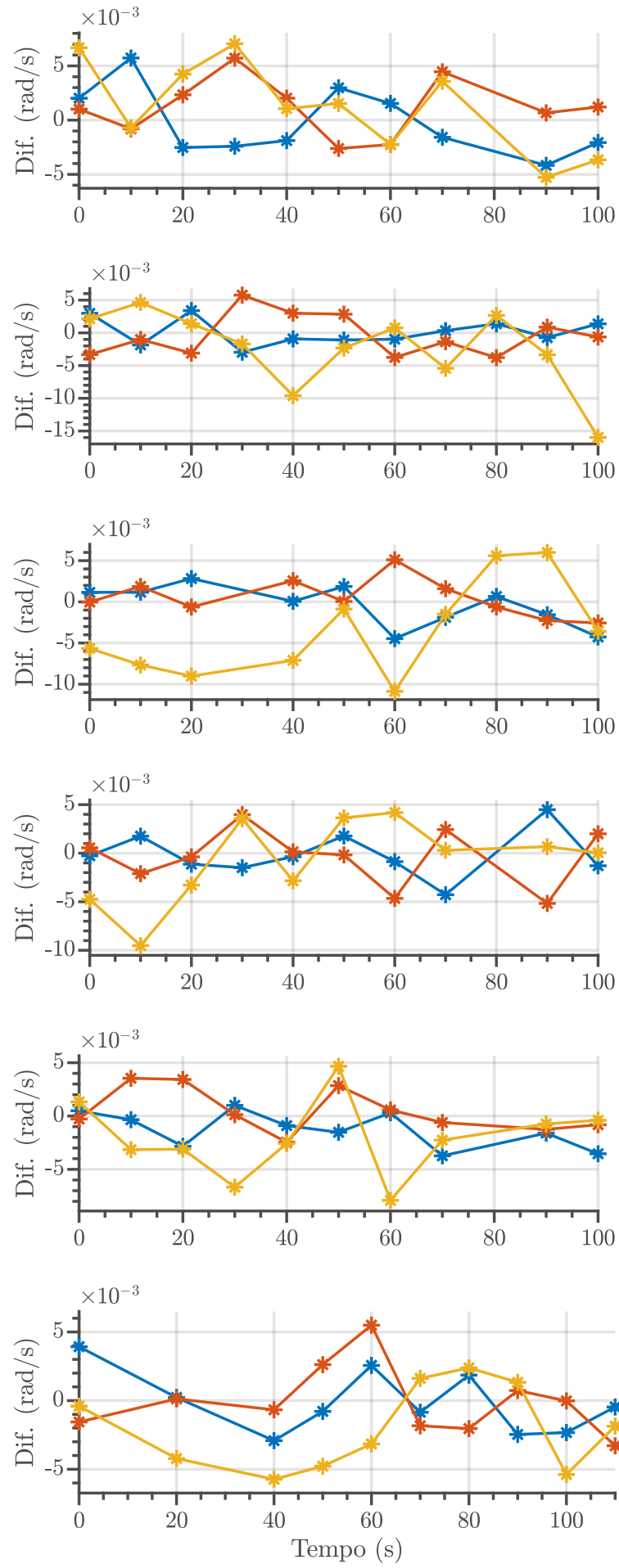

* dif. $\omega_{x}$

* dif. $\omega_{y}$

* dif. $\omega_{z}$

Fonte: Autor. 
Figura B.4 - Estimação de parâmetros da matriz de inércia, viés e condições iniciais Experimentos 20a a 25a.

Dados reais e simulação.
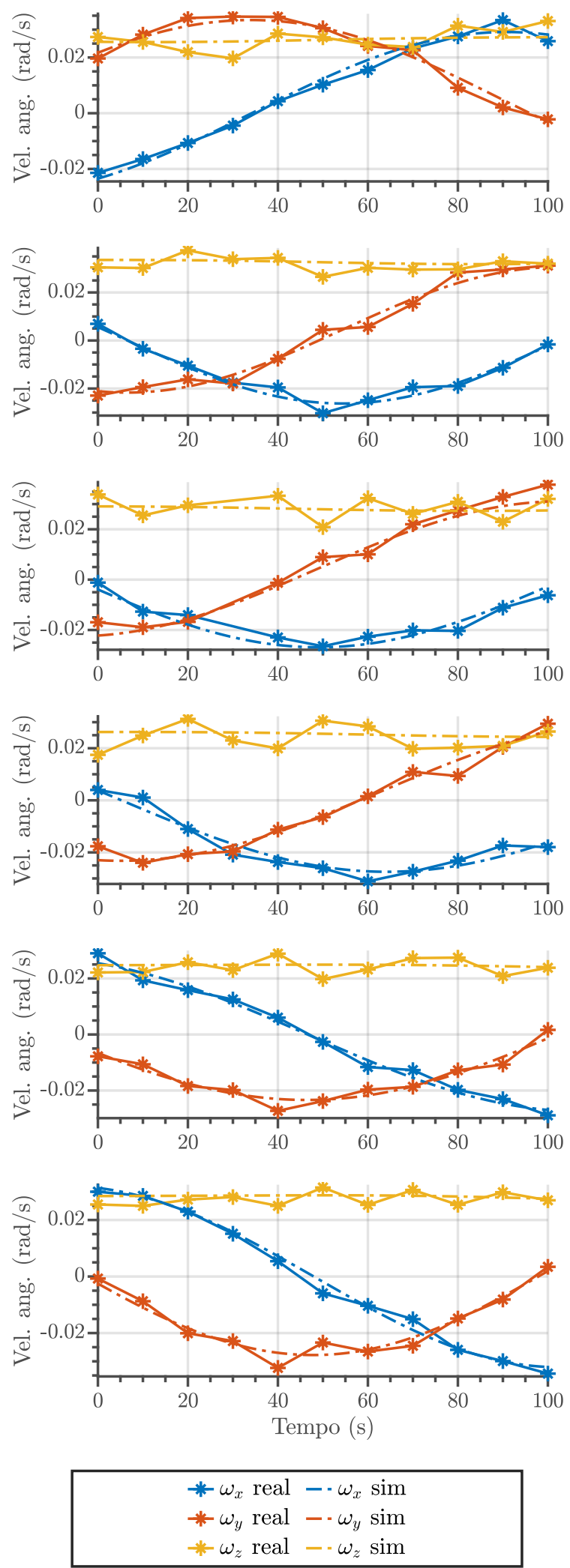

Resíduos.
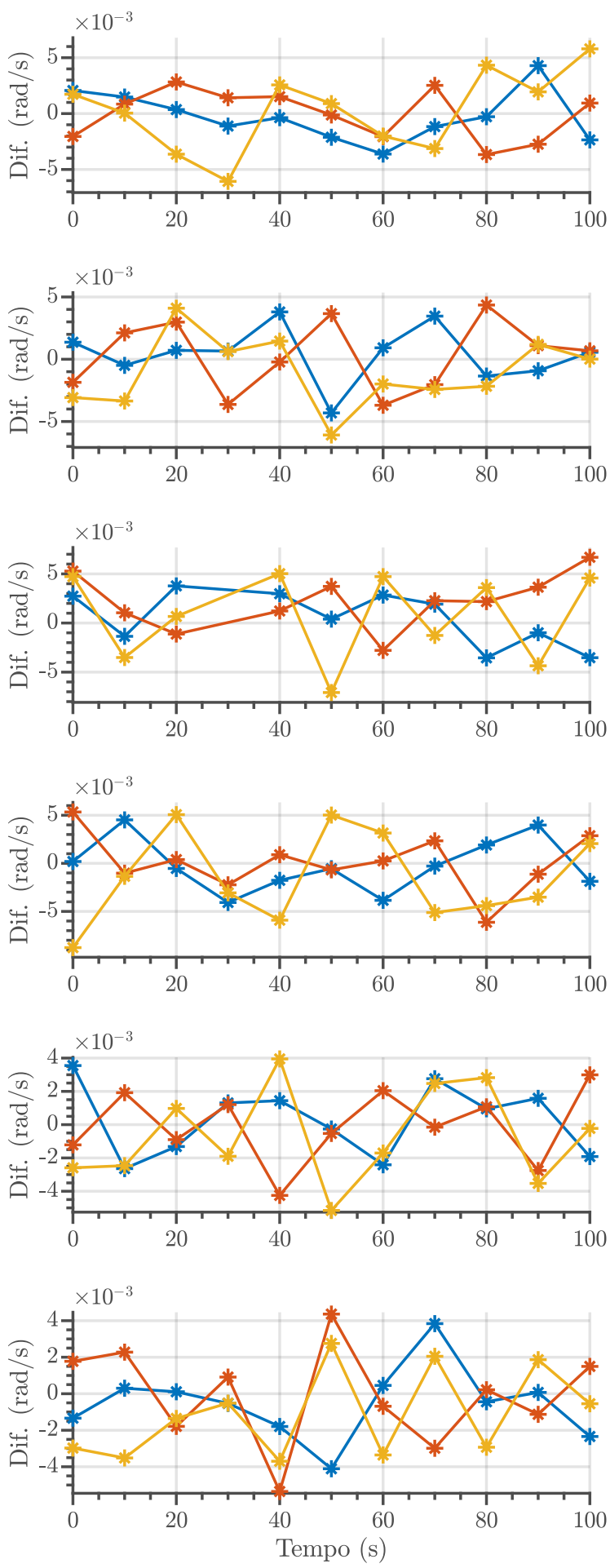

*- dif. $\omega_{x}$

* dif. $\omega_{y}$

$*$ dif. $\omega_{z}$

Fonte: Autor. 
Figura B.5 - Estimação de parâmetros da matriz de inércia, viés e condições iniciais Experimentos 26a a 31a.

Dados reais e simulação.
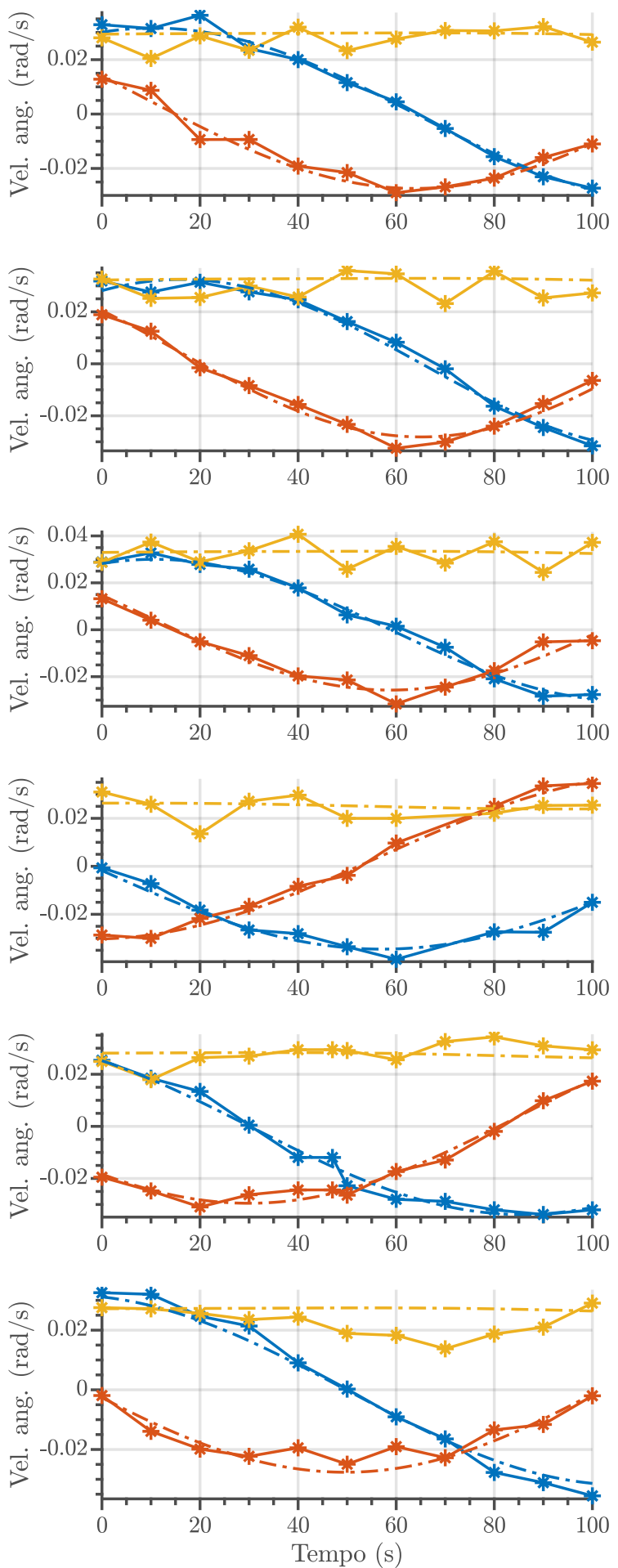

* $\omega_{x}$ real $-\cdot \omega_{x} \operatorname{sim}$

$* \omega_{y}$ real $--\omega_{y} \operatorname{sim}$

$* \omega_{z}$ real $-\omega_{z} \operatorname{sim}$
Resíduos.
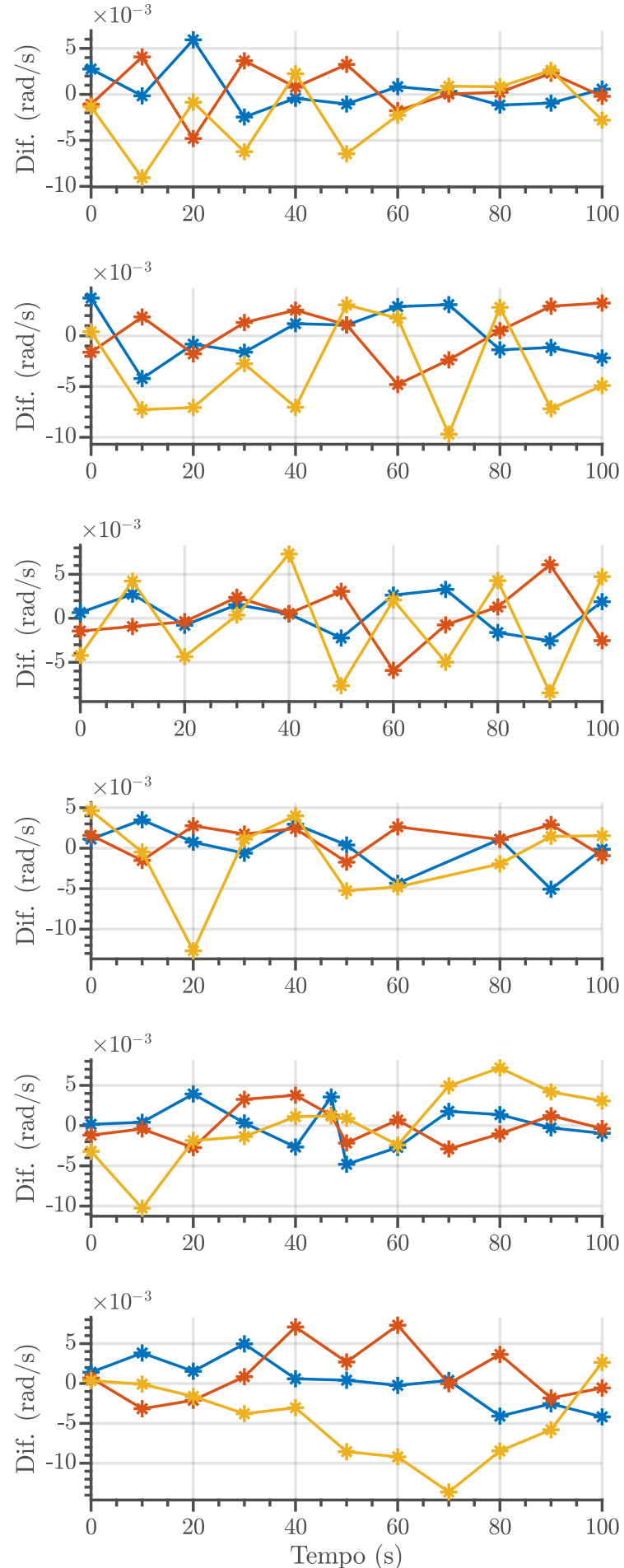

* dif. $\omega_{x}$

* dif. $\omega_{y}$

$*$ dif. $\omega_{z}$

Fonte: Autor. 
Figura B.6 - Estimação de parâmetros da matriz de inércia, viés e condições iniciais Experimento 32a.

Dados reais e simulação.

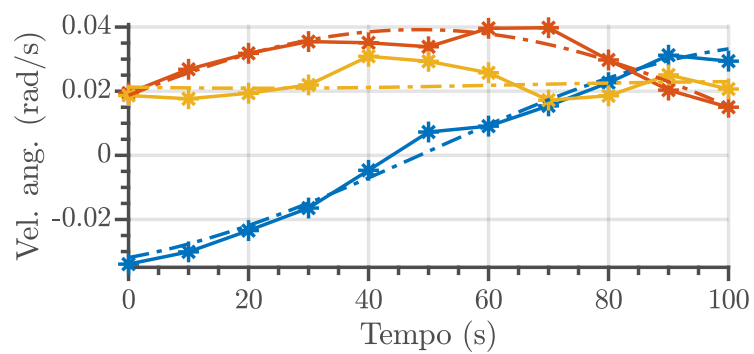

* $\omega_{x}$ real $--\omega_{x} \operatorname{sim}$

*- $\omega_{y}$ real $--\omega_{y} \operatorname{sim}$

$* \omega_{z}$ real $-\omega_{z} \operatorname{sim}$
Resíduos.

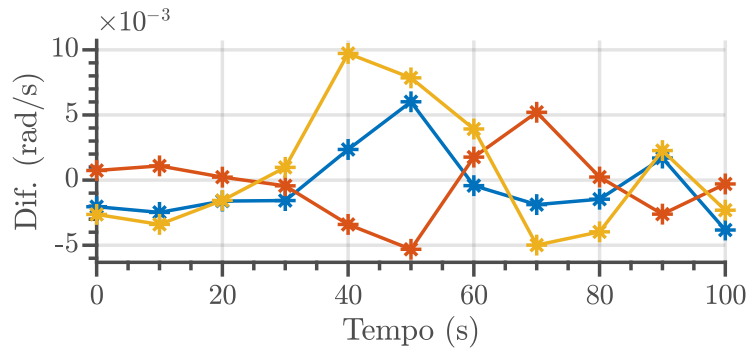

- - dif. $\omega_{x}$

$*$ dif. $\omega_{y}$

$\approx$ dif. $\omega_{z}$

Fonte: Autor. 
Figura B.7 - Validação de parâmetros da matriz de inércia, bias e condições iniciais Experimentos $2 \mathrm{~b}$ a $7 \mathrm{~b}$.

Dados reais e simulação.
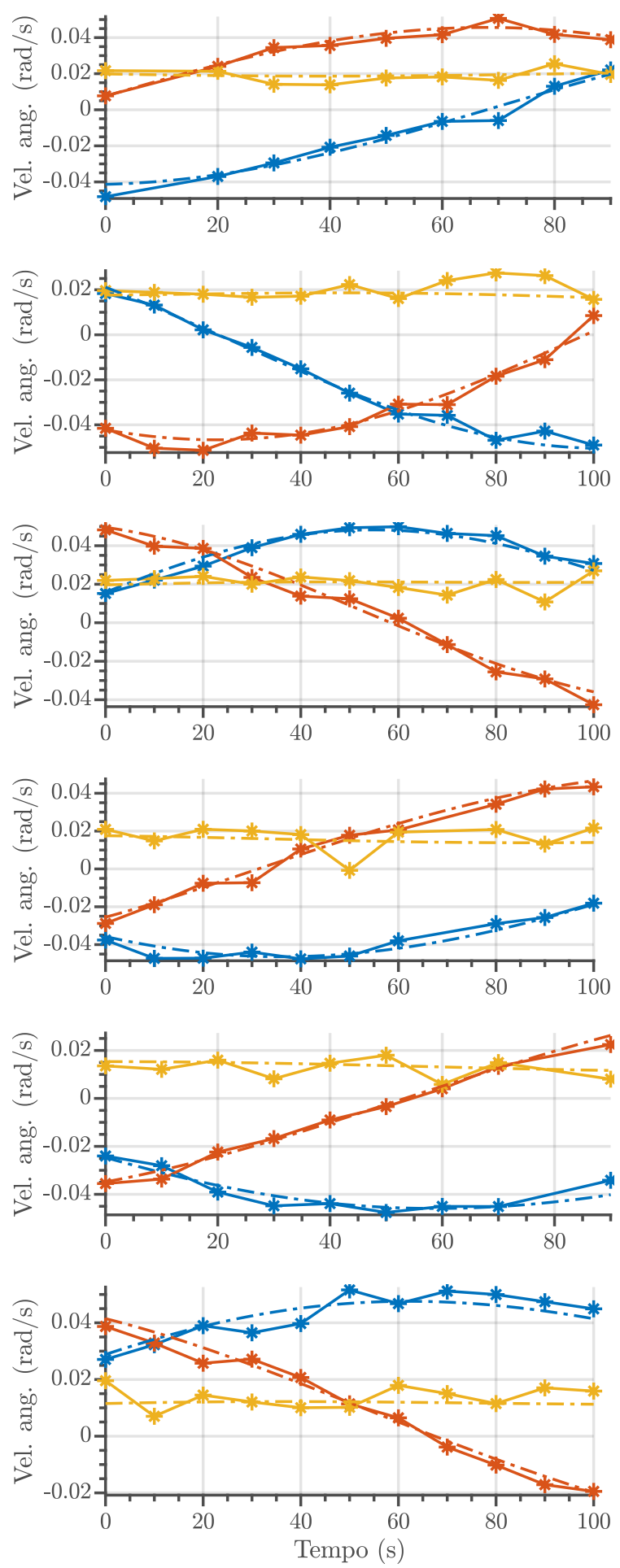

* $\omega_{x}$ real $-\cdot \omega_{x} \operatorname{sim}$

$* \omega_{y}$ real $-\omega_{y} \operatorname{sim}$

$* \omega_{z}$ real $-\omega_{z} \operatorname{sim}$
Resíduos.
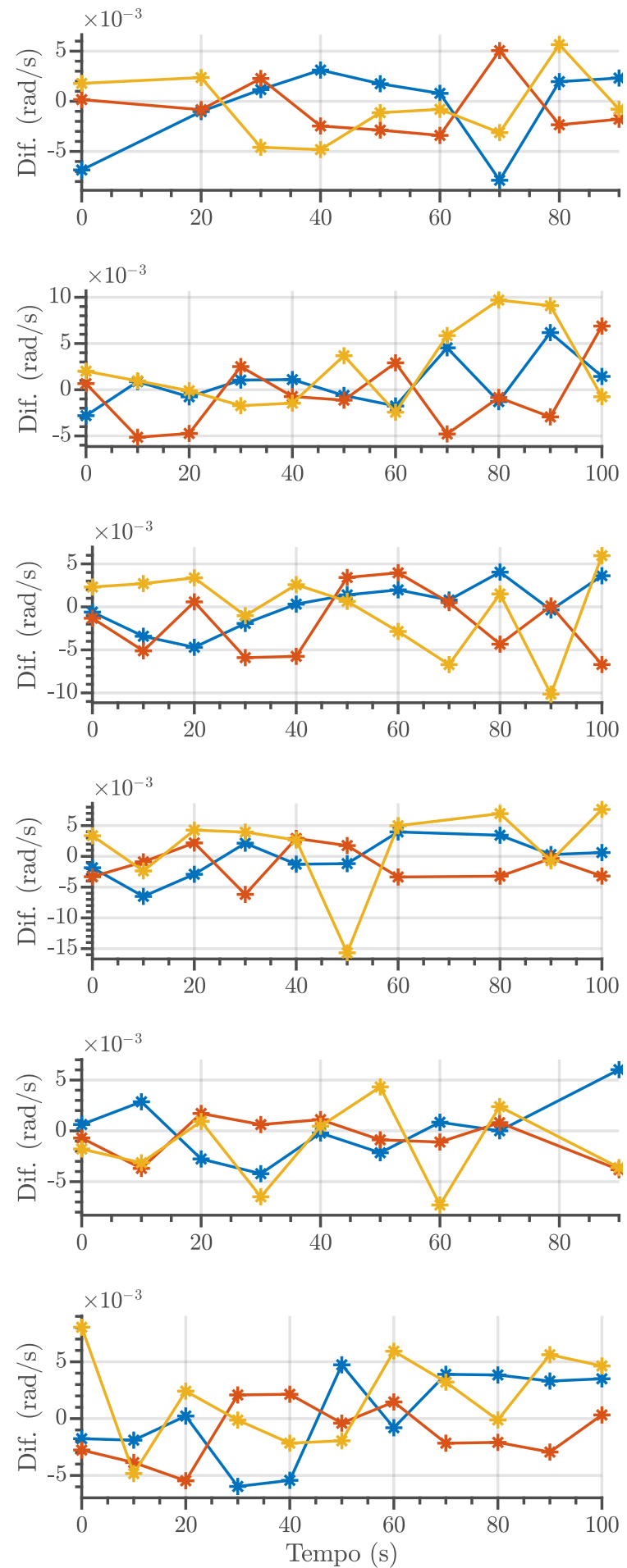

* dif. $\omega_{x}$

* dif. $\omega_{y}$

* dif. $\omega_{z}$

Fonte: Autor. 
Figura B.8 - Validação de parâmetros da matriz de inércia, bias e condições iniciais Experimentos $8 \mathrm{~b}$ a $13 \mathrm{~b}$.

Dados reais e simulação.
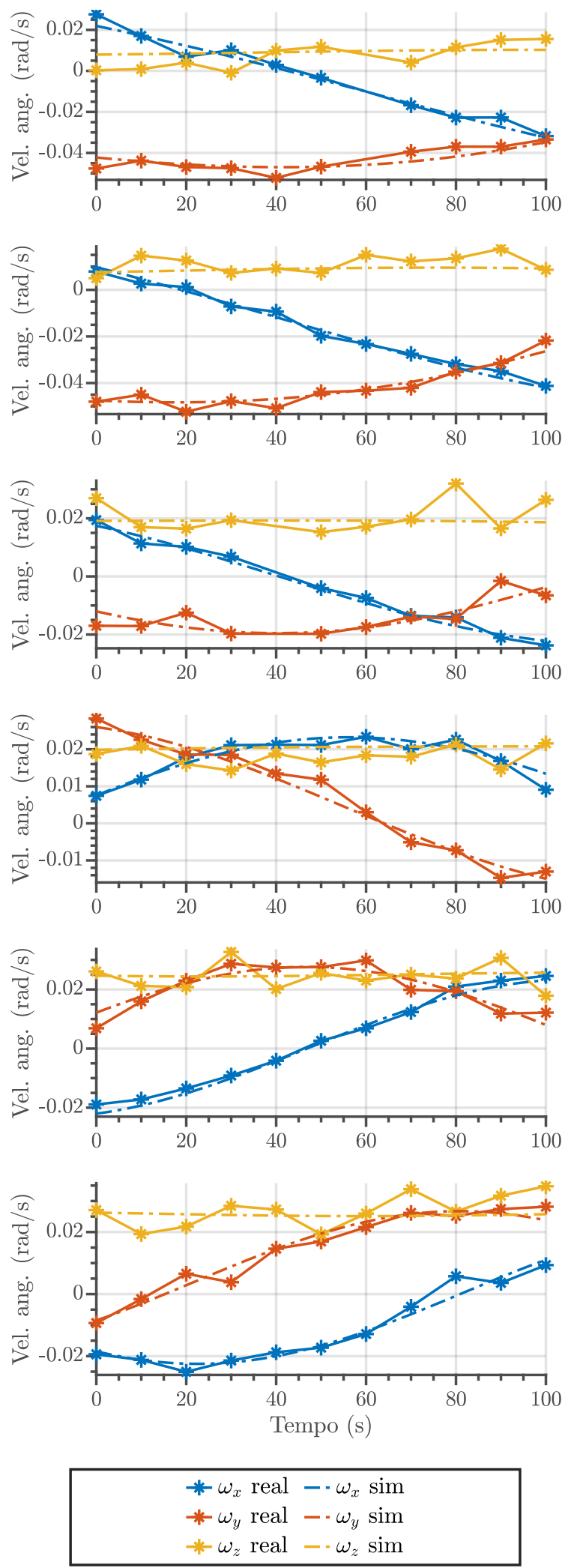

Resíduos.
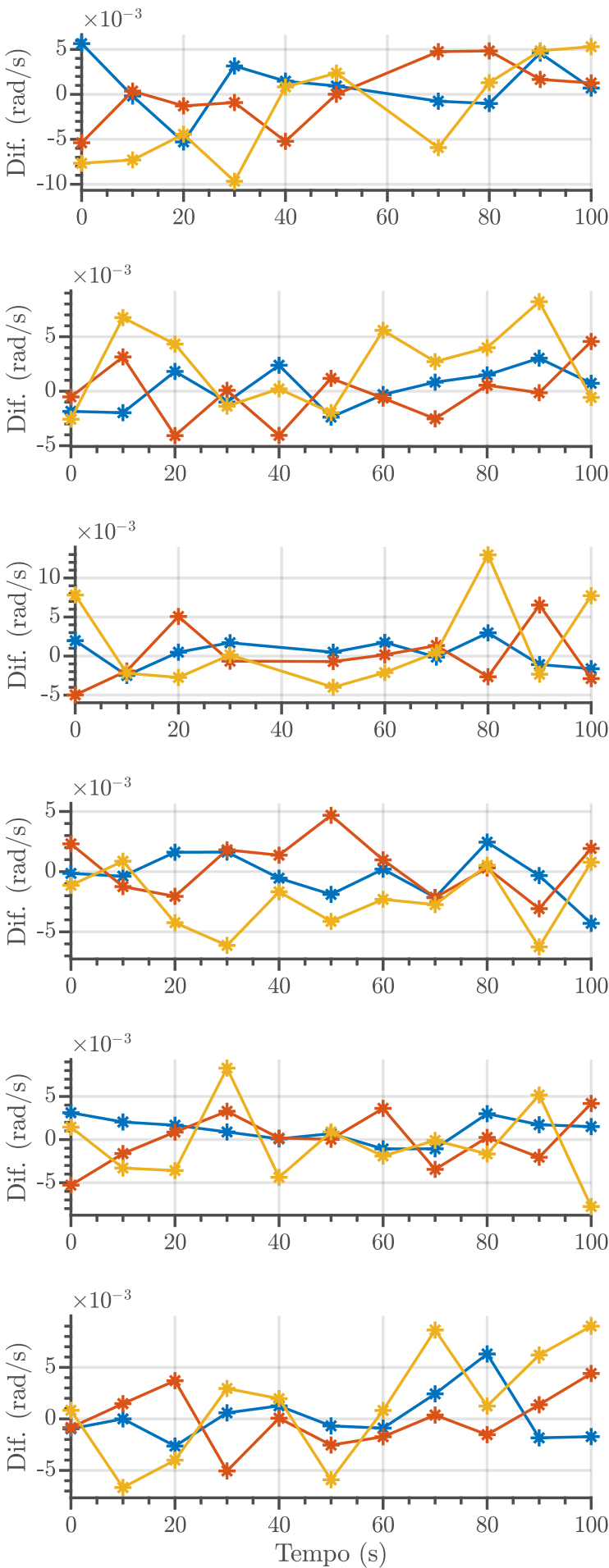

* dif. $\omega_{x}$

* dif. $\omega_{y}$

* dif. $\omega_{z}$

Fonte: Autor. 
Figura B.9 - Validação de parâmetros da matriz de inércia, bias e condições iniciais Experimentos 14b a $19 b$.

Dados reais e simulação.
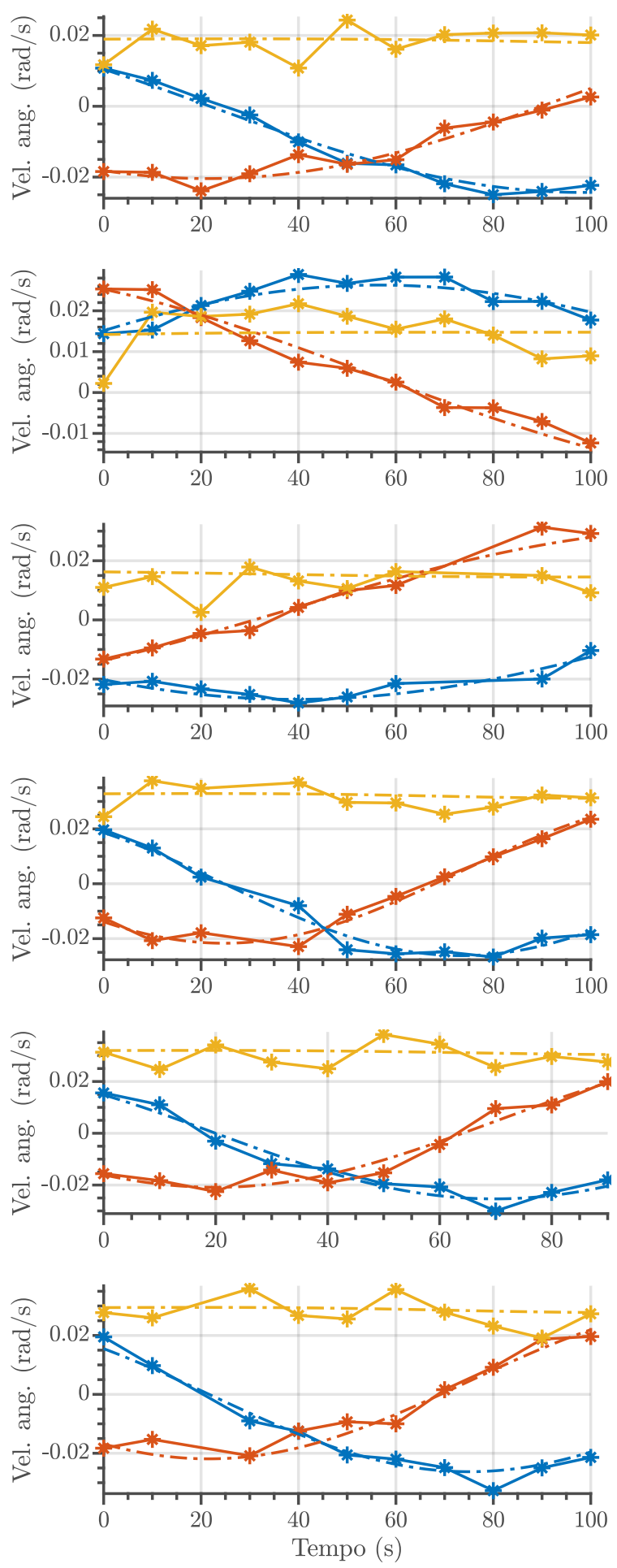

* $\omega_{x}$ real $-\cdot \omega_{x} \operatorname{sim}$

$* \omega_{y}$ real $-\omega_{y} \operatorname{sim}$

$* \omega_{z}$ real $-\omega_{z} \operatorname{sim}$
Resíduos.
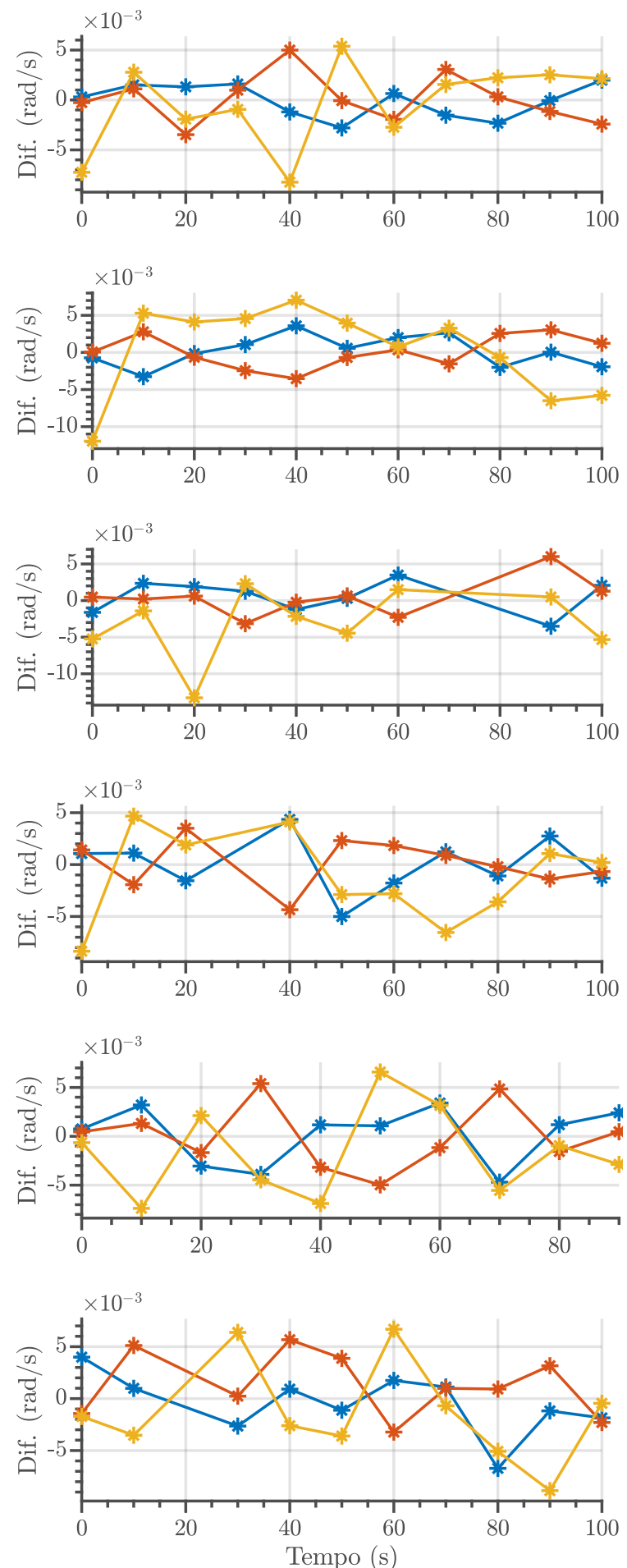

* dif. $\omega_{x}$

* dif. $\omega_{y}$

* dif. $\omega_{z}$

Fonte: Autor. 
Figura B.10 - Validação de parâmetros da matriz de inércia, bias e condições iniciais Experimentos 20b a 25b.

Dados reais e simulação.
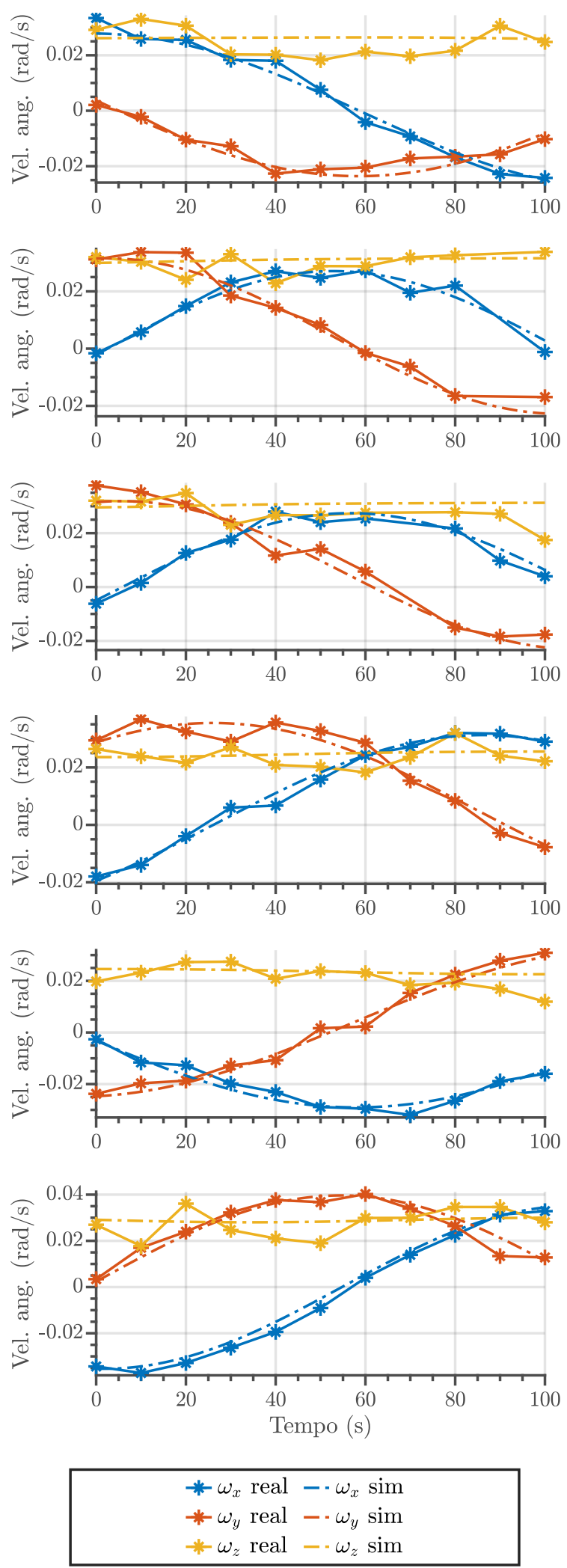

Resíduos.
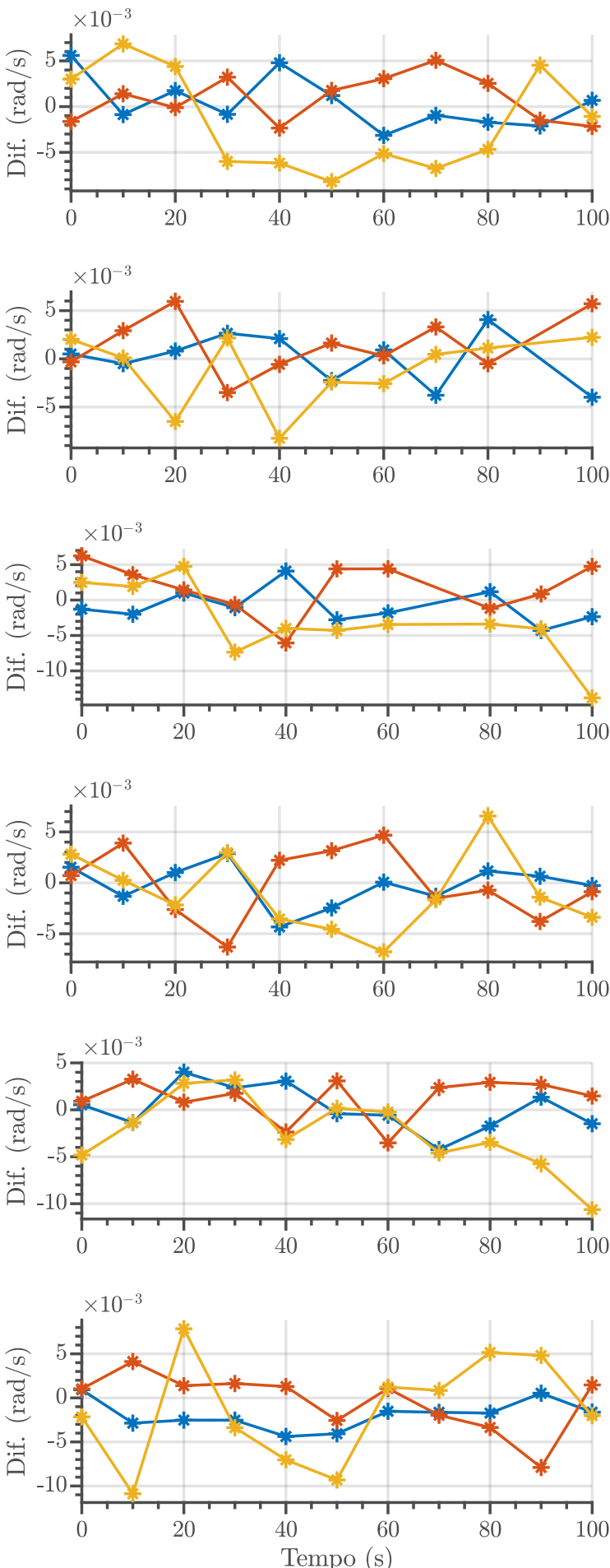

$*$ dif. $\omega_{x}$

* dif. $\omega_{y}$

$*$ dif. $\omega_{z}$

Fonte: Autor. 
Figura B.11 - Validação de parâmetros da matriz de inércia, bias e condições iniciais Experimentos 26b a $31 b$.

Dados reais e simulação.
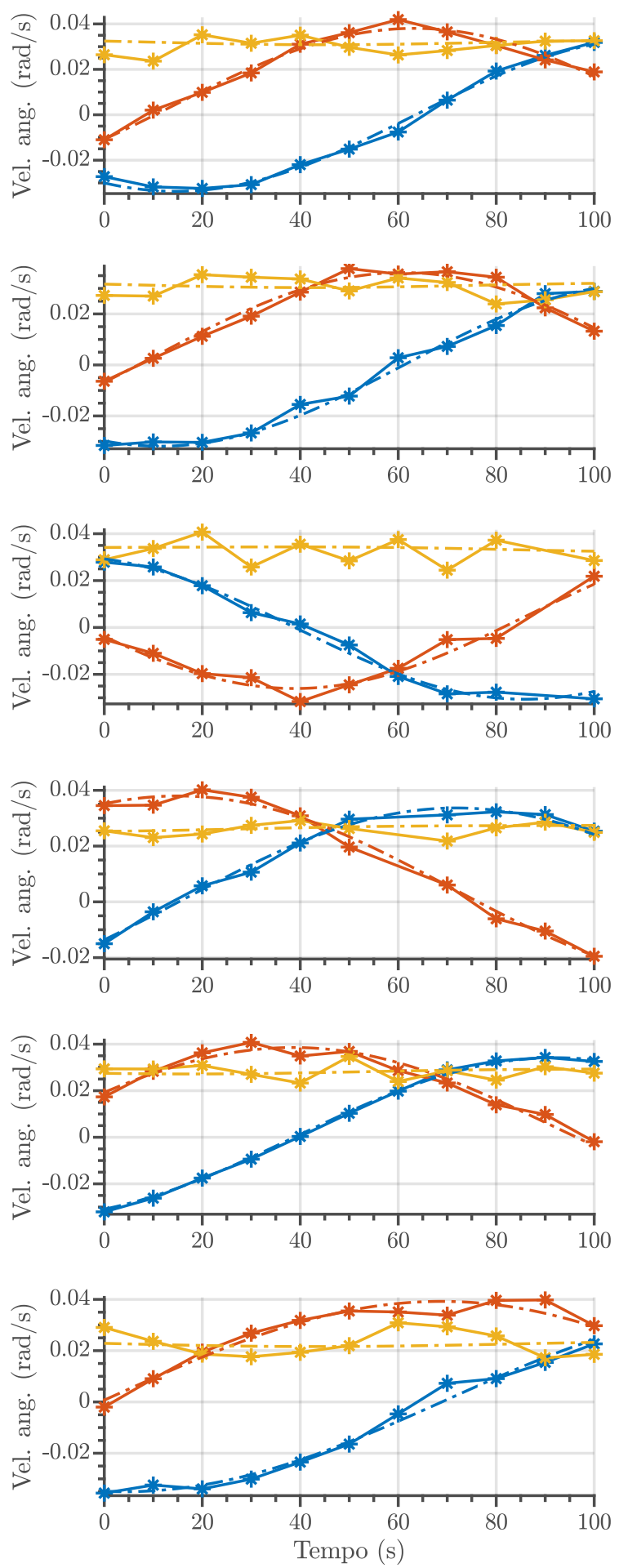

* $\omega_{x}$ real $--\omega_{x} \operatorname{sim}$

$* \omega_{y}$ real $-\omega_{y} \operatorname{sim}$

$* \omega_{z}$ real $-\omega_{z} \operatorname{sim}$
Resíduos.
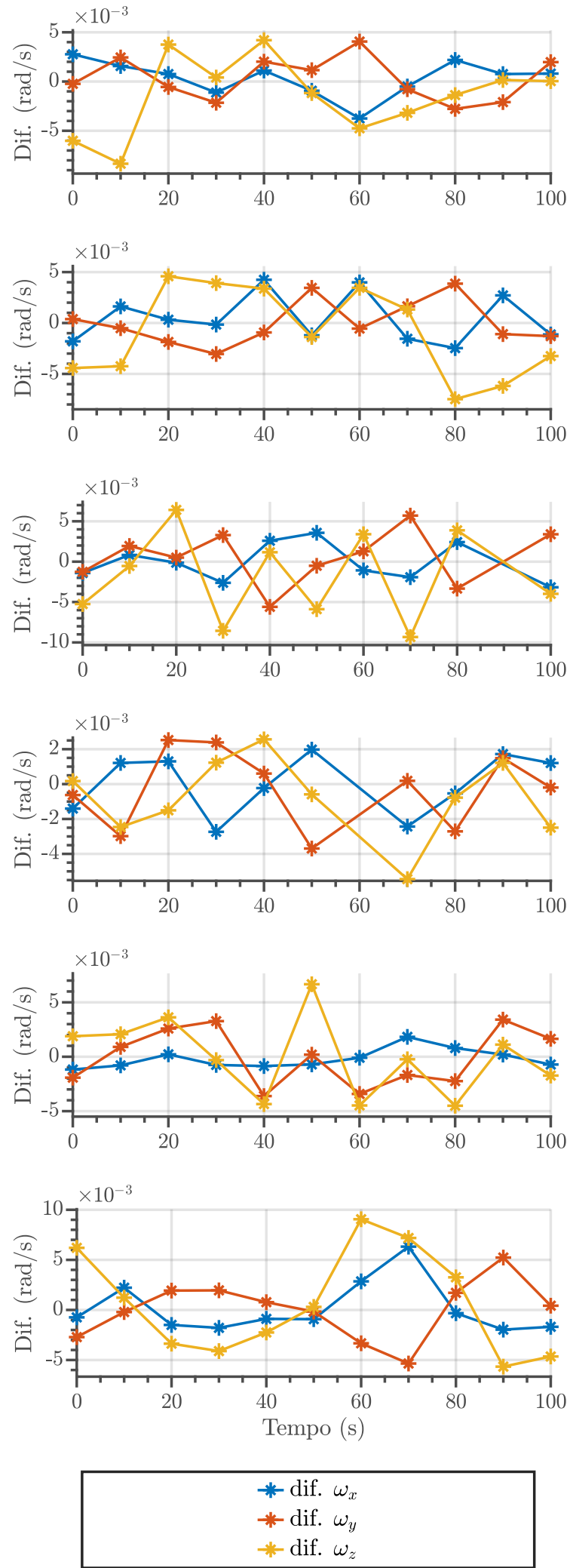

Fonte: Autor. 
Figura B.12 - Estimação dos parâmetros de perturbação - Experimentos 2a a 5a.

Dados reais e simulação.
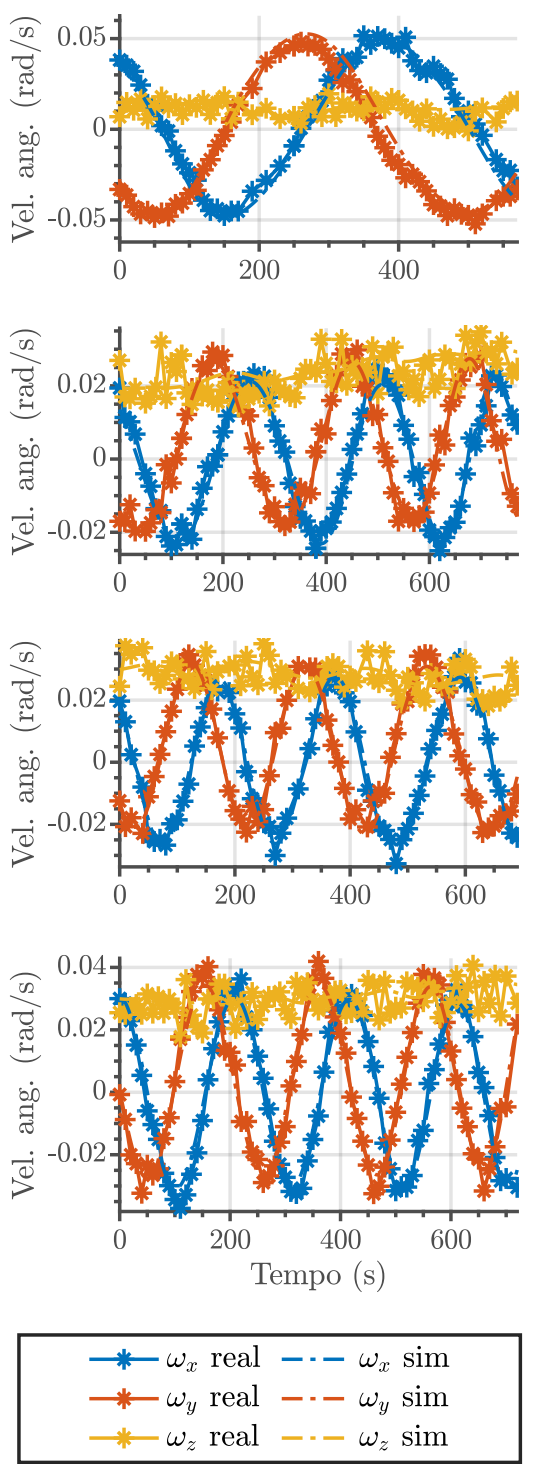

Fonte: Autor.
Resíduos.
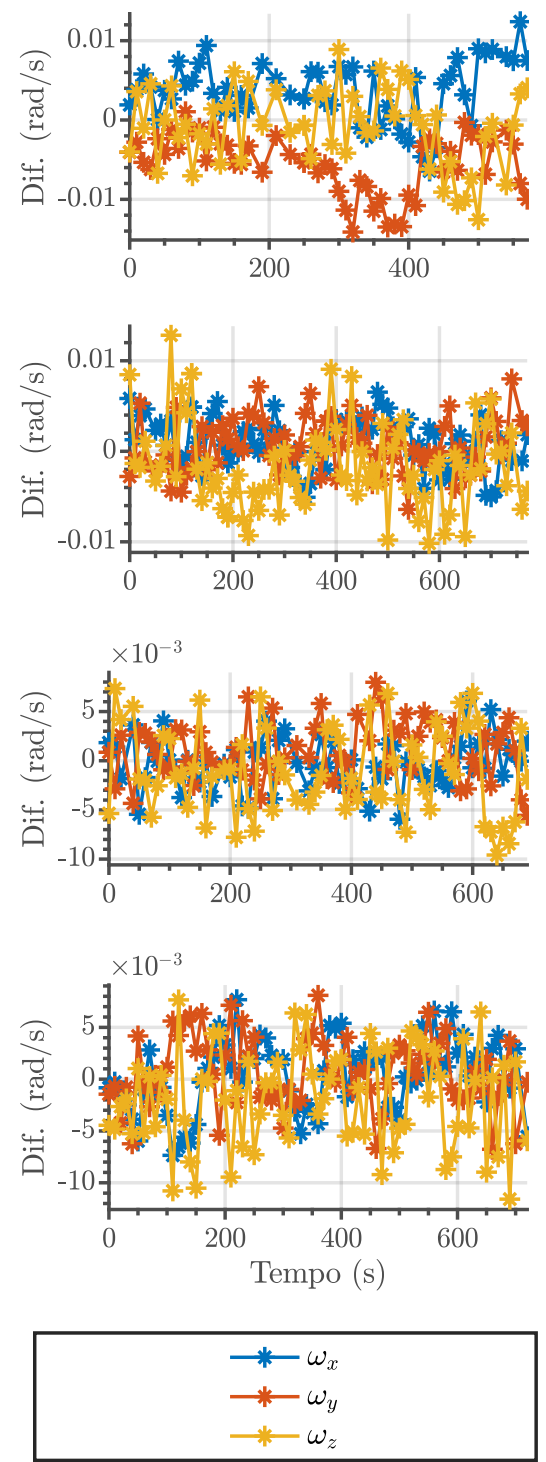
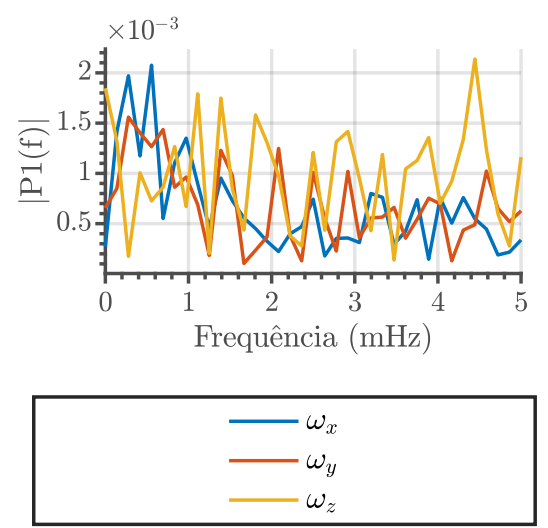

Espectro de potência
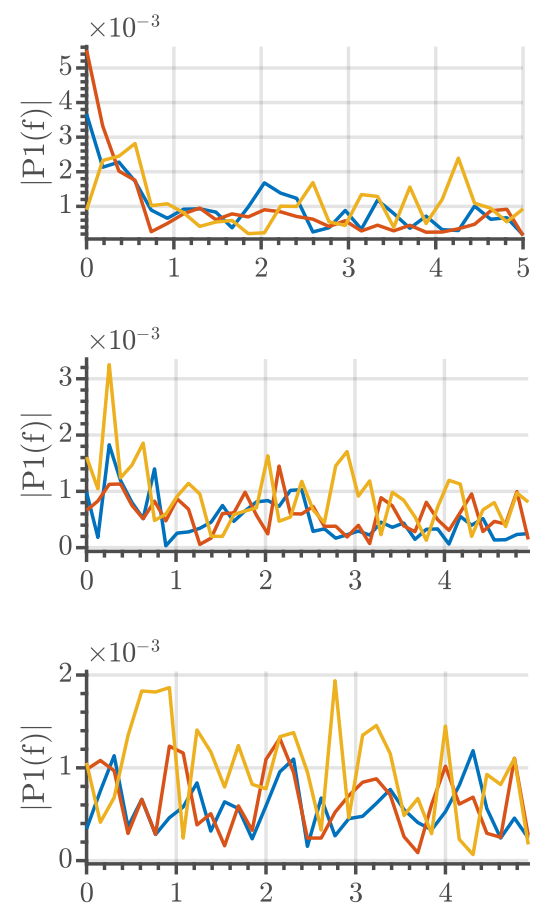
Figura B.13 - Validação dos parâmetros de perturbação - Experimentos 2b a 5b.

Dados reais e simulação.
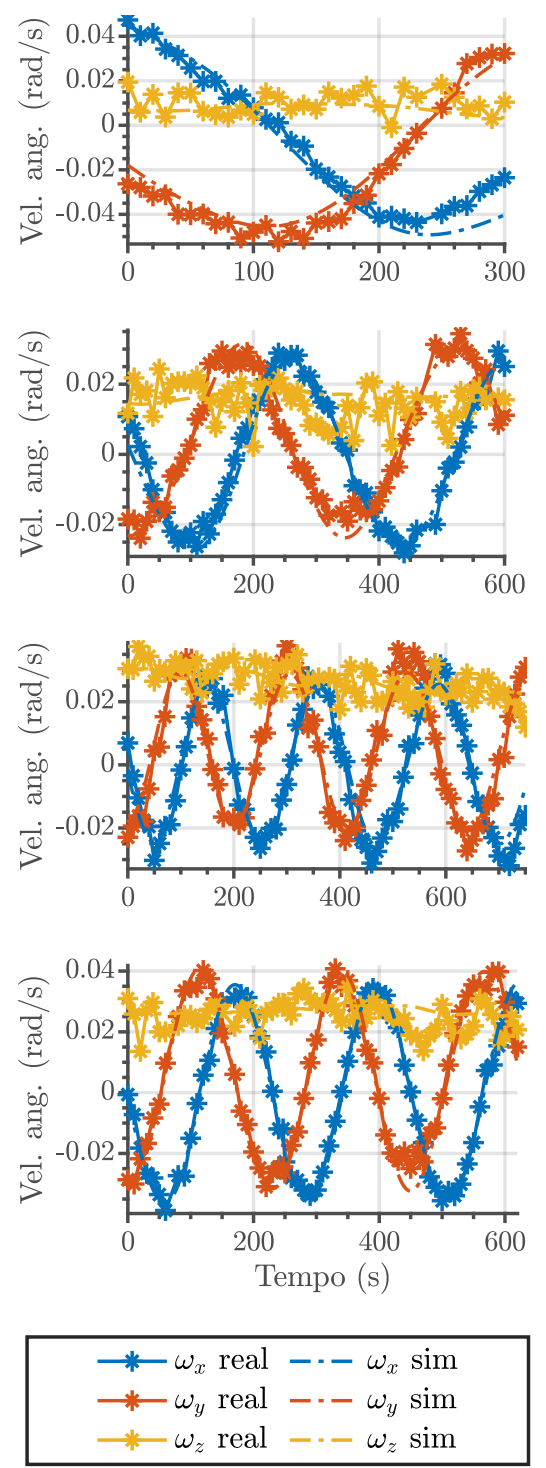

Fonte: Autor.
Resíduos.
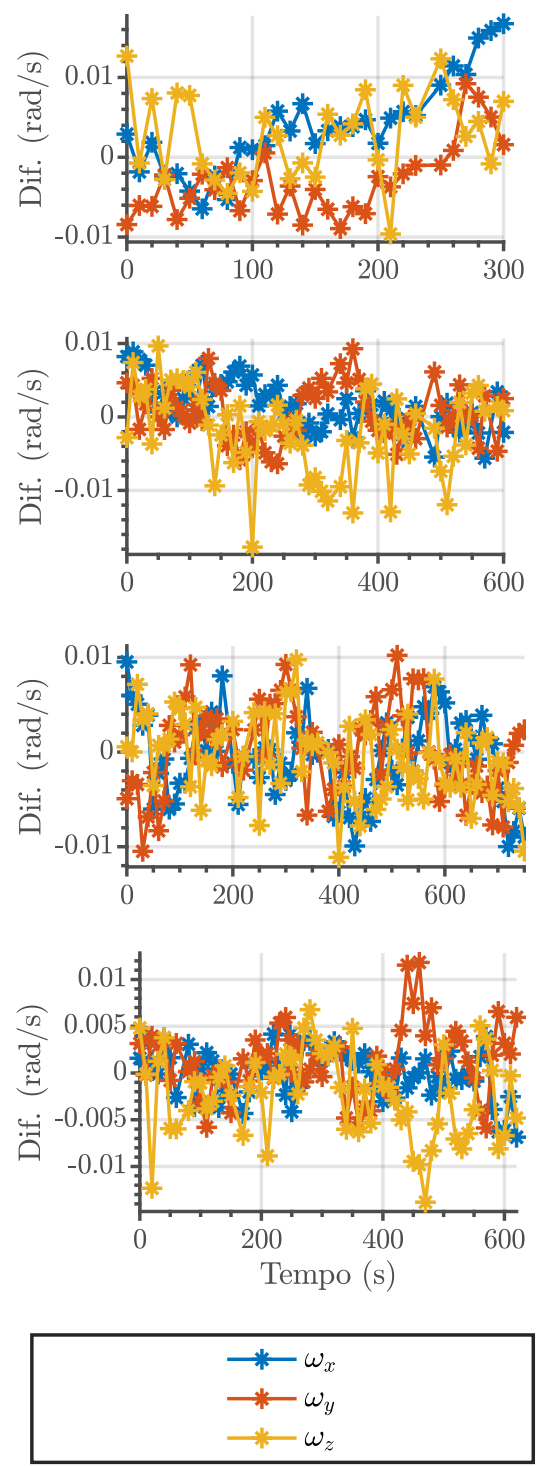

Espectro de potência
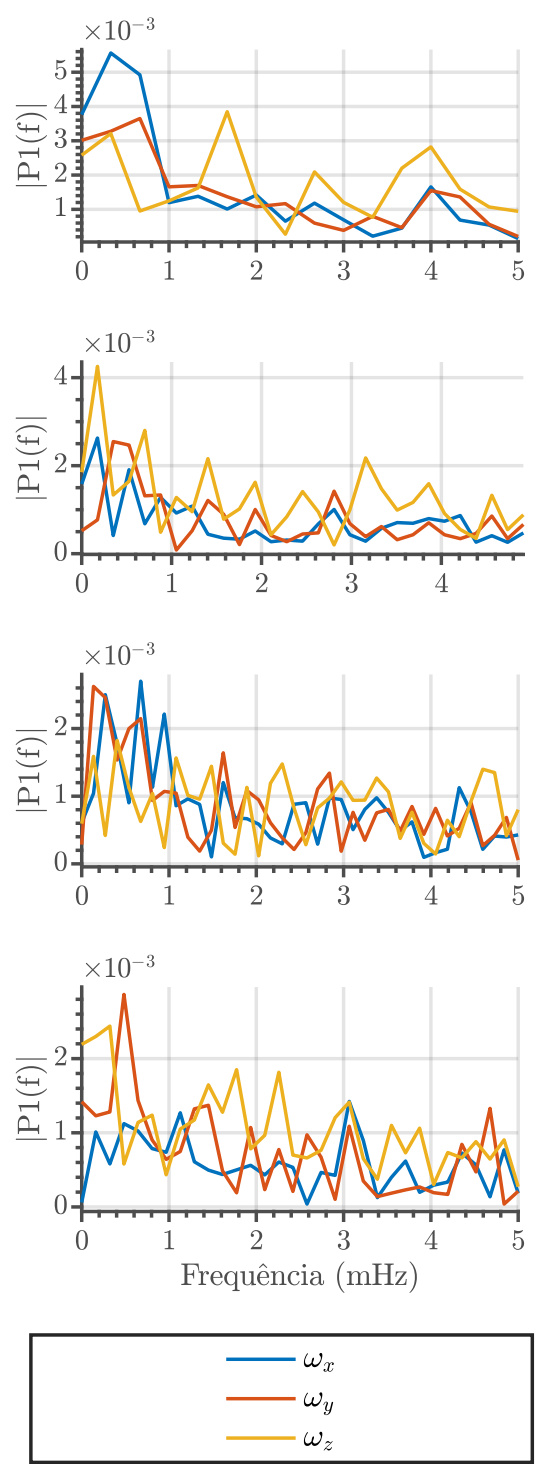
Figura B.14 - Influência das perturbações no tempo - Trechos 2 a 7.

Dados reais e simulação.

Relação entre $\omega_{\text {prt }}$ e $\omega_{\text {free }}$.

Perturbações.
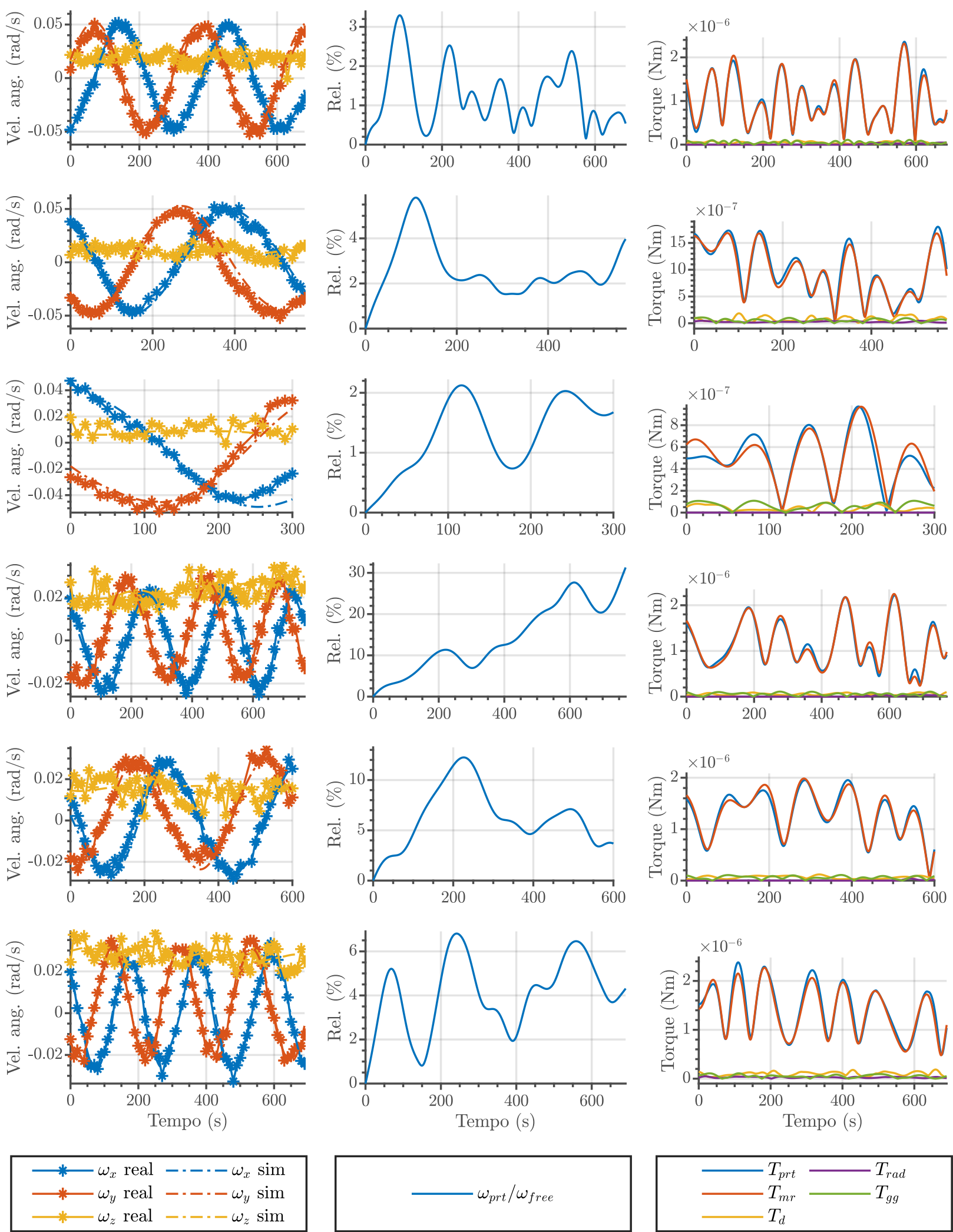

Fonte: Autor. 
Figura B.15 - Influência das perturbações no tempo - Trechos 8 a 10.

Dados reais e simulação.
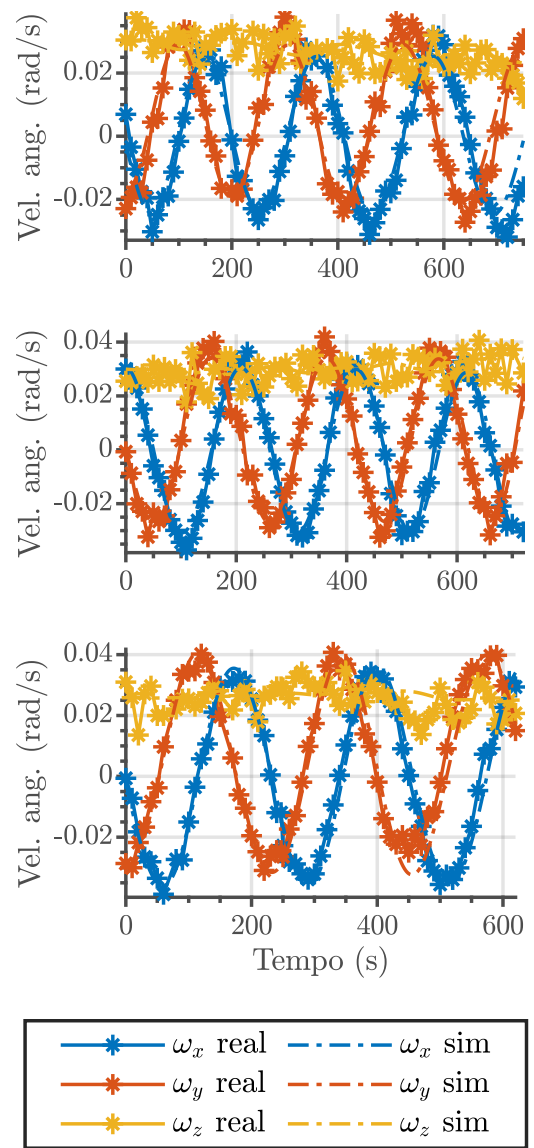

Fonte: Autor.
Relação entre $\omega_{p r t}$ e $\omega_{f r e e}$.
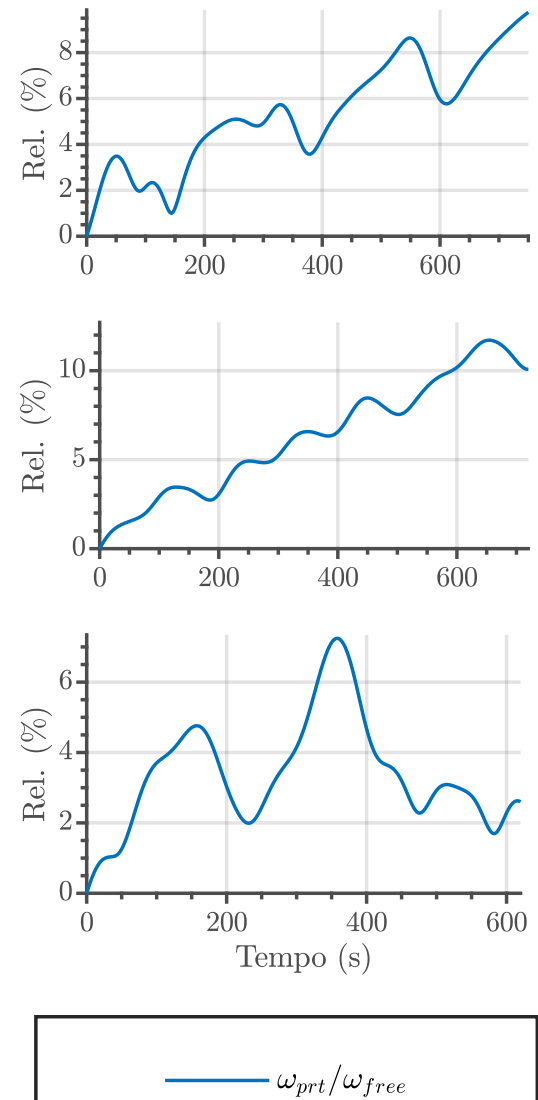

Perturbações.
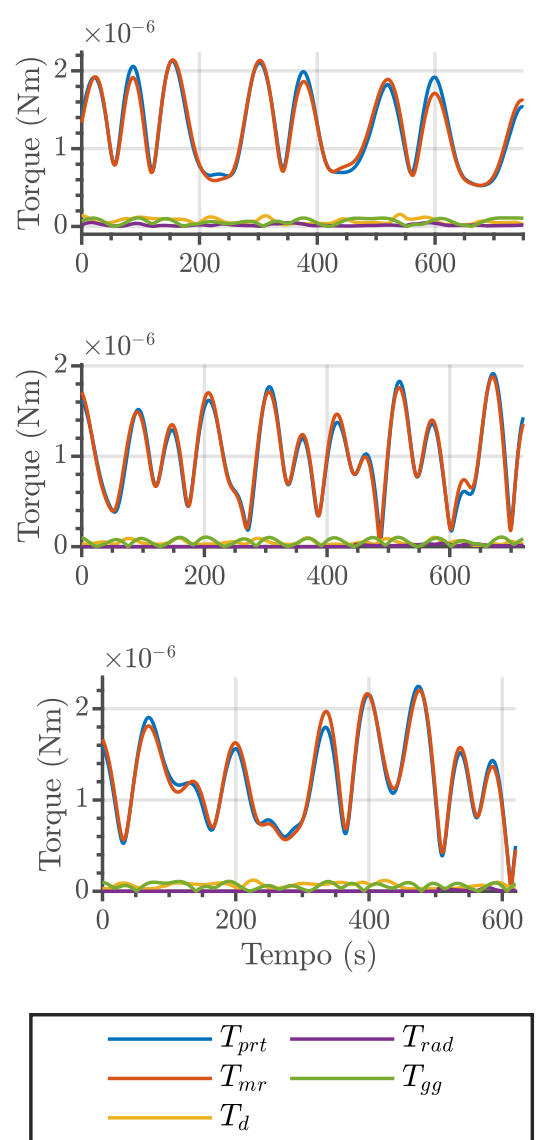
Figura B.16 - Comparação da presença e ausência das perturbações no tempo - Trechos 2 a 7 .

Dados reais e simulações.
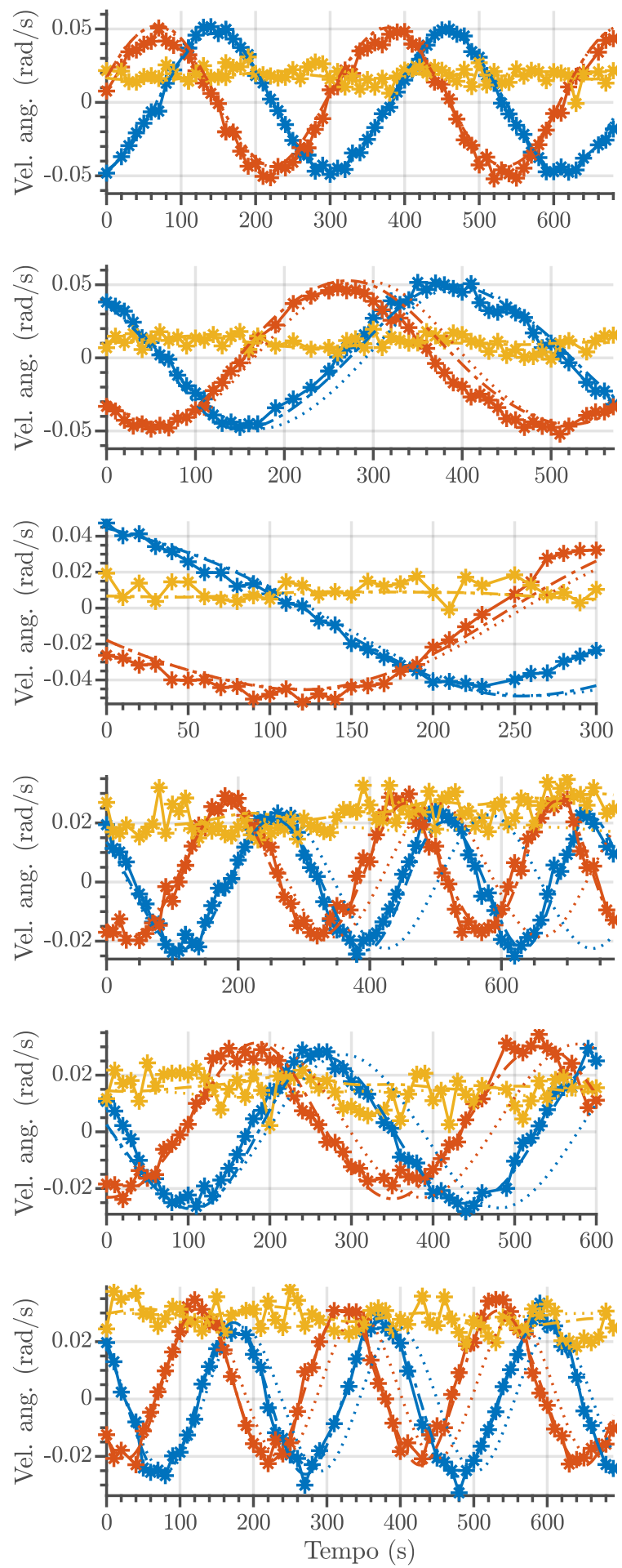

$$
\begin{aligned}
& \text { * }-\omega_{x} \text { real }-\cdot-\omega_{x} \text { sim. c/ prt } \cdots \cdots \omega_{x} \text { sim. s/prt } \\
& \rightarrow-\omega_{y} \text { real }--\omega_{y} \text { sim. c/ prt } \cdots . \omega_{y} \text { sim. s/prt } \\
& * \omega_{z} \text { real }-=\omega_{z} \operatorname{sim} . \mathrm{c} / \text { prt } \ldots . . \omega_{z} \text { sim. s/prt }
\end{aligned}
$$

Fonte: Autor.
Módulo da diferença das simulações.
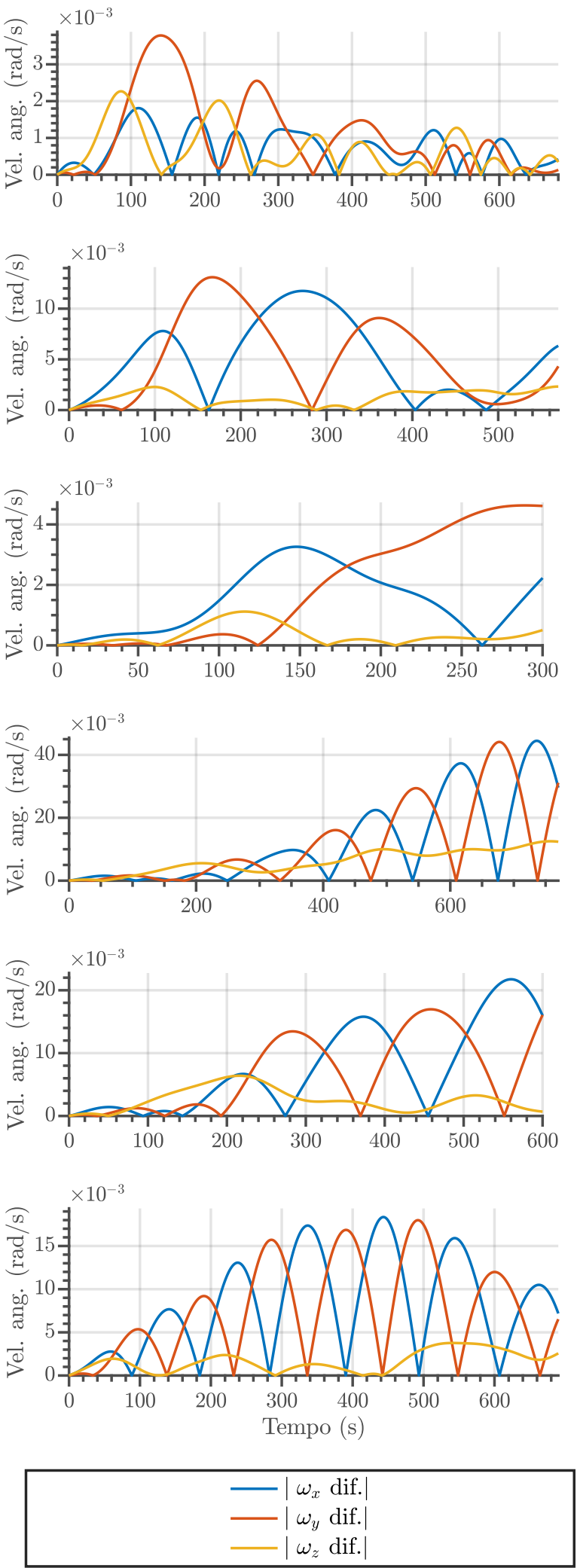
Figura B.17 - Comparação da presença e ausência das perturbações no tempo - Trechos 8 a 10.

Dados reais e simulações.
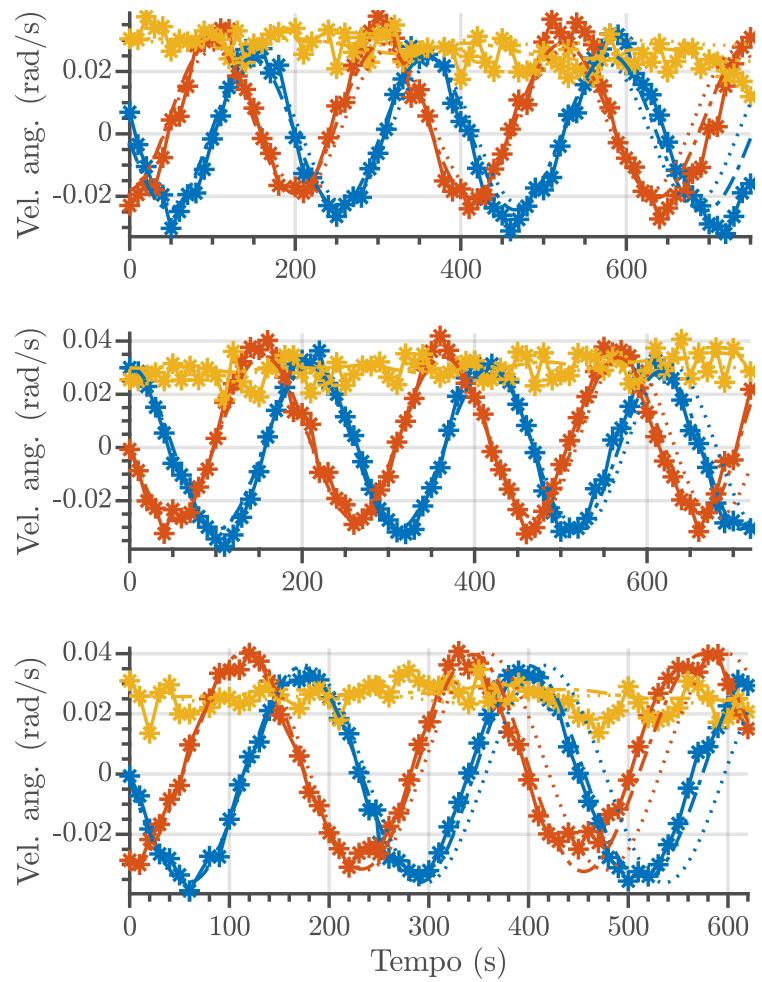

$$
\begin{aligned}
& -*-\omega_{x} \text { real }--\omega_{x} \operatorname{sim} . \mathrm{c} / \text { prt } \cdots \cdots \omega_{x} \operatorname{sim} . \mathrm{s} / \mathrm{prt} \\
& \text { * } \omega_{y} \text { real }-=-\omega_{y} \text { sim. c/ prt } \cdots . \omega_{y} \text { sim. s/ prt } \\
& -\omega_{z} \text { real }--\omega_{z} \text { sim. c/ prt } \cdots . \omega_{z} \text { sim. s/ prt }
\end{aligned}
$$

Fonte: Autor.
Módulo da diferença das simulações.
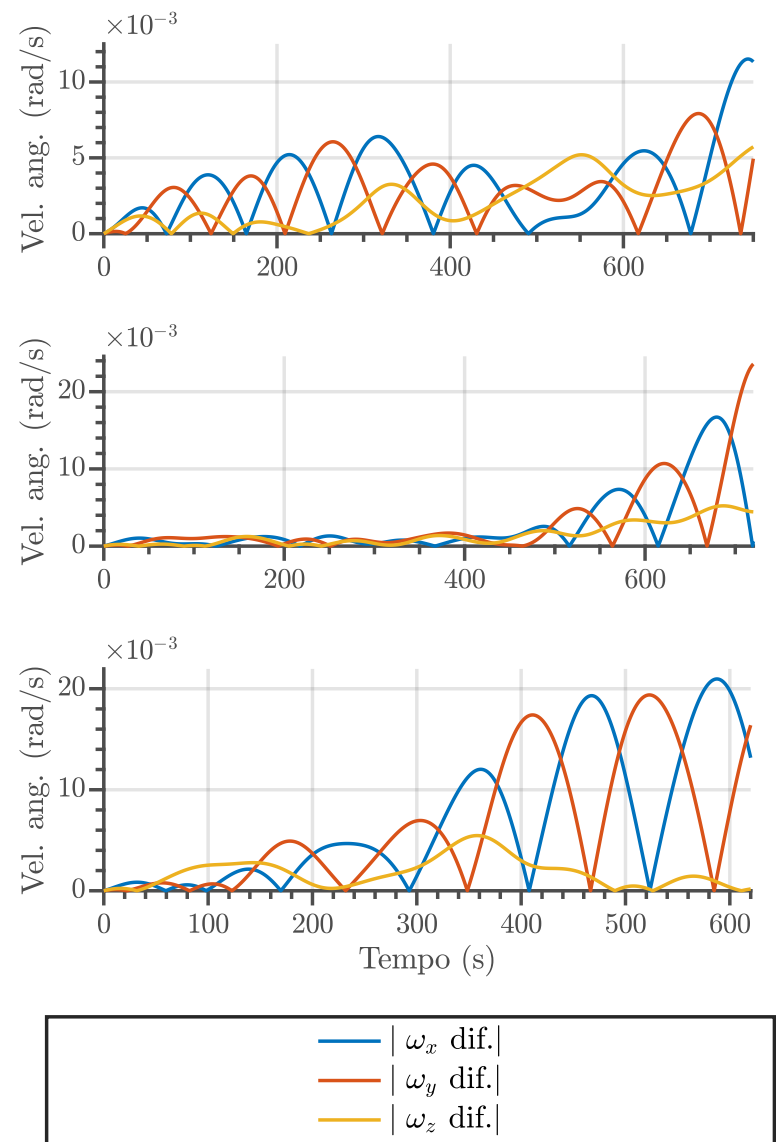


\section{ANEXO A - FOLHA DE PARÂMETROS DO MOTOR MAXON EC 20 FLAT [351100]}




\section{EC 20 flat $\varnothing 20 \mathrm{~mm}$, brushless, 3 Watt}
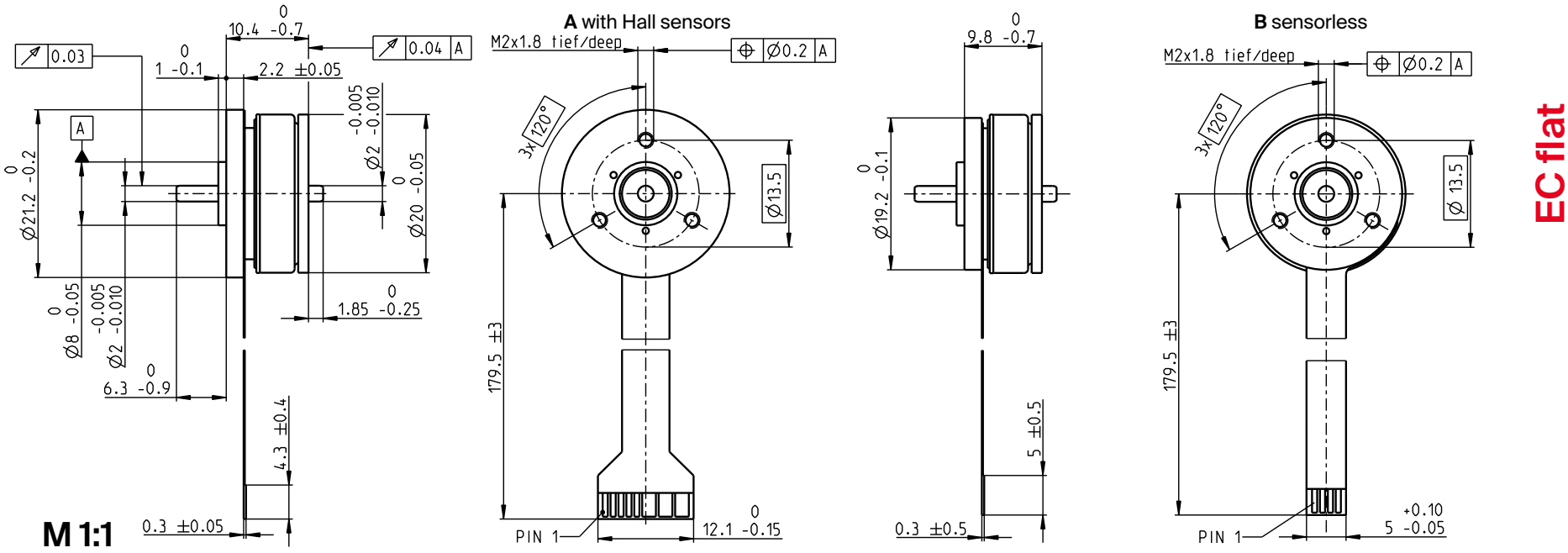

Stock program

Standard program

Special program (on request)

\begin{tabular}{l|l|l|l|l|} 
B sensorless & 339255 & 241916 & 339257 & 339258 \\
\hline
\end{tabular}

\section{Motor Data}

Values at nominal voltage

1 Nominal voltage

2 No load speed

3 No load current

4 Nominal speed

5 Nominal torque (max. continuous torque)

6 Nominal current (max. continuous current)

7 Stall torque ${ }^{1}$

8 Stall current

9 Max. efficiency

Characteristics

10 Terminal resistance phase to phase

11 Terminal inductance phase to phase

12 Torque constant

13 Speed constant

14 Speed/torque gradient

15 Mechanical time constant

16 Rotor inertia

\section{Specifications}

(20)

\section{Thermal data}

17 Thermal resistance housing-ambient

18 Thermal resistance winding-housing

19 Thermal time constant winding

20 Thermal time constant motor

21 Ambient temperature

22 Max. winding temperature

Mechanical data (preloaded ball bearing 23 Max. speed

24 Axial play at axial load $<2.0 \mathrm{~N}$

25 Radial play

26 Max. axial load (dynamic)

27 Max. force for press fits (static)

(static, shaft supported)

28 Max. radial load, $5 \mathrm{~mm}$ from flange

Other specifications

9 Number of pole pairs

30 Number of phases

31 Weight of moto

Values listed in the table are nominal.

Connection with Hall sensors sensorless

$\begin{array}{lll}\text { Connection } & \text { with Hall sensors } & \text { sensorless } \\ \text { Pin } 1 & V_{\text {Hall }} 4.5 . .24 \text { VDC } & \text { Motor winding } 1\end{array}$

Pin 2

Pin 4

Pin 5

Pin 6

Pin 7

Pin 8 Hall sensor 3

Motor winding 2

Hall sensor 1 Motor winding 3

Hall sensor 2

入 neutral point

GND

Motor winding 3

Motor winding 2

Motor winding 1

Adapter

Soe p. 514

220300

Part number

Part number

ME

1-84953-1

220310

Part number

84953-4

Pin for design with Hall sensors:

FPC, 11-pol, Pitch $1.0 \mathrm{~mm}$, top contact style

Wiring diagram for Hall sensors see p. 49

${ }^{1}$ Calculation does not include saturation effect

(p. 61/168)

\begin{tabular}{|c|c|c|c|}
\hline V & 6 & 9 & 12 \\
\hline rpm & 9070 & 9760 & 9540 \\
\hline
\end{tabular}

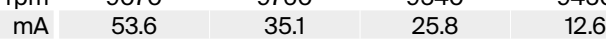

$\begin{array}{lllll}\text { rpm } & 3030 & 4140 & 3490 & 3830\end{array}$

\begin{tabular}{lllll|}
\hline $\mathrm{mm}$ & 3.22 & 4.08 & 3.28 & 3.78 \\
\hline
\end{tabular}

$\begin{array}{lllll}\text { A } & 0.56 & 0.478 & 0.294 & 0.163\end{array}$

\begin{tabular}{r|c|c|c|c|}
$\mathrm{mNm}$ & 5.29 & 8.04 & 5.67 & 7.12 \\
$\mathrm{~A}$ & 0.9 & 0.957 & 0.503 & 0.309
\end{tabular}

$\begin{array}{lllll}\% & 59 & 66 & 61 & 65\end{array}$

\begin{tabular}{r|r|r|r|r|}
$\Omega$ & 6.67 & 9.4 & 23.9 & 77.7 \\
\hline
\end{tabular}

\begin{tabular}{lllll}
$\mathrm{mH}$ & 0.639 & 1.3 & 2.35 & 9.8 \\
\hline
\end{tabular}

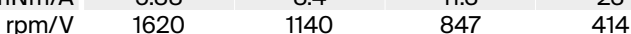

\begin{tabular}{l|r|r|r|r}
\hline $\mathrm{m} / \mathrm{mNm}$ & 1840 & 1270 & 1790 & 1400 \\
\hline
\end{tabular}

$\begin{array}{lllll}\mathrm{gcm}^{2} & 384 & 384 & 384 & 3.84\end{array}$

\section{Operating Range Comments}

n [rpm]

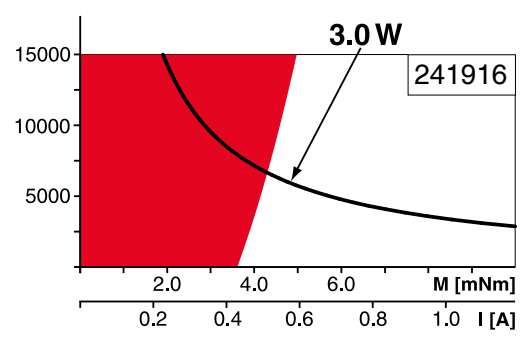

Continuous operation

In observation of above listed thermal resistance (lines 17 and 18) the maximum permissible wind

ing temperature will be reached during continuous operation at $25^{\circ} \mathrm{C}$ ambient.

$=$ Thermal limit.

Short term operation

The motor may be briefly overloaded (recurring).

_ Assigned power rating

\section{maxon Modular System}

3 Planetary Gearhead

$15 \mathrm{~g} \varnothing 22 \mathrm{~mm}$

$0.5-2.0 \mathrm{Nm}$

Page $374 / 377$

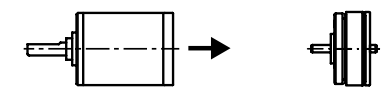

Recommended Electronics: Notes Page 38

ESCON Module 24/2 486

ESCON 36/3 EC 487

ESCON Mod. 50/4 EC-S 487

DEC Module 24/2 491

EPOS4 Micro 24/5 495

EPOS4 Mod./Comp. 24/1.5 496

EPOS4 Comp. 24/5 3-axes 497 
ANEXO B - ARTIGO APRESENTADO NO III IAA LATIN AMERICAN CUBESAT WORKSHOP 


\title{
ATTITUDE CONTROL SYSTEM STUDY FOR A UNIVERSITY CUBESAT DEDICATED TO THE MEASUREMENT OF THE EARTH'S MAGNETIC FIELD
}

\author{
Cauê Garcia Menegaldo ${ }^{(1)}$, Fábio de Oliveira Fialho(2), Eduardo Janot \\ Pacheco $^{(3)}$, Felipe Miguel Pait ${ }^{(4)}$ \\ (1) Department of Engineering of Telecommunications and Control, University of Sao \\ Paulo, Av. Prof. Luciano Gualberto, no 158, SP, Brazil, +55 113091 5427, \\ caue.menegaldo@usp.br \\ (2) Department of Engineering of Telecommunications and Control, University of Sao \\ Paulo, Av. Prof. Luciano Gualberto, no 158, SP, Brazil, +55 113091 5427, \\ fabio.fialho@usp.br \\ ${ }^{(3)}$ Department of Astronomy, University of Sao Paulo, Rua do Matão, $n^{\circ} 1226, S P$, \\ Brazil, +55 113091 2779, eduardo.janot@iag.usp.br \\ (4) Department of Engineering of Telecommunications and Control, University of Sao \\ Paulo, Av. Prof. Luciano Gualberto, $n^{\circ}$ 158, SP, Brazil, +55 1130915650 , \\ pait@usp.br
}

Keywords: CubeSats, Attitude Control System, Dynamic Modeling, Earth's Magnetic Field, South Atlantic Anomaly

The South Atlantic Anomaly (SAA) is a weakness in the Earth's magnetic field. Characterizing it has impact on technological and research programs. The Institute of Astronomy, Geophysics and Atmospheric Sciences (IAG) of the University of Sao Paulo (USP) is working on the development of a $1 \mathrm{U}$ CubeSat dedicated to its measurement. The Polytechnic School of the USP (EPUSP) is responsible for the CubeSat's Attitude Determination and Control System (ADCS) development. This paper covers the Attitude Control System (ACS) assessment studies that have been carried out so far at EPUSP. It covers the satellite dynamic simulator development, the detumbling controller as well as a Nadir direction pointing controller. The result is an ACS capable of reducing the CubeSat angular velocity after launch from $10 \mathrm{deg} \mathrm{s}^{-1}$ to $0.1 \mathrm{deg} \mathrm{s}^{-1}$ in 0.6 orbits and a Nadir reference tracking with 5 degrees of axial error in Euler angles.

\section{Introduction}

Measurements of the Earth's magnetic field at various altitudes are essential for instance, to map the Van Allen Radiation Belts that work like a shield, protecting our planet against charged particles (cosmic rays) coming from the Sun and the Galaxy. The Earth's magnetic and rotation axes have an inclination of $11^{\circ}$. This causes an asymmetry of the belts with respect to the surface of the planet, and the inner Van Allen belt is closest to the surface (down to an altitude of $200 \mathrm{~km}$ ) over the southeast of South America. In this region, the Earth's magnetic field is weakest relative to a theoretical, symmetrical central dipole field. This so-called South Atlantic Anomaly (SAA) leads to an increase in the flux of energetic particles, exposing satellites to higher levels of radiation which may cause serious damage [e.g., 1]. With the help of CoRoT's satellite data, Pinheiro da Silva et al. [2] showed that the SAA had slightly drifted to the inner continent, being at that epoch situated over the Brazilian state of Santa Catarina. Indeed, the shape of the SAA changes over time, the drift rate of 
the SAA being very close to the rotation differential between the Earth's core and its surface, estimated to be between $0.3^{\circ}$ and $0.5^{\circ}$ per year. It is then interesting, both from a scientific and technical point of view, to survey the behavior of the SAA, which is a global phenomenon occurring mainly over Brazil. The low-cost experiment proposed in this contribution may be suited to do this.

CubeSat [3] is a cube satellite with $10 \mathrm{~cm}$ edge and no more than $1.33 \mathrm{~kg}$. This dimension is called $1 \mathrm{U}$. Among its basic systems, ACS plays a key role assuring the proper satellite pointing regarding mission requirements.

The goal of this paper is to present the ACS assessment study that has been carried out so far. Such a study covers the development of the satellite dynamic simulator, the detumbling mode responsible for reducing the angular velocity of the satellite after its launch, and the pointing control mode in charge of pointing the antennas in Earth direction. This last operation mode is required to avoid losses of antenna signal and to improve communication.

This paper is organized as follows. Section 2 presents ACS requirements. Section 3 provides a satellite description. Spacecraft and disturbance dynamic modeling are detailed in Section 4. Control design for detumbling and pointing control modes are presented in Section 5. Simulation results are presented in Section 6 and conclusions are stated in Section 7.

\section{ACS Requirements}

There are no special requirements for ACS regarding the measurement of the Earth's magnetic field. On the other hand, in the ISS (International Space Station) CubeSats launching program, which is envisaged in this project, CubeSats are placed in orbit by a Poly Picosatellite Orbital Deployer ( $p-P O D)$ with an initial angular velocity of approximately $10 \mathrm{deg} \mathrm{s}^{-1}$. Therefore, a first controller must be capable of reducing such a velocity to $0.1 \mathrm{deg} \mathrm{s}^{-1}$ during three orbits. Such a reduction is necessary to ensure the proper functioning of the communication system. After that, a second controller must be capable of pointing the vehicle antennas to Nadir direction with 5 degrees of axial error in Euler angles in order to increase the communication with ground stations.

\section{Spacecraft Description}

The IAG CubeSat is still in assessment phase. Therefore, it may be subject to changes in its structure and composition. So far, it is a $1 \mathrm{U}$ CubeSat with an ACS composed by three magnetorquers and three reaction wheels placed in orthogonal positions. The Determination Control System (DCS) is composed by three-axis magnetometers, six Sun sensors, one in each cube face, and one gyroscope.

\section{Spacecraft and Disturbance Modeling}

\subsection{Reference Frames}

Both the attitude of the satellite and the orbit are represented by vector elements.

In order to define a vector in space, a reference system is necessary. In addition, for comprehensive calculation and plots, different systems are defined, appropriate to each case, that can be related to each other by coordinate transformations. We also 
use superscript letters in upper left to indicate which coordinate system is related to the variable at hand.

The Earth-Centred Inertial Frame (ECI) is an inertial system denoted by $i$. It has its origin in the Earth's center of mass, ${ }^{i} x$-axis in the direction of the equinox of March 2000, and represented by the Greek character $\gamma,{ }^{i} z$-axis in the north direction of the Earth's rotation axis and ${ }^{i} y$-axis completes the right-handed coordinate system.

The Orbit Reference Frame (ORF), denoted by $o$, is useful for the satellite pointing controller. Its origin is the vehicle's center of mass $G,{ }^{o} z$-axis in the Nadir direction, ${ }^{o} x$ axis in the vehicle's velocity direction, therefore, perpendicular to ${ }^{\circ} z$-axis, and ${ }^{\circ} y$-axis completes the right-handed coordinate system.

The Body Reference Frame (BRF), denoted by $b$, is useful to represent some elements of the vehicle and is fixed with respect to the body of the satellite. This frame has its origin $O$ in a bottom corner of the vehicle, ${ }^{b} z$-axis is normal to the side that contains the antennas, ${ }^{b} x$-axis is perpendicular to the satellite side and ${ }^{b} y$-axis completes the right-handed coordinate system.

The vehicle dynamics are simplified considerably if represented in relation to the principal axes of inertia. This is called Control Reference Frame (CRF) and is denoted by $c$, a system whose origin is the vehicle's center of mass, ${ }^{c} z$-axis being in the direction of the biggest moment of inertia, ${ }^{c} x$-axis in the direction of the smaller moment of inertia and $c^{c}$-axis completes the right-handed coordinate system.

Figure 1 shows an illustration of the reference frames.
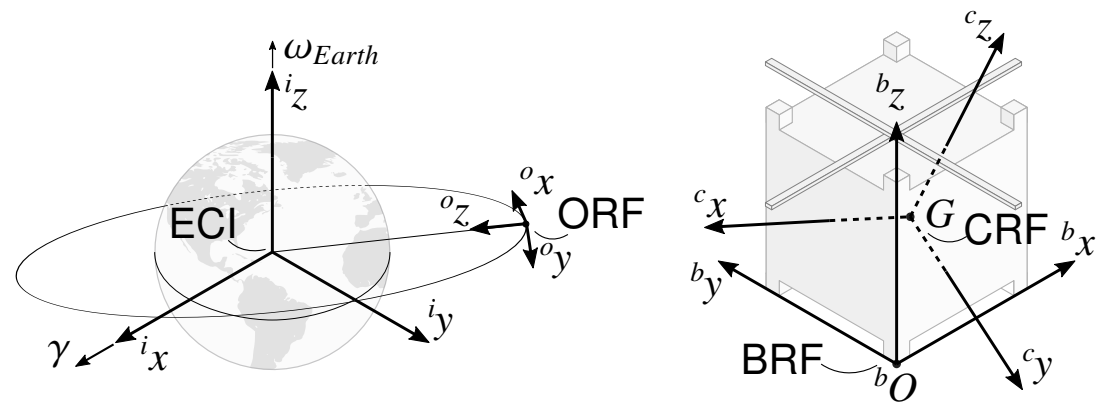

Figure 1: Reference Frame Illustration.

\subsection{Satellite Kinematics}

The satellite attitude is commonly and preferably represented by quaternions $[4$, $5,6]$. They have lower computational cost and they do not present singularity issues. A quaternion can be expressed as:

$$
\begin{aligned}
q & =q_{0}+q_{1} \hat{\mathbf{i}}+q_{2} \hat{\mathbf{j}}+q_{3} \hat{\mathbf{k}} \\
& =q_{0}+\mathbf{q},
\end{aligned}
$$

where $q_{0}$ is the scalar part and $\mathbf{q}$ is the vector or imaginary part [7].

By restricting the quaternion to be unitary, $\|q\|=\sqrt{q_{0}^{2}+q_{1}^{2}+q_{2}^{2}+q_{3}^{2}}=1$, it is possible to relate it to the symmetrical Euler parameters.

As shown in [5], the time derivative of quaternions is given by: 


$$
\frac{\mathrm{d}}{\mathrm{d} t} q=\frac{1}{2}\left[\begin{array}{cccc}
0 & \omega_{z} & -\omega_{y} & \omega_{x} \\
-\omega_{z} & 0 & \omega_{x} & \omega_{y} \\
\omega_{y} & -\omega_{x} & 0 & \omega_{z} \\
-\omega_{x} & -\omega_{y} & -\omega_{z} & 0
\end{array}\right] q,
$$

where $\omega_{x}, \omega_{y}$ and $\omega_{z}$ are, respectively, the angular velocities around $x, y$, and $z$ axes.

\subsection{Satellite Dynamics}

As shown in Equation (2), the satellite attitude represented by quaternions is a function of satellite's angular velocity. Attitude dynamics describe the angular velocity as a function of the applied torque $\mathbf{T}$, which can be derived from actuators, $\mathbf{T}_{a c t}$, and disturbances, $\mathbf{T}_{d s t r}$. The satellite can be considered a rigid body since its mass distribution remains constant over time. As a result, some Rigid Body Dynamics properties and principles can be applied. Considering $\omega^{c / i}$ the angular velocity of CRF relative to $\mathrm{ECl}$, the Euler equation, measured in $\mathrm{CRF}$, is given by $[4,5]$ :

$$
{ }^{c} \mathbf{T}={ }^{c}\left(\frac{\mathrm{d} \mathbf{H}}{\mathrm{d} t}\right)_{i}=\left(\frac{\mathrm{d} \mathbf{H}}{\mathrm{d} t}\right)_{c}+{ }^{c} \omega^{c / i} \times{ }^{c} \mathbf{H},
$$

where $\mathbf{H}$ is the angular momentum, $(\mathrm{d} \mathbf{H} / \mathrm{d} t)_{i}$ and $(\mathrm{d} \mathbf{H} / \mathrm{d} t)_{c}$ are, respectively, the angular momentum variation in time with respect to $\mathrm{ECl}$ and CRF. The angular momentum is defined by the product of the inertia matrix by the angular velocity, $(\mathbf{H}=\mathbf{I} \omega)$. Thus, by rewriting Equation (3), substituting the notation $\omega^{c / i}$ by $\omega_{v}$, and separating the total torque between the torque of the actuators and disturbances, we have:

$$
{ }^{c} \mathbf{T}_{a c t}+{ }^{c} \mathbf{T}_{d s t r}=\mathbf{I}_{v}{ }^{c} \dot{\boldsymbol{\omega}}_{v}+{ }^{c} \boldsymbol{\omega}_{v} \times\left(\mathbf{I}_{v}{ }^{c} \boldsymbol{\omega}_{v}\right),
$$

where $\mathbf{I}_{v}$ and ${ }^{c} \omega_{v}$ are the inertia matrix and the angular velocity of the vehicle, respectively.

\subsection{Actuators}

The CubeSat has magnetorquers $\left(\mathbf{T}_{m}\right)$ for detumbling control and reaction wheels $\left(\mathbf{T}_{r w}\right)$ for pointing control. The actuators torque $\left(\mathbf{T}_{a c t}\right)$ will be the sum of torques $\mathbf{T}_{m}$ and $\mathbf{T}_{r w}$.

\subsubsection{Magnetorquers}

In Low Earth Orbit (LEO), the intensity of Earth's magnetic field is significant [7]. Its interaction with magnetorquers is capable of producing torque in the vehicle. In vector form, the torque of the magnetorquers, $\mathbf{T}_{m}$, is given by the vector product of the magnetic moment of each dipole, $\mathbf{m}_{m_{i}}$, and the Earth's magnetic field $\mathbf{B}$. It is calculated as follows:

$$
{ }^{c} \mathbf{T}_{m}=\sum_{i=1}^{3}{ }^{c} \mathbf{m}_{m_{i}} \times{ }^{c} \mathbf{B}={ }^{c} \mathbf{m}_{m} \times{ }^{c} \mathbf{B} .
$$




\subsubsection{Reaction Wheels}

Reaction wheels (RW) allow more precise pointing control [8]. Considering $\mathbf{I}_{r w}$ and $\omega_{r w}$ the moment of inertia and the angular velocity of reaction wheels and applying the Euler characteristic equation (Eq. (3)), we obtain, for each reaction wheel $i$ :

$$
{ }^{c} \mathbf{T}_{r w_{i}}={ }^{c} \dot{\mathbf{H}}_{r w_{i}}+{ }^{c} \boldsymbol{\omega}_{v} \times{ }^{c} \mathbf{H}_{r w_{i}} .
$$

But some considerations need to be made. Only the first term of Equation (6) ( $\left.{ }^{c} \dot{\mathbf{H}}_{r w_{i}}\right)$ will be an object of control. The second one $\left({ }^{c} \omega_{v} \times{ }^{c} \mathbf{H}_{r w_{i}}\right)$ is a gyroscopic perturbation effect and it will be added to the satellite dynamics. Moreover, by action and reaction law, both terms must be negative. Therefore, rewriting Equations (6) and (4):

$$
{ }^{c} \mathbf{T}_{r w}=-\sum_{i=1}^{3}{ }^{c} \dot{\mathbf{H}}_{r w_{i}}=-{ }^{c} \dot{\mathbf{H}}_{r w}
$$

and

$$
{ }^{c} \mathbf{T}_{a c t}+{ }^{c} \mathbf{T}_{d s t r}=\mathbf{I}_{v}{ }^{c} \dot{\boldsymbol{\omega}}_{v}+{ }^{c} \boldsymbol{\omega}_{v} \times\left(\mathbf{I}_{v}{ }^{c} \boldsymbol{\omega}_{v}+{ }^{c} \mathbf{H}_{r w}\right) .
$$

\subsection{Disturbances}

The satellite is subject to disturbances that depend on a series of factors: mechanical characteristics of the vehicle, mission profile, solar activity, etc. In LEO, the main torques are due to the atmospheric (aerodynamic) drag, $\mathbf{T}_{d}$, the solar radiation pressure, $\mathbf{T}_{s r p}$, the gradient of gravity, $\mathbf{T}_{g g}$, and the residual magnetic dipole, $\mathbf{T}_{m a g}$. The torque due to all disturbances, $\mathbf{T}_{d s t r}$, is, thus, the sum of all these torques: $\mathbf{T}_{d s t r}=\mathbf{T}_{d}+\mathbf{T}_{s r p}+\mathbf{T}_{g g}+\mathbf{T}_{\text {mag }}$. References [4] [7] [9] [10] [11] were used to implement their dynamic equations.

\section{Control Design}

As stated in Section 2, the ACS should be able to reduce the vehicle angular velocity from $10 \mathrm{deg} \mathrm{s}^{-1}$ to $1 \mathrm{deg} \mathrm{s}^{-1}$ (called detumbling mode) and then pointing the antennas in Nadir direction with a maximum error of 5 degrees (called pointing control mode). The detumbling mode uses only magnetorquers, and the pointing control mode uses only reaction wheels.

\subsection{Detumbling Mode}

Due to its simplicity, robustness, and efficiency the algorithm known as B-dot Control was adopted for CubeSat detumbling. First presented in [12], this technique has follows the principle of gradually reducing the rotational kinetic energy of the vehicle. For didactic purposes, it is equivalent to following the Earth's magnetic field. The control law polarizes magnetorquers in the opposite direction of the local magnetic field derivative, $\dot{\mathbf{B}}$, and is expressed by:

$$
{ }^{c} \mathbf{m}_{m}=-k_{d e t}{ }^{c} \dot{\mathbf{B}},
$$

where ${ }^{c} \mathbf{m}_{m}$ is the dipole moment and $k_{\text {det }}$ is the controller gain, with $k_{d e t}>0$. As presented in Equation (5), the torque of the magnetorquers is due to interaction between the dipole moment and the Earth's magnetic field. 


\subsection{Pointing Control Mode}

For the Nadir direction, an optimum linear control method called Linear - Quadratic Regulator (LQR) has been implemented.

\subsubsection{Linear Model}

As presented by Blanke and Larsen [6], the linear model of Equation (2), the satellite kinematic model, can be expressed as

$$
\frac{\mathrm{d}}{\mathrm{d} t} q=\left[\begin{array}{c}
0 \\
-S\left(\overline{\boldsymbol{\omega}}_{v}\right) \mathbf{q}
\end{array}\right]+\frac{1}{2} \mathbf{1}_{3 \times 3} \omega,
$$

where $S(\cdot)$ is a three-dimensional skew-symmetric cross-product operator and $\mathbf{1}$ is an identity matrix. Note that $\mathbf{q}$ is the vector part of the quaternion.

Linearization of the nonlinear dynamic model presented in Equations (6) and (8) is performed using a first order Taylor expansion around the operating points $\bar{\omega}_{v}$ and $\overline{\mathbf{H}}_{r w}$. Thus, by isolating the angular velocity and suppressing the superscript letter $c$, the linear dynamic model can be expressed as

$$
\dot{\boldsymbol{\omega}}_{v}=\mathbf{I}_{v}^{-1}\left[S\left(\mathbf{I}_{v} \overline{\boldsymbol{\omega}}_{v}\right)-S\left(\overline{\boldsymbol{\omega}}_{v}\right) \mathbf{I}_{v}+S\left(\overline{\mathbf{H}}_{r w}\right)\right] \boldsymbol{\omega}_{v}-\mathbf{I}_{v}^{-1} S\left(\overline{\boldsymbol{\omega}}_{v}\right) \mathbf{H}_{r w}-\mathbf{I}_{v}^{-1} \mathbf{T}_{r w}+\mathbf{I}_{v}^{-1} \mathbf{T}_{d s t r} .
$$

In LQR formulation, torques due to external disturbances $\mathbf{T}_{d s t}$ and gyroscopic effect of the reaction wheels $S\left(\overline{\boldsymbol{\omega}}_{v}\right) \mathbf{H}_{r w}$ can be considered negligible when compared to torques due to satellite dynamics and actuators. Actuator dynamics is also neglected because it is 10-15 times faster than the vehicle dynamics [6].

Let the linear model be a space-state model given by $\dot{\mathbf{x}}=\mathbf{A x}+\mathbf{B u}$ and $\mathbf{y}=\mathbf{C x}+\mathbf{D u}$. For the state vector $\mathbf{x}=\left[\mathbf{q}, \omega_{v}\right]^{T}$ and the input vector $\mathbf{u}=\left[\mathbf{T}_{r w}\right]$ the satellite model matrices are given by

$$
\begin{gathered}
\mathbf{A}=\left[\begin{array}{cc}
-S\left(\overline{\boldsymbol{\omega}}_{v}\right) & \mathbf{1}_{3 \times 3} \\
\mathbf{0}_{3 \times 3} & \mathbf{I}_{v}^{-1}\left[S\left(\mathbf{I}_{v} \overline{\boldsymbol{\omega}}_{v}\right)-S\left(\overline{\boldsymbol{\omega}}_{v}\right) \mathbf{I}_{v}+S\left(\overline{\mathbf{H}}_{r w}\right)\right]
\end{array}\right], \\
\mathbf{B}=\left[\begin{array}{c}
\mathbf{0}_{3 \times 3} \\
-\mathbf{I}_{v}^{-1}
\end{array}\right], \quad \mathbf{C}=\left[\mathbf{1}_{6 \times 6}\right] \quad \text { and } \quad \mathbf{D}=\left[\mathbf{0}_{6 \times 3}\right],
\end{gathered}
$$

where $\mathbf{0}$ is a zero matrix.

\subsubsection{LQR Control Law}

The LQR control aims to bring all states to zero with the least control effort. For this we must determine the gain matrix $\mathbf{K}$ for the control vector $\mathbf{u}=-\mathbf{K x}$, which minimizes the quadratic cost function

$$
J=\int_{0}^{\infty}\left(\mathbf{x}^{T} \mathbf{Q} \mathbf{x}+\mathbf{u}^{T} \mathbf{R u}\right) d t
$$

where $\mathbf{Q}$ and $\mathbf{R}$ are symmetric positive semidefinite weighting matrices. The solution to this minimization problem is $\mathbf{K}=\mathbf{R}^{-1} \mathbf{B}^{T} \mathbf{P}$, where $\mathbf{P}$ is a symmetric positive definite matrix that satisfies the algebraic Riccati equation [13].

However, in the pointing control mode the goal is not to regulate the states close to zero, i. e., regulating the estate error vector $\left(\mathbf{e}=\mathbf{x}-\mathbf{x}_{r e f}\right)$ close to zero, but instead we would like to follow a reference. So, the proposed control needs a modification. As shown in Lewis et al. [14], the error dynamics is equivalent to the system dynamics, i.e. $\dot{\mathbf{e}}=\mathbf{A x}+\mathbf{B v}$ and $\mathbf{v}=-\mathbf{K e}-\mathbf{u}_{r e f}$. In this way, the proposed strategy may be used 
to reach $\mathbf{K}$, but the feedback will be given by the state error vector $\mathbf{e}$ instead of state vector $\mathbf{x}$.

The state error may be defined as the difference between BRF and ORF frames. Thus, quaternion [5] and angular velocity error can be expressed as:

$$
\begin{aligned}
q_{e} & =\left(q^{b / i}\right)^{-1} q^{o / i} \\
\omega_{e} & =\omega^{b / i}-\omega^{o / i} .
\end{aligned}
$$

For small angle variations, the quaternion error can be approximated by $q_{e} \approx\left[\left(\mathbf{q}^{o / i}-\right.\right.$ $\left.\left.\mathbf{q}^{b / i}\right), 1\right]^{T}[6]$.

Finally, the gain matrices of the LQR can be chosen by different methods. As a first approach, the method known as diagonal weights has been used. In this method the matrix $\mathbf{Q}$, which penalizes the states, is given by $\mathbf{Q}_{(i, i)}=1 / x_{i, i_{\max }}^{2}$ and the matrix $\mathbf{R}$, which penalizes the control signal, is given by $\mathbf{R}_{(i, i)}=1 / u_{i, i_{\max }}^{2}$.

\subsubsection{Desaturation}

Since the satellite is subject to external torques, the total angular momentum of the vehicle tends to increase indefinitely. Therefore, desaturation of the reaction wheels is required. This procedure can be performed with the magnetorquers and is shown in [5]. By making simple modifications to enable implementation, the magnetorquers moment to desaturation can be expressed by

$$
\mathbf{m}_{m}=\frac{-k_{d e s}}{B^{2}} S(\mathbf{B})\left[\begin{array}{l}
\operatorname{sgn}\left(H_{r w_{1}}\right)\left(\left|H_{r w_{1}}\right|-H_{d_{1}}\right) \\
\operatorname{sgn}\left(H_{r w_{2}}\right)\left(\left|H_{r w_{2}}\right|-H_{d_{2}}\right) \\
\operatorname{sgn}\left(H_{r w_{3}}\right)\left(\left|H_{r w_{3}}\right|-H_{d_{3}}\right)
\end{array}\right],
$$

where $k_{d e s}$ is the gain of the controller $\left(k_{\text {des }}>0\right), B$ is the local magnetic field, $H_{r w}$ and $H_{d}$ are the actual and desired reaction wheel's momentum, respectively.

\section{Simulation}

\subsection{Numerical Values}

Satellite simulation parameters are shown in Table 1, together with the initial orbital parameters. It is considered that the CubeSat has been launched from the International Space Station (ISS).

The linearization of the dynamics is performed around the point of operation, which in Pointing Mode occurs when BRF is aligned with ORF. Therefore, the satellite angular velocity will be the angular velocity of the orbit for the initial conditions of Table 1 , $\bar{\omega}_{v}=\left[\begin{array}{lll}-692.04 & -553.13 & 701.14\end{array}\right]^{T} 10^{-6} \mathrm{rad} \mathrm{s}^{-1}$. The desired RW's momentum, $H_{d}$, has been chosen to $1 / 3$ of its maximum momentum in order to prevent RW's speed from varying around $0 \mathrm{rad} \mathrm{s}^{-1}$, which would decrease its lifetime due to dry friction. Thus, the RW's momentum, $\overline{\mathbf{H}}_{r w}$, is linearized around $659.08 \times 10^{-6} \mathrm{~kg} \mathrm{~m}^{2} \mathrm{~s}^{-1}$. In order to obtain the LQR's $\mathbf{Q}$ and $\mathbf{R}$ gain matrices, the following considerations have been made: the maximum acceptable value for $\mathbf{x}_{1: 3}$ is 1 , since the quaternion norm is unitary; the maximum value for $\mathbf{x}_{4: 6}$ is $\approx 0.1^{\circ} \mathrm{s}^{-1}=1.7 \times 10^{-3} \mathrm{rad} \mathrm{s}^{-1}$, since it is the angular velocity after detumbling; and the maximum value for $\mathbf{u}$ is $1.22 \times 10^{-3} \mathrm{~N} \mathrm{~m}$, since this is the maximum torque of the RW. After some adjustment iterations, final gain matrices $\mathbf{Q}$, $\mathbf{R}$ and $\mathbf{K}$ are presented in Table 2 as well as the gains $k_{\text {det }}$ and $k_{\text {des }}$ that are commonly obtained through simulation iterations and behavior analysis. 
Table 1: Simulation Parameters.

\begin{tabular}{|c|c|c|c|c|}
\hline Parameter & Value & & Parameter & Value \\
\hline$m_{v}$ & $0.99 \mathrm{~kg}$ & & $e$ & 0.0002578 \\
\hline $\mathbf{I}_{v}$ & {$\left[\begin{array}{cc}181.53 & -6.87 \\
-6.87 & 181.53 \\
-6.87 & -6.87\end{array}\right.$} & $\left.\begin{array}{c}-6.87 \\
-6.87 \\
181.53\end{array}\right] 10^{-5} \mathrm{~kg} \mathrm{~m}^{2}$ & $\Omega$ & $308.63^{\circ}$ \\
\hline $\begin{array}{l}T_{r w_{\max }} \\
\left(I_{r w}\right)\end{array}$ & $\begin{array}{l}1.22 \times 10^{-3} \mathrm{~N} \mathrm{~m} \\
1.30 \times 10^{-6} \mathrm{~kg} \mathrm{~m}^{2}\end{array}$ & & $\begin{array}{l}i \\
\omega\end{array}$ & $\begin{array}{l}51.64^{\circ} \\
356.87^{\circ}\end{array}$ \\
\hline$\omega_{r w_{\max }}$ & $1.52 \mathrm{rad} \mathrm{s}^{-1}$ & & $\theta$ & $131.83^{\circ}$ \\
\hline$m_{m_{\max }}$ & $1.50 \mathrm{Am}^{2}$ & & $a$ & $6782.80 \mathrm{~km}$ \\
\hline$h$ & $51996.39 \mathrm{~km}^{2} \mathrm{~s}^{-1}$ & & $T$ & $92.66 \mathrm{~min}$ \\
\hline
\end{tabular}

Table 2: Control Parameters.

\begin{tabular}{|c|c|c|c|c|}
\hline Parameter & Value & & & \\
\hline Gain matrix, $\mathbf{Q}$ & $\operatorname{diag}\left(\left[\begin{array}{llllll}1 & 1 & 1 & 25 & 25 & 25\end{array}\right]^{T}\right)$ & & & \\
\hline Gain matrix, $\mathbf{R}$ & $\operatorname{diag}\left(\left[\begin{array}{lll}6.72 & 6.72 & 6.72\end{array}\right]^{T}\right) 10^{5}$ & & & \\
\hline Gain matrix, $\mathbf{K}$ & {$\left[\begin{array}{cccc}-1206.9 & -132.9 & 119.4 & -6263.8 \\
119.8 & -1206.8 & -132.2 & -0.9 \\
-132.6 & 119.1 & -1206.9 & -0.9\end{array}\right.$} & $\begin{array}{c}-1.1 \\
-6283.6 \\
-1.0\end{array}$ & $\left.\begin{array}{c}-1.1 \\
-1.0 \\
-6283.6\end{array}\right]$ & $10^{-5}$ \\
\hline $\begin{array}{l}\text { Detumbling gain, } k_{d e t} \\
\text { Desaturation gain, } k_{d e s}\end{array}$ & $\begin{array}{l}1 \times 10^{4} \\
1 \times 10^{-2}\end{array}$ & & & \\
\hline
\end{tabular}

\subsection{Results}

The simulations have been performed with the nonlinear equations of the vehicle (Eq. (2), (5), (6) e (8)) and subject to the torque disturbances presented in Section 4.5. A simple model of the sensors, subject to Gaussian noise and bias error, has also been implemented, in order to make the measurements more realistic. The numerical simulation has been performed in Simulink ${ }^{\circledR}$ using a third order solver (ode3) at $100 \mathrm{~Hz}$. The sample time of the controller is $10 \mathrm{~Hz}$. Satellite attitude has been implemented and controlled only in quaternions. However, they have been transformed into Euler angles (Z-Y-X) and represented in BRF, for more didactic and intuitive plots. For such a goal, we use the notation ${ }^{b} \boldsymbol{\Theta}_{v}^{b / i} \mid \boldsymbol{\Theta}=\left[\begin{array}{lll}\phi & \theta & \psi\end{array}\right]^{T}$.

In Case 1, Detumbling Mode is enabled and the initial attitude conditions are ${ }^{b} \boldsymbol{\Theta}_{v}^{b / i}=$ $\left[\begin{array}{lll}45 & 45 & 45\end{array}\right]^{T}$ degrees and ${ }^{b} \omega_{v}^{b / i}=\left[\begin{array}{lll}10 & 10 & -10\end{array}\right]^{T}$ deg s $^{-1}$. Figure 2 shows the satellite angular velocity and the magnetic dipole moment of the magnetorquers. It is possible to observe that the controller is able to reduce the angular velocity from $10 \mathrm{deg} \mathrm{s}^{-1}$ to $1 \mathrm{deg} \mathrm{s}^{-1}$ during 0.6 orbits, which is less than the 3 orbits requirement.

In Case 2, only Pointing Mode are enabled. The initial attitude conditions are ${ }^{b} \boldsymbol{\Theta}_{v}^{b / i}=\left[\begin{array}{lll}45 & 45 & 45\end{array}\right]^{T} \mathrm{deg}$ and ${ }^{b} \boldsymbol{\omega}_{v}^{b / i}=\left[\begin{array}{lll}1 & 1 & -1\end{array}\right]^{T}$ deg s${ }^{-1}$. Figure 3 shows the first $50 \mathrm{~s}$ of simulation. The first plot shows the attitude error, $\left({ }^{b} \boldsymbol{\Theta}_{v}^{b / i}-{ }^{b} \boldsymbol{\Theta}_{r}^{o / i}\right)$. The second plot shows the satellite angular position, ${ }^{b} \boldsymbol{\Theta}_{v}^{b / i}$, and the reference angular position ${ }^{b} \boldsymbol{\Theta}_{r}^{o / i}$. It is possible to observe that the vehicle reaches the maximum acceptable error ( $5 \mathrm{deg}$ ) in $36 \mathrm{~s}$. The third plot shows torques of reaction wheels. 

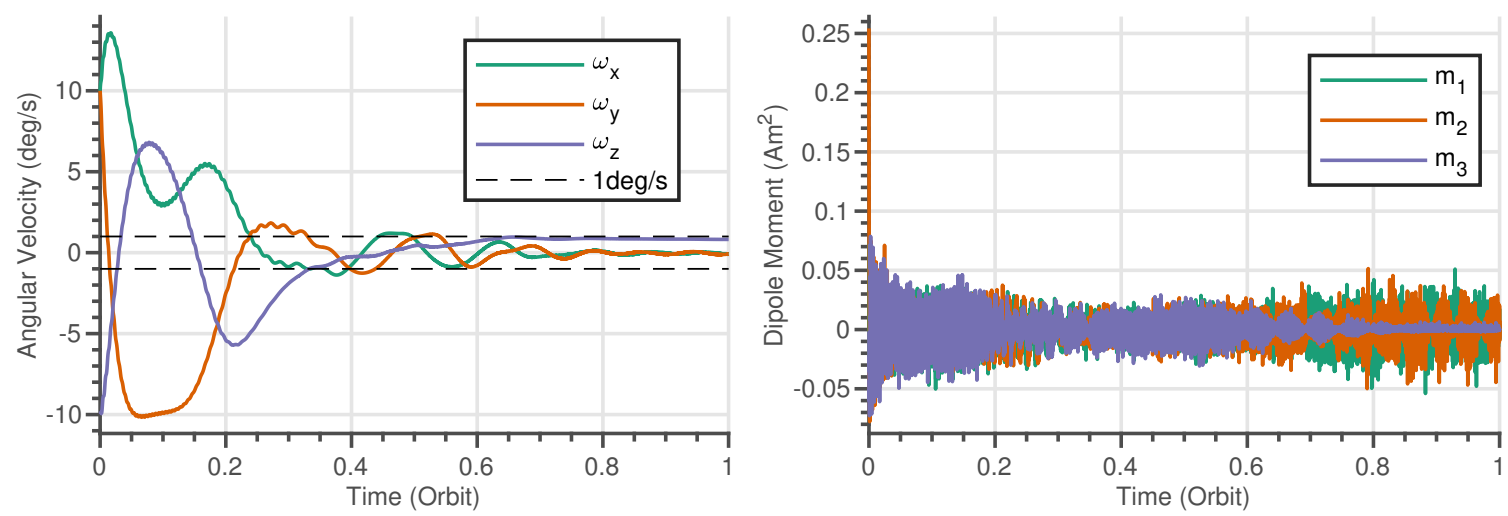

Figure 2: Detumbling Mode.
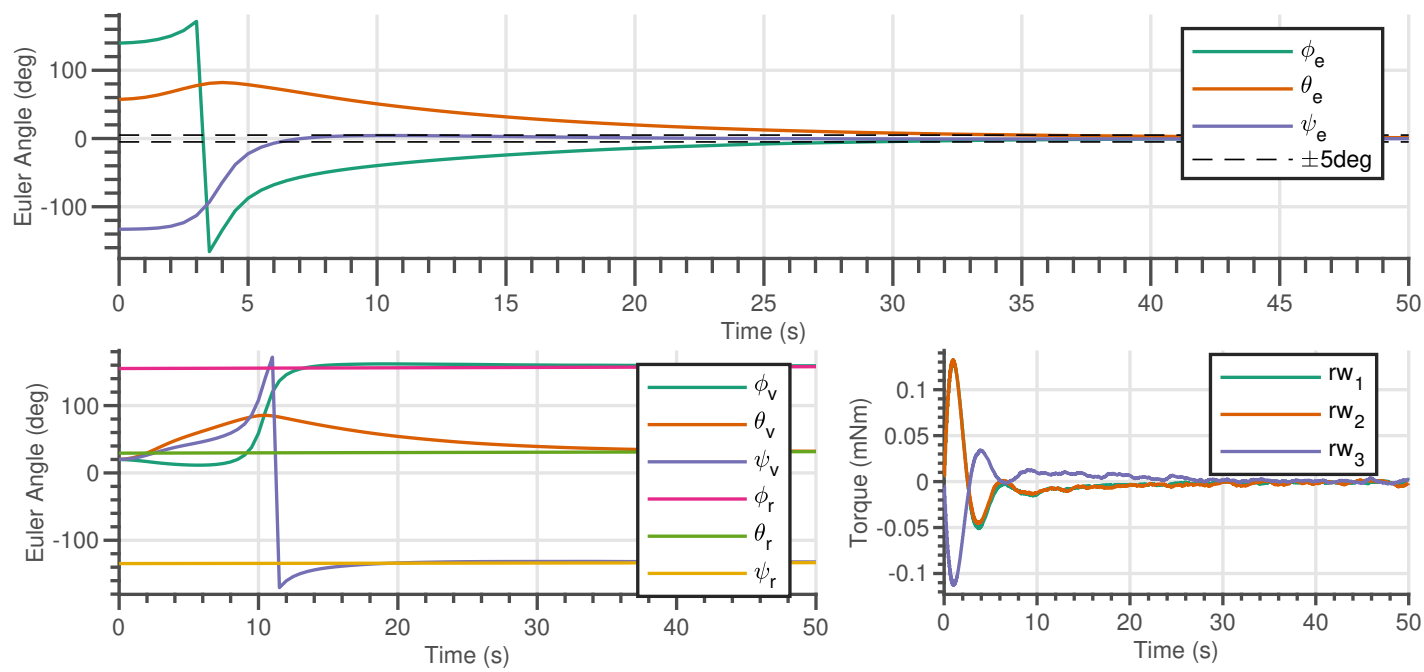

Figure 3: Pointing Mode.

In case 3, we consider a scenario just after launching by the p-POD, where six consecutive flight phases are simulated: 1 Safe Mode during $30 \mathrm{~min}$ (ACS off); 2 Detumbling Mode until angular velocity reaches $1 \mathrm{deg} \mathrm{s}^{-1} ; 3$ Pointing Control Mode during 0.5 orbits; 4 ACS failure during 0.5 orbits; 5 Detumbling Mode after ACS recovery; 6 Pointing Control Mode. Attitude initial conditions are ${ }^{b} \Theta_{v}^{b / i}=\left[\begin{array}{lll}45 & 45 & 45\end{array}\right]^{T}$ deg and ${ }^{b} \boldsymbol{\omega}_{v}^{b / i}=\left[\begin{array}{lll}10 & 10 & -10\end{array}\right]^{T} \operatorname{deg~s}^{-1}$. Figure 4 shows satellite angular velocity, attitude error, and instants at which each controller is enabled or disabled. It is observed that the ACS is able to recover satellite attitude control after failure.

\section{Conclusion}

In this paper we have presented an ACS study for the IAG-USP'S CubeSat dedicated to Earth's magnetic field measurements. Two modes of attitude control were designed: detumbling mode and pointing control mode. Simulation analyses have verified that the design approach is capable of accommodating disturbances and meeting the mission requirements. 


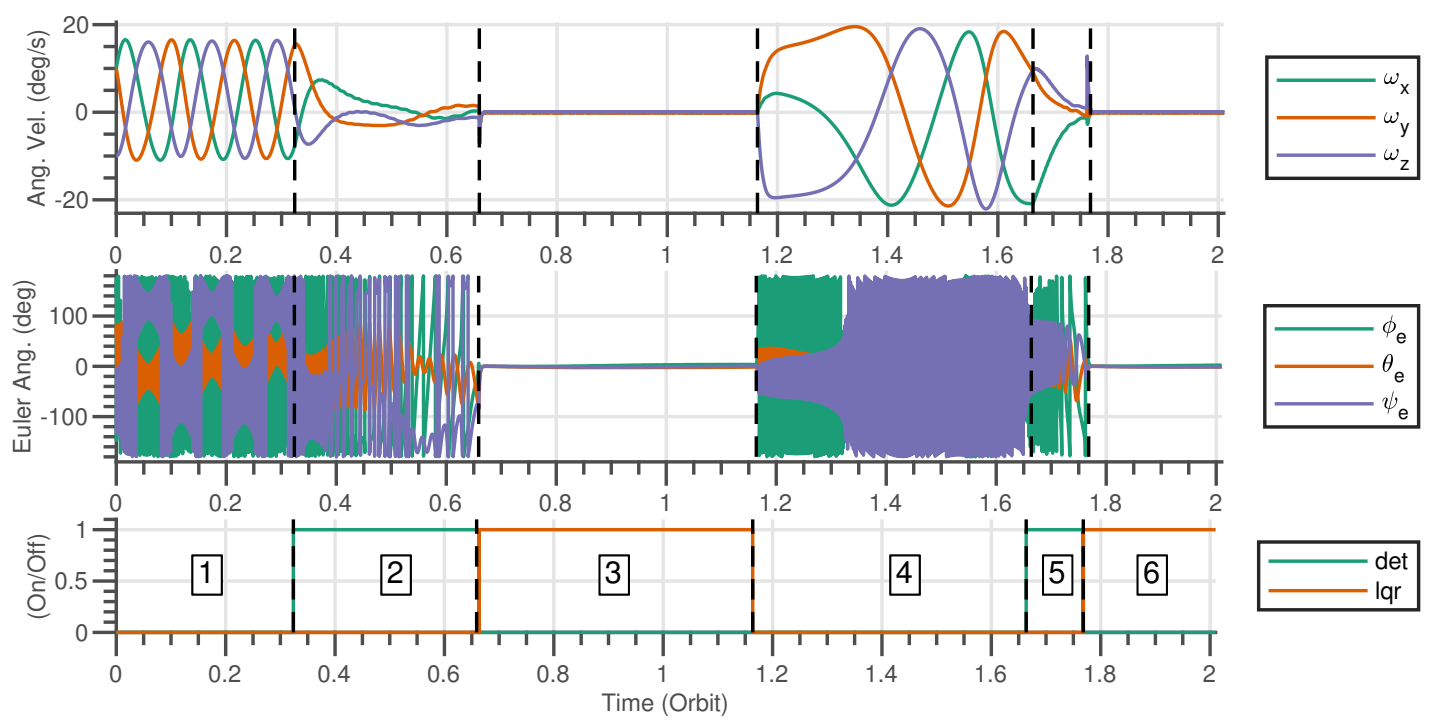

Figure 4: Six Consecutive Flight Phases.

\section{Acknowledgments}

The authors would like to thank the Núcleo de Sistemas Eletrônicos Embarcados (NSEE) from the Instituto Mauá de Tecnologia (IMT) for its help providing information and infrastructure to this work.

\section{References}

[1] O. Adriani, G. Barbarino, G. Bazilevskaya, R. Bellotti, M. Boezio, E. Bogomolov, M. Bongi, V. Bonvicini, S. Borisov, S. Bottai, others, The discovery of geomagnetically trapped cosmic-ray antiprotons, The Astrophysical Journal Letters 737 (2011) L29.

[2] L. Pinheiro da Silva, G. Rolland, V. Lapeyrere, M. Auvergne, Radiation effects on space-based stellar photometry: Theoretical models and empirical results for CoRoT Space Telescope, Monthly Notices of the Royal Astronomical Society 384 (2008) 1337-1343.

[3] A. Mehrparvar, D. Pignatelli, J. Carnahan, R. Munakat, W. Lan, A. Toorian, A. Hutputanasin, S. Lee, Cubesat design specification rev. 13, The CubeSat Program, Cal Poly San Luis Obispo, US 1 (2014) 2.

[4] H. D. Curtis, Orbital Mechanics for Engineering Students, Butterworth-Heinemann, 3 edition, 2013.

[5] M. J. Sidi, Spacecraft Dynamics and Control: A Practical Engineering Approach, Cambridge university press, 1997.

[6] M. Blanke, M. B. Larsen, Satellite Dynamics and Control in a Quaternion Formulation, Lecture Notes for Course 31365, Spacecraft Dynamics and Control (2010) 50.

[7] J. R. Wertz, Spacecraft Attitude Determination and Control, Springer Science \& Business Media, 1978.

[8] B. Yost, State of the Art of Small Spacecraft Technology, NASA (2018).

[9] NASA, Spacecraft Aerodynamic Torques, NASA-SP-8058 (1971) 38.

[10] NASA, Spacecraft Radiation Torques, NASA-SP-8027 (1969) 41.

[11] NASA, Spacecraft Gravitational Torques, NASA-SP-8018 (1969) 51.

[12] A. C. Stickler, K. Alfriend, Elementary magnetic attitude control system, Journal of spacecraft and rockets 13 (1976) 282-287.

[13] H. Kwakernaak, R. Sivan, Linear Optimal Control Systems, volume 1, Wiley-Interscience New York, 1972.

[14] F. L. Lewis, D. Vrabie, V. L. Syrmos, Optimal Control, John Wiley \& Sons, 2012. 